\title{
Large-Scale Modeling and Assessments of Climate, Land Cover, and Sea Level Change Impacts on Stormwater Runoff in Coastal Urban-Natural Environments
}

\author{
Erfanul Huq
}

Follow this and additional works at: https://researchrepository.wvu.edu/etd

Part of the Civil Engineering Commons, and the Other Civil and Environmental Engineering Commons

\author{
Recommended Citation \\ Huq, Erfanul, "Large-Scale Modeling and Assessments of Climate, Land Cover, and Sea Level Change \\ Impacts on Stormwater Runoff in Coastal Urban-Natural Environments" (2020). Graduate Theses, \\ Dissertations, and Problem Reports. 7841. \\ https://researchrepository.wvu.edu/etd/7841
}

This Dissertation is protected by copyright and/or related rights. It has been brought to you by the The Research Repository @ WVU with permission from the rights-holder(s). You are free to use this Dissertation in any way that is permitted by the copyright and related rights legislation that applies to your use. For other uses you must obtain permission from the rights-holder(s) directly, unless additional rights are indicated by a Creative Commons license in the record and/ or on the work itself. This Dissertation has been accepted for inclusion in WVU Graduate Theses, Dissertations, and Problem Reports collection by an authorized administrator of The Research Repository @ WVU.

For more information, please contact researchrepository@mail.wvu.edu. 


\title{
Large-Scale Modeling and Assessments of Climate, Land Cover, and Sea Level Change Impacts on Stormwater Runoff in Coastal Urban-Natural Environments
}

\author{
Erfanul Huq \\ Dissertation submitted \\ to the Benjamin M. Statler College of Engineering and Mineral Resources \\ at West Virginia University \\ in partial fulfillment of the requirements for the degree of \\ Doctor of Philosophy in \\ Civil Engineering
Omar I. Abdul-Aziz, Ph.D., Chair
Radhey S. Sharma, Ph.D.
Lian-Shin Lin, Ph.D.
Seung Ho Hong, Ph.D.
Yanfang Ye, Ph.D. \\ Wadsworth Department of Civil and Environmental Engineering
}

Morgantown, West Virginia

2020

Keywords: Large-scale modeling, SWMM, coastal-urban, coastal-natural, climate, land cover, sea level, stormwater runoff sensitivity, future runoff scenarios.

Copyright 2020 Erfanul Huq 


\section{ABSTRACT \\ Large-Scale Modeling and Assessments of Climate, Land Cover, and Sea Level Change \\ Impacts on Stormwater Runoff in Coastal Urban-Natural Environments}

\section{Erfanul Huq}

This dissertation investigated the potential impacts of changing climate, land cover, and sea level on the future stormwater budget and extreme runoff in coastal urban-natural environments. Two large-scale basins, namely Florida Southeast Coasts Basin $(7117 \mathrm{~km} 2)$ and Saint Johns River Basin (24928 km2), were selected for this study. The basins represented gradients in climate, land cover, and hydrology across the Atlantic coasts of Florida and the southeast U.S. Two mechanistic hydrologic models were developed for the basins using U.S. Environmental Protection Agency (U.S. EPA)'s Storm Water Management Model (SWMM) 5.1. The models were calibrated and validated with observed historical streamflow of the 2010s (2004-2013), computing the corresponding runoff volume as a historical reference. Runoffs for 2050s (20442053) and 2080s (2076-2085) were quantified by incorporating climatic projections from 20 General Circulation Models (GCMs) and land cover projections from EPA under the Representative Concentration Pathways (RCP) 4.5 and 8.5 scenarios. Results suggested a predominant climatic control on potential runoff changes and high vulnerability in the coastal urban-natural environments. The relative increases in runoff were higher during the dry season and transitional months (October-May) than the wet season (June-September). Based on the basin-scale annual averages, runoff sensitivity to changes in rainfall was substantially stronger than that to changes in watershed imperviousness and evapotranspiration. Further, the concurrent changes in climate and land cover led to synergistic (stronger) nonlinear responses of runoff, compared to the linear summation of their individual effects.

The dissertation also evaluated potential future changes in extreme events (rainfall and sea level) and associated runoff extremes across the two basins. Significance and direction of trends in 50-year annual maximum rainfall and sea level of 1-7 day durations for the 2000s (1964-2013) were evaluated by non-parametric Mann-Kendall test and Theil-Sen slope estimator. At the 5\% level of significance, statistically insignificant mixed (increasing and decreasing) trends were noted in historical rainfall and significant increasing trends were observed in sea level. Accordingly, historical and future stationary design rainfalls and nonstationary design sea levels for 1-7 day durations with varying return periods $(2,5,10,25,50$, and 100 year) were estimated using Gumbel probability distribution, representing the family of generalized extreme value distributions. Based on the analyses, the extreme rainfalls and sea levels over various durations would substantially increase in the 2050s (2025-2074) and 2080s (2050-2099). Higher (than other locations) runoff increases were noted at and around the urban centers across the two basins. The projected extreme stormwater runoff under the changing regimes of extreme rainfall, sea level, and land cover suggested intensified risks of pluvial flooding and water pollution across the Atlantic coasts of Florida. The findings would guide stormwater management and ecosystem protection for coastal built and natural environments in the southeast U.S. and around the globe. 


\section{ACKNOWLEDGMENTS}

First of all, I would like to express my utmost gratitude to Almighty God for bestowing me with endless blessings which was essential to complete this dissertation successfully.

I would like to express my most sincere gratitude and appreciation to my supervisor, Dr. Omar I. Abdul-Aziz for his continued guidance and generous help throughout this study. His careful reading of the draft of the dissertation, insightful feedbacks, and valuable suggestions were pivotal in development of the thesis.

I would like to express my gratitude and thanks to the respected committee members Dr. Radhey S. Sharma, Dr. Lian-Shin Lin, Dr. Seung Ho Hong, and Dr. Yanfang Ye; for serving as members of the examination committee and their valuable advice and guidelines in reviewing this dissertation.

The dissertation was funded by a National Science Foundation (NSF) Critical Resilient Interdependent Infrastructure Systems and Processes (CRISP 2.0) Award to Dr. Omar I. AbdulAziz (NSF CMMI Award \#1832680), and by the "Florida Public Hurricane Loss Model Enhancements" project's freshwater flood modeling award to Dr. Omar I. Abdul-Aziz. The funding agencies are gratefully acknowledged.

Finally, I would like to express my heartiest gratitude to my parents, wife, and sister. Their continued support, love, and invaluable guidance played a major role in completion of this research. 


\section{Table of Contents}

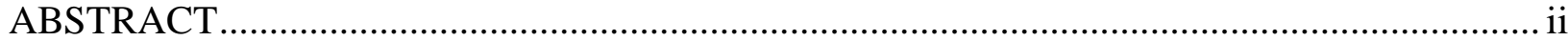

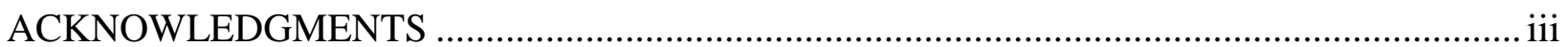

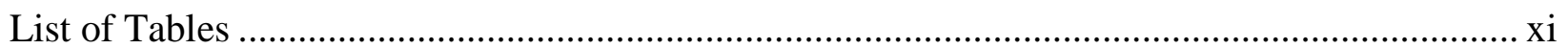

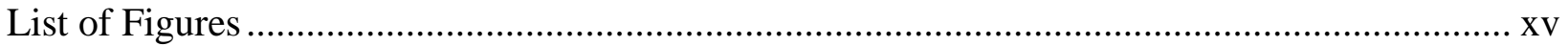

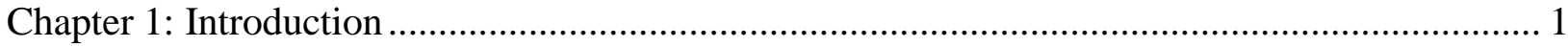

1.1 Background and motivation ................................................................................ 1

1.2 Research goal, hypotheses, and objectives .................................................................. 5

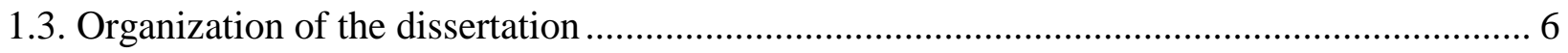

Chapter 2: Large-scale modeling and assessment of climate and land cover change impacts on the stormwater runoff in complex coastal-urban environments ....................................... 8

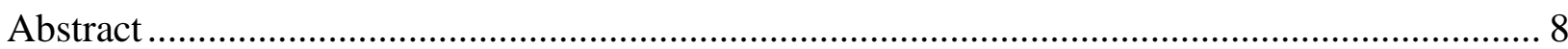

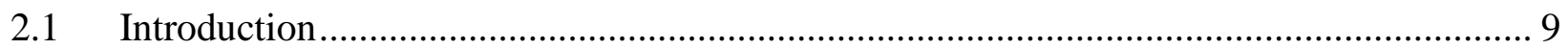

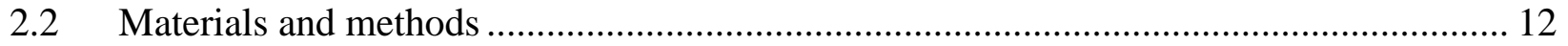

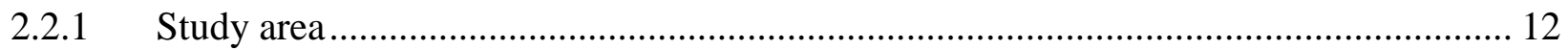

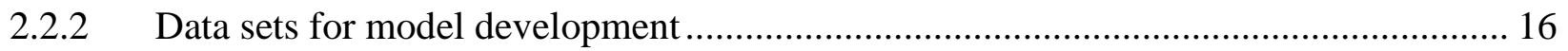

2.2.3 Development of the rainfall-runoff model using EPA SWMM 5.1 .......................... 17

2.2.4 Climate and land cover projections to determine future runoff scenarios ................... 20

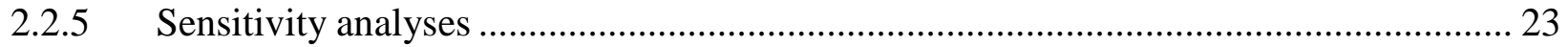

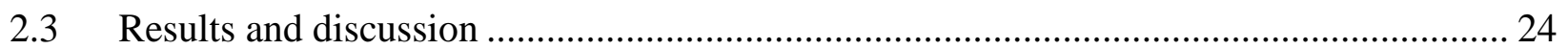

2.3.1 Model calibrations and validations ................................................................... 24 


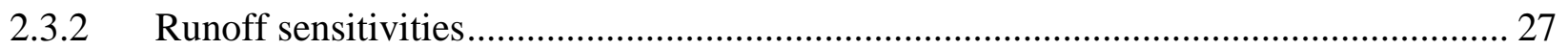

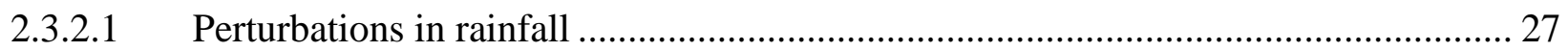

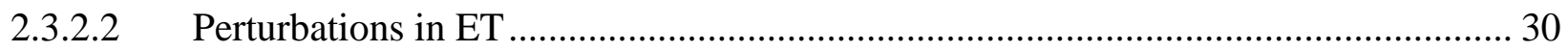

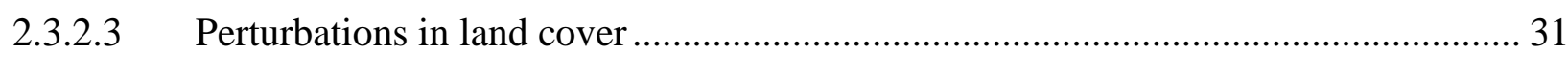

2.3.2.4 Concurrent climatic and land cover sensitivities .................................................... 32

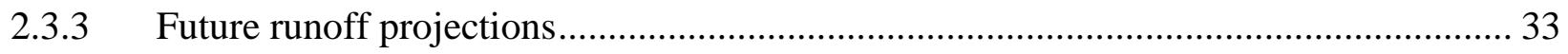

2.3.3.1 Runoff projections under changing climate............................................................. 33

2.3.3.2 Runoff projections under changing land cover......................................................... 39

2.3.3.3 Runoff projections under changing climate and land cover ...................................... 40

2.3.4 Comparative synthesis of findings with existing literature ........................................... 42

2.3.5 Implications for water resources planning and management ....................................... 44

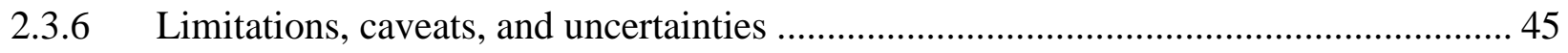

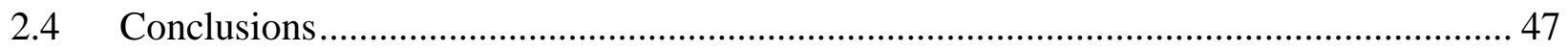

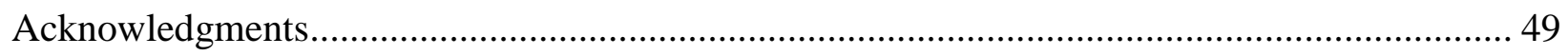

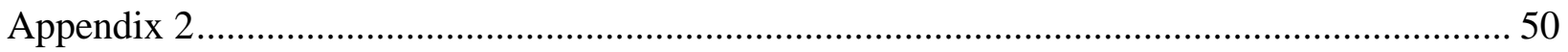

Chapter 3: Impact assessments of changing climate and land cover on coastal-natural stormwater

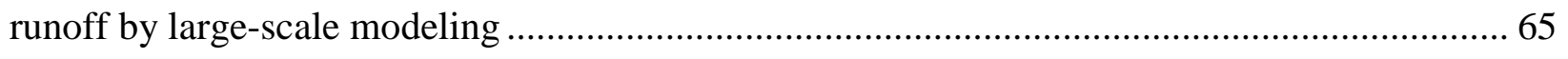

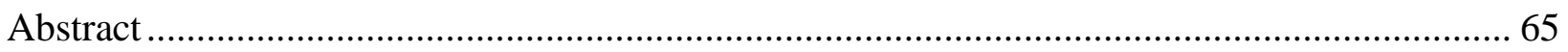

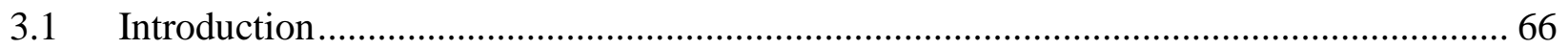

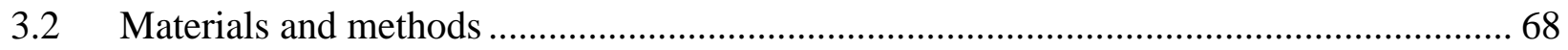


3.2.1 Study area

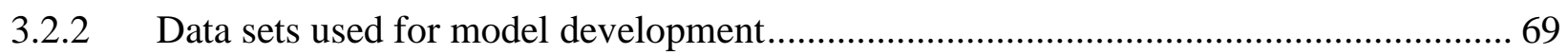

3.2.3 Development of the mechanistic rainfall-runoff model using EPA SWMM 5.1........... 73

3.2.4 Climatic and land cover projections for estimating the future runoff scenarios ............. 75

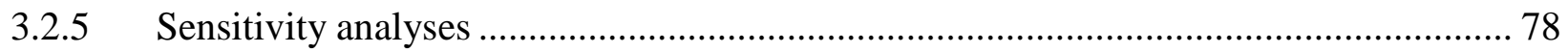

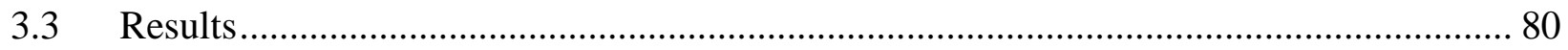

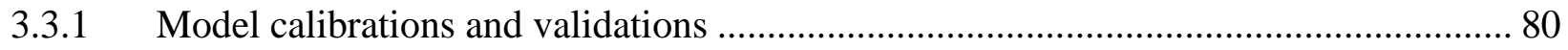

3.3.2 Sensitivities of monthly and annual basin runoff....................................................... 82

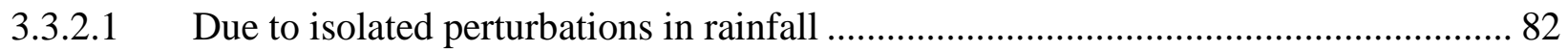

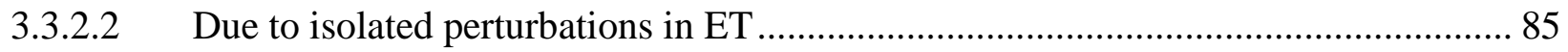

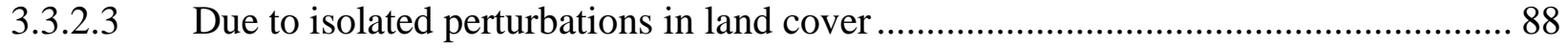

3.3.2.4 Due to simultaneous perturbations in climate and land cover ................................... 89

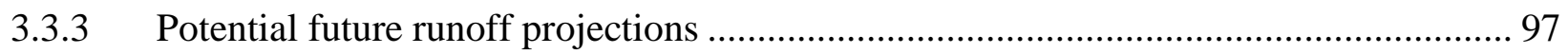

3.3.3.1 Runoff projections under changes in climate …...................................................... 97

3.3.3.2 Runoff projections under changes in land cover .................................................... 99

3.3.3.3 Runoff projections under concurrent changes in climate and land cover................. 102

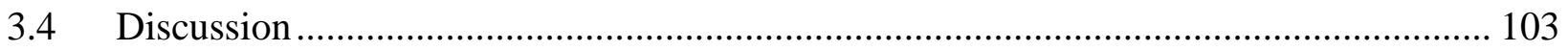

3.5 Runoff sensitivities and future runoff projections ......................................................... 103

3.4.2 Comparison of findings of the study with existing literature …….................................. 104

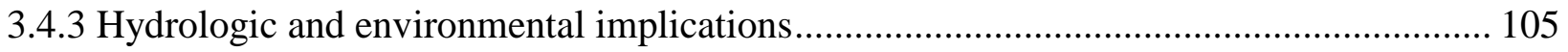




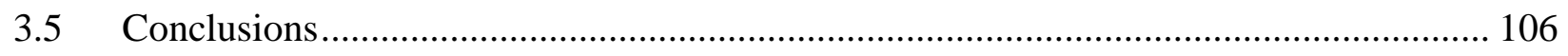

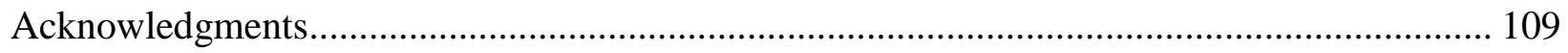

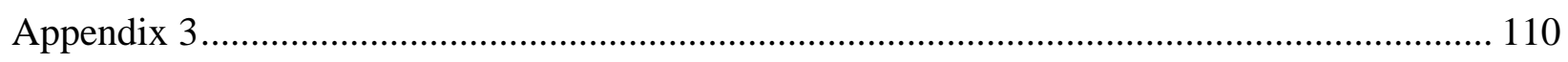

Chapter 4: Potential changes in extreme runoffs under changing climate, land cover, and sea

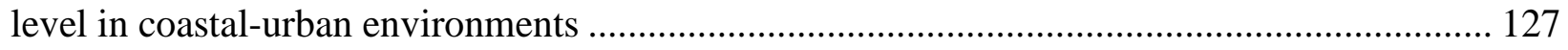

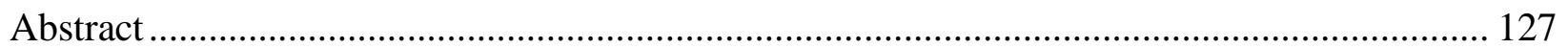

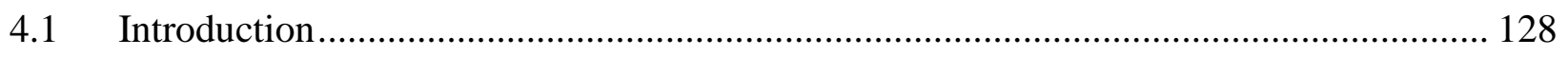

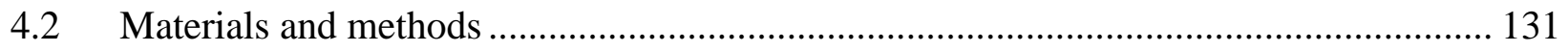

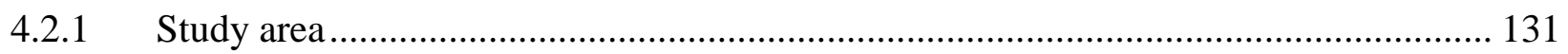

4.2.2 Data sets for model development ....................................................................... 133

4.2.3 Development of the mechanistic rainfall-runoff model using EPA SWMM 5.1 ......... 136

4.2.4 Climatic, land cover, and sea level datasets for extreme runoff computations ............ 139

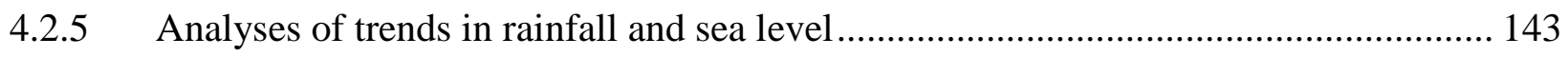

4.2.6 Estimations of historical and future extreme rainfall, sea level, and runoff ................ 143

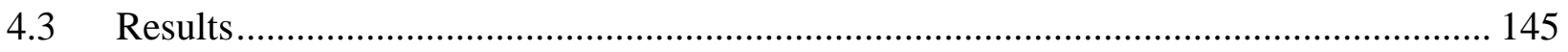

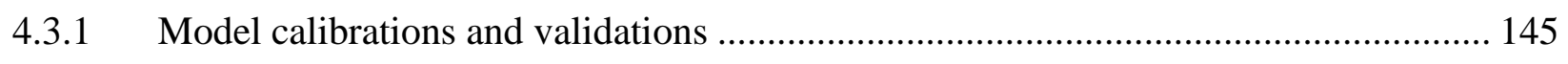

4.3.2 Historical trends and design values for rainfall and sea level .................................... 146

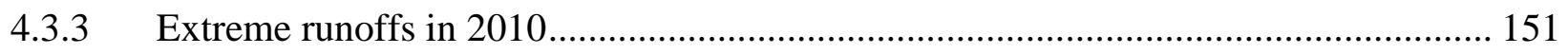

4.3.4 Extreme future runoffs under standalone changes in individual drivers ..................... 153 
4.3.4.1 Under standalone changes in climate

4.3.4.2 Under standalone changes in land cover .............................................................. 154

4.3.4.3 Under standalone changes in sea level ................................................................ 157

4.3.5 Extreme future runoffs under concurrent changes in two major drivers...................... 159

4.3.5.1 Under concurrent changes in climate and land cover............................................. 159

4.3.5.2 Under concurrent changes in climate and sea level............................................... 161

4.3.5.3 Under concurrent changes in land cover and sea level.......................................... 163

4.3.6 Extreme future runoffs under concurrent changes in all major drivers........................ 164

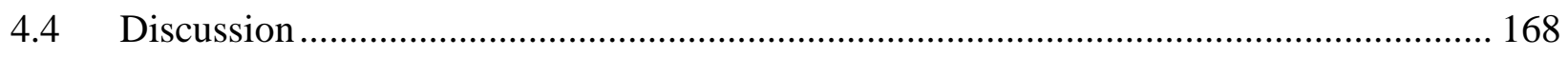

4.4.1 Historical and future scenarios of extreme rainfall, sea level, and runoff scenarios.... 168

4.4.2 Comparison of study findings with existing literature ……....................................... 170

4.4.3 Potential implications for hydrologic and environmental impact management............ 171

4.4.4 Limitations and caveats of the study and uncertainties........................................... 172

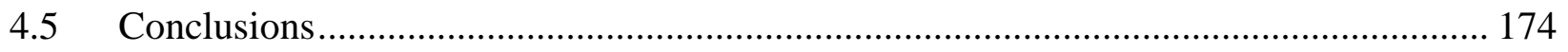

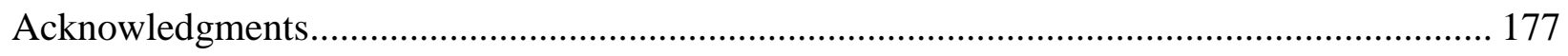

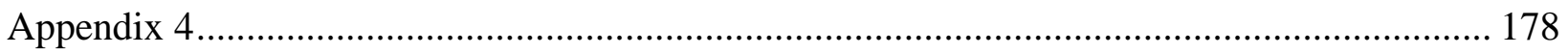

Chapter 5: Impacts of changing climate, land cover, and sea level on extreme runoffs in coastal-

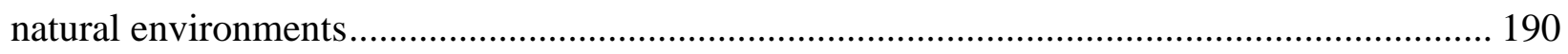

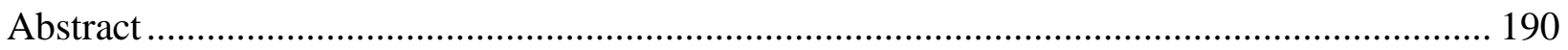

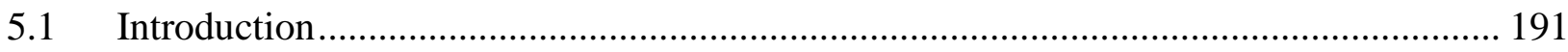


5.2 Materials and methods

5.2.1 Study area

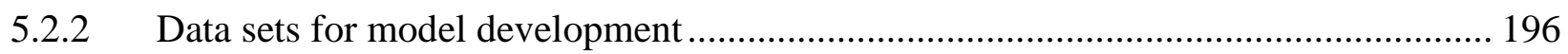

5.2.3 Development of the mechanistic hydrologic model using EPA SWMM 5.1 .............. 198

5.2.4 Climatic, land cover, and sea level datasets for impact assessments .......................... 200

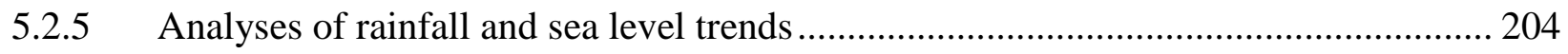

5.2.6 Estimations of historical and future extreme rainfall, sea level, and runoff ................ 204

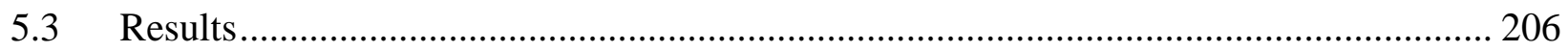

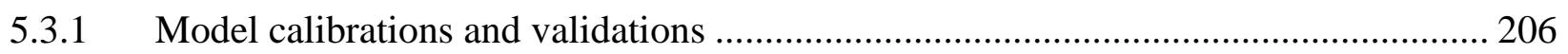

5.3.2 Historical trends in rainfall and sea level and their design values .............................. 206

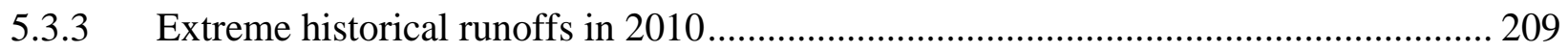

5.3.4 Extreme future runoffs under standalone changes in individual drivers ...................... 210

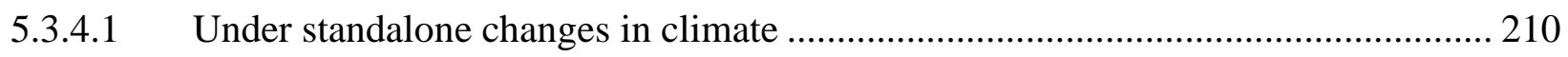

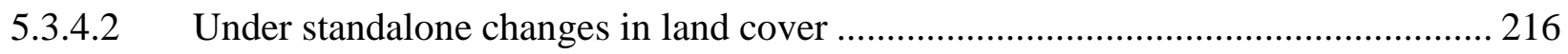

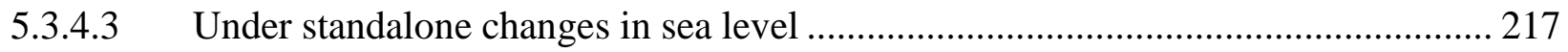

5.3.5 Extreme future runoffs under concurrent changes in two major drivers...................... 218

5.3.5.1 Under concurrent changes in climate and land cover............................................ 218

5.3.5.2 Under concurrent changes in climate and sea level............................................. 222

5.3.5.3 Under concurrent changes in land cover and sea level.......................................... 223

5.3.6 Extreme future runoffs under concurrent changes in all major drivers........................ 224 


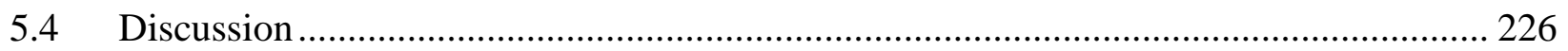

5.4.1 Historical and future extreme rainfall, sea level, and runoff scenarios ....................... 226

5.4.2 Comparison of the study outcomes with existing relevant literature .......................... 229

5.4.3 Potential hydrologic and environmental implications................................................ 231

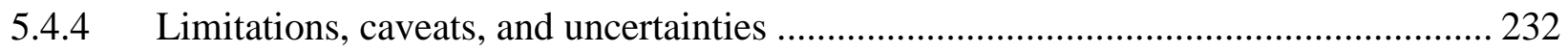

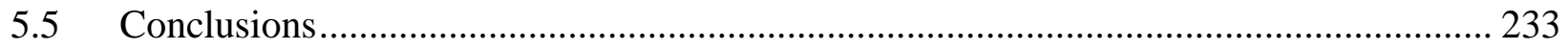

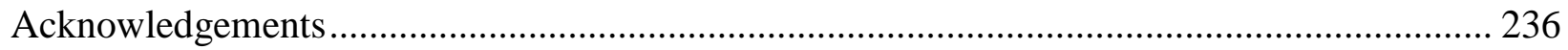

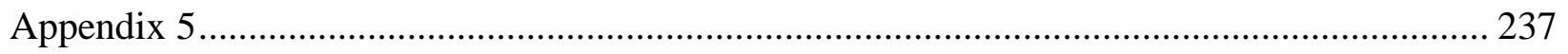

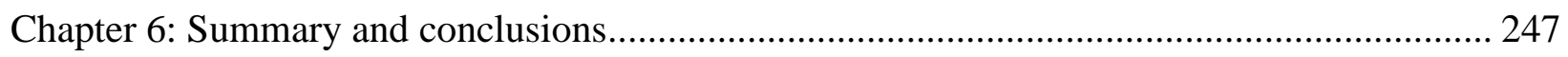

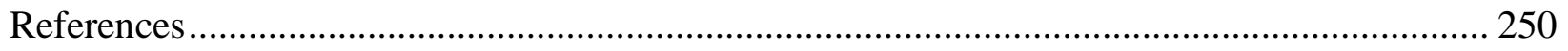




\section{List of Tables}

Table 2.1: Model variables and calibrated parameters for the Florida Southeast Coasts Basin during 2004-2013

Table 2.2: Percent changes of mean annual runoff under concurrent perturbations in rainfall and imperviousness in the Florida Southeast Coasts Basin.

Table 2.3: Percent changes of mean annual runoff under concurrent perturbations in rainfall and evapotranspiration (ET) in the Florida Southeast Coasts Basin. 35

Table 2.4: Percent changes of mean annual runoff under concurrent perturbations in evapotranspiration (ET) and imperviousness in the Florida Southeast Coasts Basin..... 35

Table 3.1: Model variables and calibrated parameters during 2004-2013 for the Saint Johns River

Basin. 74

Table 3.2: Percent changes of mean annual runoff under concurrent perturbations in rainfall and imperviousness in the Upper Saint Johns River Basin. 91 Table 3.3: Percent changes of mean annual runoff under concurrent perturbations in rainfall and imperviousness in the Ocklawaha River Basin. 91 Table 3.4: Percent changes of mean annual runoff under concurrent perturbations in rainfall and imperviousness in the Lower Saint Johns River Basin. 92 Table 3.5: Percent changes of mean annual runoff under concurrent perturbations in rainfall and imperviousness in the Saint Johns River Basin.

Table 3.6: Percent changes of mean annual runoff under concurrent perturbations in rainfall and evapotranspiration (ET) in the Upper Saint Johns River Basin. 93 Table 3.7: Percent changes of mean annual runoff under concurrent perturbations in rainfall and evapotranspiration (ET) in the Ocklawaha River Basin. 93 
Table 3.8: Percent changes of mean annual runoff under concurrent perturbations in rainfall and evapotranspiration (ET) in the Lower Saint Johns River Basin. 94 Table 3.9: Percent changes of mean annual runoff under concurrent perturbations in rainfall and evapotranspiration (ET) in the Saint Johns River Basin. 94

Table 3.10: Percent changes of mean annual runoff under concurrent perturbations in evapotranspiration (ET) and imperviousness in the Upper Saint Johns River Basin. 95 Table 3.11: Percent changes of mean annual runoff under concurrent perturbations in evapotranspiration (ET) and imperviousness in the Ocklawaha River Basin...... 95 Table 3.12: Percent changes of mean annual runoff under concurrent perturbations in evapotranspiration (ET) and imperviousness in the Lower Saint Johns River Basin. 96 Table 3.13: Percent changes of mean annual runoff under concurrent perturbations in evapotranspiration (ET) and imperviousness in the Saint Johns River Basin. 96 Table 3.14: Potential future changes in basin-average runoff volume for the Saint Johns River Basin and its subwatersheds, relative to the baseline period of 2010s, under different future scenarios. 101

Table 4.1: Variables and calibrated parameters of the Southeast Coasts Basin model for simulation during 2004-2013.

Table 4.2: Sen's slope values (mm/year) for annual maximum event total rainfall depths for different durations during 1964-2013 in the Southeast Coasts Basin. Numbers in the parentheses indicate $p$-values of the Mann-Kendall test. $p>0.05$ and $p \leq 0.05$ indicates absence and presence of monotonic trend, respectively, at $5 \%$ statistical significance level. 149 Table 4.3: Sen's slope values (mm/year) for annual maximum event mean sea levels for different durations during 1964-2013 in the Southeast Coasts Basin. Numbers in the parentheses indicate 
$p$-values of the Mann-Kendall test. $p>0.05$ and $p \leq 0.05$ indicates absence and presence of monotonic trend, respectively, at 5\% statistical significance level.

Table 4.4: Historical design rainfall (mm) in 2010 for different stations in the Southeast Coasts

Basin under varying durations and return periods. 150

Table 4.5: Historical basin-average design rainfall (mm) in 2010 in the Southeast Coasts Basin under varying durations and return periods.

Table 4.6: Historical design sea level (m NAVD 88) in 2010 for different stations in the

Southeast Coasts Basin under varying durations and return periods.

Table 4.7: Historical basin total runoff volume extreme (million $\mathrm{m}^{3}$ ) in 2010 in the Southeast

Coasts Basin under extreme rainfalls and sea levels of varying durations and return periods... 152 Table 5.1: Model variables and calibrated parameters during 2004-2013 for the Saint Johns River Basin. 200

Table 5.2: Sen's slope values (mm/year) for annual maximum event total rainfall depths for different durations during 1964-2013 in the Saint Johns River Basin. Numbers in the parentheses indicate $p$-values of the Mann-Kendall test. $p>0.05$ and $p \leq 0.05$ indicates absence and presence of monotonic trend, respectively, at $5 \%$ statistical significance level. 208 Table 5.3: Sen's slope values (mm/year) for annual maximum event mean sea levels for different durations during 1964-2013 in the Saint Johns River Basin. Numbers in the parentheses indicate $p$-values of the Mann-Kendall test. $p>0.05$ and $p \leq 0.05$ indicates absence and presence of monotonic trend, respectively, at 5\% statistical significance level. 208 Table 5.4: Historical design rainfall (mm) in 2010 for different stations in the Saint Johns River Basin under varying durations and return periods. 211 
Table 5.5: Historical basin-average design rainfall ( $\mathrm{mm})$ in 2010 in the Saint Johns River basin under varying durations and return periods.

Table 5.6: Historical design sea level (m NAVD 88) in 2010 at NOAA station 8720218 in the

Saint Johns River basin under varying durations and return periods................................. 212

Table 5.7: Historical basin total runoff volume extreme (million $\mathrm{m}^{3}$ ) in 2010 in the Saint Johns

River basin under extreme rainfalls and sea levels of varying durations and return periods. .... 212 


\section{List of Figures}

Figure 2.1: Major canals, rivers, and land cover types in the Southeast Coasts Basin. The inset shows the locations of the study area, Lake Okeechobee, and the Everglades Water Conservation Areas (WCAs) in the state of Florida. Inset is not drawn to the map-scale. 13

Figure 2.2: Locations of boundary conditions, model calibrations and validation points, rainfall gauging stations, and groundwater monitoring stations used in the Southeast Coasts Basin model. The inset shows the location of the study area, Lake Okeechobee, and the Everglades Water

Conservation Areas (WCAs) in the state of Florida. Inset is not drawn to the map-scale. 15

Figure 2.3: Plots of model calibrations and validations with historical daily streamflow for the Florida Southeast Coasts Basin. 01/01/05 refers to January 01, 2005. Calibration and validation periods are, respectively, 01/01/2006 to $12 / 31 / 2008$ and $01 / 01 / 2009$ to $12 / 31 / 2013$ for C-24 Canal; 01/01/2005 to $12 / 31 / 2008$ and $01 / 01 / 2009$ to $12 / 31 / 2013$ for West Palm Beach Canal; and 01/01/2006 to 12/09/2008 and 01/01/2009 to 10/03/2011 for the Miami River. For the remaining streams, calibration and validation periods are $01 / 01 / 2004$ to $12 / 31 / 2008$ and $01 / 01 / 2009$ to $12 / 31 / 2013$, respectively.

Figure 2.4: Monthly and annual variation in the sensitivity of 10-year (2010s) mean runoff to perturbations in rainfall, evapotranspiration (ET), and imperviousness in the Florida Southeast Coasts Basin. 28

Figure 2.5: Spatial variation of the predicted changes in 10-year mean annual runoff depth due to the projected changes in (a) climate, (b) land cover, and (c) both climate and land cover under different future scenarios in the Florida Southeast Coasts Basin. 36 Figure 2.6: Percentage changes in 10-year mean monthly and annual runoff under the projected changes in (a) climate, (b) land cover, and (c) both climate and land cover for different future 
scenarios in the Florida Southeast Coasts Basin. For (a) and (c), the box-whiskers represent variations in runoff change across the general circulation models (GCMs); the lower, intermediate, and upper horizontal lines in the boxes indicate $25^{\text {th }}, 50^{\text {th }}$, and $75^{\text {th }}$ percentiles; plus signs indicate extreme outliers. Jan: January; Feb: February; Mar: March; Apr: April; Jun: June; Jul: July; Aug: August; Sep: September; Oct: October; Nov: November; Dec: December; Ann: Annual 38

Figure 3.1: Subwatersheds, major streams, and land cover types in the Saint Johns River Basin. The inset showing location of the study area in the state of Florida is not drawn to the map-scale.

Figure 3.2: Locations of boundary conditions, model calibrations and validation points, rainfall gauging stations, and groundwater monitoring stations used in the Saint Johns River Basin model. The inset showing location of the study area in the state of Florida is not drawn to the map-scale.

Figure 3.3: Plots of model calibrations and validations with historical daily streamflow for the Saint Johns River Basin. 01/01/04 refers to January 01, 2004. Calibration and validation periods are, respectively, 01/01/2004 to 12/31/2008 and 01/01/2009 to 12/31/2013 for Saint Johns River near Melbourne; 01/01/2004 to 12/31/2008 and 03/01/2009 to 12/31/2013 for Saint Johns River near DeLand; 06/01/2004 to 12/31/2008 and 01/01/2009 to 12/31/2013 for Saint Johns River near Satsuma; and 02/01/2004 to 12/31/2008 and 01/01/2009 to 12/31/2013 for Saint Johns River near Jacksonville. 81 Figure 3.4: Monthly and annual variation in the sensitivity of 10-year (2010s) mean runoff to perturbations in rainfall in the Saint Johns River Basin and its subwatersheds. 83 
Figure 3.5: Monthly and annual variation in the sensitivity of 10-year (2010s) mean runoff to perturbations in evapotranspiration (ET) in the Saint Johns River Basin and its subwatersheds. 87 Figure 3.6: Monthly and annual variation in the sensitivity of 10-year (2010s) mean runoff to perturbations in imperviousness in the Saint Johns River Basin and its subwatersheds. 90 Figure 3.7: Spatial variation of the simulated changes in 10-year mean annual runoff depth due to the projected changes in (a) climate, (b) land cover, and (c) climate and land cover under different future scenarios in the Saint Johns River Basin. 98

Figure 3.8: Percentage changes in 10-year mean monthly and annual runoff under the projected changes in (a) climate, (b) land cover, and (c) climate and land cover for different future scenarios in the Saint Johns River Basin. For (a) and (c), the box-whiskers represent variations in runoff change across the general circulation models (GCMs); the lower, intermediate, and upper horizontal lines in the boxes indicate 25th, 50th, and 75th percentiles; plus signs indicate extreme outliers. Jan: January; Feb: February; Mar: March; Apr: April; Jun: June; Jul: July; Aug: August; Sep: September; Oct: October; Nov: November; Dec: December; Ann: Annual. 100

Figure 4.1: Major canals, rivers, and land cover types in the Southeast Coasts Basin. The inset showing the location of the study area, Lake Okeechobee, and the Everglades WaterConservation Areas (WCAs) in the state of Florida is not drawn to the map-scale. 132 Figure 4.2: Locations of boundary conditions, model calibrations and validation points, rainfall gauging stations, and groundwater monitoring stations used in the Southeast Coasts Basin model. The inset showing the location of the study area, Lake Okeechobee, and the Everglades Water Conservation Areas (WCAs) in the state of Florida is not drawn to the map-scale. 135 Figure 4.3: Locations of rainfall and tide stations used for extreme rain and sea level estimations in the Southeast Coasts Basin. The numbers beside the station locations indicate station IDs 
assigned by NOAA. The NOAA tide station 8724580 was used to develop the 50-year annual maximum water levels at tide station 8723214 and 8722670 . The inset showing the location of the study area, Lake Okeechobee, and the Everglades Water Conservation Areas (WCAs) in the state of Florida is not drawn to the map-scale. 141

Figure 4.4: Model calibration and validation plots with historical daily streamflow for the Southeast Coasts Basin. 01/01/05 refers to January 01, 2005. Calibration and validation periods are, respectively, $01 / 01 / 2006$ to $12 / 31 / 2008$ and $01 / 01 / 2009$ to $12 / 31 / 2013$ for the C-24 Canal; 01/01/2005 to 12/31/2008 and 01/01/2009 to 12/31/2013 for the West Palm Beach Canal; and 01/01/2006 to 12/09/2008 and 01/01/2009 to 10/03/2011 for the Miami River. For the remaining streams, calibration and validation periods are $01 / 01 / 2004$ to $12 / 31 / 2008$ and $01 / 01 / 2009$ to $112 / 31 / 2013$, respectively. 147 Figure 4.5: Spatial variation of the predicted changes in 7-day total runoff depth due to the projected standalone changes in (a) climate (100-year rainfall together with ET), (b) land cover, and (c) 100-year sea level under different future scenarios in the Southeast Coasts Basin. 155 Figure 4.6: Percentage changes in 1-7 day total runoff due to the projected standalone changes in (a) climate (rainfall of varying return periods and ET), (b) land cover, and (c) sea level of varying return periods under different future scenarios in the Southeast Coasts Basin. 156 Figure 4.7: Spatial variation of the predicted changes in 7-day total runoff depth due to the projected simultaneous changes in (a) climate (100-year rainfall together with ET) and land cover, (b) climate and 100-year sea level, and (c) land cover and 100-year sea level under different future scenarios in the Southeast Coasts Basin. 160 Figure 4.8: Percentage changes in 1-7 day total runoff due to the projected simultaneous changes in (a) climate (rainfall of varying return periods and ET) and land cover, (b) climate and sea level 
of varying return periods, and (c) land cover and sea level of varyig return periods under different future scenarios in the Southeast Coasts Basin.

Figure 4.9: Spatial variation of the predicted changes 7-day total runoff depth due to the projected simultaneous changes in climate (100-year rainfall together with ET), land cover, and 100-year sea level in the Southeast Coasts Basin. 166

Figure 4.10: Percentage changes in 1-7 day total runoff due to the projected simultaneous changes in climate (rainfall of varying return periods and ET), land cover, and sea level of varying return periods under different future scenarios in the Southeast Coasts Basin. 167

Figure 5.1: Subwatersheds, major streams, and land cover types in the Saint Johns River Basin. The inset showing location of the study area in the state of Florida is not drawn to the map-scale.

Figure 5.2: Locations of boundary conditions, model calibrations and validation points, rainfall gauging stations, and groundwater monitoring stations used in the Saint Johns River Basin model. The inset showing location of the study area in the state of Florida is not drawn to the map-scale.

Figure 5.3: Locations of rainfall and tide stations used for extreme rain and sea level estimations in the Saint Johns River Basin. The numbers beside the station locations indicate station IDs assigned by NOAA. The inset shows location of the study area in the state of Florida and the NOAA tide station 8724580 which was used to develop the 50-year annual maximum water levels at tide station 8720218 . Inset is not drawn to the map-scale. 202 Figure 5.4: Plots of model calibrations and validations with historical daily streamflow for the Saint Johns River Basin. 01/01/04 refers to January 01, 2004. Calibration and validation periods are, respectively, 01/01/2004 to 12/31/2008 and 01/01/2009 to 12/31/2013 for Saint Johns River 
near Melbourne; 01/01/2004 to 12/31/2008 and 03/01/2009 to 12/31/2013 for Saint Johns River near DeLand; 06/01/2004 to 12/31/2008 and 01/01/2009 to 12/31/2013 for Saint Johns River near Satsuma; and 02/01/2004 to 12/31/2008 and 01/01/2009 to 12/31/2013 for Saint Johns River near Jacksonville. 207 Figure 5.5: Spatial variation of the predicted changes in 7-day total runoff depth due to the projected standalone changes in (a) climate (100-year rainfall together with ET), (b) land cover, and (c) 100-year sea level under different future scenarios in the Saint Johns River Basin....... 213 Figure 5.6: Percentage changes in 1-7 day total runoff due to the projected standalone changes in (a) climate (rainfall of varying return periods and ET), (b) land cover, and (c) sea level of varying return periods under different future scenarios in the Saint Johns River Basin. 215 Figure 5.7: Spatial variation of the predicted changes in 7-day total runoff depth due to the projected simultaneous changes in (a) climate (100-year rainfall together with ET) and land cover, (b) climate and 100-year sea level, and (c) land cover and 100-year sea level under different future scenarios in the Saint Johns River Basin. 219 Figure 5.8: Percentage changes in 1-7 day total runoff due to the projected simultaneous changes in (a) climate (rainfall of varying return periods and ET) and land cover, (b) climate and sea level of varying return periods, and (c) land cover and sea level of varying return periods under different future scenarios in the Saint Johns River Basin. 221 Figure 5.9: Spatial variation of the predicted changes 7-day total runoff depth due to the projected simultaneous changes in climate (100-year rainfall together with ET), land cover, and 100-year sea level in the Saint Johns River Basin 225 
Figure 5.10: Percentage changes in 1-7 day total runoff due to the projected simultaneous changes in climate (rainfall of varying return periods and ET), land cover, and sea level of varying return periods under different future scenarios in the Saint Johns River Basin. .......... 227 


\section{Chapter 1: Introduction}

\subsection{Background and motivation}

Land cover changes from urbanization can increase atmospheric concentrations of greenhouse gases and lead to consequent rise in temperature. The increased temperature is anticipated to bring increased stormwater runoff especially in areas of higher latitudes and the wet tropical areas; however, most dry tropical regions are expected to experience runoff decreases (IPCC, 2014a). Global warming from anthropogenic activities can also be responsible for increasing extreme rainfall (Trenberth et al., 2003; Groisman et al., 2005) and the consequent increased urban flooding risks (Pedersen et al., 2012). Meanwhile, human interventions through increase in impervious covers, loss of natural depressions, and alteration of natural drainage paths can contribute to increased runoff (McMahon et al., 2003; White and Greer, 2006; Huang et al., 2008; Hawley and Bledsoe, 2011). The shifting climate and hydrology along with the changing landscape can therefore substantially impact both urban and natural water resources. Inshore areas, on top of all these, are subject to sea-level rise risks. Urbanization and climate change can bring massive flooding risks in the cities with an estimated global annual flood losses of $\$ 52$ billion by 2050 ; inclusion of the risks of sea-level rise and sinking land make the estimated loss to be $\$ 1$ trillion per year (Hallegatte et al., 2013). Therefore, it would be crucial to develop a comprehensive understanding of the consequences of future developments, climatic changes, and sea level rise in order to assess climatic resilience of the urban and natural areas and minimize the potential vulnerabilities.

Much research has investigated the role of different stressors of stormwater runoff and receiving streamflow for watersheds around the world. Sensitivity analyses of runoff to changing climate and land cover has been a major focus of research in the recent decade (e.g., Zhang et al., 
2008; Mateus et al., 2015; Abdul-Aziz and Al-Amin, 2015). Research on this line has extensively applied mechanistic rainfall-runoff models that can integrate different drivers of stormwater runoff and streamflow in watersheds of varying spatial scales based on numerical representation of the principal physical processes. For example, Olang and Fürst (2011) reported notable increase in annual runoff volume due to land cover changes between 1973 and 2002 in the Nyando River Basin in Kenya by implementing the Hydrologic Modeling System (HECHMS) (USACE, 2000). Cuo et al. (2013) reported significant changes in seasonal and annual streamflow under changing precipitation, evapotranspiration (ET), and land cover in the upper Yellow River Basin of China during the past decades by using the Variable Infiltration Capacity (VIC) model (Liang et al., 1994). Furthermore, mechanistic rainfall-runoff models have been applied in simulating the rapid increases in runoff and streamflow caused by extreme rainfall events. Sharif et al. (2010) simulated response of the lower Guadalupe River Basin in Texas, USA under heavy rainfall on November 2004 with reasonable accuracy using the Gridded Surface Subsurface Hydrologic Analysis (GSSHA) model (Downer and Ogden, 2006). Borah et al. (2007) implemented the dynamic watershed simulation model (DWSM) (Borah et al., 2002) to model high and peak flows of the Little Wabash River in Illinois, USA with acceptable error margins during the extreme storm events on March 1995, May 1995, and May 2002.

Hydrological research have incorporated projected changes in climate and land cover into the mechanistic rainfall-runoff models to predict future changes in both long-term stormwater runoff and extreme event induced flooding. Franczyk and Chang (2009) estimated changes in mean annual runoff under increasing mean annual precipitation and high-density urban developments in the 2040s (2030-2059), relative to the baseline period of 1973-2002 for the Rock Creek Basin in Oregon, USA by employing the ArcView Soil and Water Assessment Tool 
(AVSWAT) (AVSWAT-X, 2006). Salathé et al. (2014) applied the VIC model (Liang et al., 1994) for the Pacific Northwest of USA; their results suggested increased occurrences of extreme storm events and corresponding general increases in flood intensity in early fall. Zheng et al. (2018) reported increases in mean annual runoff due to climatic changes during 2046-2075, relative to the 1976-2005 period, across the Indian subcontinent of south Asia by using a global hydrological model, H08 (Hanasaki et al., 2008a, b).

Data-driven approaches, which establish relationships between response (dependent) variables with predictor (independent) variables based on their respective observed records, have been implemented for simulating runoff and streamflow responses in recent hydrological research. Data-driven approaches can be categorized further as empirical and machine-learning approaches. Reitz et al. (2017) applied empirical non-linear regressions for estimation of annual quick-flow runoffs (i.e., direct runoffs) for the contiguous USA. Fang et al. (2015) used empirical partial least squares regression (PLSR) approach to identify controlling variables of runoff for the Three Gorges Area in China. Among the machine learning techniques, artificial neural network (ANN; e.g., Sinha et al., 2015; Chen et al., 2013; Chakravarti et al., 2015), support vector machine (SVM; e.g., Sedighi et al., 2016; Granata et al., 2016), and regression tree (e.g., Ji et al., 2013; Zhang et al., 2019) have been extensively used for assessments of runoff, streamflow, and flooding risks. The major drawback of the black-box data-driven approaches, however, is they cannot represent the underlying physical processes regarding the rainfall-runoff relationships. Moreover, the data-driven hydrologic models are often lumped in nature and, therefore, are not suitable for modeling of large-scale watersheds due to their inability to account for spatial variation in the parameters, forcing variables, and the model outputs. 
Although the existing research on the changing runoff regimes and potential flooding scenarios has addressed different regions over the world, relatively limited research has focused on the highly complex coastal hydrological settings such as the eastern part of Florida, USA along the Atlantic coast. Obeysekera et al. (2015) assessed the overall hydrologic responses of south Florida under different climate change scenarios. Their results indicated substantial changes in the regional water budget and consequent adverse impacts on livelihoods in agricultural, ecosystems, and urban areas of south Florida under changing precipitation and rising temperature. Abdul-Aziz and Al-Amin (2015) computed both individual and combined hydro-climatic and land cover sensitivities of stormwater runoff for the highly urbanized Miami River Basin of southeast Florida. They found rainfall to be the dominant driver of runoff as compared to land use/cover, with notable seasonal variation of the sensitivities. The authors also reported stronger non-linear responses of runoff under combined changes in climate (rainfall) and land cover (imperviousness) than the linear summation of impacts of individual changes in these drivers. It would be, however, crucial to investigate whether the runoff sensitivities reported by Abdul-Aziz and Al-Amin (2015) for the Miami River Basin scale up for the largescale urban-natural environments along the Atlantic coast of Florida which contain many prominent urban centers and agro-natural landscapes as well. Projection of the potential future stormwater runoff scenarios and extreme event induced pluvial (i.e., rainfall accumulation) flooding in this region would also be a prime requisite. The existing knowledge gap regarding the pattern of stormwater runoff and pluvial flooding responses along the coastal urban-natural gradient is the key stimulus of this research. The eastern Florida would be considered as an ideal representation of the coastal urban-natural transitions for our research, and the outcomes would globally aid in achieving sustainability of the vulnerable coastal environments. 


\subsection{Research goal, hypotheses, and objectives}

The goal of this research is to examine the dynamics of stormwater runoffs in complex coastal urban-natural environments. The central research hypothesis is that potential changes in stormwater runoff responses in coastal environments would represent similarities in runoff sensitivities, stormwater budget changes, and extreme runoff regime changes across the urbannatural gradient under a changing climate, land cover, and sea level. This dissertation intends to evaluate three component hypotheses as follows:

Hypothesis-1: Stormwater runoff in coastal environments would have notable sensitivities to standalone changes in climate and land cover while concurrent changes in these drivers would bring about nonlinear runoff responses.

Hypothesis-2: Anticipated changes in climate and land cover in the future would lead to overall runoff increase in large coastal watersheds.

Hypothesis-3: Extreme event induced pluvial flooding risks in coastal environments would intensify in the future under changes in climate, land cover, and sea level.

The research would quantify the monthly and annual sensitivities of stormwater runoff to its drivers in coastal watersheds, and predict the potential future changes in stormwater runoff and pluvial flooding risks while appraising the component hypotheses. The specific objectives are stated as follows:

Objective-1: To quantify the sensitivities of historical stormwater runoff under standalone and concurrent changes in climate and land cover in large-scale coastal watersheds. 
Objective-2: To project the potential future stormwater runoff scenarios under changing climate and land cover in large-scale coastal watersheds.

Objective-3: To assess the changes in extreme event induced runoff and pluvial flooding risks under potential future changes in climate, land cover, and sea level in large-scale coastal watersheds.

Objective-4: To evaluate the similarities in runoff sensitivities, stormwater budget changes, and extreme runoff regime changes across the Atlantic coasts of Florida under a changing climate, land cover, and sea level.

\subsection{Organization of the dissertation}

The dissertation is organized into six chapters. Chapter 1 presents the background and motivation of the research, the research hypothesis, and the supporting objectives.

Chapters 2 and 3 test the first and second hypothesis through the first two objectives. Two large-scale hydrologic models were developed, calibrated and validated for coastal-urban and coastal-natural environments along the Atlantic coast of Florida. The calibrated and validated models were used to evaluate sensitivities of runoff to both isolated and combined changes in climate and land cover. By incorporating future climatic and land cover projections, potential future changes in coastal-urban and coastal-natural runoffs were estimated.

Chapters 4 and 5 test the third hypothesis through the third objective. Significance and direction of trends in annual maximum rainfalls and sea levels of 1-7 day durations were determined for the coastal-urban and coastal-natural environments. Historical and future extreme rainfalls and sea levels were then estimated. The future extreme rainfalls and sea levels together 
with projected land cover changes were incorporate into the hydrologic models as inputs to compute the potential future changes in extreme runoff volume.

Chapter 6 synthesizes the study findings and evaluates the applicability of the research hypotheses. This chapter also discusses the potential implications of the study findings and provides suggestions and recommendations for future research. 


\title{
Chapter 2: Large-scale modeling and assessment of climate and land cover change impacts on the stormwater runoff in complex coastal-urban environments
}

\begin{abstract}
The individual and synergistic controls of climatic and land cover changes on stormwater runoff regimes were determined for coastal-urban environments, representing complex drainage networks. A large-scale $\left(7117 \mathrm{~km}^{2}\right)$ mechanistic hydrologic model was developed for Florida Southeast Coasts Basin as the study area using U.S. Environmental Protection Agency (U.S. EPA)'s Storm Water Management Model (SWMM) 5.1. The model was calibrated and validated with daily streamflow observations (Nash-Sutcliffe Efficiency $=0.74$ to 0.92 ) during 2004-2013 (termed 2010s), computing the corresponding runoff volume as a historical reference. Runoffs for 2050s (2044-2053) and 2080s (2076-2085) were quantified by incorporating climatic projections from 20 General Circulation Models (GCMs) and land cover projections from EPA under the Representative Concentration Pathways (RCP) 4.5 and 8.5 scenarios. The future runoff scenarios suggested a predominant climatic control on potential runoff changes and high

vulnerability in the coastal-urban environments. Based on the basin-scale annual averages, runoff sensitivity to changes in rainfall was 2.5 and 5 times stronger than that to changes in watershed imperviousness and evapotranspiration, respectively. Further, the concurrent changes in climate and land cover led to synergistic (stronger) nonlinear responses of runoff, compared to the linear summation of their individual effects. The projected changes in climate and land cover together would increase the annual basin runoff by $118 \%, 106 \%, 86 \%$, and $80 \%$ under the 2080 s-RCP 4.5, 2050s-RCP 4.5, 2050s-RCP 8.5, and 2080s-RCP 8.5 scenarios, respectively. Higher (than other locations) runoff increases were noted at and around the urban centers across the basin. The relative increases in runoff were higher during the dry season and transitional months (October-
\end{abstract}


May) than the wet season (June-September). The study findings would guide stormwater management and ecosystem protection for southeast Florida and coastal built environments across the world.

\subsection{Introduction}

The increasing global temperature is expected to increase rainfall and stormwater runoff in high latitude and wet tropical areas; however, dry tropical and semi-arid regions are expected to experience decrease in rainfall and runoff (IPCC, 2014a). Human interventions can also lead to increased urban runoff due to the increasing impervious cover, loss of natural depressions, and alteration of drainage (White and Greer, 2006; Huang et al., 2008; Hawley and Bledsoe, 2011). A changing climate and hydrology, in concert with various components of built environments, would substantially affect urban water resources (Johnson et al., 2015). Urbanization and climate change can specifically increase widespread flooding risk in cities, amounting to an annual estimated loss of $\$ 52$ billion globally by the mid- $21^{\text {st }}$ century (Hallegatte et al., 2013). A comprehensive analysis and understanding of the potential changes in urban runoff regimes is, therefore, necessary to adjust for the detrimental outcomes under future developments and climatic changes (Jacobson, 2011).

Much research has been conducted to investigate the influence of various environmental drivers on stormwater runoff and receiving streamflow in watersheds around the world. In particular, runoff sensitivity to the historical and/or experimental changes in climate and land cover has been a major research focus for decades (e.g., Zhang et al., 2008; Mateus et al., 2015; Abdul-Aziz and Al-Amin, 2015). Mechanistic (process-based) hydrologic models have primarily been employed for this purpose, where different environmental drivers and watershed components of stormwater runoff and streamflow are conceptualized and parameterized. For 
example, Hamdi et al. (2011) used Surface Externalisée model (Le Moigne et al., 2009) to report a significant increase in annual runoff due to a $35 \%$ increase in imperviousness in Brussels, Belgium during 1960-1999. Olang and Fürst (2011) also found notable increases in annual runoff due to land cover changes between 1973 and 2002 by using the HEC-HMS model (USACE, 2000) for the Nyando River Basin in Kenya. Cuo et al. (2013) employed the variable infiltration capacity model (Liang et al., 1994) in the Yellow River Basin of China, and reported significant changes in seasonal and annual streamflows due to changes in precipitation, evapotranspiration (ET), and land cover over the previous decades.

Mechanistic hydrologic models have also been widely used to compute potential changes in runoff by incorporating the projected future changes in climate and land cover. Franczyk and Chang (2009) employed Soil and Water Assessment Tool (SWAT) (Neitsch et al., 2005) and reported potential increases in annual runoff due to the projected increases in precipitation and urbanization during 2030-2059 (relative to 1973-2002) for the Rock Creek Basin in Portland, Oregon, USA. Wagesho et al. (2012) built a model with SWAT for the Rift Valley Lakes Basin of Ethiopia, and found both increases and decreases in annual runoff across the basin under the projected climate during 2080-89, relative to 1990-99. Chiew and McMahon (2002) built MODHYDROLOG models for many catchments across Australia, and found amplified changes (increases and decreases) in runoff in response to the projected changes in rainfall for 2030, relative to 1990. Zheng et al. (2018) used a global hydrological model, H08 (Hanasaki et al., 2008a, b) and reported increases in mean annual runoff due to climatic changes during 20462075, relative to the 1976-2005 period, across the Indian subcontinent of south Asia.

Although the existing literature on the effects of changing climate and land cover on runoff has represented different regions of the world, research focusing on the thriving coastal-urban 
environments has been scarce. Further research is, therefore, warranted to assess vulnerabilities and achieve resilience in coastal-urban environments, which often represent major population centers and economic hubs. Southeast Florida, USA is an ideal representation and living laboratory of coastal-urban hydrologic settings, with a highly complex drainage network and continuing developments since the $20^{\text {th }}$ century (Hughes and White, 2016). Obeysekera et al. (2015) examined the hydrologic responses of south Florida under different climate change scenarios. They reported significant variation in precipitation and runoff along with rising temperature, which might substantially change the regional water budget and adversely impact the associated communities. Abdul-Aziz and Al-Amin (2015) quantified individual as well as combined hydro-climatic and land cover sensitivities of stormwater runoff for the Miami River Basin (drainage area $\sim 175 \mathrm{~km}^{2}$ ) of Florida. They reported rainfall as the stronger controlling driver of runoff than land use/cover, with salient seasonal variation. They also reported a stronger, nonlinear response of runoff to concurrent changes in climate (rainfall) and land cover (imperviousness) than the linear summation of their standalone, individual effects. The study, however, encompassed a relatively small area of southeast Florida and did not incorporate future projections of climate or land uses/cover to evaluate the potential impacts on storm runoff.

This study aims to assess the influence of climate and land cover drivers on stormwater runoff, and performs a comparative analysis of historical and future runoff scenarios for large complex coastal-urban environments. Pluvial runoff volume (excess rainfall on the ground) is regarded as the stormwater runoff in this study based on the conventional terminology (Falconer et al., 2009; Carter et al., 2015; Rosenzweig et al., 2018). A large-scale mechanistic hydrologic model is developed considering the Southeast Coasts Basin of Florida as the study area using the Storm Water Management Model (SWMM) 5.1 of the U.S. Environmental Protection Agency 
(U.S. EPA) (Rossman, 2015). The model is calibrated and validated with historical streamflows. Stormwater runoff sensitivities to reference changes in climatic variables and land cover features are first computed. The future stormwater runoff for the basin is then computed by incorporating projections of climatic and land cover variables as inputs to the model, identifying the potential risk areas of exacerbated flooding and environmental pollutions.

\subsection{Materials and methods}

\subsubsection{Study area}

The Florida Southeast Coasts Basin drains an area of approximately $7117 \mathrm{~km}^{2}$ (Figure 2.1). Majority of the basin represents highly urbanized land uses such as single-family housing units, apartment complexes, and commercial and industrial areas. However, the western (especially northwestern) and southern parts of the basin represent significant other land uses/cover, including croplands, pasture lands, and wetlands (Figure 2.1). Miami, Fort Lauderdale, West Palm Beach, Doral, Hialeah, Delray Beach, Boca Raton, and Hollywood are the eminent, highly urbanized, and evergrowing cities in the basin. Further, the cities of Homestead, Weston, Sunrise, Jupiter, Fort Pierce, and Port St. Lucie represent other fast growing urban centers in this coastal-urban basin. 


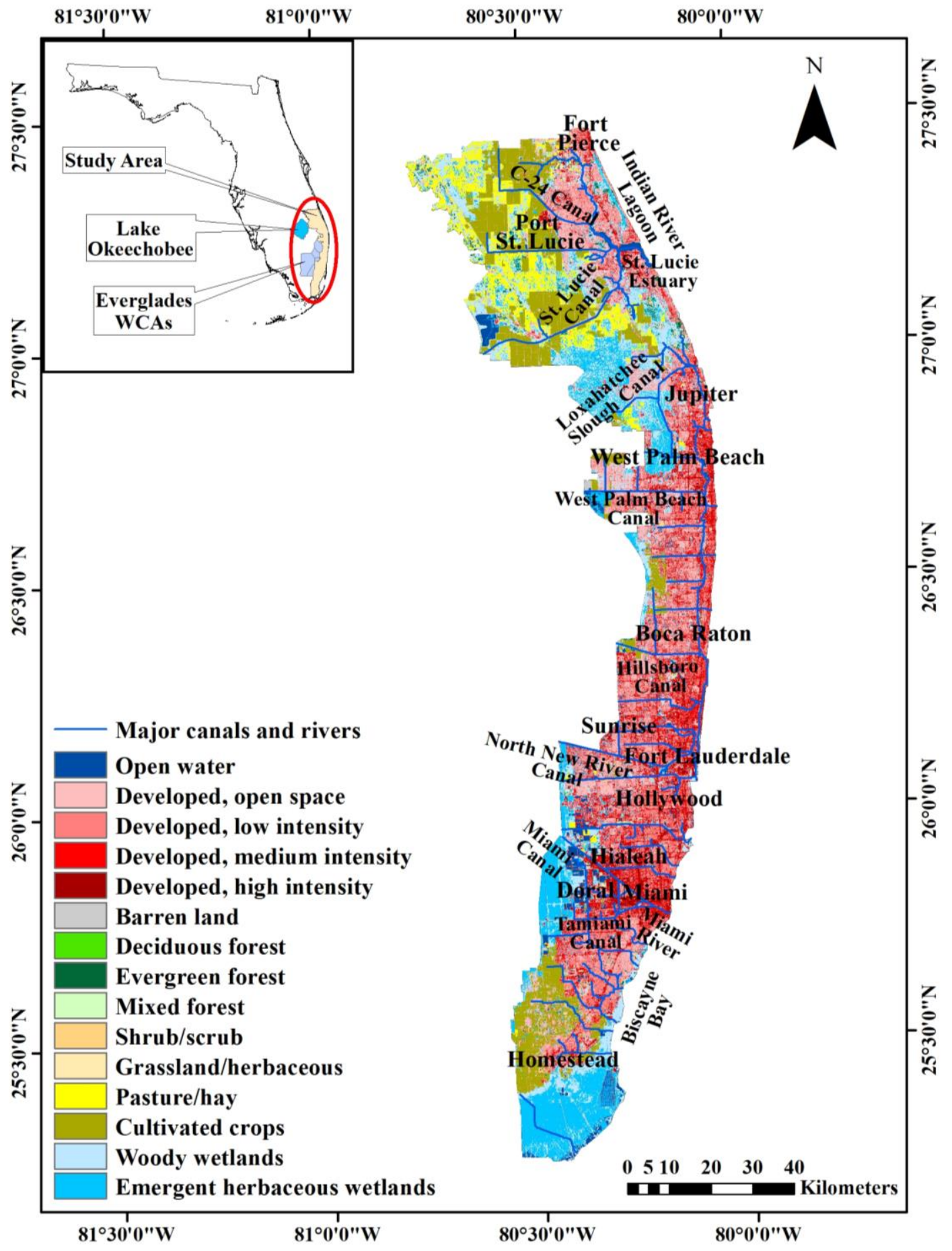

Figure 2.1: Major canals, rivers, and land cover types in the Southeast Coasts Basin. The inset shows the locations of the study area, Lake Okeechobee, and the Everglades Water Conservation Areas (WCAs) in the state of Florida. Inset is not drawn to the map-scale. 
A distinct and complex drainage networks of rivers and canals drain the Southeast Coasts Basin to the Atlantic Ocean (Figure 2.1 and 2.2). Tamiami Canal (also known as C4 canal), Miami River (C6 canal), North New River Canal, Hillsboro Canal, West Palm Beach Canal, St. Lucie River, and Loxahatchee Slough Canal are some of the major streams in the basin. Most major streams originate from Lake Okeechobee (the largest freshwater lake in Florida), and pass through the Everglades Water Conservation Areas (WCAs) before entering the Southeast Coasts Basin. These streams typically drain into the estuarine water bodies (e.g., St. Lucie Estuary, Indian River Lagoon, and Biscayne Bay), prior to reaching the Atlantic Ocean. The rivers and canals are managed by control structures and gates to mitigate flooding and salinity intrusion.

As per the Köppen-Geiger climate classification (Kottek et al., 2006; Rubel et al., 2017), there is a gradient of climate zones across the study basin (ORNL DAAC, 2017). The upper northeastern part (e.g., Port St. Lucie) is characterized by humid subtropical climate with highly varying rainfall over the year. However, places such as Jupiter experience tropical rainforest climate with approximately uniformly distributed rainfall over the year. The middle part of the basin from Miami to West Palm Beach are predominantly subject to tropical climate with a relatively long monsoon season and a short dry season. The lower southern part (e.g., Homestead) undergoes tropical savannah climate having longer dry seasons than tropical monsoon climate. 


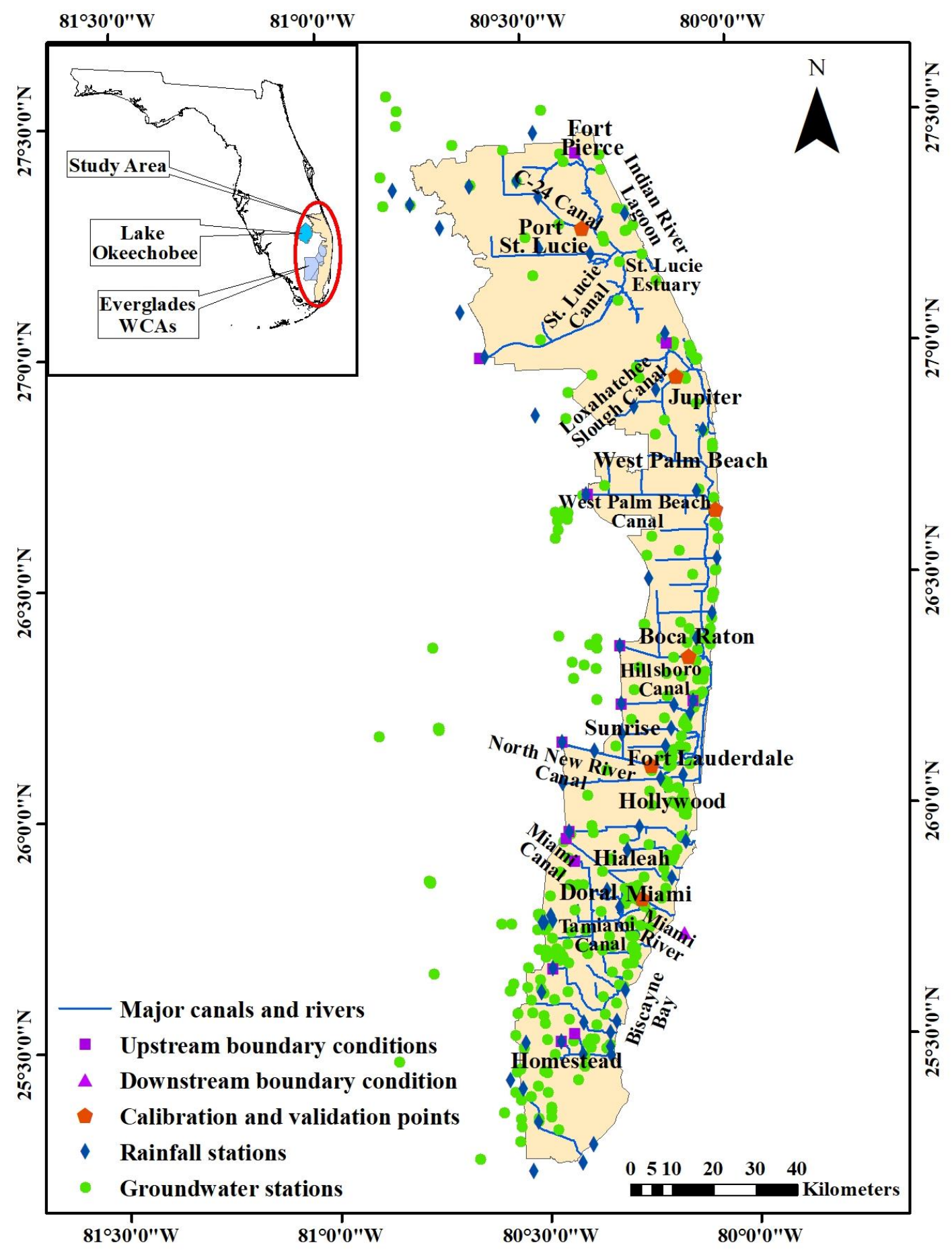

Figure 2.2: Locations of boundary conditions, model calibrations and validation points, rainfall gauging stations, and groundwater monitoring stations used in the Southeast Coasts Basin model. The inset shows the location of the study area, Lake Okeechobee, and the Everglades Water Conservation Areas (WCAs) in the state of Florida. Inset is not drawn to the map-scale. 


\subsubsection{Data sets for model development}

The boundaries of Southeast Coasts Basin were determined based on the hydrological unit code (HUC8; ID: 03090206), delineated by the U.S. Geological Survey (USGS) (USGS, 2016a). Isolated areas and barrier islands in the ocean (e.g., Miami Beach, Key Biscayne) were not included in the study basin. Digital elevation models (DEMs), with a resolution of 1/3 arc-second (approximately $10 \mathrm{~m}$ ), were obtained from the National Elevation Dataset (NED) (USGS, 2016b). Spatial variation of land cover over the basin was represented by using $30 \mathrm{~m}$ percent imperviousness data from the National Land Cover Database (NLCD) (Fry et al., 2011; Homer et al., 2015). Soil types for the subbasins were determined based on the hydrologic soil groups of the soil survey geographic database (SSURGO; USDA-NRCS, 2015) and following guidelines from the National Engineering Handbook (USDA-NRCS, 2009) and Rawls et al. (1983).

Observations of volumetric streamflow rate for different canals and rivers during 2004-13 were obtained from the national water information system (USGS, 2017) and from the environmental database (called DBHYDRO) of South Florida Water Management District (SFWMD) (SFWMD, 2017). Streamflow from 14 stations were used as the upstream boundary conditions in the model (Figure 2.2; Table A2.1 in Appendix 2). Hourly water levels from the National Oceanic and Atmospheric Administration (NOAA)'s tidal station 8723214 at Virginia Key, Biscayne Bay were utilized as the downstream boundary conditions at the Miami River outlet. Downstream boundary conditions for other major streams were not available in close proximity. The Southeast Coasts Basin has numerous control structures (e.g., culverts, spillways, gates). The locations of model calibrations and validations represented 6 control structures (Figure 2.2). Structural attributes (e.g., number of gates, gate size, and crest elevation) and real time gate opening data for the control structures were obtained from DBHYDRO. 
Surveyed data on stream cross section and bed elevation for Tamiami Canal and Miami River, as well as for their branches and tributaries, were obtained from SFWMD (see Abdul-Aziz and Al-Amin, 2015). The geometric information for rivers and canals at the northern parts of the basin were obtained from a technical report of SFWMD on the bathymetric survey of St. Lucie Estuary (Morris, 1986). Trapezoidal cross sections and bed elevation data on the remaining drainage networks were also obtained from SFWMD.

Hourly rainfall records of 2004-2013 for 71 stations within and around the Southeast Coasts Basin (Figure 2.2) were used to account for spatiotemporal variability. Rainfall data for 65 stations were collected from DBHYDRO, and for 6 stations from NOAA's National Climatic Data Center (NCDC) database. Satellite-based gridded $(2 \mathrm{~km})$ daily potential ET data for 20042013 were downloaded from USGS (USGS, 2016c) to compute monthly average ET rates (mm/day) in SWMM. Observed groundwater level (GWL) data for 410 stations [160 SFWMD stations, 2 Everglades National Park (ENP) Stations, and 248 USGS stations] were used to represent the interactions of surface water and groundwater in the basin (Figure 2.2).

\subsubsection{Development of the rainfall-runoff model using EPA SWMM 5.1}

The U.S. EPA SWMM 5.1 is a process-based, dynamic rainfall-runoff model that integrates different components of urban hydrology, hydro-climatological variables, and land cover features (Rossman, 2015). A summary of major model variables and parameters for the Florida Southeast Coasts Basin is provided in Table 2.1. As a first step, the large-scale basin was split into smaller subbasins, which were drained by networks of links (stream segments) and nodes (junctions). The initial set was generated based on 10 m DEMs by using Arc Hydro (Maidment and Morehouse, 2002) for ESRI ArcGIS 10.2. The subbasins and link-node networks were then modified to practically represent the complex hydrologic networks of southeast Florida (see 
details in Text A2.1 of Appendix 2). Finally, we had 333 subbasins, 434 links, and 436 nodes. Given the large basin area, the underground sewers and catch-basins were not explicitly parameterized, as runoff from the subbasins ultimately drained to the rivers and canals.

Hourly rainfall data from 71 stations were assigned to the different subbasins (Figure A2.1 in Appendix 2) based on Thiessen polygons (see Text A2.2 for details). Spatially averaged monthly potential ET rates (mm/day) were assigned to the model since the ET had a low spatial variability across the basin (coefficient of variation $=1.56$ to $8.8 \%$ for different months). SWMM requires initial GWL only. Dry season observations (on or near 01/01/2004) from different monitoring wells (Figure 2.2) were assigned as the initial GWL for the different subbasins (see Text A2.3 and A2.4 for details). The GWL is updated dynamically in SWMM through a groundwater mass balance and dynamic interactions with the surface water (Rossman, 2016).

The slopes of the subbasins were determined from the percent slope raster, which was generated from the 10 meter DEM by using Arc Hydro. Temporally averaged percent imperviousness for 2004-2013 (Figure A2.2) were obtained from the 'percent developed imperviousness' raster of NLCD 2006 and NLCD 2011 (Fry et al., 2011; Homer et al., 2015). Initial values of overland roughness coefficients and depression storage depths of the subbasins were determined based on the recommended values in SWMM Reference Manual (Rossman, 2016) and SWMM User's Manual (Rossman, 2015). Characteristic width of the subbasins were determined based on the channel lengths and shape of drainage areas (see Text A2.5). Depending on the soil types of subbasins, initial values of Green-Ampt infiltration parameters and aquifer parameters (Table 2.1) were determined based on recommendations given in SWMM Reference Manual (Rossman, 2016). Further, the model was constrained with 14 upstream boundary 
conditions and 1 downstream boundary condition (Figure 2.2; Table A2.1) to account for external influence from upstream (Lake Okeechobee, Everglades, WCAs) and tides at the downstream.

Table 2.1: Model variables and calibrated parameters for the Florida Southeast Coasts Basin during 2004-2013.

\begin{tabular}{|c|c|}
\hline Variables and Parameters & Range \\
\hline \multicolumn{2}{|l|}{ Climate } \\
\hline Rainfall* (mm/hr) & 0 to 181.10 \\
\hline Potential evapotranspiration* (mm/day) & 1.74 to 5.44 \\
\hline \multicolumn{2}{|l|}{ Overland flow } \\
\hline Characteristic width (m) & 171.27 to 42806.45 \\
\hline Imperviousness* $(\%)$ & 0.01 to 75.60 \\
\hline Slope $(\%)$ & 0.01 to 3.21 \\
\hline Overland roughness coefficient (Manning's n) for impervious subarea & 0.01 to 0.019 \\
\hline Overland roughness coefficient (Manning's n) for pervious subarea & 0.017 to 0.20 \\
\hline Depression storage depth for impervious subarea (mm) & 1.27 to 2.54 \\
\hline Depression storage depth for pervious subarea (mm) & 2.54 to 7.62 \\
\hline \multicolumn{2}{|l|}{ Infiltration and groundwater flow } \\
\hline Initial suction head (mm) & 88.37 to 109 \\
\hline Saturated hydraulic conductivity $(\mathrm{mm} / \mathrm{hr})$ & 3 to 170.40 \\
\hline Initial moisture deficit ${ }^{\mathrm{a}}$ & 0.02 to 0.25 \\
\hline Soil porosity & 0.43 to 0.49 \\
\hline Field capacity & 0.06 to 0.19 \\
\hline Permanent wilting point & 0.024 to 0.085 \\
\hline Lower evaporation depth ${ }^{\mathrm{b}}(\mathrm{m})$ & 0.25 to 3.5 \\
\hline Initial groundwater elevation (m NAVD 88) & -3.5 to 7.84 \\
\hline Unsaturated zone moisture content & 0.24 to 0.41 \\
\hline Groundwater flow coefficient, A1 & 0.001 to 0.041 \\
\hline Groundwater flow exponent, B1 & 1 \\
\hline Surface water flow coefficient, A2 & 0.01 to 0.0106 \\
\hline Surface water flow exponent, B2 & 1 \\
\hline Surface water-ground water exchange coefficient, A3 & -0.0002 to 0 \\
\hline \multicolumn{2}{|l|}{ Streamflow } \\
\hline Channel roughness (Manning's n) & 0.02 to 0.04 \\
\hline
\end{tabular}

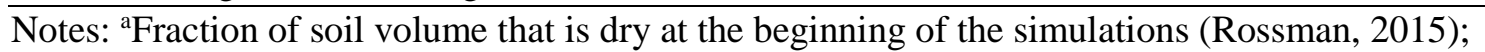
${ }^{b}$ maximum depth below the surface at which evapotranspiration can take place from the lower saturated zone (Rossman, 2015); " variables or parameters used for sensitivity analyses. 
The overall structure of Southeast Coasts Basin SWMM model was summarized through a diagram (Figure A2.3). The model was run at hourly reporting time-step for continuous simulation during 2004-2013. We calibrated and validated the model with daily mean observed streamflow of, respectively, 01/01/2004-12/31/2008 and 01/01/2009-12/31/2013 at 6 different streams (Figure 2.2; Table A2.2). Subbasin parameters such as characteristic width and overland roughness coefficients (Manning's n), infiltration parameters, aquifer parameters, coefficients (A1, A2, A3) of the lateral groundwater flow equation, and channel roughness coefficient (Manning's n) were adjusted for model calibration (Table 2.1). In parallel to the calibration process, we also ensured that the temporal pattern of the simulated GWL for each subbasin was realistic by bounding the lower limit of fluctuations within the vicinity of the initial (i.e., dry season) GWL.

Metrics used for model performance evaluation were the Nash-Sutcliffe Efficiency (NSE) (Nash and Sutcliffe, 1970) and the ratio of the root-mean-square error to the standard deviation of observations (RSR) (see Text A2.6 for details). The 6 streamflow stations used for calibrations and validations of the Southeast Coasts Basin model represented control structures. Since real time gate opening data for these structures were used in the model, no streamflow was allowed when the gates had been closed. Therefore, effective NSE and RSR were computed by excluding zero flowrate records in the observed as well as simulated time-series.

\subsubsection{Climate and land cover projections to determine future runoff scenarios}

Downscaled climatic projections of the 20 Coupled Model Intercomparison Project's fifth phase (CMIP5) general circulation models (GCMs) (see Table A2.3) from the multivariate adaptive constructed analogs (MACA) dataset (Abatzoglou and Brown, 2012) were used. This dataset provided historical climate simulations for 1950-2005 and future projections for 2006-2099 
under the Representative Concentration Pathways (RCP) 4.5 and 8.5 scenarios (IPCC, 2014b). Based on the availability of observed (gauge) hourly rainfall at 71 stations (Figure 2.2), the 10 years of model evaluation period (2004-2013) was defined as the historical baseline period of 2010s. The future 10-year periods of 2050s (2044-2053) and 2080s (2076-2085) were then defined for comparative evaluations of changes in rainfall, land cover, and runoff in the study basin. The daily modeled (GCM-MACA) rainfalls were extracted for 2010s, 2050s, and 2080s at the 71 historical stations. Monthly potential ET for these periods were also obtained from the MACA dataset, which presented modeled ET using the Penman-Monteith method (Allen et al., 1998).

Based on the historical and future MACA climatic datasets, station-specific, biascorrected future projections of rainfall and ET were constructed by adopting a delta change factor methodology (Teutschbein and Seibert, 2012; Chen et al., 2013). GCMs perform better in representing rainfall variability on the monthly scale than that on the daily scale (Zhang, 2013; Langousis et al., 2016). Therefore, relative change in rainfall between the historical 2010s and a future period (2050s, 2080s) was represented as the ratio of model-projected future monthly rainfall $\left(Y_{\text {fut,proj }}\right)$ over model-simulated historical monthly rainfall $\left(Y_{\text {hist,sim }}\right)$. This approach resulted in 10 ratio values (for the 10-year study periods) for each month. The monthly ratio values outside the range between a lower boundary of $Q_{1}-1.5 * I Q R$ and an upper boundary of $Q_{3}+1.5 * I Q R\left(Q_{1}=25^{\text {th }}\right.$ percentile; $Q_{3}=75^{\text {th }}$ percentile; $\left.I Q R=Q_{3}-Q_{1}\right)$ were identified as outliers (Tukey, 1977). The outlying ratio values were replaced with the closest boundary (i.e., upper or lower) values. The observed historical (2010s) monthly rainfall $\left(Y_{\text {hist,obs }}\right)$ was then multiplied by the final set of change ratio values $\left(Y_{\text {fut,proj }} / Y_{\text {hist,sim }}\right)$ to construct the future 
monthly rainfall $\left(Y_{f u t, r e c}\right)$ for 2050s and 2080s. Future monthly ET scenarios were similarly constructed by incorporating the corresponding relative change ratios.

Future projections of land cover (imperviousness) were obtained from the Integrated Climate and Land-Use Scenarios (ICLUS) dataset (version 1.3.2) (U.S. EPA, 2010). The ICLUS land cover projections were available for the Special Report on Emissions Scenarios (SRES) (Nakicenovic et al., 2000). Since the CMIP5 climatic projections were available for the RCP scenarios, it was necessary to relate the SRES to the RCP scenarios. In terms of atmospheric $\mathrm{CO}_{2}$ concentrations, global radiative forcing, and global mean temperature, SRES A1FI was similar to RCP 8.5, while SRES B1 showed resemblances to RCP 4.5 (Van Vuuren and Carter, 2014). Therefore, the imperviousness projections were obtained for SRES A1 and B1. Future percent imperviousness of the subbasins were then computed based on the corresponding relative changes between the historical and future periods given by the ICLUS dataset. For a subbasin, ratio of the projected future imperviousness in 2050 or $2080\left(I_{f u t, p r o j}\right)$ over simulated historical imperviousness of $2010\left(I_{\text {hist,sim }}\right)$ was first computed. The subbasin-level future imperviousness $\left(I_{f u t, r e c}\right)$ was then constructed by multiplying this relative change ratio of imperviousness (i.e., $\left.I_{\text {fut,proj }} / I_{\text {hist,sim }}\right)$ with the observed historical (NLCD) imperviousness of 2010s $\left(I_{\text {hist,obs }}\right)$. To avoid the impact of outliers in the construction of future scenarios, maximum value of $I_{f u t, r e c}$ was set as 95\%, which is typical of downtown commercial areas (Urban Drainage and Flood Control District, 2016). Further, there were a few subbasins where the ICLUS dataset either projected no relative change or relative decrease in imperviousness (i.e., $I_{\text {fut,proj }} / I_{\text {hist,sim }} \leq 1$ ), which did not represent the persistent urbanization in southeast Florida. $I_{f u t, r e c}$ for these 
subbasins were replaced by a realistic ratio $\left(I_{f u t, p r o j} / I_{\text {hist,sim }}>1\right)$ of the nearest subbasin with most similarity in observed historical land cover between them.

The constructed climatic and land cover projections under both RCP 4.5 and 8.5 were incorporated in the calibrated Southeast Coasts Basin model to obtain the potential future runoff scenarios in the 2050s and the 2080s. Specifically, the constructed GCM projections of monthly rainfall were distributed to the hourly time-step as inputs to SWMM. Given the well-known lack of skills of GCMs in reproducing the smaller (than monthly) scale variability of observed rainfalls (Zhang, 2013; Langousis et al., 2016), it was assumed that the hourly distribution of rainfall in the 10 years of 2050s and 2080s were similar to that in the 2010s (see Text A2.7 for details). The 10-year historical and future simulations of runoff were then conducted on an hourly reporting time-step over the entire basin. Insubstantial changes in subbasin and stream characteristics, soil and groundwater parameters, boundary conditions, and control structure features and operations between the historical and future periods were assumed. Although this assumption may not be always accurate, it serves the purpose of scenario analyses in this study.

\subsubsection{Sensitivity analyses}

To understand runoff responses to the individual as well as simultaneous changes in the environmental drivers, the dimensionless relative sensitivity coefficients $\left(S^{*}\right)$ on monthly and annual scales were also computed as follows (Abdul-Aziz et al., 2010):

$S^{*}=\frac{\Delta R / R}{\Delta V / V}$ 
where $V$ = baseline value of the forcing variable or parameter (i.e., rainfall, ET, and percent imperviousness value); $\Delta V=$ change in the forcing variable or parameter $R=$ baseline runoff simulated by the model; and $\Delta R=$ change in model-simulated runoff.

Reference changes were applied to rainfall, ET, and imperviousness for the baseline period (2010s) of the calibrated Southeast Coasts Basin model to compute the corresponding changes in runoff. The reference changes for these sensitivity analyses were formulated based on the future climatic and land cover projections. The four future scenarios (2050s-RCP 4.5, 2080s-RCP 4.5, 2050s-RCP 8.5, and 2080s-RCP 8.5) represented nonuniform changes in rainfall, ET, and imperviousness (Table A2.4 in Supplemental materials). However, a uniform set of reference changes was chosen by perturbing the baseline values from -30 to $+30 \%$ (with an increment of $5 \%$ ) for both climatic and land cover variables so that their impacts on runoff generation could be compared. Although the ensemble average projections of all GCMs suggested overall increases in these drivers, some GCMs represented potential decreases in rainfall and ET. Therefore, both increases and decreases in the drivers were considered for sensitivity analyses to understand the impacts of diverse changes and runoff generation mechanisms in the basin. Percent changes in runoff were computed for both individual (one-at-a-time) and simultaneous changes in rainfall, ET, and imperviousness. The individual and simultaneous changes in these variables led to 469 sensitivity scenarios for runoff.

\subsection{Results and discussion}

\subsubsection{Model calibrations and validations}

NSE and RSR for the Southeast Coasts Basin model ranged, respectively, from 0.74 to 0.92 and 0.28 to 0.51 in calibrations and validations at the 6 stations during 2004-2013 (Figure 2.3). These statistics indicated very good to excellent prediction performance of the model (Moriasi et al., 
2007). The prediction performance at stations located across the basin (Figure 2.2) suggested suitability of the developed model for analyzing sensitivities of historical runoff and constructing projections of future runoff scenarios under a changing climate and land cover. The baseline 10year (2010s) mean annual runoff varied widely (5 to $1151 \mathrm{~mm}$ per $\mathrm{m}^{2}$ watershed area) across the basin (Figure A2.4). The corresponding baseline mean annual rainfall varied from 926 to 1627 $\mathrm{mm}$ across the basin, with higher (than other locations) rainfall depths in Greater Miami, Fort Lauderdale, Boca Raton, West Palm Beach, and St. Lucie areas (Figure A2.1). However, the spatial variation of the baseline 2010s annual runoff mainly reflected that of the percent imperviousness (Figure A2.2), with higher runoff depths in different urbanized locations (representing 30 to 76\% imperviousness). For example, the north-central (e.g., West Palm Beach, Boca Raton), central (e.g., Fort Lauderdale, Hollywood, Sunrise), and the south-central (e.g., Miami, Doral, Hialeah, Homestead) regions of the basin had baseline runoff depths of 314 to 837 $\mathrm{mm}, 246$ to $863 \mathrm{~mm}$, and 314 to $1151 \mathrm{~mm}$, respectively. Notably, the greater Miami area had the highest baseline runoff depths. In contrast, storm runoff in portions of the northern, western, and southern basin areas - representing 1 to $3 \%$ imperviousness due to croplands, pasture, grasslands, and wetlands (Figure 2.1) - had much lower baseline runoff depths (18 to $45 \mathrm{~mm}$ ). 

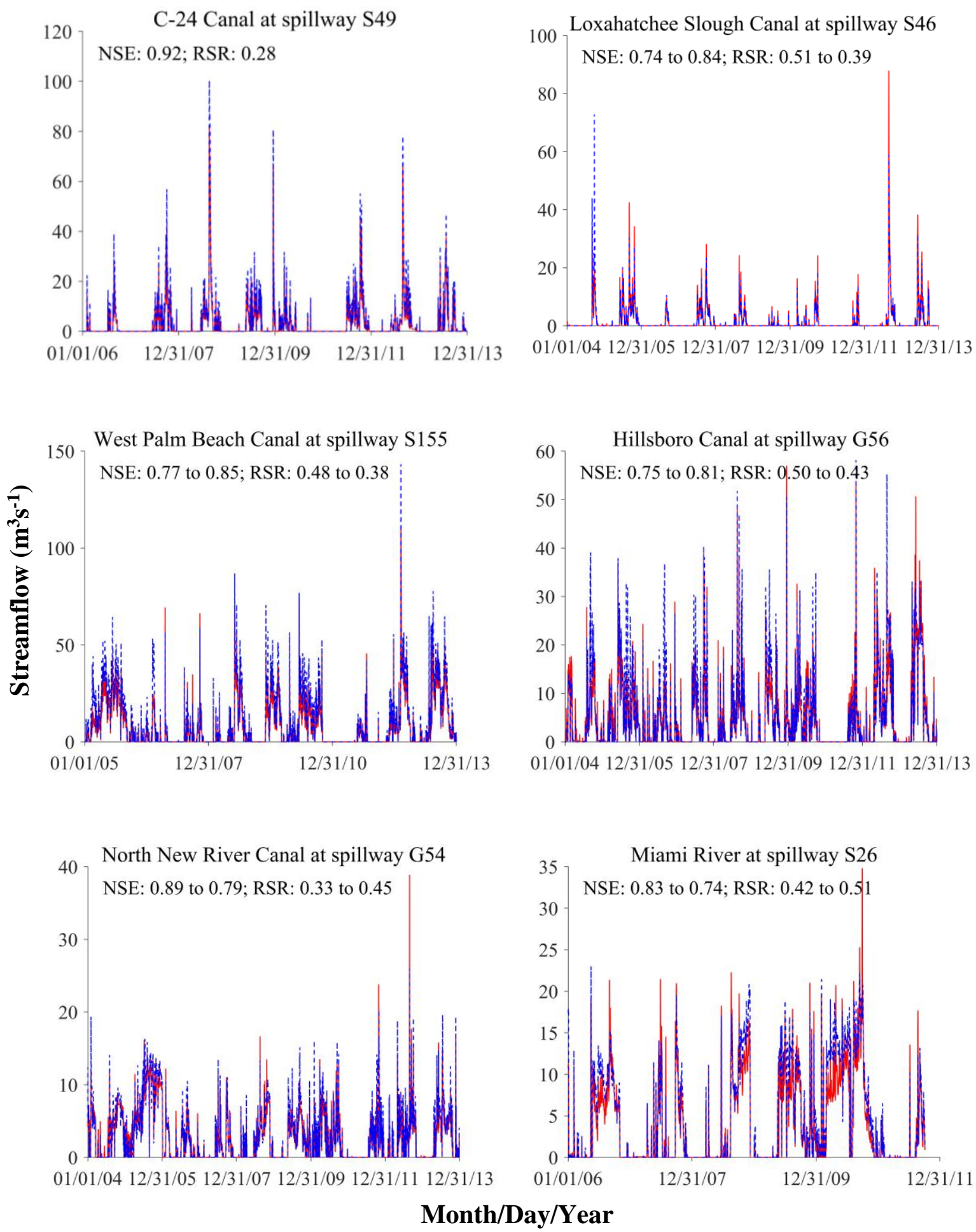

\section{-.--Observed — Predicted}

Figure 2.3: Plots of model calibrations and validations with historical daily streamflow for the Florida Southeast Coasts Basin. 01/01/05 refers to January 01, 2005. Calibration and validation 
periods are, respectively, $01 / 01 / 2006$ to $12 / 31 / 2008$ and $01 / 01 / 2009$ to $12 / 31 / 2013$ for C-24 Canal; 01/01/2005 to 12/31/2008 and 01/01/2009 to 12/31/2013 for West Palm Beach Canal; and 01/01/2006 to 12/09/2008 and 01/01/2009 to 10/03/2011 for the Miami River. For the remaining streams, calibration and validation periods are $01 / 01 / 2004$ to $12 / 31 / 2008$ and $01 / 01 / 2009$ to $12 / 31 / 2013$, respectively.

\subsubsection{Runoff sensitivities}

\subsubsection{Perturbations in rainfall}

The 10-year (2004-2013) mean monthly runoff in the Southeast Coasts Basin showed notably different seasonal sensitivities to standalone changes made in hourly rainfall depths, while keeping the number and duration of rainfall events unchanged (Figure 2.4a). The monthly sensitivity curves indicated nonlinear responses of runoff to perturbations in rainfall. For example, a $30 \%$ increase in rainfall led to 38 to $70 \%$ increases in runoff across different months. In contrast, a 30\% decrease in rainfalls resulted in a much lower range of decreases (35 to 49\%) in the corresponding monthly runoffs. On average, the annual runoff increased by $59 \%$ and decreased by $43 \%$ for, respectively, increasing and decreasing the hourly rainfall depths by $30 \%$. The sensitivity coefficients ( $S^{*}$, Eq. 2.1) of runoff to the various percent changes in rainfall ranged from 1.18 to 2.35 (mean $=1.59)$ across the different months (Table A2.5 in Supplemental materials). The runoff sensitivity coefficients typically increased in magnitude with increasing rainfall. 

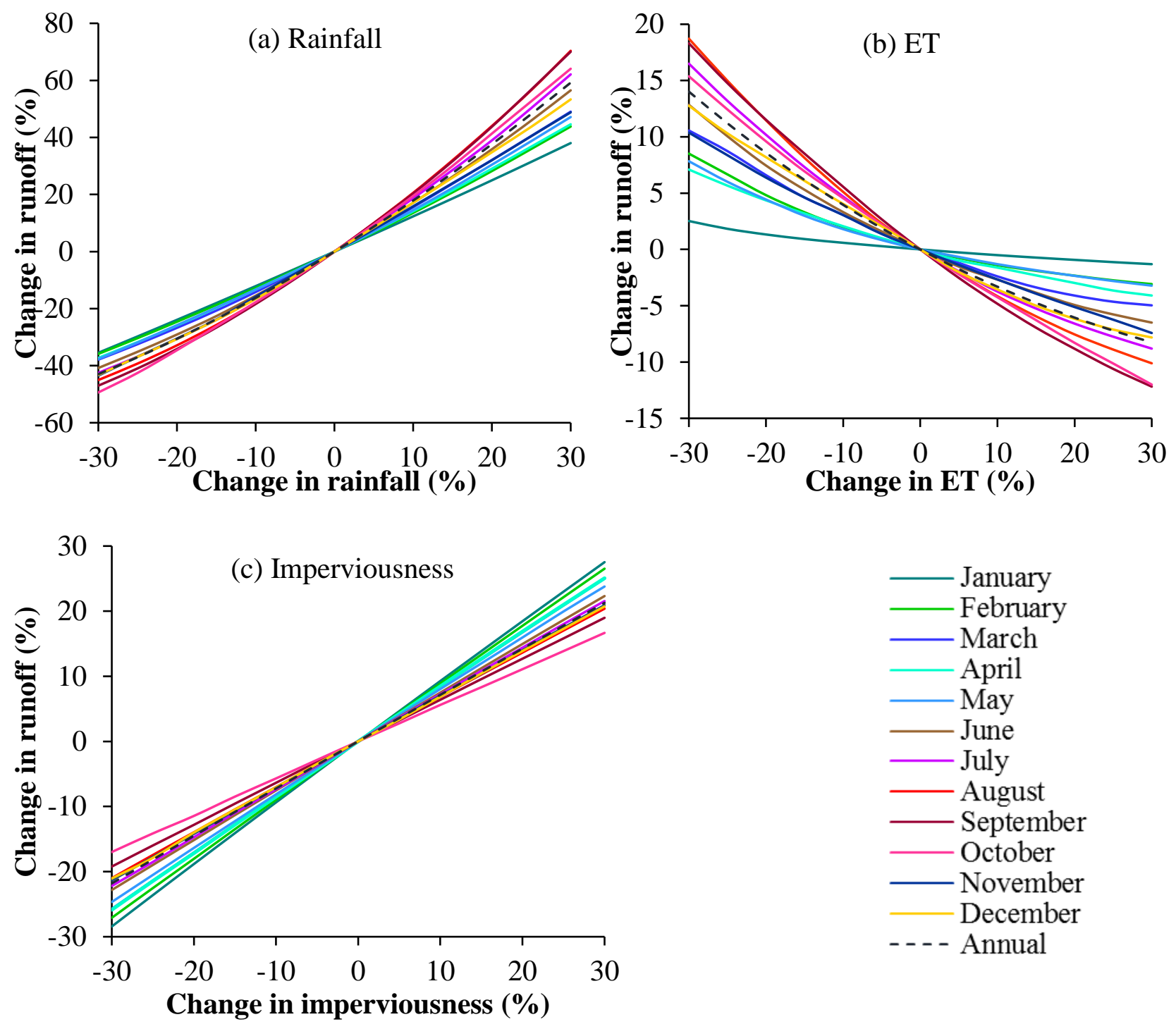

Figure 2.4: Monthly and annual variation in the sensitivity of 10-year (2010s) mean runoff to perturbations in rainfall, evapotranspiration (ET), and imperviousness in the Florida Southeast Coasts Basin. 
The seasonal differences in runoff sensitivities (Figure 2.4a) may be attributed to the monthly variation in rainfall depth, number of rainfall events, and ET rate (Figure A2.5). According to Pathak (2001), June-September and November-April are deemed, respectively, wet and dry seasons in south Florida; May and October are transitional months. The substantially high rainfall depth and frequent rainfall events during the wet season months (Figure A2.5) likely led to frequent soil saturation (despite a high ET), high antecedent soil moisture, and fast runoff generation — resulting in high runoff sensitivities. For example, the June-September runoffs increased by 57 to $70 \%$ due to $30 \%$ increases in their rainfall depths. Conversely, a $30 \%$ decrease in the wet season rainfalls resulted in 41 to $47 \%$ decreases of the monthly runoffs. Further, runoff sensitivities were higher in August-September than in June-July; this may be attributed to a higher antecedent soil moisture and faster runoff generation during the later wet months, compared to that in the early wet season (especially June, which succeeded the dry season). A high runoff sensitivity was also found for the transitional month of October - similar to that of wet season (despite having a notably lower magnitude and frequency of rainfalls) apparently due to a lower ET rate and a high antecedent soil moisture carried from the wet season.

Runoff sensitivities to rainfall were considerably lower in the dry season than the wet season (Figure 2.4a). Runoff during November-April increased by 38 to $53 \%$ and decreased by 35 to $43 \%$ for, respectively, increasing and decreasing the monthly rainfalls by $30 \%$. Contrary to the wet season, the lower runoff sensitivities during the dry season may be attributed to the lower rainfall depth and less number of rainfall events (Figure A2.5), presumably leading to a less frequent soil saturation (despite a lower ET, except for April), low antecedent soil moisture, and slow runoff generation. January runoff had the least sensitivity to changes in rainfall, apparently 
due to the smallest rainfall depth and lowest baseline runoff generation (Figure A2.5). In contrast, the early dry season months (November-December) experienced more frequent rainfall events - on top of a likely high antecedent soil moisture carried from the wet season — leading to a faster runoff generation and a higher runoff sensitivity. The transitional month of May also had a low runoff sensitivity to changes in rainfall, similar to that of February-April, despite having a notably higher rainfall depth and frequency (Figure A2.5). The low sensitivity in May might be caused by the high ET rate and the lack of antecedent soil moisture following the dry season.

\subsubsection{Perturbations in ET}

Runoff sensitivities to standalone changes in ET (Figure 2.4b) were much lower in magnitude than that of the changing rainfall. The sensitivity coefficients $\left(S^{*}\right)$ of runoff to the various percent changes in ET ranged from -0.04 to -0.62 (mean = -0.31) across the different months (Table A2.6 in Supplemental materials). The runoff sensitivity coefficients typically decreased in magnitude with increasing ET. However, like rainfall perturbations, runoff sensitivities to changes in ET were nonlinear and generally higher in the wet season than that in the dry season (Figure 2.4b). For example, increasing ET by $30 \%$ caused 1 to $12 \%$ decreases in the monthly runoffs and $8 \%$ decrease in the annual runoff. In contrast, runoff increased by 2.5 to $19 \%$ across different months and by $14 \%$ annually for a $30 \%$ decrease in ET. During June-October, monthly runoff decreased from 6.5 to $12 \%$ and increased from 13 to $19 \%$ for, respectively, increasing and decreasing ET by 30\%. Runoff sensitivities during the early dry months (November-December) were similar to that of the early wet months (e.g., June). However, during January-May, a 30\% increase in ET resulted in 1 to $5 \%$ decreases in monthly runoff, which, in turn, increased by 2.5 
to $11 \%$ for a $30 \%$ decrease in ET. Overall, January runoff had the lowest sensitivity to ET, whereas September had the highest sensitivity overall (i.e., for increasing and decreasing ET).

Similar to the rainfall-runoff sensitivities, the seasonal variation in runoff sensitivities to ET were presumably caused by the seasonal variation in rainfall magnitude and frequency and in ET rates, leading to variability in antecedent soil moisture, soil saturation, and runoff generation process. For example, the higher runoff sensitivity to ET during June-October could be explained by the availability of relatively high soil moisture and higher volume of runoff generated from frequent and intense rainfalls, supporting generally a high rate of ET (except for October) (Figure A2.5). In contrast, the lower runoff sensitivity during the later dry season months can be attributed to the low soil moisture and infrequent and small rainfall events, leading to a slow runoff generation to support ET that ranged from a relatively low rate in January-March to a high rate in April (Figure A2.5). Further, despite having a higher magnitude and frequency of rainfall in May, the high ET rate and lack of antecedent soil moisture following the dry season might have resulted in its low runoff sensitivity to ET. Conversely, the higher runoff sensitivity in November-December than the rest of the dry season can be attributed to a faster runoff generation due to a higher magnitude and frequency of rainfall events, on top of a presumably high antecedent soil moisture carried from the wet season.

\subsubsection{Perturbations in land cover}

Runoff sensitivity to standalone changes in basin imperviousness was much lower than that of rainfall, but higher than ET (Figure 2.4c). The sensitivity coefficients $\left(S^{*}\right)$ of runoff to the various percent changes in imperviousness ranged from 0.55 to 0.95 (mean $=0.76)$ across the different months (Table A2.7 in Supplemental materials). The runoff sensitivity coefficients slightly decreased in magnitude with increasing imperviousness. However, unlike rainfall and 
ET perturbations, runoff sensitivities to changes in imperviousness were mostly linear, and were higher in the dry season than that of the wet season (Figure 2.4c). The monthly runoffs both increased and decreased by 17 to $28 \%$ for, respectively, increasing and decreasing the imperviousness of all subbasins by $30 \%$, for example. On average, the annual runoff changed (increased or decreased) by 21 to $22 \%$ for the corresponding changes in the imperviousness by $30 \%$. Runoff during June-October changed by 17 to $23 \%$, whereas runoff during November-May changed by 21 to $28 \%$ for a $30 \%$ change in the basin imperviousness. Compared to the runoff changes due to the rainfall perturbations (section 2.3.2.1), the results indicated more than 2 to 3 times stronger control of climate (rainfall) on runoff than imperviousness in the highly urbanized Florida Southeast Coast Basin. The stronger sensitivities of dry season runoff to imperviousness perturbations indicated a more prominent role of imperviousness in runoff generation than that during the wet season, given typically lower depths and frequency of rainfall and lower ET in the dry season.

\subsubsection{Concurrent climatic and land cover sensitivities}

Concurrent changes in rainfall and imperviousness, as well as in rainfall and ET, led to stronger nonlinear responses of runoff than the linear summation of their standalone (i.e., one-at-a-time) individual effects (Table 2.2, 2.3). For example, when both rainfall and imperviousness were simultaneously increased by $30 \%$, the annual basin runoff increased by $86 \%$, which was 6 percentage points higher than the linear summation of their standalone individual contributions (i.e., 59\% + 21\%; Table 2.2). Further, a concurrent $30 \%$ increase in both rainfall and ET increased the annual basin runoff by $44 \%$, which was 7 percentage points lower than the linear summation of their standalone individual contributions (Table 2.3). However, runoff responses to concurrent changes in both imperviousness and ET were mostly linear - similar to that obtained 
by summing their standalone individual contributions (Table 2.4). The results reemphasized a stronger role of rainfall, quicker soil saturation, and faster runoff generation in driving runoff sensitivities.

\subsubsection{Future runoff projections}

\subsubsection{Runoff projections under changing climate}

Simulated ensemble mean runoff depth, in response to the climatic (rainfall and ET) projections of $20 \mathrm{GCMs}$, suggested high (on spatial average, 142 to $267 \mathrm{~mm}$ per $\mathrm{m}^{2}$ basin area) increases in the 10-year mean annual storm runoff for the Southeast Coasts Basin across the RCP scenarios by 2050s and 2080s (Figure 2.5), relative to the 2010s (Figure A2.4). The corresponding projected ensemble mean increases in the 10-year mean annual rainfall ranged from 174 to 407 $\mathrm{mm}$ under different future scenarios (Figure A2.6a). Spatial variation in the projected increases of rainfall led to higher (than other locations) projected increases of storm runoff in different urbanized locations, more notably across a long stretch from the south-central to the northcentral region of the basin (spatial mean of 241 to $437 \mathrm{~mm}$ ), including the major cities of Miami, Fort Lauderdale, and West Palm Beach (Figure 2.1, 2.5a). Much of the northern, western, and southern basin areas — primarily characterized by croplands, pasture, grasslands, and wetlands (Figure 2.1) - would experience relatively lower increases in runoff depth (spatial mean of 30 to $45 \mathrm{~mm}$; Figure 2.5a), despite relatively high projected increases in rainfall. However, these runoff increases represented high relative increases (246 to 364\%) due to the corresponding lower baseline runoffs in these natural and unbuilt areas (Figure A2.4), and can therefore be hydrologically impactful. Overall, the highest runoff increases were observed for the 2080s-RCP 4.5 scenario (Figure 2.5a), resulting from the highest rainfall increases (Figure A2.6a) across the basin. In contrast, the lowest increases in the annual runoff resulted under the 2080s-RCP 8.5 
scenario - in response to the corresponding lowest ensemble mean increases in rainfall and the highest increases in ET (Figure A2.6a, Table A2.4).

Table 2.2: Percent changes of mean annual runoff under concurrent perturbations in rainfall and imperviousness in the Florida Southeast Coasts Basin.

\begin{tabular}{|c|c|c|c|c|c|c|c|c|c|c|c|c|c|}
\hline \multirow{2}{*}{$\begin{array}{c}\text { Change in } \\
\text { imperviousness }(\%)\end{array}$} & \multicolumn{13}{|c|}{ Change in rainfall $(\%)$} \\
\hline & -30 & -25 & -20 & -15 & -10 & -5 & 0 & 5 & 10 & 15 & 20 & 25 & 30 \\
\hline-30 & -58 & -53 & -48 & -42 & -36 & -29 & -22 & -14 & -6 & 3 & 12 & 22 & 32 \\
\hline-25 & -56 & -51 & -45 & -39 & -33 & -26 & -18 & -10 & -2 & 7 & 16 & 26 & 36 \\
\hline-20 & -53 & -48 & -42 & -36 & -29 & -22 & -15 & -6 & 2 & 11 & 21 & 31 & 41 \\
\hline-15 & -51 & -45 & -39 & -33 & -26 & -19 & -11 & -3 & 6 & 15 & 25 & 35 & 46 \\
\hline-10 & -48 & -42 & -36 & -30 & -23 & -15 & -7 & 1 & 10 & 19 & 29 & 39 & 50 \\
\hline-5 & -45 & -40 & -33 & -27 & -19 & -12 & -4 & 5 & 14 & 23 & 33 & 44 & 55 \\
\hline 0 & -43 & -37 & -31 & -24 & -16 & -8 & 0 & 9 & 18 & 28 & 38 & 48 & 59 \\
\hline 5 & -40 & -34 & -28 & -21 & -13 & -5 & 4 & 12 & 22 & 32 & 42 & 53 & 64 \\
\hline 10 & -38 & -32 & -25 & -18 & -10 & -2 & 7 & 16 & 26 & 36 & 46 & 57 & 68 \\
\hline 15 & -35 & -29 & -22 & -15 & -7 & 2 & 11 & 20 & 30 & 40 & 50 & 61 & 73 \\
\hline 20 & -33 & -26 & -19 & -11 & -3 & 5 & 14 & 24 & 33 & 44 & 54 & 66 & 77 \\
\hline 25 & -31 & -24 & -16 & -8 & 0 & 9 & 18 & 27 & 37 & 48 & 59 & 70 & 82 \\
\hline 30 & -28 & -21 & -14 & -5 & 3 & 12 & 21 & 31 & 41 & 52 & 63 & 74 & 86 \\
\hline
\end{tabular}

Note: Positive sign indicates increase, while negative indicates decrease. 
Table 2.3: Percent changes of mean annual runoff under concurrent perturbations in rainfall and evapotranspiration (ET) in the Florida Southeast Coasts Basin.

\begin{tabular}{cccccccccccccc}
\hline \multirow{2}{*}{ Change in ET (\%) } & \multicolumn{10}{c}{ Change in rainfall $(\%)$} \\
\cline { 2 - 13 } & -30 & -25 & -20 & -15 & -10 & -5 & 0 & 5 & 10 & 15 & 20 & 25 & 30 \\
\hline-30 & -37 & -30 & -22 & -14 & -5 & 4 & 14 & 24 & 35 & 46 & 57 & 69 & 81 \\
-25 & -39 & -31 & -24 & -16 & -7 & 2 & 11 & 21 & 31 & 42 & 53 & 65 & 77 \\
-20 & -40 & -33 & -26 & -18 & -9 & -1 & 9 & 18 & 28 & 39 & 50 & 61 & 73 \\
-15 & -41 & -34 & -27 & -19 & -11 & -3 & 6 & 16 & 25 & 36 & 47 & 58 & 69 \\
-10 & -42 & -35 & -28 & -21 & -13 & -5 & 4 & 13 & 23 & 33 & 43 & 54 & 66 \\
-5 & -42 & -36 & -30 & -22 & -15 & -7 & 2 & 11 & 20 & 30 & 40 & 51 & 62 \\
0 & -43 & -37 & -31 & -24 & -16 & -8 & 0 & 9 & 18 & 28 & 38 & 48 & 59 \\
5 & -43 & -38 & -31 & -25 & -18 & -10 & -2 & 7 & 16 & 25 & 35 & 45 & 56 \\
10 & -44 & -38 & -32 & -26 & -19 & -11 & -3 & 5 & 14 & 23 & 33 & 43 & 53 \\
15 & -44 & -39 & -33 & -26 & -20 & -12 & -5 & 3 & 12 & 21 & 30 & 40 & 51 \\
20 & -44 & -39 & -33 & -27 & -21 & -14 & -6 & 2 & 10 & 19 & 28 & 38 & 48 \\
25 & -45 & -39 & -34 & -28 & -21 & -15 & -7 & 1 & 9 & 17 & 26 & 36 & 46 \\
30 & -45 & -40 & -34 & -28 & -22 & -15 & -8 & -1 & 7 & 16 & 25 & 34 & 44 \\
\hline
\end{tabular}

Note: Positive sign indicates increase, while negative indicates decrease.

Table 2.4: Percent changes of mean annual runoff under concurrent perturbations in evapotranspiration (ET) and imperviousness in the Florida Southeast Coasts Basin.

\begin{tabular}{cccccccccccccc}
\hline Change in & \multicolumn{10}{c}{ Change in ET $(\%)$} \\
\cline { 2 - 13 } imperviousness (\%) & -30 & -25 & -20 & -15 & -10 & -5 & 0 & 5 & 10 & 15 & 20 & 25 & 30 \\
\hline-30 & -7 & -10 & -13 & -15 & -18 & -20 & -22 & -24 & -25 & -27 & -28 & -29 & -30 \\
-25 & -4 & -7 & -9 & -12 & -14 & -16 & -18 & -20 & -21 & -23 & -24 & -25 & -26 \\
-20 & 0 & -3 & -6 & -8 & -10 & -13 & -15 & -16 & -18 & -19 & -21 & -22 & -23 \\
-15 & 3 & 0 & -2 & -5 & -7 & -9 & -11 & -13 & -14 & -16 & -17 & -18 & -19 \\
-10 & 7 & 4 & 1 & -1 & -3 & -5 & -7 & -9 & -11 & -12 & -13 & -14 & -15 \\
-5 & 10 & 8 & 5 & 3 & 0 & -2 & -4 & -5 & -7 & -8 & -10 & -11 & -12 \\
0 & 14 & 11 & 9 & 6 & 4 & 2 & 0 & -2 & -3 & -5 & -6 & -7 & -8 \\
5 & 18 & 15 & 12 & 10 & 8 & 5 & 4 & 2 & 0 & -1 & -2 & -4 & -5 \\
10 & 21 & 18 & 16 & 13 & 11 & 9 & 7 & 5 & 4 & 2 & 1 & 0 & -1 \\
15 & 25 & 22 & 19 & 17 & 15 & 13 & 11 & 9 & 7 & 6 & 5 & 4 & 2 \\
20 & 28 & 25 & 23 & 20 & 18 & 16 & 14 & 13 & 11 & 10 & 8 & 7 & 6 \\
25 & 32 & 29 & 26 & 24 & 22 & 20 & 18 & 16 & 14 & 13 & 12 & 11 & 10 \\
30 & 35 & 32 & 30 & 27 & 25 & 23 & 21 & 20 & 18 & 17 & 15 & 14 & 13 \\
\hline
\end{tabular}

Note: Positive sign indicates increase, while negative indicates decrease. 
(a) Climate
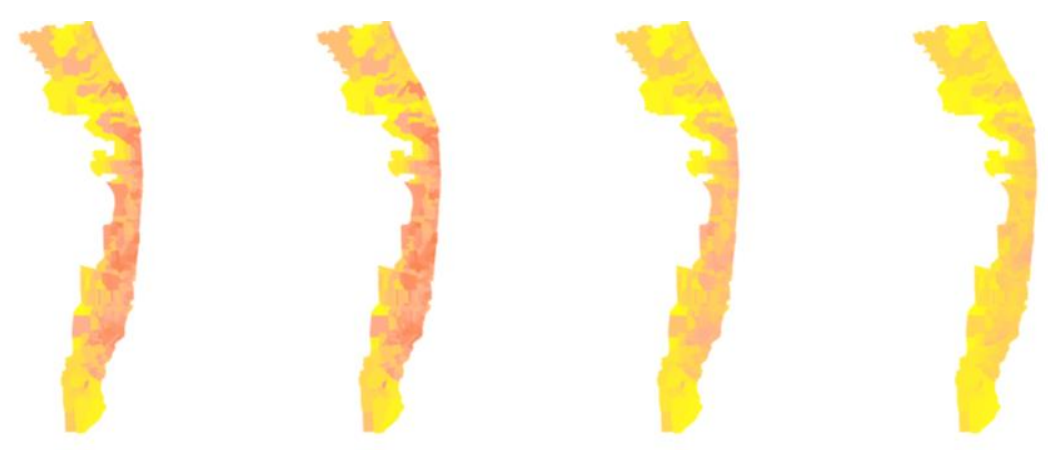

(b) Land cover
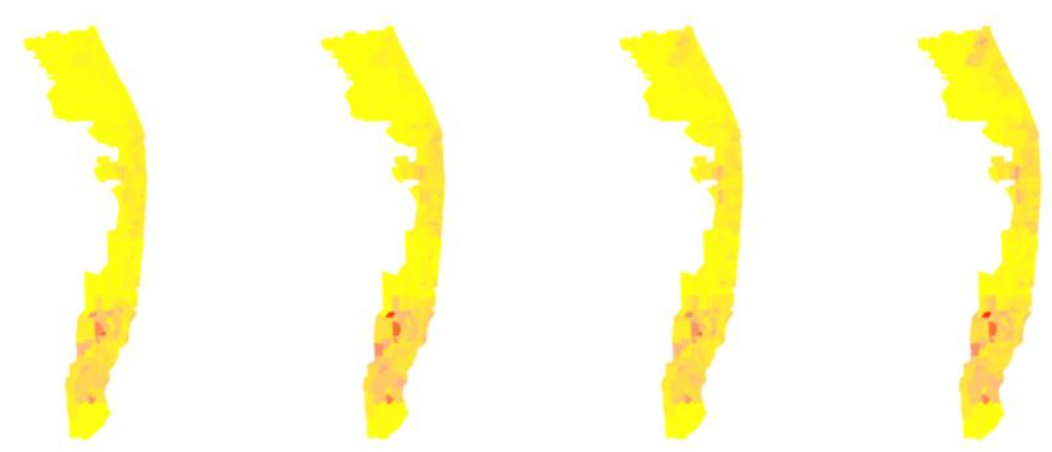

(c) Climate and land
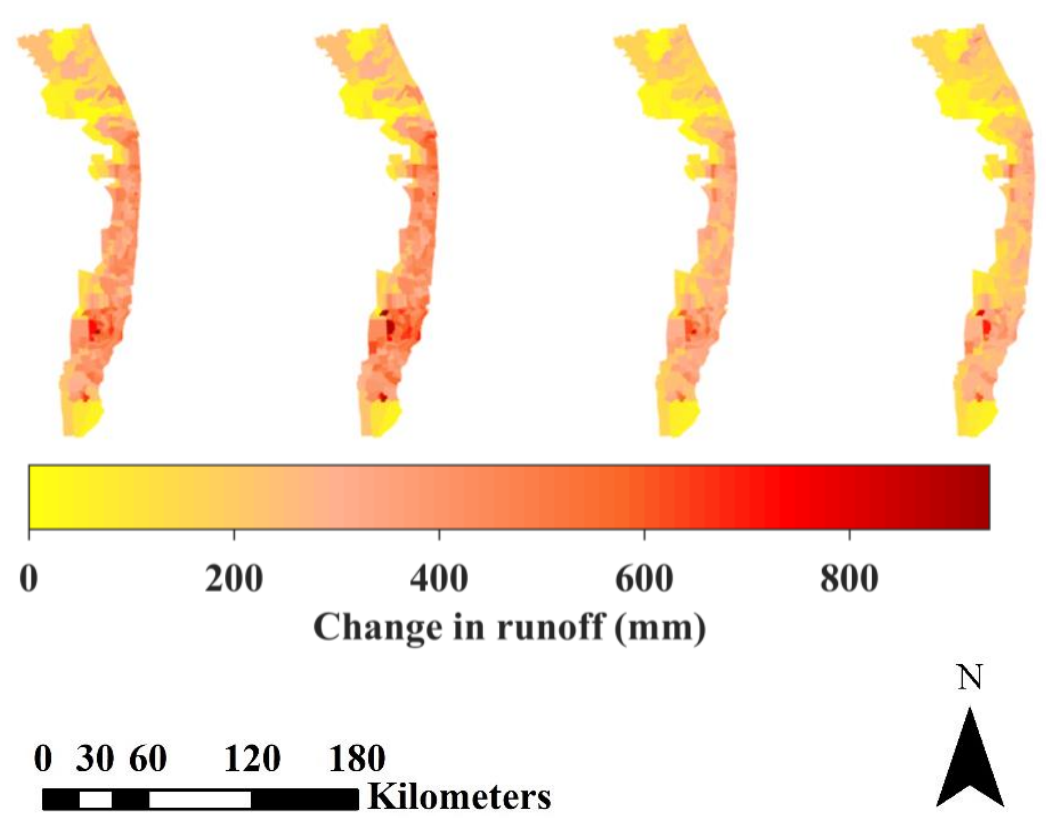

Figure 2.5: Spatial variation of the predicted changes in 10-year mean annual runoff depth due to the projected changes in (a) climate, (b) land cover, and (c) both climate and land cover under different future scenarios in the Florida Southeast Coasts Basin. 
Based on the total basin runoff, higher relative changes in the 10-year mean runoffs were observed for the dry season and transitional months (October-May; 92 to $165 \%$ increases on average) than that for the wet season (June-September; from $13 \%$ decrease to $66 \%$ increase) under different future scenarios (Figure 2.6a). The seasonal pattern contrasted with the results of runoff sensitivity analysis to rainfall perturbations by up to $30 \%$ (section 2.3 .2 .1 ). The reverse seasonal pattern of the projected future runoff changes was primarily caused by the much higher relative changes in the projected rainfall (18 to $70 \%$ increase) during October-May than during June-September (ranging from $22 \%$ decrease to $22 \%$ increase; Figure A2.7a). Based on the ensemble model average, the overall basin rainfall was projected to increase by approximately $30 \%, 29 \%, 20 \%$, and $13 \%$, respectively, under the 2080s-RCP 4.5, 2050s-RCP 4.5, 2050s-RCP 8.5, and 2080s-RCP 8.5 scenarios (Table A2.4). The basin ET was also projected to increase by 8.5\% (2080s-RCP 8.5), 4.6\% (2050s-RCP 8.5), 4.5\% (2080s-RCP 4.5), and 2.9\% (2050s-RCP 4.5). The projected changes in climate generally caused high ensemble mean increases in the annual runoff volume under all scenarios: 2080s-RCP 4.5 (87\%), 2050s-RCP 4.5 (83\%), 2050sRCP 8.5 (60\%), and 2080s-RCP 8.5 (47\%) (Table 2.5). The smaller ensemble mean increases in the annual basin runoff under the RCP 8.5 scenarios stemmed from the higher mix of projected increases and decreases in runoff than the RCP 4.5 scenarios (Figure 2.6a). This, in turn, were mainly caused by the corresponding higher mix of projected increases and decreases in annual rainfall by the GCMs under the RCP 8.5 scenarios (Figure A2.7a). The smallest runoff increase was observed under 2080s-RCP 8.5, since it had the largest number of GCMs projecting decreases in basin rainfall. 
(a) Climate
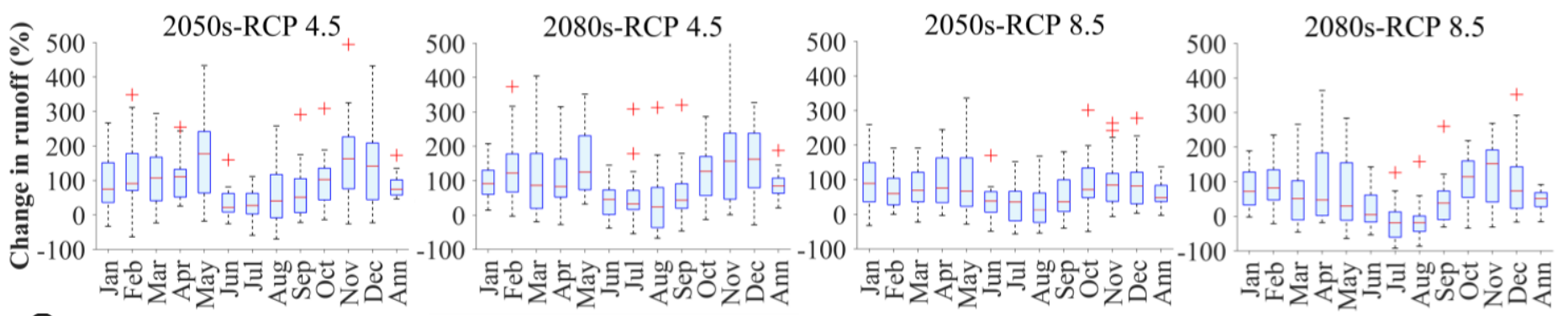

(b) Land
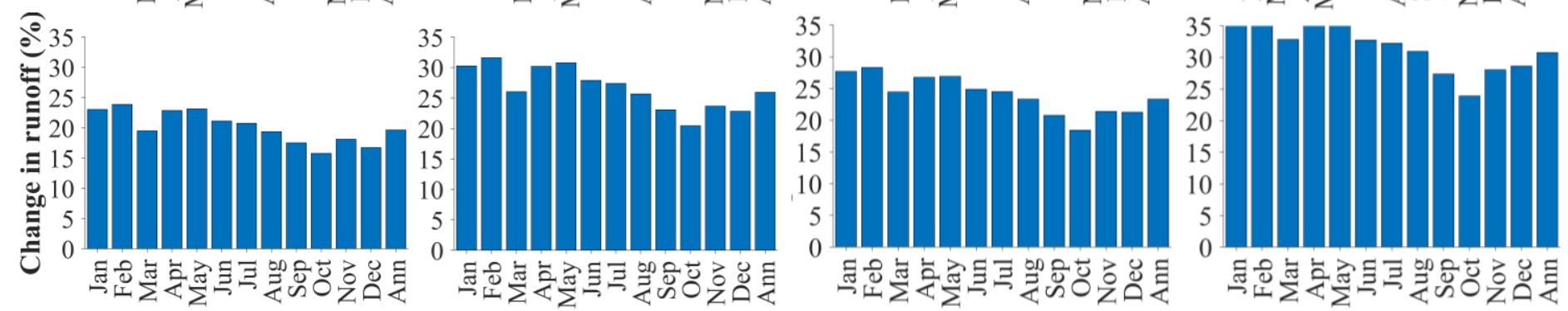

(c) Climate and land cover
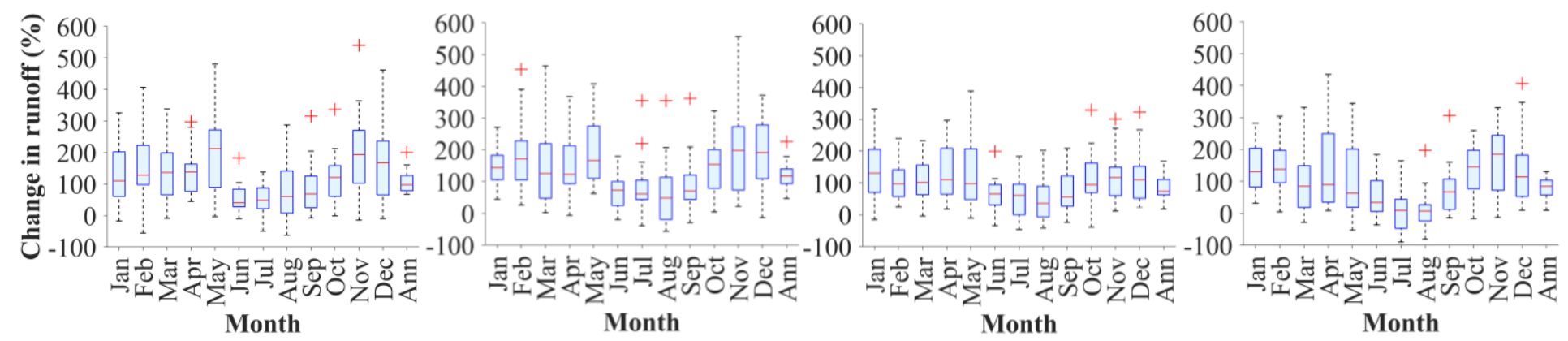

Figure 2.6: Percentage changes in 10-year mean monthly and annual runoff under the projected changes in (a) climate, (b) land cover, and (c) both climate and land cover for different future scenarios in the Florida Southeast Coasts Basin. For (a) and (c), the boxwhiskers represent variations in runoff change across the general circulation models (GCMs); the lower, intermediate, and upper horizontal lines in the boxes indicate $25^{\text {th }}, 50^{\text {th }}$, and $75^{\text {th }}$ percentiles; plus signs indicate extreme outliers. Jan: January; Feb: February; Mar: March; Apr: April; Jun: June; Jul: July; Aug: August; Sep: September; Oct: October; Nov: November; Dec: December; Ann: Annual. 
Table 2.5: Potential future increases (model-projected ensemble averages) in the mean annual runoff volume for the Florida Southeast Coasts Basin under different scenarios of changing climate and/or land cover, relative to the baseline period of 2010 s.

\begin{tabular}{ccccc}
\hline & \multicolumn{4}{c}{ Projected increases in runoff (\%) } \\
\cline { 2 - 5 } Changing drivers/scenarios & 2050s-RCP 4.5 & 2080s-RCP 4.5 & 2050s-RCP 8.5 & 2080s-RCP 8.5 \\
\hline Climate & 83 & 87 & 60 & 47 \\
Land cover & 20 & 26 & 23 & 31 \\
Climate and land cover & 106 & 118 & 86 & 80 \\
\hline
\end{tabular}

\subsubsection{Runoff projections under changing land cover}

Commensurate with the increasing urbanization and developments, increases in surface imperviousness were projected throughout the Southeast Coasts Basin under all scenarios (Figure A2.6b). However, the overall (basin average) 7 to 10 percentage points increase in imperviousness led to much lower increases ( 70 to $98 \mathrm{~mm}$ per $\mathrm{m}^{2}$ basin area; Figure $2.5 \mathrm{~b}$ ) in mean annual storm runoff depth than that for climatic changes by the 2050s and 2080s, relative to the 2010s. The basin-wide highest and lowest increases in runoff due to the corresponding increases in imperviousness were obtained under the 2080s-RCP 8.5 and 2050s-RCP 4.5 scenarios, respectively. Across the four future scenarios, 14 to 22 percentage points (spatial mean) increases in imperviousness (Figure A2.6b) caused 155 to $233 \mathrm{~mm}$ (spatial mean) increases in 10-year mean annual runoff (Figure 2.5b) at urban centers in the northeast (e.g., Fort Pierce, Port St. Lucie, Jupiter), north-central (e.g., West Palm Beach, Boca Raton), and southcentral (e.g., Doral, Hialeah, Miami, Homestead) regions. Further, spatial mean increases of 177 to $337 \mathrm{~mm}$ in runoff at the northern, western, and southern basin areas were caused by the projected conversion of croplands, pasture, grasslands, and wetlands (Figure 2.1) to more impervious land uses (on spatial average, 20 to 40 percentage points increases in imperviousness; Figure A2.6b). 
Potential land cover change impacts on the total basin runoff were overall more pronounced during the dry season than the wet season (Figure 2.6b). Under different future scenarios, monthly basin runoff was projected to increase by 17 to $37 \%$ and 16 to $33 \%$ during November-May and June-October, respectively. The projected seasonal pattern was consistent with the findings of sensitivity analysis (section 2.3.2). Based on the ensemble model average, the overall basin imperviousness was projected to increase by approximately $36 \%, 31 \%, 28 \%$, and $25 \%$, respectively, under the 2080s-RCP $8.5,2080 \mathrm{~s}-\mathrm{RCP} 4.5,2050 \mathrm{~s}-\mathrm{RCP} 8.5$, and 2050sRCP 4.5 scenarios (Table A2.4). The potential land cover changes would lead to moderate increases in basin-scale runoff volume under 2080s-RCP 8.5 (31\%), followed by 2080s-RCP 4.5 (26\%), 2050s-RCP 8.5 (23\%), and 2050s-RCP 4.5 (20\%) (Table 2.5). The much lower potential runoff increases under land cover changes than that under climatic changes further manifested the overall dominance of climate in runoff generation in the Southeast Coasts Basin.

\subsubsection{Runoff projections under changing climate and land cover}

Simultaneous projected changes in climate and land cover produced more widespread and higher increases in storm runoff depth (244 to $367 \mathrm{~mm}$ per $\mathrm{m}^{2}$ basin area) in the Southeast Coasts Basin than that due to the standalone climatic or land cover changes under all four scenarios (Figure $2.5 \mathrm{c}$ ), relative to the 2010s. High potential ensemble increases in 10-year mean annual runoff caused by concurrent moderate to high ensemble mean increases in rainfall and impervious cover (Figure A2.6a, b) - were noted at and around majority of the urban centers across the basin by 2050s to 2080s. For example, future runoff increases (spatial averages) of 354 to $512 \mathrm{~mm}, 224$ to $375 \mathrm{~mm}$, and 392 to $610 \mathrm{~mm}$ were projected, respectively, across the north-central (e.g., West Palm Beach, Boca Raton), central (e.g., Fort Lauderdale, Hollywood, Sunrise), and the southcentral (e.g., Miami, Doral, Hialeah, Homestead) regions of the basin. Remarkably, the greater 
Miami area (Figure 2.1,2.5c) would experience the highest increases in runoff under all four scenarios. Furthermore, spatial mean storm runoff in portions of the northern, western, and southern basin areas — representing croplands, pasture, grasslands, and wetlands (Figure 2.1) was projected to increase by 59 to $77 \mathrm{~mm}$ ( 218 to $306 \%$ increase relative to the 2010s) by 2050s to 2080s (Figure 2.5c). Overall, the spatial patterns of projected runoff increases under concurrent climatic and land cover changes were dominated by that due to the climatic changes (Figure 2.5a). Therefore, the basin-wide higher and lower increases in runoff under the combined changes were noted, respectively, under the RCP 4.5 and RCP 8.5 scenarios.

The combined changes in climatic and land cover variables produced higher relative increases in future runoff volume during the dry season and transitional months than that during the wet season (Figure 2.6c). Monthly basin runoff was projected to increase by 100 to $201 \%$ during October-May and by 10 to $90 \%$ during June-September under the different scenarios. The seasonal patterns in predicted runoff changes appeared to be largely reflective of the seasonal variation in projected changes in rainfall (Figure A2.7a). The 10-year mean annual basin runoff volume would increase by $118 \%, 106 \%, 86 \%$, and $80 \%$ under the 2080 s-RCP $4.5,2050$ s-RCP 4.5, 2050s-RCP 8.5, and 2080s-RCP 8.5 scenarios, respectively (Table 2.5). The smaller ensemble mean runoff increases under the two RCP 8.5 scenarios were caused by the corresponding higher mix of projected increases and decreases in annual rainfall by the GCMs (Figure A2.7a). Consistent with the sensitivity analysis (section 2.3.2.4), the relative basin runoff increases in the 2050s and 2080s under concurrent climatic and land cover changes are higher than the superposed runoff increases under standalone changes in climate and land cover. Based on the basin-scale changes, 2050s-RCP 4.5 and 2080s-RCP 4.5 provided the most critical future 
runoff scenario for, respectively, the near term and longer term infrastructure design, construction, and maintenance.

\subsubsection{Comparative synthesis of findings with existing literature}

The overall runoff sensitivities to climatic and land cover changes in our current study with the large scale Southeast Coasts Basin were similar to that of the much smaller scale study of AbdulAziz and Al-Amin (2015) on Miami River Basin, supporting scale-transition of the findings. However, some discrepancies were noted in the dry season months of November and December, which had high runoff sensitivities to rainfall in the Miami River Basin. Apart from the stark difference in the spatial scales of the two studies, it is also worth mentioning here that AbdulAziz and Al-Amin (2015) mainly focused on evaluating the runoff sensitivities using historical data of one year (2010). In contrast, the current study evaluated the potential changes in runoff by directly incorporating GCMs-projected climate and land cover projections, in addition to the sensitivity analysis, using the 10-year periods of 2010s, 2050s, and 2080s.

The occasional differences in rainfall-runoff sensitivities between the current study and Abdul-Aziz and Al-Amin (2015) were likely contributed by the associated variation in temporal rainfalls and surface imperviousness, which may modulate the response of surface runoff to changes in rainfall. Previous studies (e.g., Ali and Abtew, 1999) reported spatial variation in annual percentage of dry season rainfall over south Florida. Seasonal rainfall distributions can also vary due to the periodic influence of large-scale circulations such as El Niño-Southern Oscillation (ENSO), Pacific Decadal Oscillation (PDO), Atlantic Multi-decadal Oscillation (AMO), North Atlantic Oscillation (NAO), Arctic Oscillation (AO), sea-breeze convection, and tropical storms/hurricanes (Schmidt et al., 2001; Obeysekera et al., 2011; Abdul-Aziz and Al- 
Amin, 2015). The monthly rainfall distributions and the runoff sensitivities may, therefore, vary in different years and locations.

Outcomes of the sensitivity analyses and the future runoff scenarios for the Southeast Coasts Basin reinforced the findings across different regions of the globe. The runoff in the Southeast Coasts Basin was more sensitive to rainfall than ET on both monthly and annual scale (Figure 2.4a, b). Berghuijs et al. (2017) obtained higher sensitivity of runoff to changing rainfall than to changing ET globally. Chiew and McMahon (2002) reported an amplified annual runoff variation of -5 to $+15 \%$ (negative and positive signs indicating decrease and increase, respectively) in response to -4 to $+7 \%$ (respectively) changes in annual rainfall for the northeast coast of Australia, which has a tropical climate (ORNL DAAC, 2017). In the sensitivity analysis experiments for the Florida Southeast Coasts Basin, a proportionally similar response (-43 to $+59 \%$ changes) in mean annual runoff was found for -30 to $+30 \%$ (respectively) changes in the mean annual rainfall during 2004-2013 (Figure 2.4a). Further, the GCMs-projected 13 to 30\% increases in annual basin rainfall (Table A2.4) led to 47 to $87 \%$ increases in annual basin runoff by 2050s and 2080s under different scenarios (Table 2.5).

The results with the Florida Southeast Coasts Basin suggested that climatic (rainfall) change would be substantially more impactful on basin-scale runoff generation than land cover change under different future scenarios and time-frames. This is consistent with the existing literature on other regions around the world (e.g., Li et al., 2009; Öztürk et al., 2013; Wang and Stephenson, 2018) - indicating climate as the principal driver of potential future changes in runoffs, while land cover changes were also important contributors. For example, Olivera and DeFee (2007) attributed 77\% increase in annual runoff in the Whiteoak Bayou watershed of Texas, USA to $181 \%$ growth in the impervious area. In comparison, the perturbations-based 
sensitivity analyses in the current study suggested $21 \%$ increase in mean annual runoff for a $30 \%$ increase in imperviousness (Figure 2.5c). Further, the future projections suggested 20 to $31 \%$ increases in annual runoff due to 25 to $36 \%$ (respectively) increases in imperviousness under different scenarios (Table 2.5). The runoff sensitivity analyses and future projections also underlined nonlinear responses of runoff when both changing climate and land cover were considered in hydrologic simulations for the Southeast Coasts Basin — reinforcing the message from the previous studies (e.g., Abdul-Aziz and Al-Amin, 2015; Hovenga et al., 2016).

\subsubsection{Implications for water resources planning and management}

Future shifts in runoff under projected climatic and land cover changes can have drastic hydrologic and environmental impacts in the Southeast Coasts Basin. High ensemble mean increases in monthly and annual runoff by the 2050s and 2080s (Figure 2.5, 2.6) would lead to potentially higher than average water levels in the drainage streams and flood control systems over the southeast Florida. The runoff projections suggested a substantially higher risk for freshwater flooding and stream water pollutions in major urban centers (e.g., Greater Miami, Fort Lauderdale, Boca Raton, West Palm Beach, Jupiter, Fort Pierce) throughout the basin. Given the non-linear watershed hydrologic processes, it would be imperative to evaluate storm runoff responses under concurrent climatic and land cover changes, instead of just superposing their isolated impacts, in these complex coastal-urban environments. The remarkably high mean increases in watershed runoff calls for drastic upgradations of existing stormwater drainage infrastructure through retrofitting, rehabilitations, and new constructions, as appropriate. Furthermore, the potential increases in urban and agricultural runoff would result in much enhanced pollutant (e.g., nutrients) discharges to the downstream waters such as the Indian River Lagoon, St. Lucie Estuary, and Biscayne Bay. Increase in nutrient concentrations, for example, 
can promote harmful algal blooms in these estuarine waterbodies - endangering oyster reefs, sea grasses, and many other marine species by producing harmful toxins, blocking the sunlight, and depleting dissolved oxygen (Boesch et al., 1997). Excessive nutrient loading, high turbidity, and low salinity in the freshwater influx may also lead to bleaching and subsequent death of the coral reefs of the adjacent estuaries (e.g., St. Lucie Estuary; see Lapointe et al., 2012).

\subsubsection{Limitations, caveats, and uncertainties}

This study did not report the consideration of potential sea level rise (SLR) in constructing the future scenarios of stormwater runoff for 2050s and 2080s. However, based on the projected SLR scenarios for southeast Florida (SFRCCC Sea Level Rise Work Group, 2015), the potential impacts of SLR on the basin-scale stormwater budget (pluvial runoff generated by rainfall accumulations) were investigated. In the modeling experiments, these analyses were conducted by first fixing the observed or modeled water level (if observations were not available) during the baseline 2010 s period as the downstream boundary conditions. SWMM was then run by increasing the boundary conditions by the recommended scenarios of SLR $(25$ to $150 \mathrm{~cm})$, relative to the 2010s water level. The projected SLR scenarios did not appreciably affect runoff generation during the 10-year period in the basin, except for small (i.e., line-shape) areas adjacent to the stream outlets to the ocean. Furthermore, the impacts of potential changes in the upstream boundary conditions for rivers and canals that had originated outside the Southeast Coasts Basin (e.g., from Lake Okeechobee) were investigated. The boundary conditions were perturbed by -30 (decrease) to $+30 \%$ (increase), with an increment of $5 \%$. The perturbation experiments did not notably change runoff depth during 2010s in the basin, except for small areas adjacent to the upstream boundaries. Overall, the basin-scale storm runoff of 2010s was not notably sensitive to the projected SLR or to the perturbations in the upstream boundary 
conditions. Therefore, it was reasonable to mainly construct the future scenarios of basin runoff based on the projected changes in climate (rainfall, ET) and land cover/uses (imperviousness).

In constructing the runoff scenarios of 2050s and 2080s for the Southeast Coasts Basin, the current study assumed similar drainage network and stream hydrology between the historical and future periods. Subject to the poor skills of GCMs in accurately reproducing hourly rainfalls, the hourly observed distributions of rainfall within a month from the 2010s were used to distribute the projected total rainfall for the corresponding month to different hours for 2050s and 2080s. Given the large area of the study basin, the hundreds of thousands of local management structures such as street inlets, underground sewers, and catch-basins were not explicitly parameterized in the model. Instead, runoff from the subbasins were assumed to ultimately drain into the rivers and canals. These may be considered as caveats of the study given that any future changes in rainfall hyetograph, management structures, and drainage network are inherently expected to influence the process of soil saturation, runoff generation, and mass transport.

Climate in southeast Florida often experiences seasonal anomalies driven by the large-scale ocean-atmospheric phenomena such as PDO, AMO, NAO, AO, ENSO, sea-breeze related convection, and tropical storms/hurricanes (Obeysekera et al., 2011; Abdul-Aziz and Al-Amin, 2015). Limited abilities of the CMIP5 GCMs to parameterize these phenomena have been discussed in previous studies (e.g., Zhao et al., 2017; Lu et al., 2018). Any future runoff projections would be prone to the concomitant uncertainties in the modeled and projected rainfalls. Furthermore, disagreement in the projections of rainfall and ET among the GCMs resulted in a wide range of possible future runoff scenarios. The high uncertainty of the ICLUS land cover projections is also a caveat given the dynamic human-landscape interactions. 
Therefore, the ensembled runoff projections were employed to obtain an overall, generalized perspective on the impacts of changing climate and land cover on the basin-scale runoff.

\subsection{Conclusions}

This study evaluated the individual as well as synergistic controls of climatic and land cover changes on stormwater runoff regimes in complex coastal-urban environments, considering Florida Southeast Coasts Basin as the study area. A large-scale $\left(7117 \mathrm{~km}^{2}\right)$ mechanistic hydrologic model was developed for this basin using U.S. EPA SWMM 5.1. The model was calibrated and validated (NSE $=0.74$ to $0.92, \mathrm{RSR}=0.28$ to 0.51 ) with daily streamflow observations for the historical 10-year period of 2010s (2004-2013). It was then utilized to evaluate runoff responses to reference changes in climate (rainfall and ET) and land cover (imperviousness), and to perform comparative assessments of the historical and potential future stormwater runoffs. The basin-scale storm runoff had notably different seasonal sensitivities to standalone perturbations (-30 to $+30 \%$, with $5 \%$ increments) in rainfall, ET, and imperviousness. The runoff sensitivities to rainfall and ET were strongly nonlinear across the range of perturbations, whereas the sensitivities to imperviousness were mostly linear. The sensitivity results suggested that climatic changes would be substantially more impactful on storm runoff generation than land cover changes in these coastal-urban environments. Based on annual averages, rainfall had approximately 2.5 and 5 times stronger control on runoff than that of imperviousness and ET, respectively. Further, stronger nonlinear responses of runoff were obtained due to concurrent changes in climate and land cover than the linear summations of their individual effects.

Based on the climatic projections of $20 \mathrm{GCMs}$ and land cover projections of EPA

ICLUS dataset, the Southeast Coasts Basin would experience high ensemble increases in 10-year 
mean annual storm runoff by 2050s (2044-2053) and 2080s (2076-2085), relative to the 2010s. Higher runoff increases were noted at and around majority of the urban centers across the basin, including major cities in the northeast (e.g., Fort Pierce, Port St. Lucie, Jupiter), north-central (e.g., West Palm Beach, Boca Raton), central (e.g., Fort Lauderdale, Hollywood, Sunrise), and the south-central (e.g., Miami, Doral, Hialeah, Homestead) regions. Remarkably, the highest potential runoff increases were projected in the greater Miami area under all scenarios. Further, much of the northern, western, and southern basin areas — currently representing croplands, pasture, grasslands, and wetlands - would experience a substantial relative increase in runoff, primarily due to their projected conversions to more impervious (e.g., built-up) land uses.

Based on the basin-scale ensemble changes, the projected climatic changes would lead to high increases (relative to 2010s) in annual storm runoff under the 2080s-RCP 4.5 (87\%), 2050sRCP 4.5 (83\%), 2050s-RCP 8.5 (60\%), and 2080s-RCP 8.5 (47\%) scenarios. In contrast, the projected land cover changes would cause moderate increases in the basin-scale annul storm runoff: 2080s-RCP 8.5 (31\%), 2080s-RCP 4.5 (26\%), 2050s-RCP 8.5 (23\%), and 2050s-RCP 4.5 (20\%). However, under the projected concurrent changes in climate and land cover, the annual storm runoff would increase by $118 \%, 106 \%, 86 \%$, and $80 \%$ under 2080 s-RCP $4.5,2050$ s-RCP 4.5, 2050s-RCP 8.5, and 2080s-RCP 8.5, respectively. A higher mixture of projected increases and decreases in rainfalls from different GCMs led to the counter-intuitive, smaller ensemble changes in runoff under the RCP 8.5 scenarios than under the RCP 4.5 scenarios. The relative increases in runoff due to the combined changes in climate and land cover were higher during the dry season and transitional months (October-May) than the wet season (June-September). The seasonal variation in the projected changes of rainfall and runoff were nearly identical. The 
basin-scale runoff increases and the seasonal patterns reiterated the predominant climatic control on storm runoff and high vulnerability in complex coastal-urban environments.

The findings of this study would be beneficial in minimizing the impacts of climate and land cover changes in southeast Florida and coastal built environments around the world. The projected runoff increases across the Southeast Coasts Basin by 2050s and 2080s indicated the critical areas of potentially increased flooding risk and water quality impacts in streams and the surrounding ecosystems. Major upgradations of existing stormwater drainage infrastructure should be pursued to convey the projected high increases in runoff. Appropriate management and remediation measures should also be undertaken to alleviate the potentially enhanced pollutant discharges from urban and agricultural areas to the downstream waters. The findings are particularly relevant in areas of high latitudes and wet tropical and subtropical regions that would experience increases in rainfall and urbanization (IPCC, 2014a). The findings of this study may, therefore, provide important guidance for development, improvement, and management of stormwater drainage infrastructure to achieve coastal-urban sustainability and resilience.

\section{Acknowledgments}

The research was funded by a National Science Foundation (NSF) Critical Resilient Interdependent Infrastructure Systems and Processes (CRISP 2.0) Award to Dr. Omar I. AbdulAziz (NSF CMMI Award \#1832680), and by the "Florida Public Hurricane Loss Model Enhancements" project's freshwater flood modeling award to Dr. Omar I. Abdul-Aziz. The research on climate and land cover change impacts on stormwater runoff was exclusively funded by the NSF project. The findings and conclusions of this research are those of the authors, and do not necessarily reflect the views of NSF and the State of Florida or any of its sub-agencies. 


\section{Appendix 2}

Text A2.1: Modification of the subbasins and link-node networks derived from Arc Hydro Drainage networks generated using Arc Hydro (Maidment and Morehouse, 2002) were compared with the streams from the National Hydrography Dataset (NHD) of U. S. Geological Survey (USGS) (USGS, 2016); significant discrepancies were found, especially in the urbanized regions of the basin. It was also necessary to ensure smaller subbasins in the highly urbanized areas. The subbasins, links, and nodes found from Arc Hydro were, consequently, modified to match the actual drainage networks based on ESRI basemap, Google Earth platform, and the NHD streams.

\section{Text A2.2: Assigning hourly rainfall observations to the subbasins}

Hourly rainfall data were assigned to subbasins of the Southeast Coasts Basin model using Thiessen polygons. When multiple Thiessen polygons fell within a single subbasin, weighted (based on percentage of area of the concerned subbasin falling in different Thiessen polygons) average rainfalls (See Figure A2.1 for subbasin-scale rainfalls.) were computed.

\section{Text A2.3: Selection and utilization of initial groundwater level (GWL)}

Since the model simulation for the Southeast Coasts Basin starts from January 01 2004, GWL for 01/01/2004 was used for most of the subbasins as the initial GWL. There were some groundwater stations without data on the first day of 2004. In those cases, GWL information within either 60 days before or after 01/01/2004 was treated as the initial GWL; there were very low fluctuations of groundwater in the dry season months of November, December, January, and February. 


\section{Text A2.4: Assigning GWL to the subbasins}

An interpolated raster dataset of initial GWL was developed using Kriging (Goovaerts, 1997) based on the observed initial GWL records. Then, spatial mean initial GWL was computed for each subbasin using the 'Zonal Statistics as Table' tool of ESRI ArcGIS 10.2.

\section{Text A2.5: Computation of characteristic width of the subbasins}

Following Digiano et al. (1977), subbasin characteristic width ( $W$ ) was computed as follows:

$W=L+2 L(1-Z)$

where $L=$ length of the main drainage channel of the subbasin; $Z=A_{m} / A=$ skew factor; $A_{m}=$ larger of the two areas on each side of the drainage channel of the subbasin; and $A=$ total area of the subbasin.

\section{Text A2.6: Statisical metrics for model performance evaluation}

The Nash-Sutcliffe Efficiency (NSE) was computed as:

$$
N S E=1-\frac{\sum_{i=1}^{N}\left(Y_{i, o b s}-Y_{i, \mathrm{mod}}\right)^{2}}{\sum_{i=1}^{N}\left(Y_{i, \mathrm{obs}}-Y_{m e a n, o b s}\right)^{2}}
$$

where $N$ is the total number of observations; $Y_{i, \text { mod }}$ and $Y_{i, o b s}$ are the $i$-th model prediction and the corresponding observation, respectively; and $Y_{\text {mean,obs }}$ is the mean of all observations. NSE = 1.0 indicates a perfect model that has predictions exactly matching with the respective observations. NSE $<0$ indicates a model that is a worse predictor than the mean of all observations as an alternative model. 
The ratio of the root-mean-square error to the standard deviation of observations (RSR) was computed as follows:

$R S R=\frac{\sqrt{\sum_{i=1}^{N}\left(Y_{i, \bmod }-Y_{i, o b s}\right)^{2} / N}}{\sigma_{o b s}}$

where $N$ is the total number of observations; $Y_{i, \text { mod }}$ and $Y_{i, o b s}$ are the $i$-th model prediction and the corresponding observation, respectively; and $\sigma_{o b s}$ is the standard deviation of observations. $\mathrm{RSR}=0.00-0.50,0.50-0.60$, and 0.60-0.70 indicate very good, good, and satisfactory models, respectively (Moriasi et al., 2007). A model with RSR > 0.70 is considered unsatisfactory.

\section{Text A2.7: Disaggregation of projected monthly rainfall to hourly rainfall}

The reconstructed monthly rainfall projections from the general circulation models (GCMs) were disaggregated to hourly rainfalls —assuming that the hourly rainfall distribution in the 2050s (2044-2053) and 2080s (2076-2085) were similar to that in the 2010s (2004-2013) - as follows:

$P_{j, k, l, m}=P_{j, k} \times r_{i, k, l} \times r_{i, k, l, m}$

where $P_{j, k, l, m}=$ hourly rainfall for hour $m$ of day $l$ of month $k$ in future year $j ; P_{j, k}=$ corrected monthly rainfall for month $k$ in future year $j ; r_{i, k, l}=$ ratio of daily rainfall over monthly rainfall for day $l$ of month $k$ in historical year $i$; and $r_{i, k, l, m}=$ ratio of hourly rainfall over daily rainfall for hour $m$ of day $l$ of month $k$ in historical year $i$. These ratios can be expressed as:

$$
\begin{gathered}
r_{i, k, l}=\frac{P_{i, k, l}}{P_{i, k}} \\
r_{i, k, l, m}=\frac{P_{i, k, l, m}}{P_{i, k, l}}
\end{gathered}
$$


where $P_{i, k, l}=$ daily rainfall for day $l$ of month $k$ in historical year $i ; P_{i, k}=$ monthly rainfall for month $k$ in historical year $i$; and $P_{i, k, l, m}=$ hourly rainfall for hour $m$ of day $l$ of month $k$ in historical year $i$. Note that $i$ and $j=1,2,3, \ldots . ., 10$ (simultaneously for both indices) for this disaggregation.

Table A2.1: Streamflow stations used for inflow boundary conditions in the Florida Southeast Coasts Basin model.

\begin{tabular}{llll}
\hline Station ID & Stream name & Data frequency & Agency \\
\hline S38_C & Cypress Creek Canal & Instantaneous & SFWMD \\
G57_S & Pompano Canal & Instantaneous & SFWMD \\
S34_C & North New River Canal & Instantaneous & SFWMD \\
Kitching & Kitching Creek & Daily & SFWMD \\
272524080221800 & Fivemile Creek & Daily & USGS \\
S308.DS & St. Lucie Canal & Daily & SFWMD \\
02287395 & Miami Canal & Daily & USGS \\
S30_C & Snake Creek Canal & Instantaneous & SFWMD \\
S338_C & Black Creek Canal & Instantaneous & SFWMD \\
2287497 & Snapper Creek Extension Canal & Daily & USGS \\
S167_S & Mowry Canal & Instantaneous & SFWMD \\
S166_S & C-103N Canal & Instantaneous & SFWMD \\
S5AE_C & West Palm Beach Canal & Instantaneous & SFWMD \\
S39_S & Hillsboro Canal & Instantaneous & SFWMD \\
\hline
\end{tabular}

Note: SFMWD refers to South Florida Water Management District. 
Table A2.2: Streamflow stations used for calibrations and validations of the Florida Southeast Coasts Basin model.

\begin{tabular}{cccccc}
\hline Station & $\begin{array}{c}\text { Type of control } \\
\text { structure }\end{array}$ & Canal/Stream & Agency & $\begin{array}{c}\text { Calibration } \\
\text { period }\end{array}$ & $\begin{array}{c}\text { Validation } \\
\text { period }\end{array}$ \\
\hline S49 & Gated spillway & C-24 Canal & SFWMD & $01 / 01 / 2006-$ & $01 / 01 / 2009-$ \\
& & & & $12 / 31 / 2008$ & $12 / 31 / 2011$ \\
S46 & Gated spillway & Loxahatchee & SFWMD & $01 / 01 / 2004-$ & $01 / 01 / 2008-$ \\
& & Slough Canal & & $12 / 31 / 2007$ & $12 / 31 / 2011$ \\
S155 & Gated spillway & West Palm & SFWMD & $01 / 01 / 2005-$ & $01 / 01 / 2009-$ \\
& & Beach Canal & & $12 / 31 / 2008$ & $12 / 31 / 2011$ \\
G56 & \multirow{2}{*}{ Gated spillway } & Hillsboro & SFWMD & $01 / 01 / 2004-$ & $01 / 01 / 2008-$ \\
& & Canal & & $12 / 31 / 2007$ & $12 / 31 / 2011$ \\
G54 & \multirow{2}{*}{ Gated spillway } & North New & SFWMD & $01 / 01 / 2006-$ & $01 / 01 / 2009-$ \\
& & River Canal & & $03 / 31 / 2008$ & $12 / 31 / 2011$ \\
A2.26 & \multirow{2}{*}{ Gated spillway } & Miami River & SFWMD & $01 / 01 / 2006-$ & $01 / 01 / 2009-$ \\
& & & & $12 / 31 / 2008$ & $12 / 31 / 2011$ \\
\hline
\end{tabular}

Note: SFMWD refers to South Florida Water Management District 
Table A2.3: List of the Coupled Model Intercomparison Project's fifth phase (CMIP5) general circulation models (GCMs) used to obtain future projections of rainfall and potential evapotranspiration in the Southeast Coasts Basin.

\begin{tabular}{|c|c|c|}
\hline Name & Agency & $\begin{array}{c}\text { Resolution } \\
\text { (Long. } \times \text { Lat.) }\end{array}$ \\
\hline bcc-csm1-1 & Beijing Climate Center, China Meteorological Administration & $2.8^{\circ} \times 2.8^{\circ}$ \\
\hline bcc-csm1-1-m & Beijing Climate Center, China Meteorological Administration & $1.12^{\circ} \times 1.12^{\circ}$ \\
\hline BNU-ESM & $\begin{array}{c}\text { College of Global Change and Earth System Science, Beijing } \\
\text { Normal University, China }\end{array}$ & $2.8^{\circ} \times 2.8^{\circ}$ \\
\hline CanESM2 & Canadian Centre for Climate Modeling and Analysis & $2.8^{\circ} \times 2.8^{\circ}$ \\
\hline CCSM4 & National Center of Atmospheric Research, USA & $1.25^{\circ} \times 0.94^{\circ}$ \\
\hline CNRM-CM5 & National Centre of Meteorological Research, France & $1.4^{\circ} \times 1.4^{\circ}$ \\
\hline CSIRO-Mk3-6-0 & $\begin{array}{c}\text { Commonwealth Scientific and Industrial Research } \\
\text { Organization/Queensland Climate Change Centre of } \\
\text { Excellence, Australia }\end{array}$ & $1.8^{\circ} \times 1.8^{\circ}$ \\
\hline GFDL-ESM2M & NOAA Geophysical Fluid Dynamics Laboratory, USA & $2.5^{\circ} \times 2.0^{\circ}$ \\
\hline GFDL-ESM2G & NOAA Geophysical Fluid Dynamics Laboratory, USA & $2.5^{\circ} \times 2.0^{\circ}$ \\
\hline HadGEM2-ES & Met Office Hadley Center, UK & $1.88^{\circ} \times 1.25^{\circ}$ \\
\hline HadGEM2-CC & Met Office Hadley Center, UK & $1.88^{\circ} \times 1.25^{\circ}$ \\
\hline inmem4 & Institute for Numerical Mathematics, Russia & $2.0^{\circ} \times 1.5^{\circ}$ \\
\hline IPSL-CM5A-LR & Institut Pierre Simon Laplace, France & $3.75^{\circ} \times 1.8^{\circ}$ \\
\hline IPSL-CM5A-MR & Institut Pierre Simon Laplace, France & $2.5^{\circ} \times 1.25^{\circ}$ \\
\hline IPSL-CM5B-LR & Institut Pierre Simon Laplace, France & $2.75^{\circ} \times 1.8^{\circ}$ \\
\hline MIROC5 & $\begin{array}{l}\text { Atmosphere and Ocean Research Institute (The University of } \\
\text { Tokyo), National Institute for Environmental Studies,and } \\
\text { Japan Agency for Marine-Earth Science and Technology }\end{array}$ & $1.4^{\circ} \times 1.4^{\circ}$ \\
\hline MIROC-ESM & $\begin{array}{l}\text { Japan Agency for Marine-Earth Science and Technology, } \\
\text { Atmosphere and Ocean Research Institute (The University of } \\
\text { Tokyo), and National Institute for Environmental Studies }\end{array}$ & $2.8^{\circ} \times 2.8^{\circ}$ \\
\hline $\begin{array}{l}\text { MIROC-ESM- } \\
\text { CHEM }\end{array}$ & $\begin{array}{l}\text { Japan Agency for Marine-Earth Science and Technology, } \\
\text { Atmosphere and Ocean Research Institute (The University of } \\
\text { Tokyo), and National Institute for Environmental Studies }\end{array}$ & $2.8^{\circ} \times 2.8^{\circ}$ \\
\hline MRI-CGCM3 & Meteorological Research Institute, Japan & $1.1^{\circ} \times 1.1^{\circ}$ \\
\hline NorESM1-M & Norwegian Climate Center, Norway & $2.5^{\circ} \times 1.9^{\circ}$ \\
\hline
\end{tabular}


Table A2.4: Baseline and future basin-average percent changes in annual rainfall, ET, and imperviousness for the Florida Southeast Coasts Basin relative to the baseline period of 2010s.

\begin{tabular}{cccccc}
\hline \multirow{2}{*}{ Variable } & $\begin{array}{c}\text { Baseline 2010s } \\
\text { values }\end{array}$ & \multicolumn{4}{c}{ Projected changes (\%) } \\
\cline { 3 - 6 } & & 2050s-RCP 4.5 & 2080s-RCP 4.5 & 2050s-RCP 8.5 & 2080s-RCP 8.5 \\
\hline Rainfall & $1346.4 \mathrm{~mm}$ & +29.2 & +30.2 & +20.2 & +12.9 \\
ET & $3.8 \mathrm{~mm} /$ day & +2.9 & +4.5 & +4.6 & +8.5 \\
Imperviousness & $27.1 \%$ & +24.7 & +30.5 & +28.3 & +35.6 \\
\hline
\end{tabular}

Note: Positive sign indicates increases.

Table A2.5: Sensitivity coefficients of runoff to changes in rainfall in the Florida Southeast Coasts Basin.

\begin{tabular}{ccccccccccccc}
\hline \multirow{2}{*}{ Month } & \multicolumn{10}{c}{ Change in rainfall (\%) } \\
\cline { 2 - 13 } & -30 & -25 & -20 & -15 & -10 & -5 & 5 & 10 & 15 & 20 & 25 & 30 \\
\hline January & 1.18 & 1.19 & 1.20 & 1.20 & 1.21 & 1.21 & 1.23 & 1.23 & 1.24 & 1.25 & 1.26 & 1.27 \\
February & 1.20 & 1.21 & 1.23 & 1.25 & 1.27 & 1.29 & 1.33 & 1.36 & 1.38 & 1.41 & 1.44 & 1.46 \\
March & 1.26 & 1.30 & 1.34 & 1.38 & 1.42 & 1.45 & 1.52 & 1.56 & 1.59 & 1.61 & 1.62 & 1.63 \\
April & 1.24 & 1.27 & 1.30 & 1.32 & 1.33 & 1.36 & 1.40 & 1.41 & 1.43 & 1.45 & 1.47 & 1.49 \\
May & 1.26 & 1.28 & 1.29 & 1.31 & 1.33 & 1.36 & 1.42 & 1.45 & 1.49 & 1.52 & 1.55 & 1.57 \\
June & 1.36 & 1.40 & 1.45 & 1.51 & 1.55 & 1.58 & 1.69 & 1.71 & 1.75 & 1.79 & 1.84 & 1.88 \\
July & 1.42 & 1.47 & 1.53 & 1.60 & 1.65 & 1.71 & 1.82 & 1.87 & 1.91 & 1.95 & 2.01 & 2.07 \\
August & 1.50 & 1.57 & 1.64 & 1.71 & 1.79 & 1.85 & 2.01 & 2.06 & 2.14 & 2.20 & 2.26 & 2.35 \\
September & 1.57 & 1.64 & 1.71 & 1.77 & 1.83 & 1.90 & 1.99 & 2.04 & 2.11 & 2.19 & 2.27 & 2.33 \\
October & 1.65 & 1.70 & 1.73 & 1.75 & 1.77 & 1.82 & 1.90 & 1.95 & 2.00 & 2.07 & 2.11 & 2.14 \\
November & 1.45 & 1.47 & 1.52 & 1.59 & 1.58 & 1.55 & 1.56 & 1.59 & 1.60 & 1.60 & 1.62 & 1.63 \\
December & 1.44 & 1.48 & 1.53 & 1.60 & 1.66 & 1.70 & 1.70 & 1.71 & 1.73 & 1.74 & 1.75 & 1.78 \\
Annual & 1.43 & 1.48 & 1.53 & 1.58 & 1.62 & 1.67 & 1.75 & 1.79 & 1.84 & 1.88 & 1.93 & 1.97 \\
\hline
\end{tabular}


Table A2.6: Sensitivity coefficients of runoff to changes in evapotranspiration (ET) in the Florida Southeast Coasts Basin.

\begin{tabular}{ccccccccccccc}
\hline \multirow{2}{*}{ Month } & \multicolumn{10}{c}{ Change in ET (\%) } \\
\cline { 2 - 12 } & -30 & -25 & -20 & -15 & -10 & -5 & 5 & 10 & 15 & 20 & 25 & 30 \\
\hline January & -0.08 & -0.07 & -0.07 & -0.06 & -0.06 & -0.06 & -0.05 & -0.05 & -0.05 & -0.05 & -0.05 & -0.04 \\
February & -0.28 & -0.27 & -0.24 & -0.22 & -0.20 & -0.18 & -0.15 & -0.14 & -0.13 & -0.12 & -0.11 & -0.10 \\
March & -0.35 & -0.35 & -0.33 & -0.31 & -0.31 & -0.28 & -0.24 & -0.24 & -0.22 & -0.20 & -0.19 & -0.17 \\
April & -0.24 & -0.23 & -0.22 & -0.21 & -0.21 & -0.20 & -0.20 & -0.16 & -0.15 & -0.15 & -0.15 & -0.14 \\
May & -0.26 & -0.24 & -0.22 & -0.20 & -0.18 & -0.17 & -0.13 & -0.13 & -0.12 & -0.12 & -0.11 & -0.11 \\
June & -0.43 & -0.40 & -0.37 & -0.35 & -0.33 & -0.32 & -0.31 & -0.27 & -0.26 & -0.25 & -0.23 & -0.22 \\
July & -0.55 & -0.53 & -0.51 & -0.49 & -0.47 & -0.45 & -0.39 & -0.37 & -0.35 & -0.33 & -0.31 & -0.29 \\
August & -0.62 & -0.60 & -0.57 & -0.54 & -0.51 & -0.46 & -0.43 & -0.42 & -0.40 & -0.38 & -0.36 & -0.34 \\
September & -0.61 & -0.59 & -0.58 & -0.57 & -0.56 & -0.53 & -0.51 & -0.48 & -0.46 & -0.44 & -0.42 & -0.41 \\
October & -0.51 & -0.50 & -0.48 & -0.46 & -0.46 & -0.44 & -0.44 & -0.42 & -0.42 & -0.41 & -0.41 & -0.40 \\
November & -0.35 & -0.33 & -0.32 & -0.31 & -0.31 & -0.27 & -0.28 & -0.27 & -0.26 & -0.26 & -0.25 & -0.25 \\
December & -0.43 & -0.41 & -0.41 & -0.41 & -0.40 & -0.41 & -0.40 & -0.36 & -0.33 & -0.31 & -0.28 & -0.26 \\
Annual & -0.47 & -0.45 & -0.43 & -0.41 & -0.40 & -0.38 & -0.35 & -0.33 & -0.32 & -0.30 & -0.29 & -0.28 \\
\hline
\end{tabular}

Table A2.7: Sensitivity coefficients of runoff to changes in imperviousness in the Florida Southeast Coasts Basin.

\begin{tabular}{cccccccccccccc}
\hline \multirow{2}{*}{ Month } & \multicolumn{10}{c}{ Change in imperviousness (\%) } \\
\cline { 2 - 13 } & -30 & -25 & -20 & -15 & -10 & -5 & 5 & 10 & 15 & 20 & 25 & 30 \\
\hline January & 0.95 & 0.94 & 0.94 & 0.94 & 0.94 & 0.93 & 0.93 & 0.93 & 0.92 & 0.92 & 0.92 & 0.92 \\
February & 0.90 & 0.90 & 0.90 & 0.90 & 0.90 & 0.90 & 0.89 & 0.89 & 0.89 & 0.89 & 0.89 & 0.88 \\
March & 0.86 & 0.85 & 0.85 & 0.85 & 0.85 & 0.84 & 0.84 & 0.84 & 0.84 & 0.84 & 0.83 & 0.83 \\
April & 0.86 & 0.86 & 0.86 & 0.85 & 0.85 & 0.85 & 0.84 & 0.84 & 0.85 & 0.84 & 0.84 & 0.84 \\
May & 0.82 & 0.82 & 0.82 & 0.82 & 0.81 & 0.81 & 0.81 & 0.80 & 0.80 & 0.80 & 0.80 & 0.79 \\
June & 0.76 & 0.76 & 0.76 & 0.75 & 0.75 & 0.75 & 0.75 & 0.75 & 0.75 & 0.75 & 0.75 & 0.74 \\
July & 0.74 & 0.74 & 0.74 & 0.73 & 0.74 & 0.74 & 0.73 & 0.72 & 0.72 & 0.72 & 0.72 & 0.72 \\
August & 0.70 & 0.70 & 0.70 & 0.70 & 0.70 & 0.70 & 0.69 & 0.69 & 0.69 & 0.68 & 0.68 & 0.68 \\
September & 0.64 & 0.64 & 0.64 & 0.64 & 0.64 & 0.63 & 0.64 & 0.64 & 0.64 & 0.63 & 0.63 & 0.63 \\
October & 0.57 & 0.57 & 0.57 & 0.57 & 0.57 & 0.57 & 0.55 & 0.56 & 0.55 & 0.55 & 0.55 & 0.56 \\
November & 0.71 & 0.71 & 0.71 & 0.71 & 0.71 & 0.71 & 0.70 & 0.70 & 0.69 & 0.70 & 0.70 & 0.70 \\
December & 0.70 & 0.72 & 0.70 & 0.70 & 0.71 & 0.69 & 0.67 & 0.69 & 0.70 & 0.69 & 0.69 & 0.69 \\
Annual & 0.73 & 0.73 & 0.73 & 0.72 & 0.72 & 0.72 & 0.72 & 0.71 & 0.71 & 0.71 & 0.71 & 0.71 \\
\hline
\end{tabular}




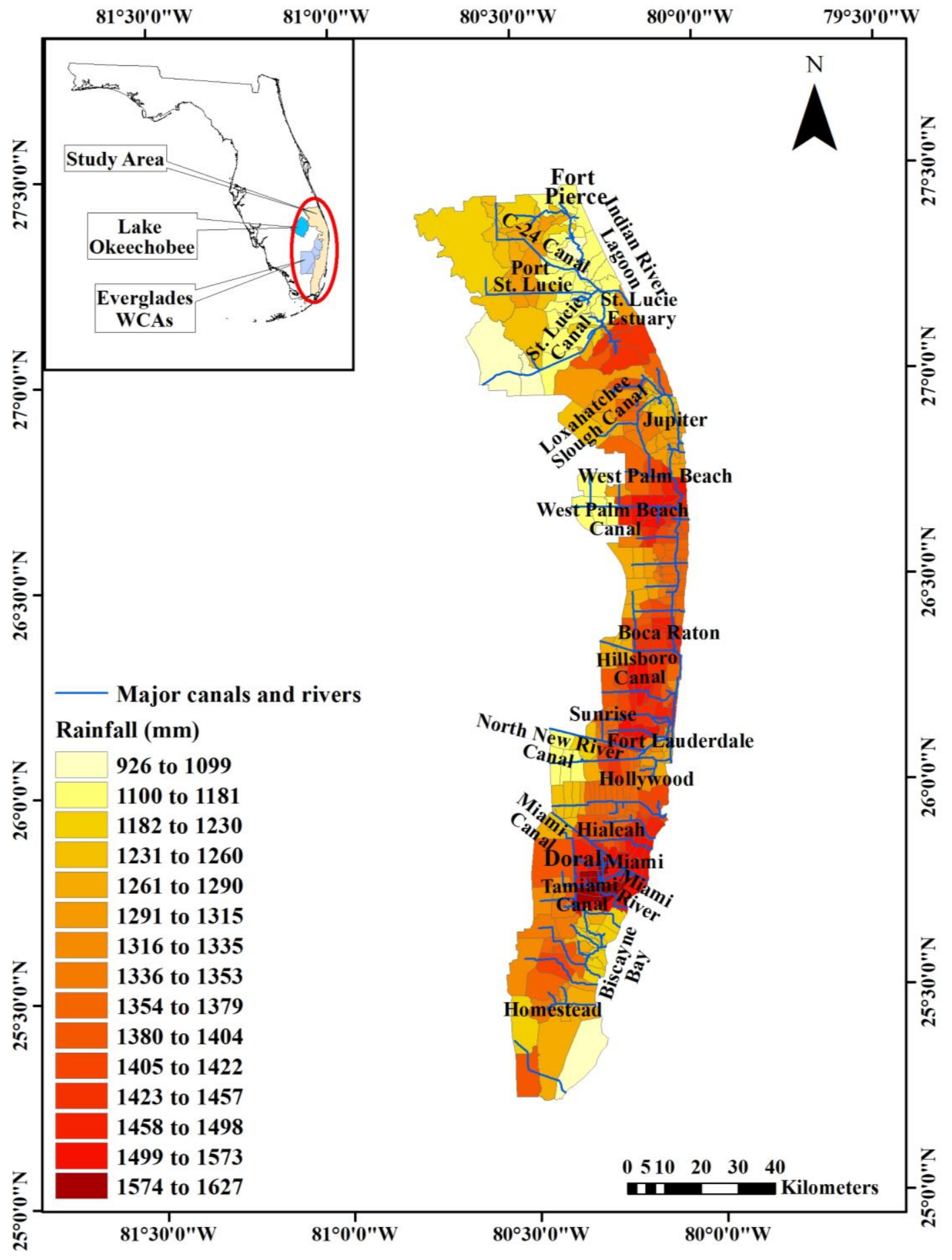

Figure A2.1: Spatial variation of observed 10-year mean annual rainfall in the Florida Southeast Coasts Basin for 2004-2013 (2010s). The inset shows the location of the study area, Lake Okeechobee, and the Everglades Water Conservation Areas (WCAs) in the state of Florida. Inset is not drawn on the map-scale. 


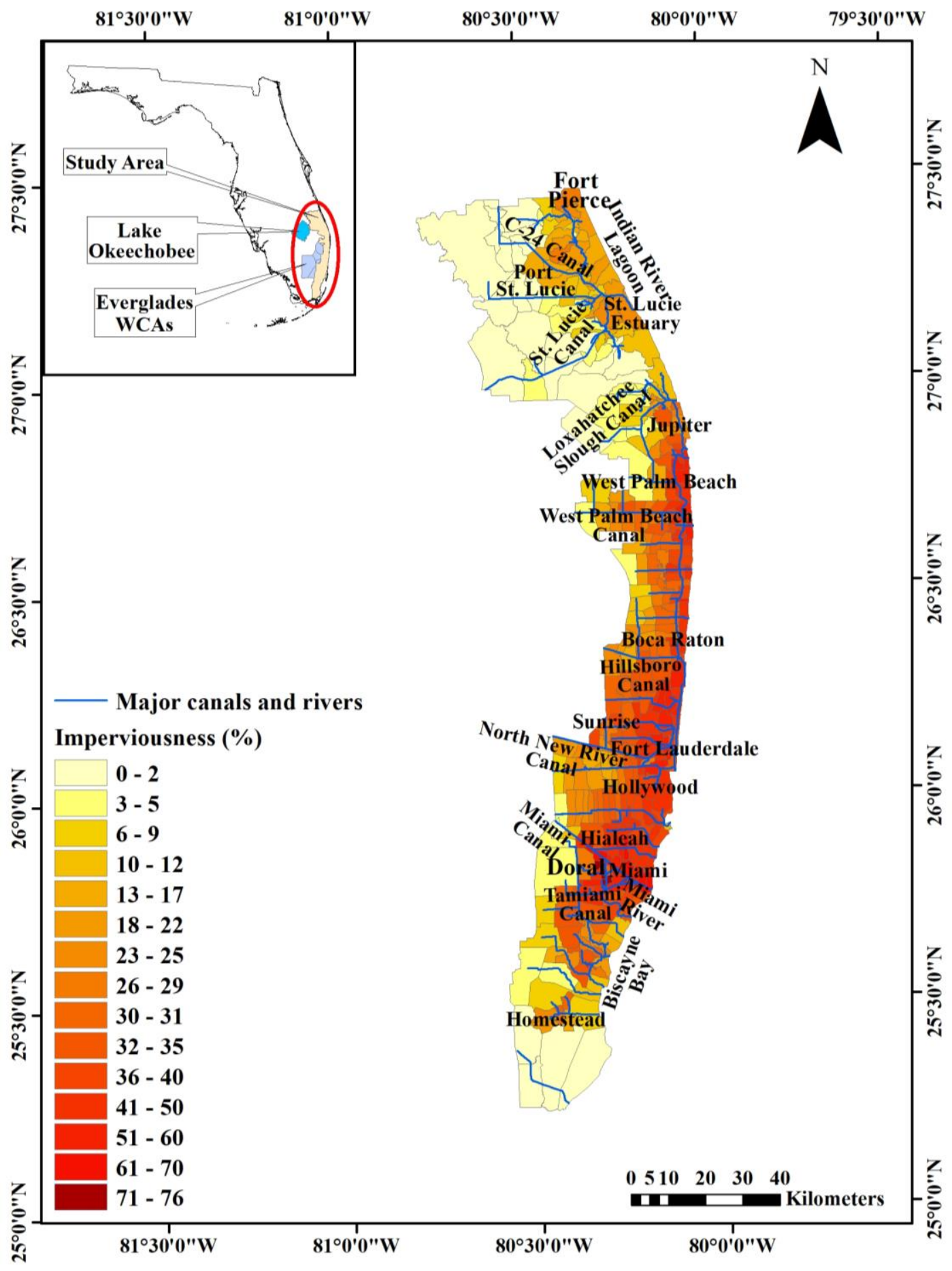

Figure A2.2: Spatial variation of imperviousness in the Florida Southeast Coasts Basin. The inset shows the location of the study area, Lake Okeechobee, and the Everglades Water Conservation Areas (WCAs) in the state of Florida. Inset is not drawn on the map-scale. 


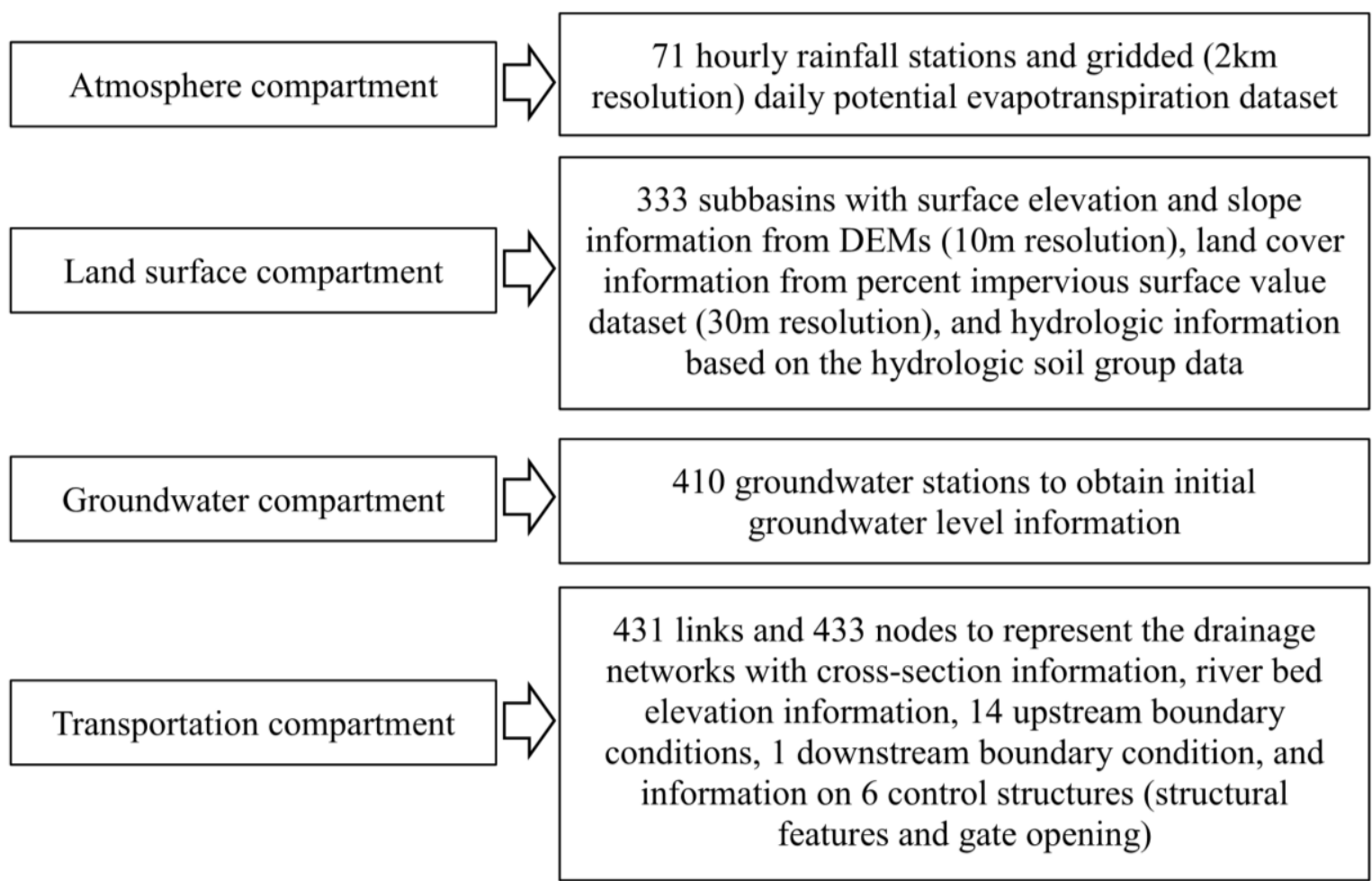

Figure A2.3: Summary of SWMM developments for the Florida Southeast Coasts Basin. 


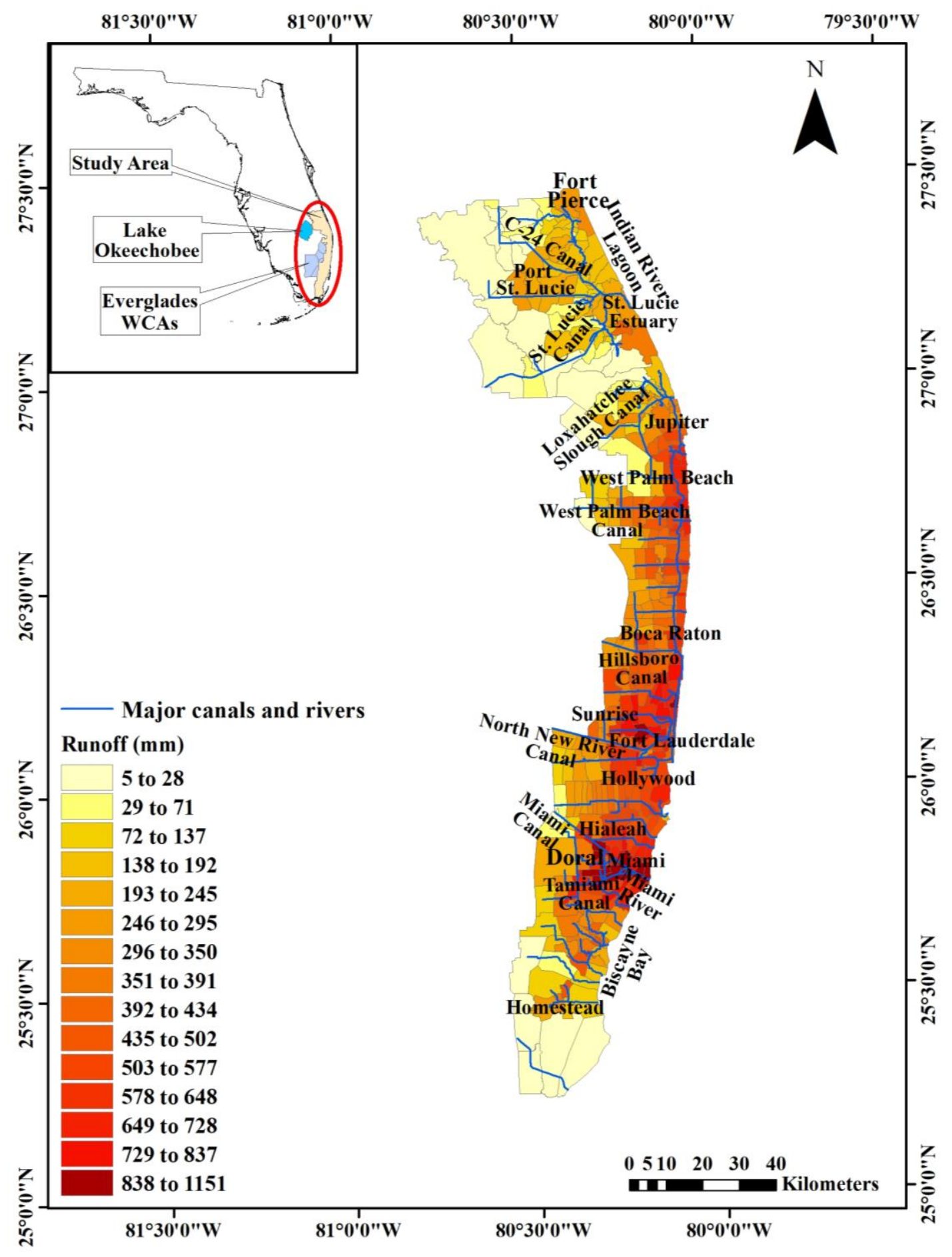

Figure A2.4: Spatial variation of simulated subbasin-scale 10-year mean annual runoff in the Florida Southeast Coasts Basin for 2004-2013 (2010s). The inset shows the location of the study area, Lake Okeechobee, and the Everglades Water Conservation Areas (WCAs) in the state of Florida. Inset is not drawn on the map-scale. 
(a)

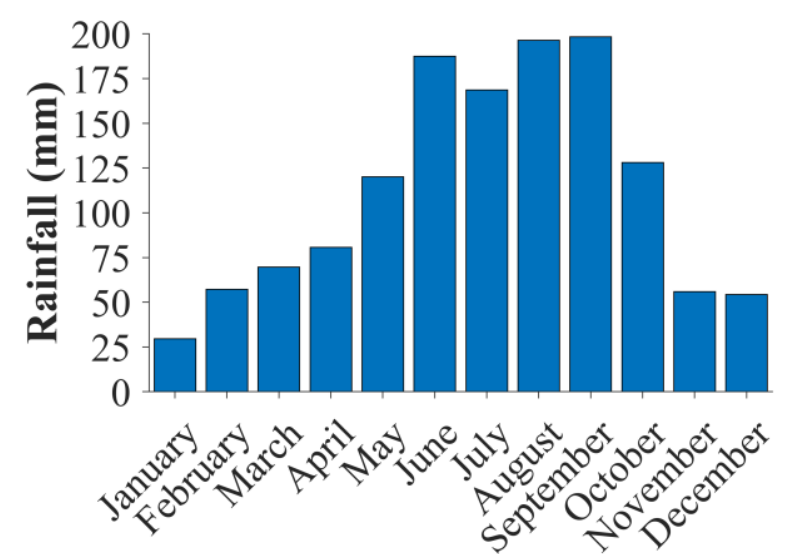

Month

(c)

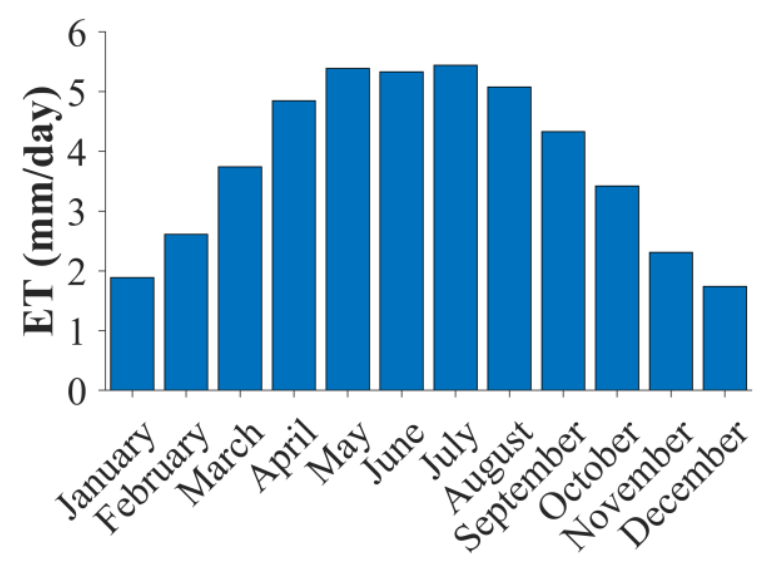

Month (b)

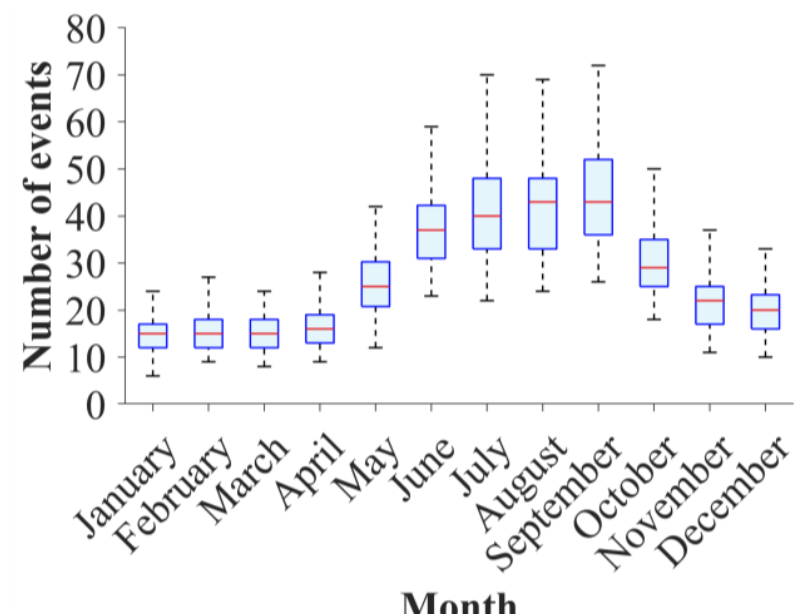

(d)

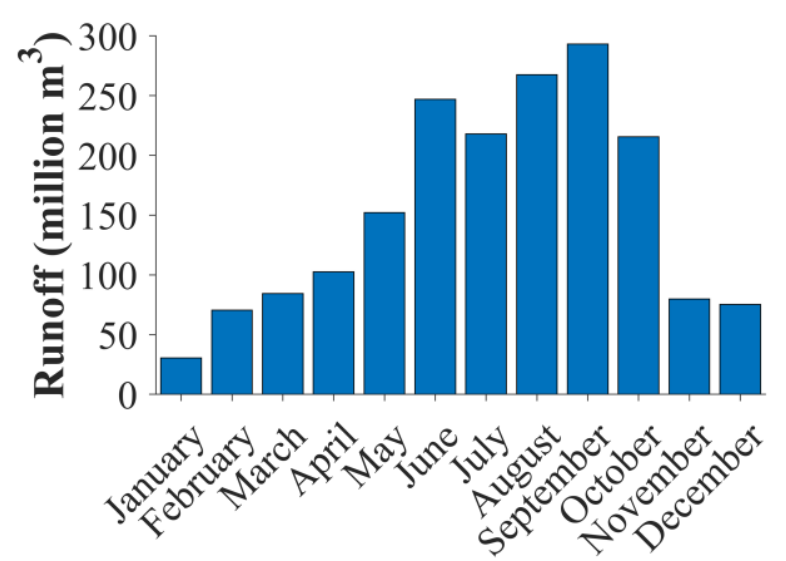

Month

Figure A2.5: Monthly variation in 10-year mean (a) rainfall, (b) number of events, (c) potential evapotranspiration, and (d) baseline runoff volume for 2004-2013 (i.e., 2010s) in the Florida Southeast Coasts Basin. In (b), the box-whiskers represent variations in number of rainfall events across the subbasins; the lower, intermediate, and upper horizontal lines in the boxes indicate $25^{\text {th }}, 50^{\text {th }}$, and $75^{\text {th }}$ percentiles, respectively. 
(a) Rainfall
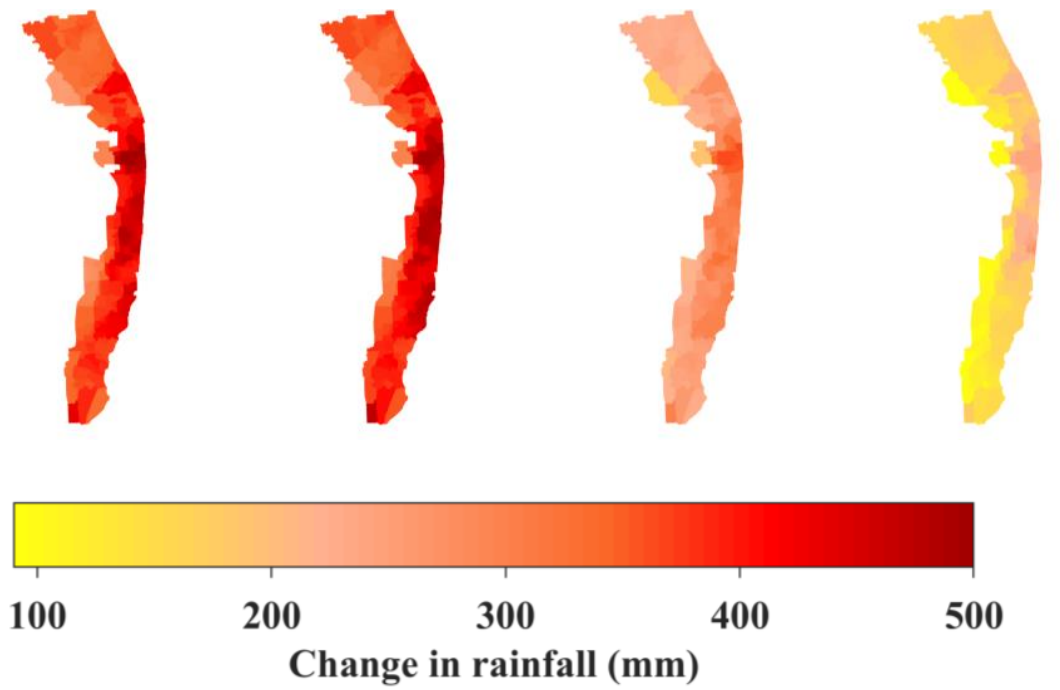

(b) Imperviousness
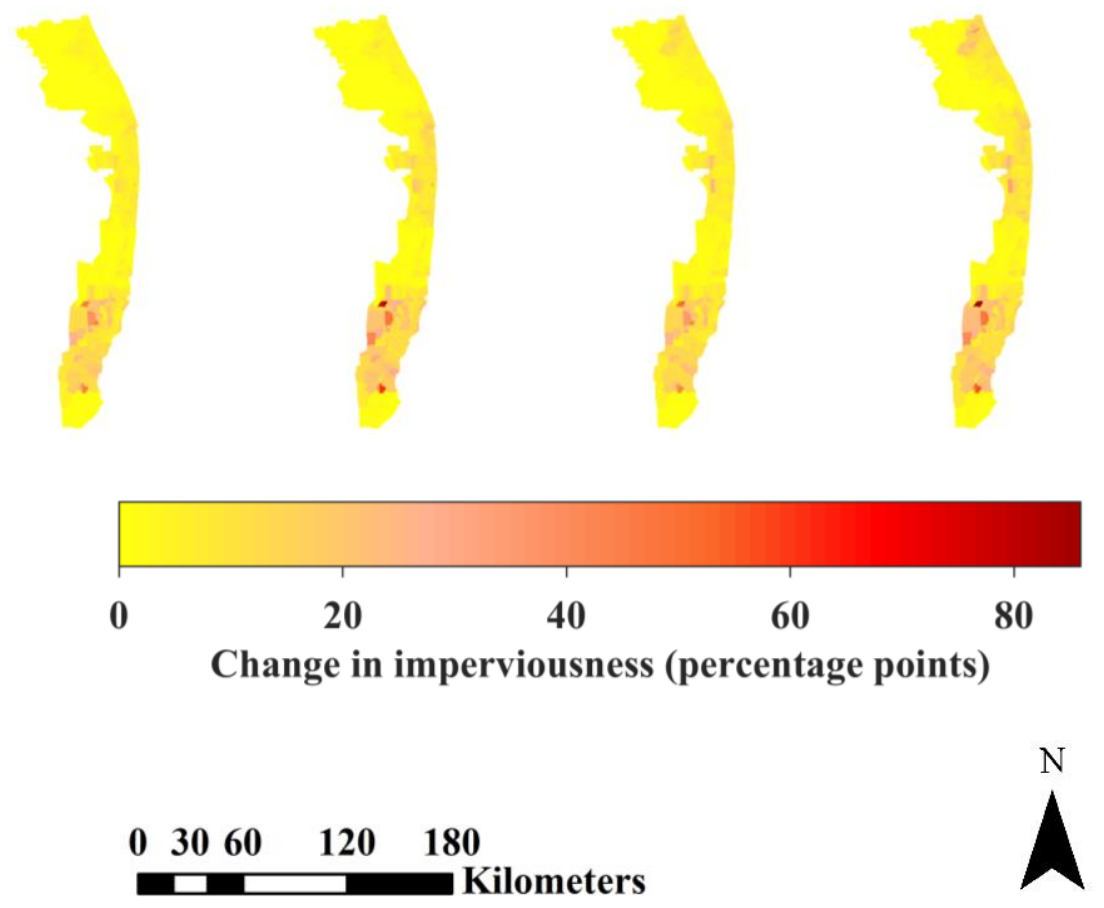

Figure A2.6: Spatial variation of (a) changes in 10-year mean annual rainfall depth based on ensemble mean rainfall projections of the 20 general circulation models (GCMs), and (b) percentage points change in 10-year mean imperviousness under different future scenarios in the Florida Southeast Coasts Basin. 
(a)

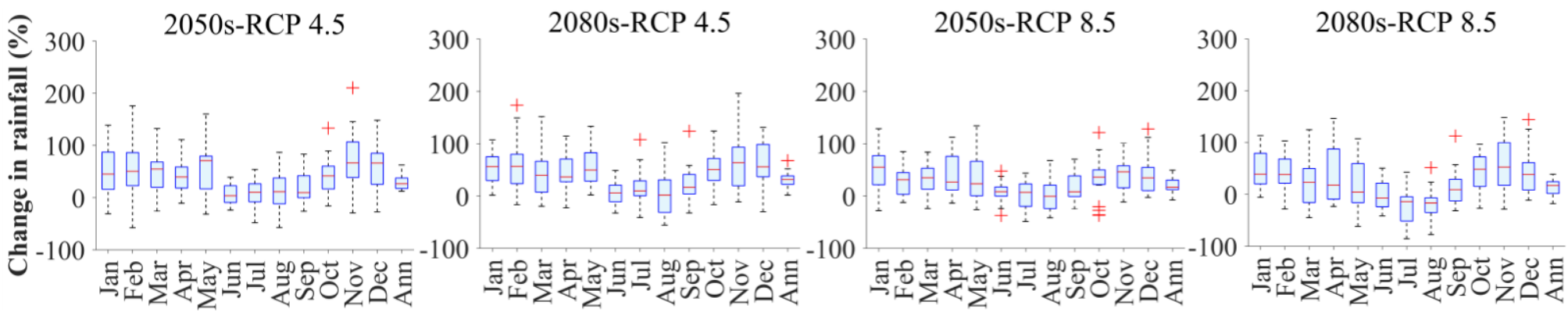

(b)

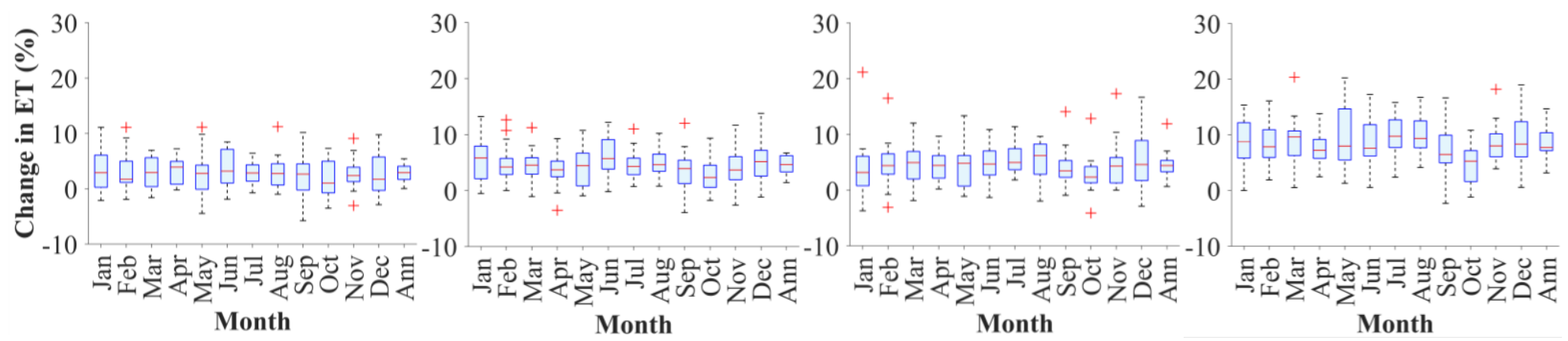

Figure A2.7: Percentage changes in 10-year mean monthly and annual (a) rainfall and (b) evapotranspiration (ET) across the general circulation models (GCMs) for different future scenarios in the Florida Southeast Coasts Basin. The lower, intermediate, and upper horizontal lines in the boxes indicate $25^{\text {th }}, 50^{\text {th }}$, and $75^{\text {th }}$ percentiles, respectively; plus signs indicate extreme outliers. Jan: January; Feb: February; Mar: March; Apr: April; Jun: June; Jul: July; Aug: August; Sep: September; Oct: October; Nov: November; Dec: December; Ann: Annual. 


\title{
Chapter 3: Impact assessments of changing climate and land cover on coastal-natural stormwater runoff by large-scale modeling
}

\begin{abstract}
The individual as well as combined controls of climatic and land cover changes on stormwater runoff regimes were evaluated for coastal-natural environments. Using U.S. Environmental Protection Agency (U.S. EPA)'s Storm Water Management Model (SWMM) 5.1, a large-scale $\left(24928 \mathrm{~km}^{2}\right)$ mechanistic hydrologic model was developed for the Saint Johns River Basin of northeast Florida as the study area. The model was calibrated and validated with daily streamflow observations (Nash-Sutcliffe Efficiency $=0.70$ to 0.82) during 2004-2013 (termed the 2010s), and the corresponding runoff volume was computed as a historical reference. Runoffs for the 2050s (2044-2053) and 2080s (2076-2085) were estimated by incorporating climatic (rainfall and ET) projections from 20 General Circulation Models (GCMs) and land cover projections from EPA under the Representative Concentration Pathways (RCP) 4.5 and 8.5 scenarios. The study results suggested a predominant climatic control on basin-wide runoff responses. Based on annual runoff sensitivities, rainfall had approximately 2 and 8 times stronger control on runoff than imperviousness and ET, respectively. Moreover, the concurrent changes in climate and land cover led to stronger nonlinear runoff responses, compared to superposition of their individual impacts. The projected simultaneous changes in climate and land cover would increase the mean annual basin runoff by $176 \%, 164 \%, 160 \%$, and $159 \%$ under the 2080s-RCP 4.5, 2080s-RCP 8.5, 2050s-RCP 4.5, and 2050s-RCP 8.5 scenarios, respectively. Higher (than other locations) runoff increases were noted for the major urban centers and their nearby areas. The projected relative runoff increases in future under simultaneously changing climate and land cover were higher during October-May. The findings would be beneficial for stormwater
\end{abstract}


management and ecosystem protection for northeast Florida and other coastal-natural environments across the globe.

\subsection{Introduction}

Rise in surface temperature due to anthropogenic activities is altering the hydrologic cycle around the world. Rainfall and runoff would increase in high latitude and wet tropical areas, whereas dry tropical and semi-arid regions would be subject to decrease in rainfall and runoff, on account of global warming (IPCC, 2014a). Decreases in natural landscapes (wetlands, forests, croplands, pasture, etc.) from expanding urban footprints can increase runoffs as well. Runoff increases under climatic and land cover changes can lead to increased overland flow and streamflow (Fletcher et al., 2013; Miller et al., 2014), reduced groundwater recharge and stream base flow (Wang et al., 2011), and increased flooding hazards, especially in the urbanized areas. It would be, therefore, vital to holistically investigate the impacts of potential changes in climate and land cover for watersheds representing natural-urban gradients in order to sustainably adapt to the changing hydrologic regimes.

Several studies have investigated the control of important drivers of runoff and streamflow for different regions over the world. Evaluation of runoff sensitivity to historical changes and/or experimental perturbations in climate and land cover has been a prime research emphasis area in this regard (e.g., Mateus et al., 2015; Abdul-Aziz and Al-Amin, 2015; Liu et al., 2017). Much research has utilized mechanistic (i.e., process-based) hydrologic models for the runoff sensitivity analyses by conceptualizing and parameterizing the dominant drivers of runoff and streamflow and different watershed features. For example, Baker and Miller (2013) used the Soil and Water Assessment Tool (SWAT) (Neitsch et al., 2005) model to estimate substantial increases in surface runoff across majority of the River Njoro watershed of Kenya under land use 
and land cover (LULC) changes during 1986-2003. Wang et al. (2017) employed the SWBM model (Zhang and Wang, 2007), and reported notable decreases in runoff under a 10\% precipitation decrease in 21 climatically different catchments across China. Using the Budyko's hydrologic model (Budyko, 1974), Donohue et al. (2011) found that, for average 1981-2006 conditions, a $10 \mathrm{~mm} /$ year increase in basin-average precipitation would result in significant annual increases in basin-wide runoff for the Murray Darling Basin in Australia.

Furthermore, scientists have incorporated future climatic and land cover projections into mechanistic hydrologic models to estimate the potential future changes in runoff and streamflow. Mishra et al. (2010) applied the variable infiltration capacity (VIC) model (Liang et al., 1994) in Wisconsin, USA to conclude that with respect to 2005 , the projected climatic and land cover changes in the year 2030 would increase flashiness of the streamflow. Using the PrecipitationRunoff Modeling System (PRMS; Leavesley and Stannard, 1995), Chang and Jung (2010) found potential increased seasonal variability of runoff with increase and decrease in winter and summer flow, respectively for the Willamette River Basin of Oregon, USA in 2030-2059 and 2070-2099 relative to 1960-1989. Cuo et al. (2011) used the distributed hydrology-soilvegetation model (DHSVM) (Wigmosta et al., 2002) to investigate the impacts of changing climate and land cover in 2015-2045 and 2035-2065 for the Puget Sound Basin in Washington, USA; they reported notable future increases in seasonal and annual freshwater flux to the basin with respect to the baseline 1970-2000.

In comparison to ample hydrologic research across different global regions, the inadequacy of detailed investigation on coastal-natural environments, regarding the runoff responses under changing climate and land cover, is quite evident. Northeast Florida of USA represents an ideal example of complex coastal-natural hydrologic settings. The Apparent 
changes in climate and land cover (Jagtap et al., 2002; Volk et al., 2017) are expected to impact its long-term hydrologic responses which hasn't been studied yet. The existing knowledge gap entails a comprehensive assessment of changes in stormwater runoff regimes across Northeast Florida subject to the anticipated changes in climate and land cover.

The goal of this study is to perform a large-scale evaluation of the relative as well as combined control of climatic and land cover drivers and to assess the changes across the historical and future runoff regimes for complex-coastal environments. A large-scale mechanistic hydrologic model is developed for the Saint Johns River Basin of Northeast Florida, considered as the study area, using the Storm Water Management Model (SWMM) 5.1 of the U.S. Environmental Protection Agency (U.S. EPA) (Rossman, 2015). The model is calibrated and validated with observed historical streamflow, and is used to determine the stormwater runoff sensitivities to reference changes in climatic variables and land cover features. Finally, projections of future climate and land cover are incorporated into the model as inputs to estimate the future runoff scenarios. Based on the potential future runoff changes, areas under risks of pluvial flooding (Carter et al., 2015; Rosenzweig et al., 2018) and environmental pollutions across the Saint Johns River Basin are identified.

\subsection{Materials and methods}

\subsubsection{Study area}

The Saint Johns River Basin has an area of approximately $24928 \mathrm{~km}^{2}$ (Figure 3.1). The basin is primarily characterized by natural land uses/cover such as croplands, evergreen forests, pasture lands, grasslands, and wetlands; some scattered urban footprints spread over the basin as well. Jacksonville, Gainesville, and Orlando represent the major urban centers in the basin; Ocala, 
Palatka, Palm Coast, Daytona Beach, Clermont, Titusville, and Melbourne are the growing urban centers (Figure 3.1). The Saint Johns River Basin consists of three subwatersheds: the Upper Saint Johns River Basin $\left(10427 \mathrm{~km}^{2}\right)$, the Ocklawaha River Basin $\left(7224 \mathrm{~km}^{2}\right)$, and the Lower Saint Johns River Basin $\left(7277 \mathrm{~km}^{2}\right)$. The Upper and Lower Saint Johns River Basin is drained by the Saint Johns River which is the longest river in the State of Florida. It originates from the south of Melbourne and drains into the Atlantic Ocean to the northeast of Jacksonville. The Ocklawaha River Basin is drained by the Ocklawaha River, the largest tributary of the Saint Johns River. The Saint Johns River Basin experiences humid subtropical climate characterized by highly varying rainfalls over the year (ORNL DAAC, 2017), according to the Köppen-Geiger climate classification (Kottek et al., 2006; Rubel et al., 2017).

\subsubsection{Data sets used for model development}

The extent of the Saint Johns River Basin was established using the third-level hydrological unit code (HUC6; ID: 030801), of the U.S. Geological Survey (USGS) (USGS, 2016a). Extents of its different subwatersheds were defined based on the fourth-level hydrological unit codes (HUC8): ID: 03080101 (the Upper Saint Johns River Basin); ID: 03080102 (the Ocklawaha River Basin); and ID: 03080103 (the Lower Saint Johns River Basin). 1/3 arc-second (approximately $10 \mathrm{~m}$ ) digital elevation models (DEMs) obtained from the National Elevation Dataset (NED) (USGS, 2016b) were used to represent the basin-wide topographical variations. Percent imperviousness data of $30 \mathrm{~m}$ resolution data were collected from the National Land Cover Database (NLCD) (Fry et al., 2011; Homer et al., 2015) to account for the spatial variation in land cover across the basin. Based on the hydrologic soil groups given by the soil survey geographic database (SSURGO; USDA-NRCS, 2015) and the guidelines from the National Engineering Handbook (USDA-NRCS, 2009) and Rawls et al. (1983), subbasin soil types were determined. 


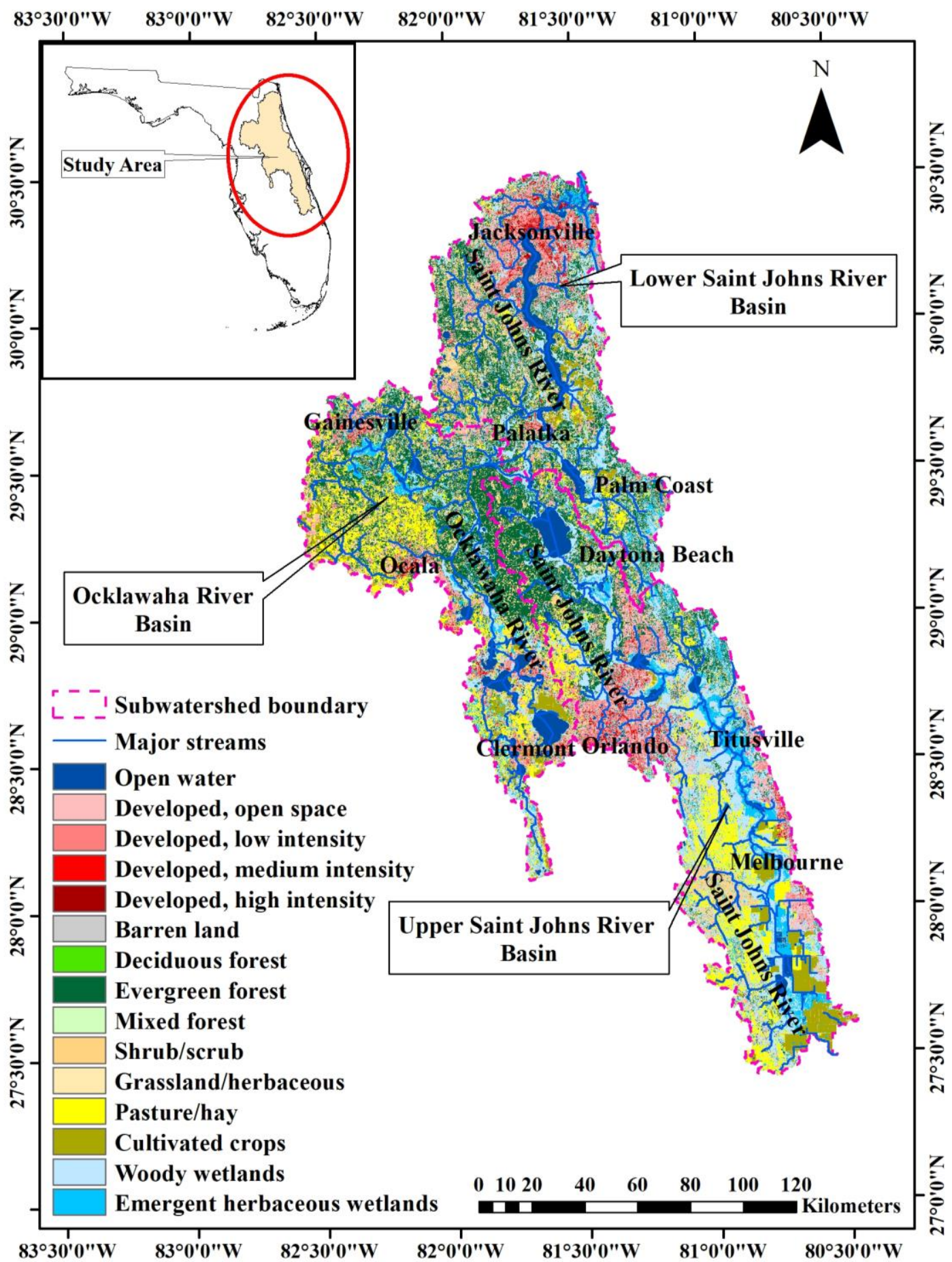

Figure 3.1: Subwatersheds, major streams, and land cover types in the Saint Johns River Basin. The inset showing location of the study area in the state of Florida is not drawn to the map-scale. 
Observed volumetric streamflow rate during 2004-2013 were collected from the national water information system of USGS (USGS, 2018). Streamflows at different locations along the Saint Johns River were used for calibration and validation of the model; streamflow records for the Ocklawaha River at Rodman Dam, downstream of Lake Ocklawaha, were used as the inflow boundary conditions of the model (Figure 3.2). Hourly observed water levels during 2004-2013 were obtained for the National Oceanic and Atmospheric Administration (NOAA)'s tidal station 8720218 at Mayport Bar Pilots Dock, and were incorporated as the outfall boundary conditions at the mouth of the Saint Johns River. Outfall boundary conditions for the other smaller streams were not available. Surveyed data of the stream geometry (cross section and bed elevation) for the Saint Johns River and its branches and tributaries were obtained from The Saint Johns River Water Management District (SJRWMD).

Hourly rainfall records of 2004-2013 for 16 stations within and around the Saint Johns River Basin (Figure 3.2) were used to represent the basin-wide spatiotemporal variability in rainfall. Rainfall data for 13 stations were collected from the National Centers for Environmental Information (NCEI) database of NOAA; rainfall for the remaining 3 stations were obtained from NOAA's National Climatic Data Center (NCDC) database. Satellite-based gridded (2 km) daily potential evapotranspiration (ET) data during 2004-2013 were obtained from USGS (USGS, 2016c) for computing the monthly average ET rates (mm/day) to be used as inputs to SWMM. Observed groundwater level (GWL) data for 151 stations, collected from USGS, were used to represent the surface water-groundwater interactions in the basin (Figure 3.2). 


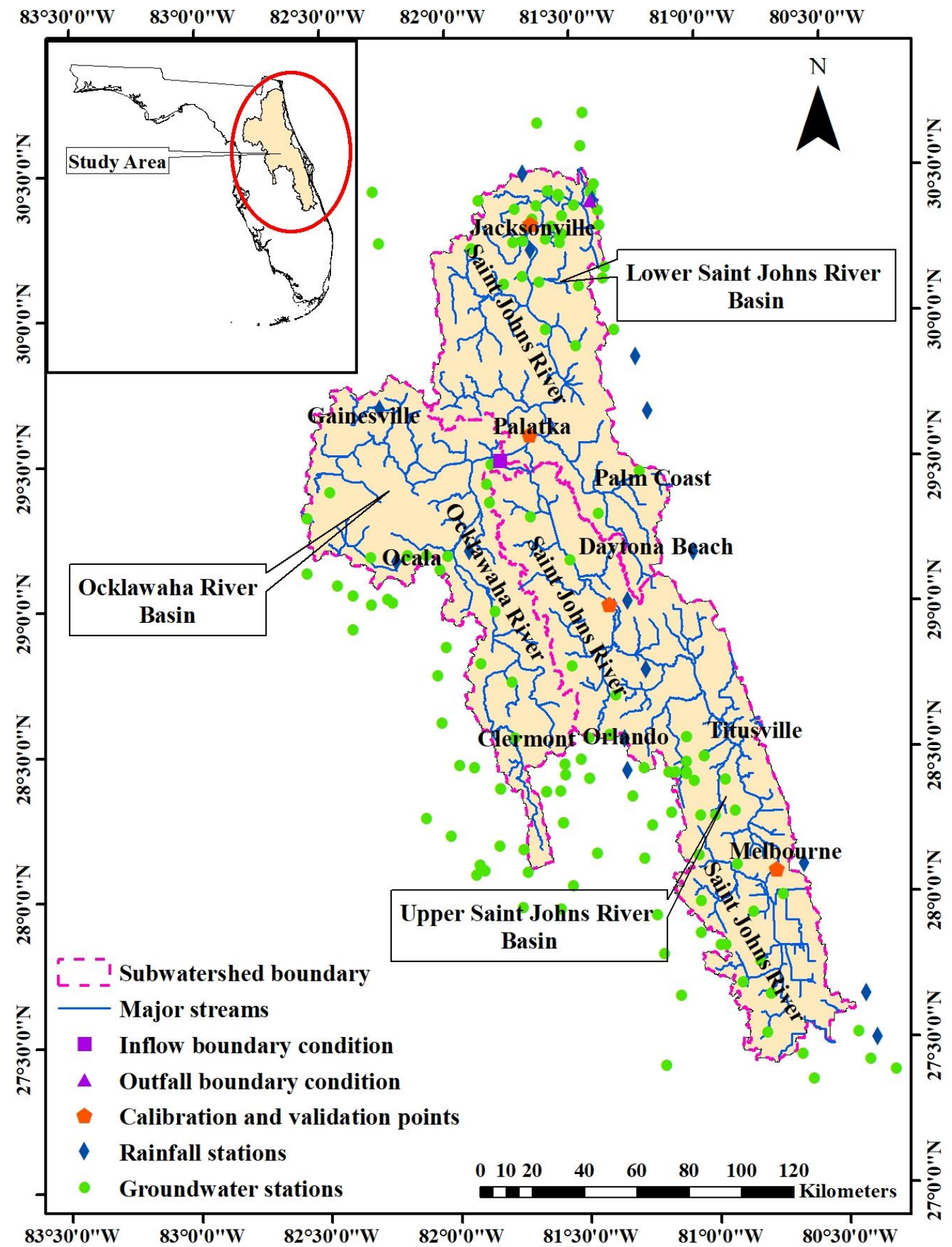

Figure 3.2: Locations of boundary conditions, model calibrations and validation points, rainfall gauging stations, and groundwater monitoring stations used in the Saint Johns River Basin model. The inset showing location of the study area in the state of Florida is not drawn to the map-scale. 


\subsubsection{Development of the mechanistic rainfall-runoff model using EPA SWMM 5.1}

The U.S. EPA SWMM 5.1 is a mechanistic rainfall-runoff model that parameterizes different components of urban and natural hydrology, hydro-climatological variables, and land cover properties and dynamically integrates them (Rossman, 2015). Based on the $10 \mathrm{~m}$ DEMs, the large-scale Saint Johns River Basin was first split into 490 smaller subbasins and developed link (stream)-node (junction) networks, consisting of 533 links and 542 nodes, that drain the subbasins; Arc Hydro (Maidment and Morehouse, 2002) for ESRI ArcGIS 10.2 was used in this regard. Table 3.1 summarizes the major variables and parameters for the Saint Johns River Basin model.

Hourly rainfall during 2004-2013 for the 16 stations (Figure 3.2) were distributed among different subbasins (Figure A3.1) based on the Thiessen Polygons (see Text A2.2 in Appendix 2). Since, the potential ET rates ( $\mathrm{mm} /$ day) for different months showed low spatial variability in terms of coefficient of variation of 2.93 to $13.72 \%$, spatially averaged monthly potential ET rates were used in the model. Observed GWL on or around 01/01/2004, representative of the dry season, were used as initial GWL (see Text A2.3 and A2.4 in Appendix 2) which would be dynamically updated in the Saint Johns River Basin model through groundwater mass balance and hyporheic exchanges (Rossman, 2016). 
Table 3.1: Model variables and calibrated parameters during 2004-2013 for the Saint Johns River Basin.

\begin{tabular}{|c|c|}
\hline Variables and Parameters & Range \\
\hline \multicolumn{2}{|l|}{ Climate } \\
\hline Rainfall* (mm/hr) & 0 to 253.24 \\
\hline Potential evapotranspiration* (mm/day) & 1.24 to 5.42 \\
\hline \multicolumn{2}{|l|}{ Overland flow } \\
\hline Characteristic width (m) & 1238.04 to 65012.12 \\
\hline Imperviousness $*(\%)$ & 0.0001 to 49.5274 \\
\hline Slope $(\%)$ & 0.0001 to 5.0715 \\
\hline Overland roughness coefficient (Manning's n) for impervious subarea & 0.01 to 0.019 \\
\hline Overland roughness coefficient (Manning's n) for pervious subarea & 0.017 to 0.20 \\
\hline Depression storage depth for impervious subarea (mm) & 1.27 to 2.54 \\
\hline Depression storage depth for pervious subarea $(\mathrm{mm})$ & 2.54 to 7.62 \\
\hline \multicolumn{2}{|l|}{ Infiltration and groundwater flow } \\
\hline Initial suction head (mm) & 131.01 to 148.73 \\
\hline Saturated hydraulic conductivity $(\mathrm{mm} / \mathrm{hr})$ & 3.16 to 108.25 \\
\hline Initial moisture deficit ${ }^{\mathrm{a}}$ & 0.265 to 0.280 \\
\hline Soil porosity & 0.38 to 0.40 \\
\hline Field capacity & 0.168 to 0.234 \\
\hline Permanent wilting point & 0.090 to 0.095 \\
\hline Lower evaporation depth ${ }^{\mathrm{b}}(\mathrm{m})$ & 1 to 5 \\
\hline Initial groundwater elevation (m NAVD 88) & -11.28 to 47.11 \\
\hline Unsaturated zone moisture content & 0.100 to 0.135 \\
\hline Groundwater flow coefficient, A1 & 0.015 to 0.05 \\
\hline Groundwater flow exponent, B1 & 1.1 to 1.5 \\
\hline \multicolumn{2}{|l|}{ Streamflow } \\
\hline Channel roughness (Manning's n) & 0.01 to 0.09 \\
\hline
\end{tabular}

Notes: ${ }^{\text {F}}$ Fraction of soil volume that is dry at the beginning of the simulations (Rossman, 2015); ${ }^{\mathrm{b}}$ maximum depth below the surface at which evapotranspiration can take place from the lower saturated zone (Rossman, 2015); *variables or parameters used for sensitivity analyses.

Characteristic width of the subbasins were computed based on their shapes and length of the corresponding draining channels (see text A2.5 in Appendix 2). The NLCD 'percent developed imperviousness' raster dataset of 2006 and 2011 (Fry et al., 2011; Homer et al., 2015) were used to compute temporally averaged historical percent imperviousness (Figure A3.2) for model simulation during 2004-2013. 10 meter DEM was used to obtain slope of the subbasins on the Arc Hydro platform. Initial overland roughness coefficient and depression storage depth 
values for different subbasins were found from the SWMM Reference Manual (Rossman, 2016) and SWMM User's Manual (Rossman, 2015). Initial estimations of Green-Ampt infiltration parameters and aquifer properties were performed based on soil type of the subbasins and recommended values from the SWMM Reference Manual (Rossman, 2016). 1 inflow boundary condition and 1 outfall boundary condition (Figure 3.2) were used in the model to represent the influence of Lake Ocklawaha and the Atlantic ocean tides, respectively. The overall model structure for the Saint Johns River Basin is depicted in Figure A3.3.

The Saint Johns River Basin model was run for continuous simulation for 2004-2013 at hourly reporting time-step. The model was calibrated and validated at 4 streamflow stations along the Saint Johns River (Figure 3.3; Table A3.1) during 01/01/2004-12/31/2008 and 01/01/2009-12/31/2013, respectively. Major parameters that were adjusted for model calibration (Table 4.1) were subbasin characteristic width and overland roughness coefficients (Manning's n), Green-Ampt infiltration parameters, aquifer parameters, ground water flow coefficient (A1) and exponent (B1), and channel roughness coefficient (Manning's n). Realistic patterns in simulated GWLs were ensured by confining their lower limits in close proximity of the initial GWLs which were representative of the dry season conditions. Model performance was evaluated based on the Nash-Sutcliffe Efficiency (NSE) (Nash and Sutcliffe, 1970) and RSR, i.e., the ratio of the root-mean-square error to the standard deviation of observations (see Text A2.6 in Appendix 2).

\subsubsection{Climatic and land cover projections for estimating the future runoff scenarios}

Downscaled climatic projections of 20 Coupled Model Intercomparison Project's fifth phase (CMIP5) general circulation models (GCMs) (see Table A3.2 in Appendix 3) given by the multivariate adaptive constructed analogs (MACA) dataset (Abatzoglou and Brown, 2012) were 
used to estimate future runoff scenarios in the Saint Johns River Basin. Under the Representative Concentration Pathways (RCP) 4.5 and 8.5 scenarios (IPCC, 2014b), MACA historical climatic simulations and future climatic projections were available for 1950-2005 and 2006-2099, respectively. There were 16 hourly NOAA rainfall stations within and around the basin (Figure 3.2) with 10-year historical observations during 2004-2013, defined as the historical baseline period of the 2010s. The future 10-year periods were defined as 2050s (2044-2053) and 2080s (2076-2085) to perform comparative assessments of the changes in rainfall, land cover, and runoff. The daily MACA-GCM rainfalls for the 2010s, 2050s and 2080s at the nearest MACA grid were extracted for the 16 observed rainfall stations. Monthly modeled MACA potential ET were also collected for these historical and future periods at all grids within the basin extent; MACA used the Penman-Monteith method (Allen et al., 1998) to compute these potential ET rates.

The delta change factor methodology (Teutschbein and Seibert, 2012; Chen et al., 2013), taking account of the relative changes between historical and future MACA climatic datasets, was used to estimate bias-correct future station-specific and basin-wide rainfall and ET, respectively. Since GCMs perform better in representing variabilities in monthly rainfall than that in daily rainfalls(Zhang, 2013; Langousis et al., 2016), relative changes in rainfall between the historical 2010s and a future period (i.e., the 2050s or the 2080s) were estimated as the ratio of model-projected future monthly rainfall (Yfut,proj) over model-simulated historical monthly rainfall (Yhist,sim). In regards to the 10-year study periods, the delta change approach gave 10 ratio values for each month. Outlier monthly rainfall ratios, detected as values falling beyond the range with a lower boundary of $Q_{1}-1.5 * I Q R$ and an upper boundary of $Q_{3}+1.5 * I Q R\left(Q_{1}=\right.$ $25^{\text {th }}$ percentile; $Q_{3}=75^{\text {th }}$ percentile; $\left.I Q R=Q_{3}-Q_{1}\right)$ (Tukey, 1977), were replaced with the 
nearest boundary (upper or lower) values. Future monthly rainfalls $\left(Y_{f u t}\right.$, for 2050s and 2080s were constructed by multiplying the observed historical monthly rainfalls (Yhist, ) in the 2010s by

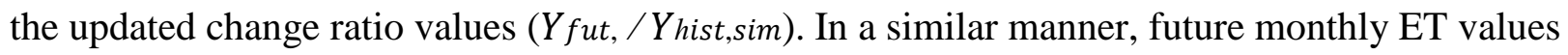
were constructed by using the corresponding relative change ratios.

Future land cover (i.e., imperviousness) projections were collected from U.S. EPA's Integrated Climate and Land-Use Scenarios (ICLUS) dataset (version 1.3.2) (U.S. EPA, 2010). The ICLUS land cover projections were available for the Special Report on Emissions Scenarios (SRES) (Nakicenovic et al., 2000), while the CMIP5 climatic projections were available for the RCP scenarios. Therefore, it was necessary to relate the SRES scenarios to the RCP scenarios. SRES A1FI and B1 scenarios show resemblances to RCP 8.5 and 4.5, respectively, in terms of atmospheric $\mathrm{CO}_{2}$ concentrations, global radiative forcing, and global mean temperature (Van Vuuren and Carter, 2014). The ICLUS imperviousness projections were, therefore, obtained for SRES A1 and B1. Future percent imperviousness of the subbasins were then computed based on the corresponding relative changes between the historical and future periods as given by the ICLUS dataset. At first, ratio of the projected future imperviousness in 2050 or 2080 (Ifut,) over simulated historical imperviousness of 2010 (Ihist,) was computed for a subbasin. Future imperviousness (Ifut, ) was constructed by multiplying the relative change ratio of imperviousness (Ifut, /Ihist,sim) with the observed historical imperviousness of 2010s (Ihist,obs) given by NLCD. Allowable upper limit of Ifut, values was set as 95\%, typical of downtown commercial areas (Urban Drainage and Flood Control District, 2016), in order to avoid the impact of outliers. For a few subbasins, it was seen that $I_{\text {fut,proj }} / I_{\text {hist,sim }} \leq 1$, i.e., ICLUS projections indicated either no relative change or relative decrease in imperviousness. Since this is atypical of the consistent land cover changes across northeast Florida (Volk et al., 2017), 
$I_{f u t, r e c}$ for such a subbasin was found through replacing its imperviousness relative change ratio by a practical ratio value (i.e., $I_{\text {fut,proj }} / I_{\text {hist,sim }}>1$ ) of the nearest subbasin with closest match in observed historical imperviousness.

The potential future runoff scenarios in the 2050s and the 2080s were estimated under both RCP 4.5 and 8.5 scenario by incorporating the climatic and land cover projections into the calibrated Saint Johns River Basin model. Since the GCMs do not perform well in representing observed rainfall variabilities for smaller (than monthly) temporal scales (Zhang, 2013; Langousis et al., 2016), it was assumed that the hourly rainfall distribution in the 10 years of 2050s and 2080s were similar to that of the 2010s (see Text A2.7 in Appendix 2 for details). The constructed GCM projections of monthly rainfall were, accordingly, distributed to the hourly time-step, and were used as inputs to SWMM. The 10-year historical and future basin-wide runoff simulations were then conducted on an hourly reporting time-step. Insignificant changes in subbasin and stream characteristics, soil and groundwater parameters, and boundary conditions were assumed between the historical and future periods. These assumptions might not always appear to be correct, but they are applicable for the current scenario analyses study.

\subsubsection{Sensitivity analyses}

In order to understand the responses of monthly and annual runoffs to changes in climatic and land cover drivers, the dimensionless relative sensitivity coefficients $\left(S^{*}\right)$ were estimated as follows (Abdul-Aziz et al., 2010):

$S^{*}=\frac{\Delta R / R}{\Delta V / V}$ 
where $V$ = baseline value of the forcing variable or parameter (i.e., rainfall, ET, and percent imperviousness value); $\Delta V=$ change in the forcing variable or parameter $R=$ baseline runoff simulated by the model; and $\Delta R=$ change in model-simulated runoff.

Based on the future climatic and land cover projections, the reference changes were designed; they were applied to the baseline (2010s) rainfall, ET, and imperviousness for computing the corresponding runoff sensitivities. Nonuniform changes in rainfall, ET, and imperviousness were observed across the four future scenarios: 2050s-RCP 4.5, 2080s-RCP 4.5, 2050s-RCP 8.5, and 2080s-RCP 8.5 (Table A3.3 in Appendix 3). A uniform set of reference changes in climatic and land cover variables were, however, picked by perturbing their baseline values from -30 to $+30 \%$ (with an increment of $5 \%$ ). The uniform set of reference changes in drivers allowed the comparative assessments of their controls on runoff generation. Even though overall increases in the climatic drivers were noted, as suggested by the ensembled average projections of the CMIP5 GCMs, some GCMs also projected potential decreases in rainfall and ET. As a result, both increases and decreases in the drivers were considered for the sensitivity analyses in order to have a comprehensive understanding of the interaction of stormwater runoff with its major drivers in the Saint Johns River Basin. Percent changes in runoff were estimated under both individual (one-at-a-time) and simultaneous changes in rainfall, ET, and imperviousness; the individual and simultaneous changes in these variables resulted in 469 sensitivity scenarios. 


\subsection{Results}

\subsubsection{Model calibrations and validations}

Range of NSE values for calibration and validation of the Saint Johns River Basin model during 2004-2013 were from 0.70 to 0.82 (Figure 3.3) across the 4 stations; RSR values varied from 0.43 to 0.55 . These statistics for different stations along the Saint Johns River (Figure 3.2) denoted good to very good predictive performance of the model (Moriasi et al., 2007), and suitability of the developed model for evaluating historical runoff sensitivities and estimating future runoff scenarios in the Saint Johns River Basin.

Substantial variation in the 10-year baseline (2010s) mean annual runoff (1 to $809 \mathrm{~mm}$ per $\mathrm{m}^{2}$ watershed area) was observed across the basin (Figure A3.4 in Appendix 3); the corresponding spatial variation in 10-year baseline mean annual rainfall ranged from 393 to 1225 $\mathrm{mm}$. Higher (than other locations) rainfall depths were noted at and around Jacksonville, Gainesville, Daytona Beach, Clermont, and Orlando (Figure A3.1 in Appendix 3). The spatial variation in the baseline runoff was primarily regulated by that in imperviousness (Figure A3.2in Appendix 3). For instance, urban centers in the northern (e.g., Jacksonville), north-eastern (e.g., Gainesville), and the south-central (e.g., Orlando, Clermont) regions of the basin had baseline runoff depths of 288 to $809 \mathrm{~mm}, 115$ to $166 \mathrm{~mm}$, and 205 to $328 \mathrm{~mm}$, respectively. Undeveloped lands in the northeastern, north-central, south-central, and southern parts of the basin, characterized by 0.5 to $2 \%$ imperviousness due to croplands, pasture, grasslands, and wetlands (Figure 3.1), had much lower baseline runoff depths (3 to $23 \mathrm{~mm}$ ). 

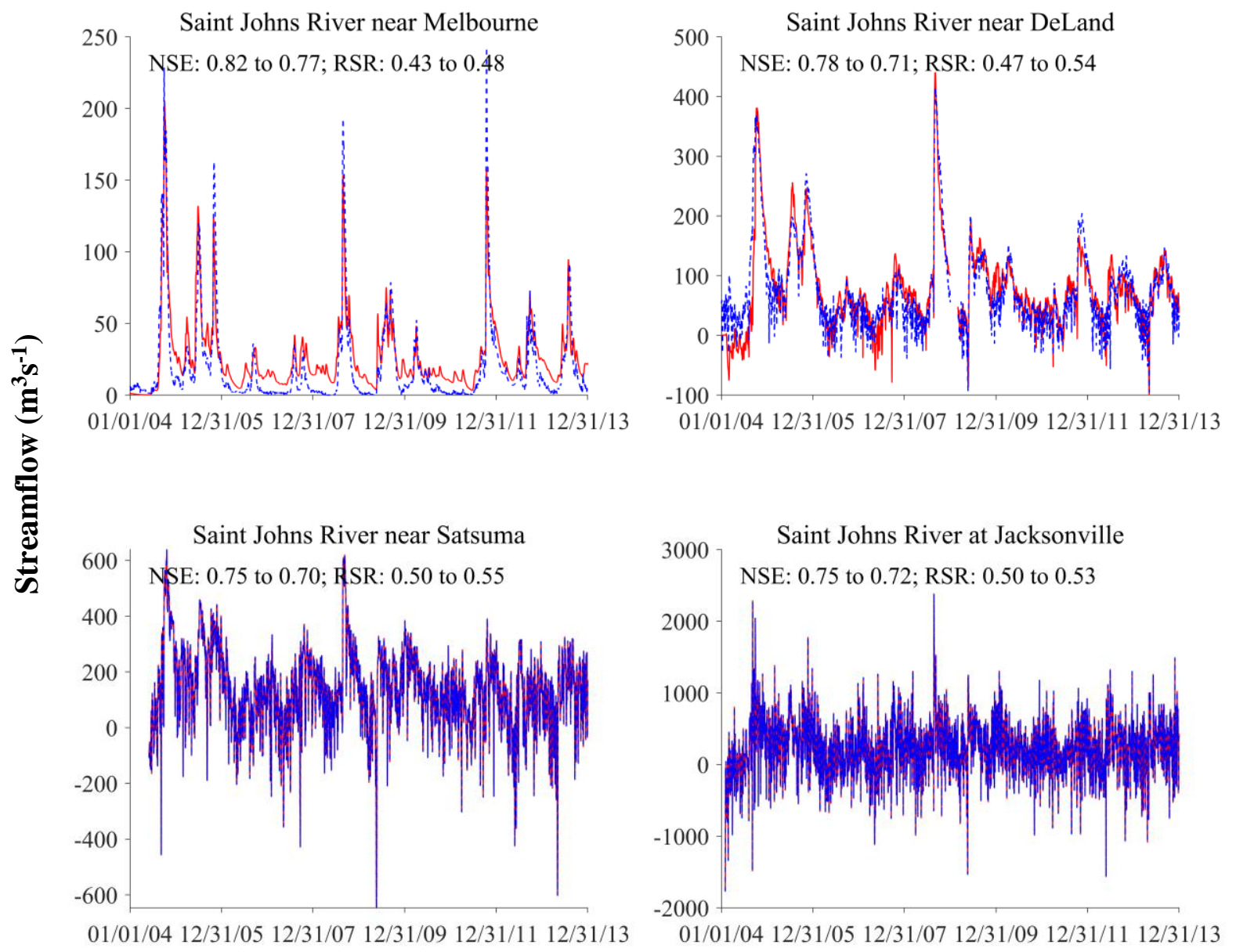

\section{Month/Day/Year}

Figure 3.3: Plots of model calibrations and validations with historical daily streamflow for the Saint Johns River Basin. 01/01/04 refers to January 01, 2004. Calibration and validation periods are, respectively, 01/01/2004 to 12/31/2008 and 01/01/2009 to 12/31/2013 for Saint Johns River near Melbourne; 01/01/2004 to 12/31/2008 and 03/01/2009 to 12/31/2013 for Saint Johns River near DeLand; 06/01/2004 to 12/31/2008 and 01/01/2009 to 12/31/2013 for Saint Johns River near Satsuma; and 02/01/2004 to 12/31/2008 and 01/01/2009 to 12/31/2013 for Saint Johns River near Jacksonville. 


\subsubsection{Sensitivities of monthly and annual basin runoff}

\subsubsection{Due to isolated perturbations in rainfall}

Notable variations in seasonal sensitivities of the 10-year (2004-2013) mean monthly runoff were noted in the Saint Johns River Basin and its subwatersheds under standalone changes in hourly rainfall depths, while keeping the number and duration of rainfall events unchanged (Figure 3.4). The monthly rainfall-runoff sensitivity results outlined nonlinear runoff responses. For example, a $30 \%$ increase in rainfall led to monthly runoff increases of 35 to $62 \%$ across the three subwatersheds (Figure 3.4a, b, c), and 46 to 54\% for the entire basin (Figure 3.4d). Under a $30 \%$ decrease in rainfalls, relatively lower range of monthly runoff decreases of 33 to $48 \%$ and 39 to $43 \%$ was observed for different subwatersheds and the basin, respectively. Annual runoff increased by 43 to $56 \%$ and decreased by 35 to $44 \%$ across the subwatersheds for increasing and decreasing the hourly rainfall depths by $30 \%$, respectively. Annual basin runoff increased and decreased by $50 \%$ and $40 \%$ respectively, under $30 \%$ increases and decreases in rainfall. The monthly runoff sensitivity coefficients for the subwatersheds (Table A3.4, A3.5, and A3.6 in Appendix 3) indicated higher runoff sensitivities for Lower Saint Johns River Basin due to higher overall rainfall depths (Table A3.3 and A3.8 in Appendix 3). The corresponding sensitivity coefficients for Lower Saint Johns River Basin varied from 1.23 to 2.08 (mean = 1.65). Monthly runoff sensitivity coefficients under changing rainfall for the entire Saint Johns River Basin varied from 1.29 to $1.70($ mean $=1.46)($ Table A3.7 in Appendix 3$)$. The sensitivity coefficients generally increased with increasing rainfalls. 

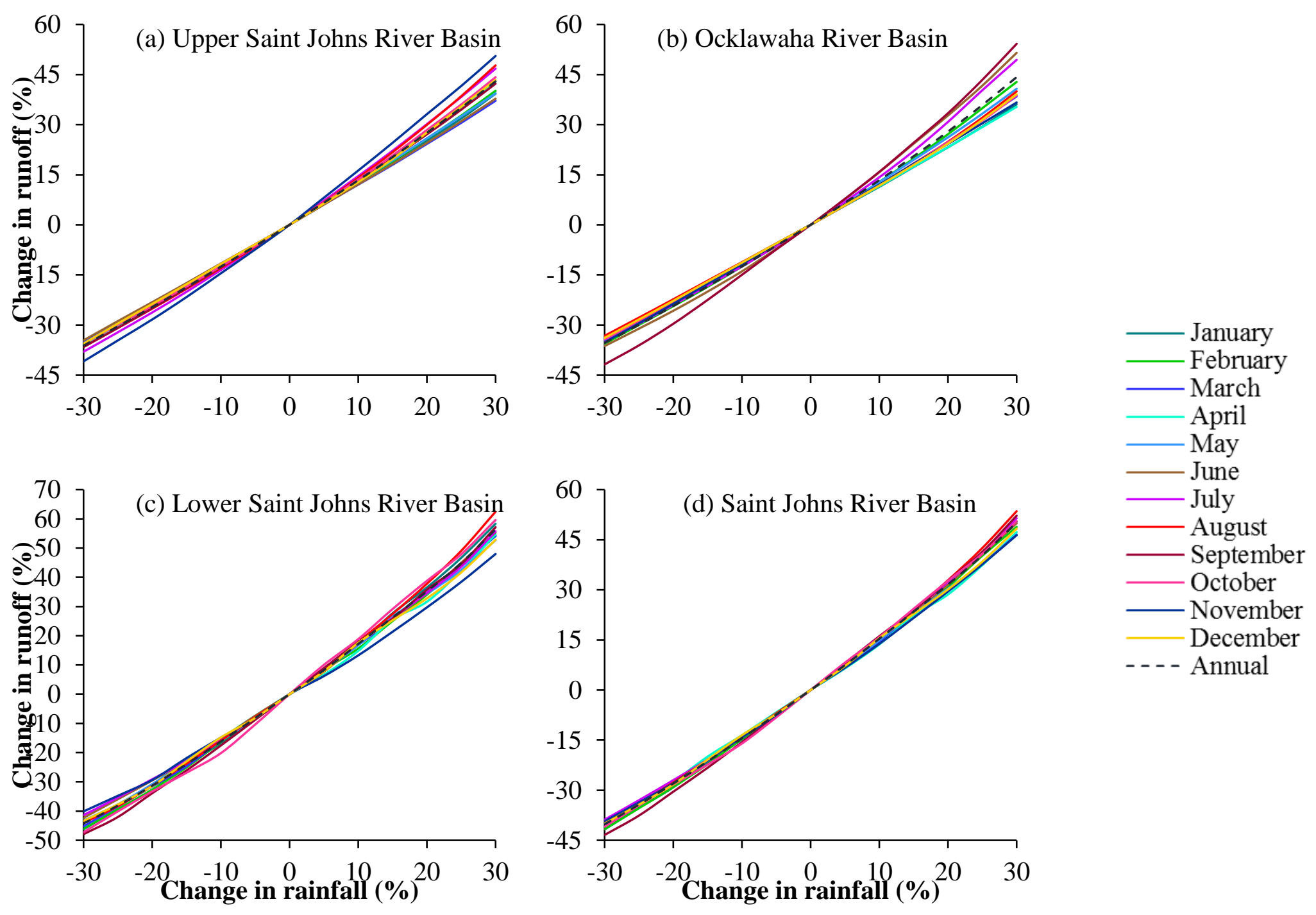

Figure 3.4: Monthly and annual variation in the sensitivity of 10-year (2010s) mean runoff to perturbations in rainfall in the Saint Johns River Basin and its subwatersheds. 
The monthly variation in rainfall depth, number of rainfall events, and ET rate led to the seasonal variability of monthly runoffs (Figure 3.4). Typically, the months of May-October and November-April are considered as wet and dry seasons, respectively in Florida, which is also reflected by the monthly rainfall depths (Table A3.8) and number of monthly rainfall events (Table A3.9) in the baseline 2010s for the Saint Johns River Basin and its subwatersheds. The wet season months bring substantially higher rainfall depths and more recurring rainfall events across the Saint Johns River Basin. Even though these months are also characterized by high ET rates (Table A3.10), the heavier and more frequent rainfalls are likely to produce higher runoff sensitivities on account of the frequent soil saturation, high antecedent soil moisture, and rapid runoff generation. Upper Saint Johns River Basin, for example, represented high monthly runoff sensitivities during July-August and October, with 44 to $48 \%$ runoff increases under $30 \%$ rainfall increases and 36 to $38 \%$ runoff decreases under $30 \%$ rainfall decreases (Figure 3.4a). Ocklawaha River Basin represented high runoff sensitivities during June-July and September with 49 to 54\% and 35 to $42 \%$ runoff increases and decreases, respectively, under $30 \%$ rainfall increases and decreases (Figure 3.4b). Lower Saint Johns River Basin showed high runoff sensitivities during August-October with 57 to $62 \%$ and 44 to $48 \%$ runoff increases and decreases, respectively, under 30\% rainfall increases and decreases (Figure 3.4c). The seasonal variation of runoff sensitivities were comparatively less apparent for the entire Saint Johns River Basin (Figure 3.4d); high wet season sensitivities were observed during August-October with 51 to 54\% increases 40 to $43 \%$ decreases in runoff in response to $30 \%$ increases and decreases in rainfall, respectively.

Monthly runoff sensitivities were relatively lower, generally, in the dry season (November-April). During January-March, runoff increases and decreases of 37 to $40 \%$ and 35- 
$36 \%$ were observed in Upper Saint Johns River Basin due to 30\% increases and decreases in rainfall. In Ocklawaha River Basin, 30\% increases and decreases in rainfall led to 35 to $38 \%$ increases and 33 to 34 decreases in runoff during January and March-April. For Lower Saint Johns River Basin, 30\% increases and decreases in rainfall produced 48 to 55\% and 40 to $44 \%$ increases and decreases in runoff. The entire Saint Johns River Basin represented lower dry season runoff sensitivities during November and March-April when 30\% increases and decreases in rainfall resulted in 46 to $47 \%$ and 39 to $40 \%$ increases and decreases in runoff, respectively. Lower runoff sensitivities during the dry season may be caused by less frequent soil saturation, low antecedent soil moisture, and delayed runoff generation due to the lower rainfall depths (Table A3.8) and less number of rainfall events (Table A3.9). For Upper Saint Johns River Basin, notable dry season runoff sensitivities in November may be attributed to faster runoff generations from the likely high antecedent soil moisture carried from the wet season. Notable

dry season runoff sensitivities were observed in January for both Lower Saint Johns River Basin and the entire Saint Johns River Basin which may be due to high antecedent soil moisture influenced by the low monthly ET rate (Table A3.10). The lower wet season runoff sensitivities during May (in the entire Saint Johns River Basin), June (in Upper and Lower Saint Johns River Basin), and August (in Ocklawaha River Basin) might have occurred due to the drop in antecedent soil moisture from the high monthly PET rates.

\subsubsection{Due to isolated perturbations in ET}

Much lower runoff sensitivities under standalone changes in ET than that under changing rainfall were noted in the Saint Johns River Basin and its subwatersheds (Figure 3.5). The monthly runoff sensitivity coefficients, under changing ET, for the three subwatersheds (Table A3.12, A3.13, and A3.14 in Appendix 3) generally increased with subwatershed-average 
imperviousness (Table A3.3 in Appendix 3). Higher runoff sensitivity coefficients of -0.06 to $0.59($ mean $=-0.34)$ were, accordingly, observed for Lower Saint Johns River Basin with maximum average imperviousness of $7.1 \%$ among the three subwatersheds. Overall increases in PET-runoff sensitivity coefficients with increases in subwatershed-average imperviousness indicates the likely dominance of evaporation over transpiration for soil moisture loss through ET. Monthly runoff sensitivity coefficients for the entire Saint Johns River Basin under changing ET varied from -0.05 to $-0.33($ mean $=-0.19)($ Table A3.15 in Appendix 3$)$.

Responses of monthly runoff due to individually changing ET represented highly nonlinear patterns, especially for Ocklawaha River Basin and Lower Saint Johns River Basin (Figure $3.5 \mathrm{~b}, \mathrm{c})$, than rainfall - suggesting substantially varying ET-runoff relationships with changing ET. The highly non-linear runoff responses in these two subwatersheds contributed to highly non-linear runoff responses for the entire Saint Johns River Basin (Figure 3.5d) as well. Lower Saint Johns River Basin represented more intensified non-linear behaviors as compared to the other subwatersheds likely due to the overall higher rainfalls (Table A3.3; Table A3.8) and the corresponding higher soil moisture available for ET. Similar to rainfall, higher runoff sensitivities under changing ET were generally observed for the wet season months. For example, in Lower Saint Johns River Basin, 30\% increases and decreases in ET, respectively, resulted in runoff decreases and increases of 9 to $11 \%$ and 12 to $14 \%$ during May, July, and October (Figure 3.5c). The entire Saint Johns River Basin represented 5 to $6 \%$ decreases and 6 to 7\% increases in runoff under 30\% increases and decreases in ET for May and October (Figure 3.5d). The generally higher runoff sensitivity to ET during the wet season months may be attributed to the high soil moisture and higher volume of runoff generated due to intense and frequent rainfalls, supporting generally a high rate of ET (Table A3.10). 

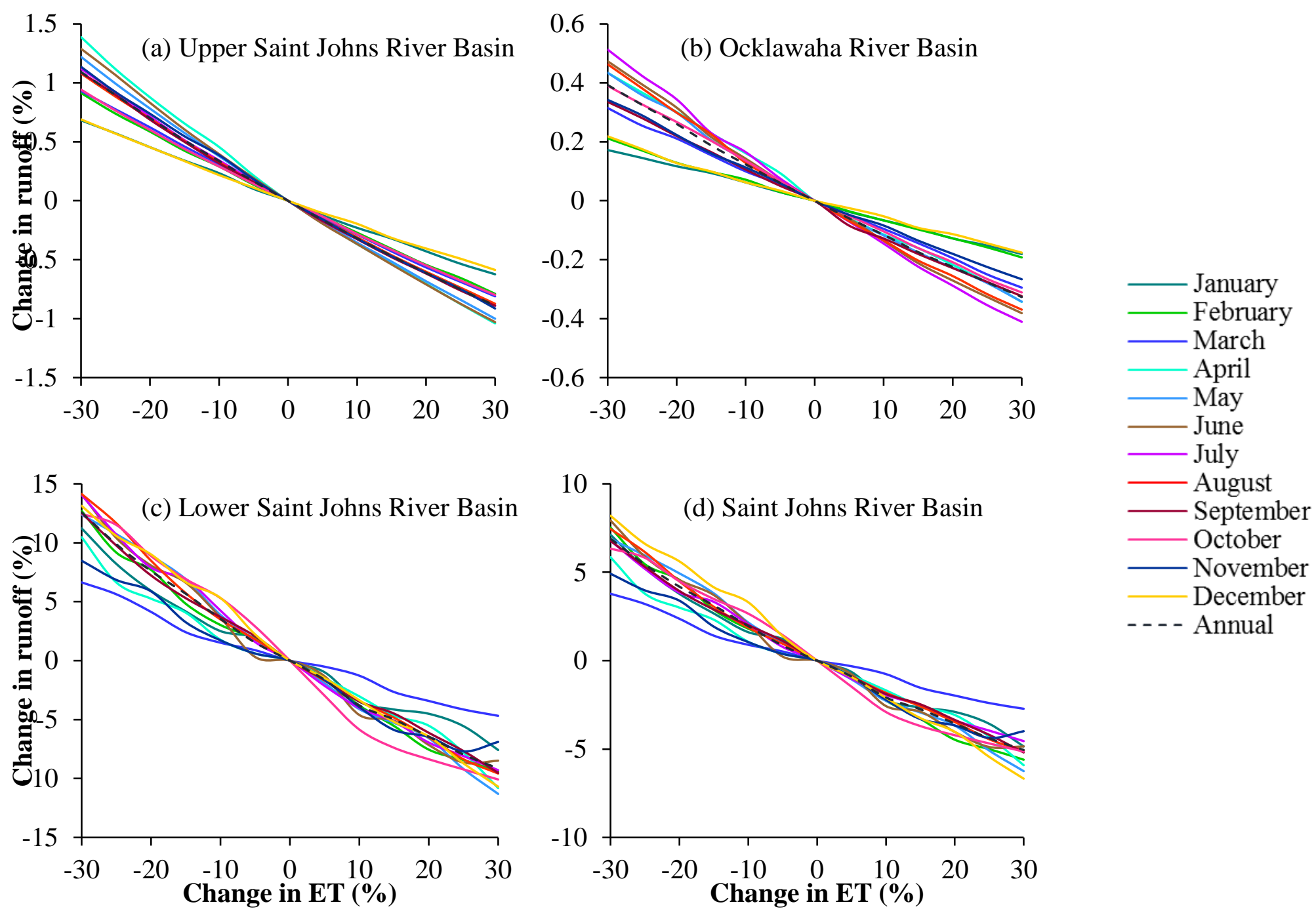

Figure 3.5: Monthly and annual variation in the sensitivity of 10-year (2010s) mean runoff to perturbations in evapotranspiration (ET) in the Saint Johns River Basin and its subwatersheds. 


\subsubsection{Due to isolated perturbations in land cover}

Runoff sensitivities to standalone changes in imperviousness were much lower than that to rainfall, but higher than that to ET in the Saint Johns River Basin and its subwatersheds (Figure 3.6). The runoff sensitivity coefficients demonstrated mixed (i.e., increasing or decreasing) trends in magnitude with increasing imperviousness (Table A3.16, A3.17, A3.18, and A3.19 in Appendix 3). The monthly runoff sensitivity coefficients, under changing imperviousness, generally increased with average imperviousness among the three subwatersheds. Higher runoff sensitivity coefficients of 0.89 to $1.10($ mean $=1.02)$ were, accordingly, observed for Ocklawaha River Basin with the lowest average imperviousness of $2.6 \%$ among the different subwatersheds (Table A3.3). For the entire Saint Johns River Basin, monthly runoff sensitivity coefficients under changing imperviousness varied from 0.75 to $1.03($ mean $=0.86)($ Table A3.19 in Appendix 3).

For Upper Saint Johns River Basin and Ocklawaha River Basin, higher runoff sensitivities under changing imperviousness were generally observed for the dry season months. In case of Upper Saint Johns River Basin, runoff increases and decreases of 30 to $32 \%$ and 31 to $31 \%$ occurred due to $30 \%$ increase and decrease in imperviousness (Figure 3.6a). For Ocklawaha River Basin, runoff increases and decreases of 31 to $32 \%$ were observed under $30 \%$ increase and decrease in imperviousness (Figure 3.6b). Lower Saint Johns River Basin represented notable $27 \%$ and $28 \%$ increases and decreases in runoff, respectively, subject to $30 \%$ increase and decrease in imperviousness (Figure 3.6c). However, monthly runoff sensitivities in this subwatershed were also notably higher (than the other months) in the wet season months of MayJuly. 30\% increase and decreases in imperviousness, respectively, led to monthly runoff increases and decreases of 23 to 25\% and 24 to 26\% during May-July for Upper Saint Johns 
River Basin. For the entire Saint Johns River Basin, higher runoff sensitivities were found during November when $28 \%$ increase and $24 \%$ decrease in runoff were noted from $30 \%$ increase and decrease in imperviousness. Higher runoff sensitivities were also observed during May, July, and October in the entire Saint Johns River Basin when 30\% increase and decrease in imperviousness, respectively, resulted in 26 to $27 \%$ increases in runoff and $27 \%$ decreases in runoff.

\subsubsection{Due to simultaneous perturbations in climate and land cover}

Concurrent changes in rainfall and imperviousness resulted in stronger nonlinear responses of runoff than the linear summation of their standalone (i.e., one-at-a-time) individual effects in the Saint Johns River Basin and its subwatersheds (Table 3.2, 3.3, 3.4, and 3.5). For example, when both rainfall and imperviousness were simultaneously increased by $30 \%$ for the entire Saint Johns River Basin, the annual basin runoff increased by $84 \%$, which was 8 percentage points higher than the linear summation of their standalone individual contributions (i.e., $50 \%+26 \%$; Table 3.5). In case of the three subwatersheds, simultaneous $30 \%$ increase in rainfall and imperviousness led to 7 to 10 percentage points higher runoff increases than the linear summation of their standalone individual impacts (Table 3.2, 3.3., 3.4). Runoff responses under concurrently changing rainfall and ET were linear, i.e., similar to that obtained by summing their standalone individual effects, for the relatively less impervious (Table A3.3) Upper Saint Johns River Basin and Ocklawaha River Basin (Table 3.6 and 3.7). In case of the Lower Saint Johns River Basin and the entire Saint Johns River Basin, nonlinear runoff responses were noted (Table 3.8 and 3.9). Finally, runoff responses under simultaneously changing imperviousness and ET (Table 3.10, 3.11, 3.12, and 3.13) were mostly linear. 

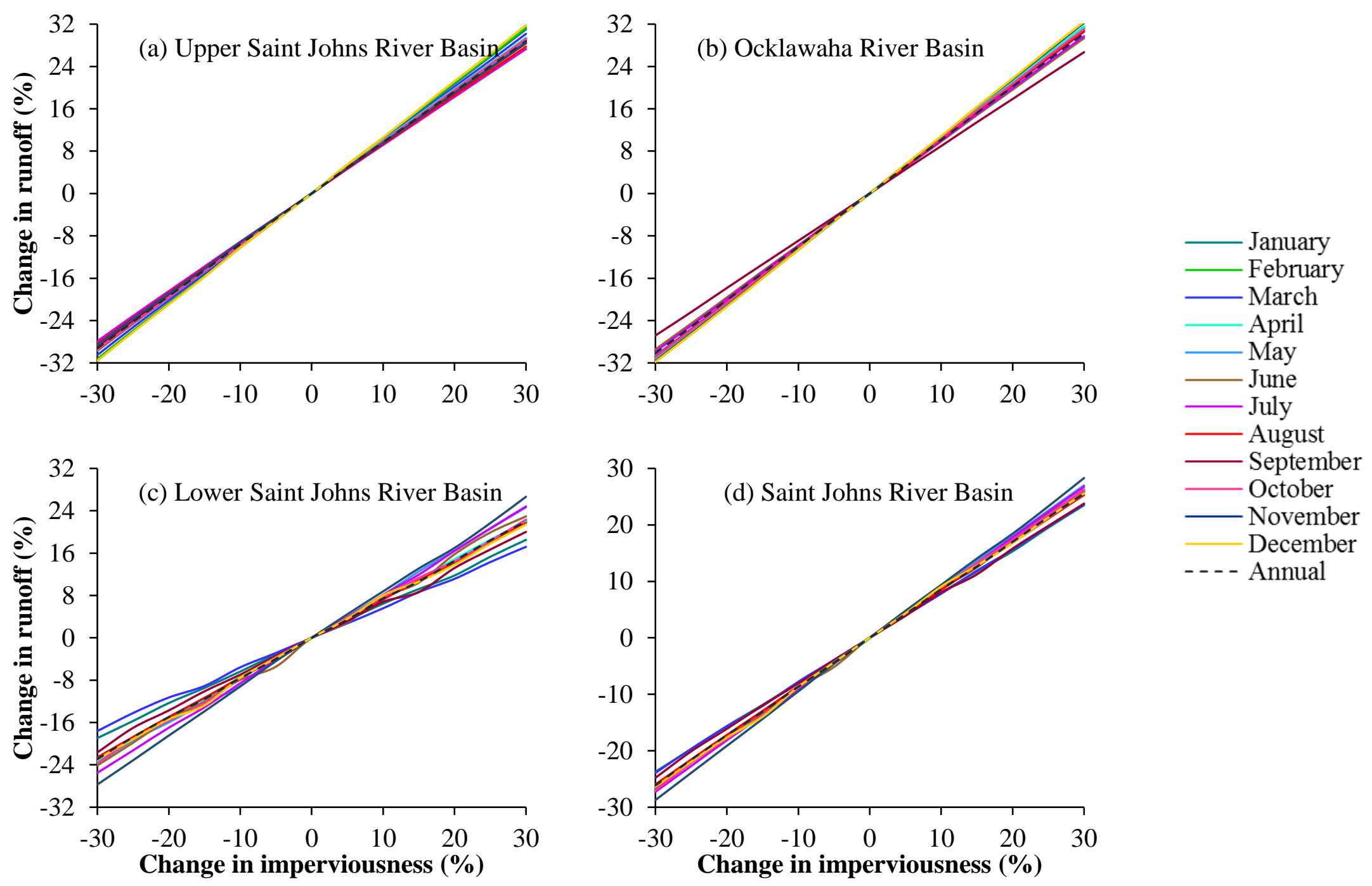

Figure 3.6: Monthly and annual variation in the sensitivity of 10-year (2010s) mean runoff to perturbations in imperviousness in the Saint Johns River Basin and its subwatersheds. 
Table 3.2: Percent changes of mean annual runoff under concurrent perturbations in rainfall and imperviousness in the Upper Saint Johns River Basin.

\begin{tabular}{cccccccccccccc}
\hline Change in & \multicolumn{10}{c}{ Change in rainfall (\%) } \\
\cline { 2 - 15 } imperviousness (\%) & -30 & -25 & -20 & -15 & -10 & -5 & 0 & 5 & 10 & 15 & 20 & 25 & 30 \\
\hline-30 & -55 & -51 & -47 & -43 & -39 & -34 & -29 & -24 & -19 & -14 & -8 & -3 & 4 \\
-25 & -52 & -48 & -43 & -39 & -34 & -29 & -24 & -19 & -14 & -8 & -2 & 4 & 10 \\
-20 & -47 & -44 & -40 & -35 & -30 & -25 & -19 & -14 & -8 & -2 & 4 & 10 & 17 \\
-15 & -47 & -41 & -36 & -31 & -25 & -20 & -14 & -9 & -3 & 3 & 10 & 16 & 23 \\
-10 & -43 & -37 & -32 & -27 & -21 & -15 & -10 & -4 & 2 & 9 & 16 & 23 & 30 \\
-5 & -39 & -34 & -28 & -23 & -17 & -11 & -5 & 1 & 8 & 15 & 22 & 29 & 36 \\
0 & -36 & -30 & -25 & -19 & -13 & -6 & 0 & 7 & 13 & 20 & 28 & 35 & 43 \\
5 & -33 & -27 & -21 & -15 & -8 & -2 & 5 & 12 & 19 & 26 & 34 & 41 & 49 \\
10 & -30 & -24 & -17 & -11 & -4 & 3 & 10 & 17 & 24 & 32 & 39 & 47 & 56 \\
15 & -27 & -20 & -13 & -7 & 0 & 7 & 14 & 22 & 29 & 37 & 45 & 54 & 62 \\
20 & -24 & -17 & -10 & -3 & 4 & 12 & 19 & 27 & 35 & 43 & 51 & 60 & 69 \\
25 & -20 & -13 & -6 & 1 & 9 & 16 & 24 & 32 & 40 & 48 & 57 & 66 & 75 \\
30 & -17 & -10 & -2 & 5 & 13 & 21 & 29 & 37 & 45 & 54 & 63 & 72 & 82 \\
\hline
\end{tabular}

Note: Positive sign indicates increase, while negative indicates decrease.

Table 3.3: Percent changes of mean annual runoff under concurrent perturbations in rainfall and imperviousness in the Ocklawaha River Basin.

\begin{tabular}{cccccccccccccc}
\hline Change in & \multicolumn{10}{c}{ Change in rainfall (\%) } \\
\cline { 2 - 14 } imperviousness (\%) & -30 & -25 & -20 & -15 & -10 & -5 & 0 & 5 & 10 & 15 & 20 & 25 & 30 \\
\hline-30 & -56 & -52 & -48 & -44 & -39 & -35 & -30 & -25 & -20 & -15 & -9 & -3 & 4 \\
-25 & -52 & -48 & -44 & -39 & -35 & -30 & -25 & -20 & -15 & -9 & -3 & 4 & 11 \\
-20 & -47 & -44 & -40 & -35 & -30 & -25 & -20 & -15 & -9 & -3 & 3 & 10 & 17 \\
-15 & -47 & -41 & -36 & -31 & -26 & -21 & -15 & -9 & -4 & 3 & 9 & 17 & 24 \\
-10 & -42 & -37 & -32 & -27 & -21 & -16 & -10 & -4 & 2 & 9 & 16 & 23 & 31 \\
-5 & -39 & -34 & -28 & -23 & -17 & -11 & -5 & 1 & 8 & 15 & 22 & 29 & 38 \\
0 & -35 & -30 & -24 & -18 & -12 & -6 & 0 & 7 & 13 & 21 & 28 & 36 & 44 \\
5 & -32 & -26 & -20 & -14 & -8 & -2 & 5 & 12 & 19 & 26 & 34 & 42 & 51 \\
10 & -29 & -23 & -16 & -10 & -4 & 3 & 10 & 17 & 25 & 32 & 40 & 49 & 58 \\
15 & -25 & -19 & -13 & -6 & 1 & 8 & 15 & 23 & 30 & 38 & 46 & 55 & 64 \\
20 & -22 & -15 & -9 & -2 & 5 & 13 & 20 & 28 & 36 & 44 & 52 & 61 & 71 \\
25 & -19 & -12 & -5 & 3 & 10 & 18 & 25 & 33 & 41 & 50 & 58 & 68 & 77 \\
30 & -15 & -8 & -1 & 7 & 14 & 22 & 30 & 38 & 47 & 55 & 65 & 74 & 84 \\
\hline
\end{tabular}

Note: Positive sign indicates increase, while negative indicates decrease. 
Table 3.4: Percent changes of mean annual runoff under concurrent perturbations in rainfall and imperviousness in the Lower Saint Johns River Basin.

\begin{tabular}{|c|c|c|c|c|c|c|c|c|c|c|c|c|c|}
\hline \multirow{2}{*}{$\begin{array}{c}\text { Change in } \\
\text { imperviousness }(\%)\end{array}$} & \multicolumn{13}{|c|}{ Change in rainfall $(\%)$} \\
\hline & -30 & -25 & -20 & -15 & -10 & -5 & 0 & 5 & 10 & 15 & 20 & 25 & 30 \\
\hline-30 & -60 & -55 & -49 & -43 & -37 & -30 & -23 & -15 & -8 & 0 & 8 & 17 & 26 \\
\hline-25 & -57 & -52 & -46 & -40 & -33 & -26 & -19 & -11 & -4 & 5 & 13 & 21 & 31 \\
\hline-20 & -53 & -49 & -43 & -37 & -30 & -23 & -15 & -8 & 1 & 9 & 17 & 26 & 36 \\
\hline-15 & -53 & -46 & -40 & -33 & -26 & -19 & -11 & -4 & 5 & 13 & 22 & 31 & 41 \\
\hline-10 & -50 & -44 & -37 & -30 & -23 & -15 & -8 & 0 & 9 & 17 & 26 & 36 & 46 \\
\hline-5 & -47 & -41 & -34 & -27 & -20 & -12 & -4 & 4 & 13 & 22 & 31 & 40 & 52 \\
\hline 0 & -44 & -38 & -31 & -24 & -16 & -8 & 0 & 8 & 17 & 26 & 35 & 45 & 56 \\
\hline 5 & -42 & -35 & -28 & -21 & -13 & -5 & 4 & 12 & 21 & 31 & 40 & 50 & 61 \\
\hline 10 & -39 & -33 & -25 & -18 & -10 & -1 & 7 & 16 & 25 & 34 & 44 & 54 & 66 \\
\hline 15 & -37 & -30 & -22 & -15 & -6 & 2 & 11 & 20 & 29 & 39 & 49 & 59 & 71 \\
\hline 20 & -34 & -27 & -19 & -11 & -3 & 6 & 15 & 24 & 33 & 43 & 53 & 64 & 76 \\
\hline 25 & -32 & -24 & -16 & -8 & 0 & 9 & 18 & 28 & 37 & 47 & 57 & 69 & 81 \\
\hline 30 & -29 & -22 & -14 & -5 & 4 & 12 & 22 & 32 & 41 & 52 & 62 & 73 & 85 \\
\hline
\end{tabular}

Note: Positive sign indicates increase, while negative indicates decrease.

Table 3.5: Percent changes of mean annual runoff under concurrent perturbations in rainfall and imperviousness in the Saint Johns River Basin.

\begin{tabular}{cccccccccccccc}
\hline Change in & \multicolumn{10}{c}{ Change in rainfall (\%) } \\
\cline { 2 - 14 } imperviousness (\%) & -30 & -25 & -20 & -15 & -10 & -5 & 0 & 5 & 10 & 15 & 20 & 25 & 30 \\
\hline-30 & -58 & -53 & -48 & -43 & -38 & -32 & -26 & -20 & -13 & -7 & 0 & 7 & 15 \\
-25 & -55 & -50 & -45 & -39 & -34 & -28 & -22 & -15 & -9 & -2 & 5 & 13 & 21 \\
-20 & -50 & -47 & -42 & -36 & -30 & -24 & -17 & -11 & -4 & 3 & 11 & 18 & 27 \\
-15 & -50 & -44 & -38 & -32 & -26 & -20 & -13 & -6 & 1 & 8 & 16 & 24 & 33 \\
-10 & -46 & -41 & -35 & -29 & -22 & -16 & -9 & -2 & 6 & 13 & 21 & 29 & 39 \\
-5 & -43 & -37 & -31 & -25 & -18 & -11 & -4 & 3 & 11 & 18 & 26 & 35 & 45 \\
0 & -40 & -34 & -28 & -21 & -14 & -7 & 0 & 7 & 15 & 23 & 32 & 40 & 50 \\
5 & -37 & -31 & -25 & -18 & -11 & -3 & 4 & 12 & 20 & 28 & 37 & 46 & 56 \\
10 & -34 & -28 & -21 & -14 & -7 & 1 & 8 & 16 & 25 & 33 & 42 & 51 & 61 \\
15 & -32 & -25 & -18 & -11 & -3 & 5 & 13 & 21 & 29 & 38 & 47 & 57 & 67 \\
20 & -29 & -22 & -15 & -7 & 1 & 9 & 17 & 26 & 34 & 43 & 52 & 62 & 73 \\
25 & -26 & -19 & -11 & -4 & 5 & 13 & 21 & 30 & 39 & 48 & 57 & 68 & 78 \\
30 & -23 & -16 & -8 & 0 & 8 & 17 & 26 & 34 & 44 & 53 & 63 & 73 & 84 \\
\hline
\end{tabular}

Note: Positive sign indicates increase, while negative indicates decrease. 
Table 3.6: Percent changes of mean annual runoff under concurrent perturbations in rainfall and evapotranspiration (ET) in the Upper Saint Johns River Basin.

\begin{tabular}{cccccccccccccc}
\hline \multirow{2}{*}{ Change in ET (\%) } & \multicolumn{10}{c}{ Change in rainfall (\%) } \\
\cline { 2 - 12 } & -30 & -25 & -20 & -15 & -10 & -5 & 0 & 5 & 10 & 15 & 20 & 25 & 30 \\
\hline-30 & -35 & -30 & -24 & -18 & -11 & -5 & 1 & 8 & 14 & 21 & 29 & 36 & 44 \\
-25 & -35 & -30 & -24 & -18 & -12 & -5 & 1 & 8 & 14 & 21 & 29 & 36 & 44 \\
-20 & -36 & -30 & -24 & -18 & -12 & -6 & 1 & 7 & 14 & 21 & 28 & 36 & 44 \\
-15 & -36 & -30 & -24 & -18 & -12 & -6 & 1 & 7 & 14 & 21 & 28 & 36 & 44 \\
-10 & -36 & -30 & -24 & -18 & -12 & -6 & 0 & 7 & 14 & 21 & 28 & 35 & 43 \\
-5 & -36 & -30 & -24 & -19 & -12 & -6 & 0 & 7 & 14 & 20 & 28 & 35 & 43 \\
0 & -36 & -30 & -25 & -19 & -13 & -6 & 0 & 7 & 13 & 20 & 28 & 35 & 43 \\
5 & -36 & -31 & -25 & -19 & -13 & -6 & 0 & 6 & 13 & 20 & 27 & 35 & 43 \\
10 & -36 & -31 & -25 & -19 & -13 & -7 & 0 & 6 & 13 & 20 & 27 & 35 & 43 \\
15 & -36 & -31 & -25 & -19 & -13 & -7 & 0 & 6 & 13 & 20 & 27 & 35 & 42 \\
20 & -37 & -31 & -25 & -19 & -13 & -7 & -1 & 6 & 13 & 20 & 27 & 34 & 42 \\
25 & -37 & -31 & -25 & -19 & -13 & -7 & -1 & 6 & 13 & 19 & 27 & 34 & 42 \\
30 & -37 & -31 & -25 & -19 & -13 & -7 & -1 & 6 & 12 & 19 & 27 & 34 & 42 \\
\hline
\end{tabular}

Note: Positive sign indicates increase, while negative indicates decrease.

Table 3.7: Percent changes of mean annual runoff under concurrent perturbations in rainfall and evapotranspiration (ET) in the Ocklawaha River Basin.

\begin{tabular}{ccccccccccccccc}
\hline \multirow{2}{*}{ Change in ET (\%) } & \multicolumn{10}{c}{ Change in rainfall $(\%)$} \\
\cline { 2 - 12 } & -30 & -25 & -20 & -15 & -10 & -5 & 0 & 5 & 10 & 15 & 20 & 25 & 30 \\
\hline-30 & -35 & -30 & -24 & -18 & -12 & -6 & 0 & 7 & 14 & 21 & 28 & 36 & 45 \\
-25 & -35 & -30 & -24 & -18 & -12 & -6 & 0 & 7 & 14 & 21 & 28 & 36 & 45 \\
-20 & -35 & -30 & -24 & -18 & -12 & -6 & 0 & 7 & 14 & 21 & 28 & 36 & 45 \\
-15 & -35 & -30 & -24 & -18 & -12 & -6 & 0 & 7 & 14 & 21 & 28 & 36 & 44 \\
-10 & -35 & -30 & -24 & -18 & -12 & -6 & 0 & 7 & 13 & 21 & 28 & 36 & 44 \\
-5 & -35 & -30 & -24 & -18 & -12 & -6 & 0 & 7 & 13 & 21 & 28 & 36 & 44 \\
0 & -35 & -30 & -24 & -18 & -12 & -6 & 0 & 7 & 13 & 21 & 28 & 36 & 44 \\
5 & -35 & -30 & -24 & -18 & -13 & -6 & 0 & 7 & 13 & 20 & 28 & 36 & 44 \\
10 & -35 & -30 & -24 & -19 & -13 & -6 & 0 & 6 & 13 & 20 & 28 & 36 & 44 \\
15 & -35 & -30 & -24 & -19 & -13 & -6 & 0 & 6 & 13 & 20 & 28 & 36 & 44 \\
20 & -36 & -30 & -24 & -19 & -13 & -6 & 0 & 6 & 13 & 20 & 28 & 36 & 44 \\
25 & -36 & -30 & -25 & -19 & -13 & -7 & 0 & 6 & 13 & 20 & 28 & 36 & 44 \\
30 & -36 & -30 & -25 & -19 & -13 & -7 & 0 & 6 & 13 & 20 & 28 & 35 & 44 \\
\hline
\end{tabular}

Note: Positive sign indicates increase, while negative indicates decrease. 
Table 3.8: Percent changes of mean annual runoff under concurrent perturbations in rainfall and evapotranspiration (ET) in the Lower Saint Johns River Basin.

\begin{tabular}{cccccccccccccc}
\hline \multirow{2}{*}{ Change in ET (\%) } & \multicolumn{10}{c}{ Change in rainfall $(\%)$} \\
\cline { 2 - 13 } & -30 & -25 & -20 & -15 & -10 & -5 & 0 & 5 & 10 & 15 & 20 & 25 & 30 \\
\hline-30 & -37 & -30 & -22 & -14 & -5 & 3 & 13 & 23 & 33 & 42 & 52 & 62 & 72 \\
-25 & -39 & -32 & -24 & -16 & -8 & 1 & 10 & 19 & 30 & 40 & 49 & 59 & 70 \\
-20 & -41 & -33 & -25 & -18 & -10 & -1 & 8 & 16 & 26 & 38 & 47 & 57 & 67 \\
-15 & -42 & -35 & -27 & -20 & -11 & -3 & 5 & 14 & 23 & 34 & 45 & 55 & 65 \\
-10 & -41 & -36 & -28 & -21 & -13 & -5 & 4 & 12 & 21 & 30 & 41 & 52 & 63 \\
-5 & -44 & -37 & -30 & -22 & -15 & -7 & 1 & 10 & 19 & 28 & 38 & 49 & 60 \\
0 & -44 & -38 & -31 & -24 & -16 & -8 & 0 & 8 & 17 & 26 & 35 & 45 & 56 \\
5 & -45 & -39 & -32 & -25 & -18 & -10 & -2 & 7 & 15 & 24 & 34 & 43 & 52 \\
10 & -46 & -40 & -33 & -27 & -19 & -12 & -4 & 5 & 14 & 22 & 31 & 41 & 50 \\
15 & -41 & -40 & -34 & -27 & -20 & -13 & -5 & 3 & 12 & 20 & 30 & 39 & 48 \\
20 & -46 & -41 & -35 & -28 & -22 & -14 & -6 & 1 & 10 & 19 & 28 & 37 & 46 \\
25 & -47 & -41 & -35 & -29 & -23 & -15 & -8 & 0 & 8 & 17 & 26 & 35 & 45 \\
30 & -47 & -42 & -36 & -30 & -24 & -16 & -9 & -2 & 7 & 15 & 24 & 33 & 43 \\
\hline
\end{tabular}

Note: Positive sign indicates increase, while negative indicates decrease.

Table 3.9: Percent changes of mean annual runoff under concurrent perturbations in rainfall and evapotranspiration (ET) in the Saint Johns River Basin.

\begin{tabular}{cccccccccccccc}
\hline \multirow{2}{*}{ Change in ET (\%) } & \multicolumn{10}{c}{ Change in rainfall $(\%)$} \\
\cline { 2 - 12 } & -30 & -25 & -20 & -15 & -10 & -5 & 0 & 5 & 10 & 15 & 20 & 25 & 30 \\
\hline-30 & -36 & -30 & -23 & -16 & -8 & -1 & 7 & 16 & 24 & 32 & 41 & 50 & 59 \\
-25 & -37 & -31 & -24 & -17 & -10 & -2 & 5 & 13 & 22 & 31 & 39 & 48 & 57 \\
-20 & -38 & -31 & -25 & -18 & -11 & -3 & 4 & 12 & 20 & 30 & 38 & 47 & 56 \\
-15 & -39 & -32 & -26 & -19 & -12 & -5 & 3 & 11 & 19 & 27 & 37 & 46 & 55 \\
-10 & -38 & -33 & -26 & -20 & -13 & -5 & 2 & 10 & 18 & 26 & 35 & 44 & 53 \\
-5 & -40 & -34 & -27 & -21 & -14 & -6 & 1 & 9 & 16 & 24 & 33 & 42 & 52 \\
0 & -40 & -34 & -28 & -21 & -14 & -7 & 0 & 7 & 15 & 23 & 32 & 40 & 50 \\
5 & -41 & -35 & -29 & -22 & -15 & -8 & -1 & 7 & 14 & 22 & 31 & 39 & 48 \\
10 & -41 & -35 & -29 & -23 & -16 & -9 & -2 & 6 & 13 & 21 & 29 & 38 & 47 \\
15 & -38 & -35 & -30 & -23 & -17 & -10 & -3 & 5 & 12 & 20 & 29 & 37 & 46 \\
20 & -41 & -36 & -30 & -24 & -17 & -11 & -3 & 4 & 11 & 19 & 27 & 36 & 45 \\
25 & -42 & -36 & -30 & -24 & -18 & -11 & -4 & 3 & 10 & 18 & 27 & 35 & 44 \\
30 & -42 & -36 & -31 & -25 & -19 & -12 & -5 & 2 & 10 & 17 & 25 & 34 & 43 \\
\hline
\end{tabular}

Note: Positive sign indicates increase, while negative indicates decrease. 
Table 3.10: Percent changes of mean annual runoff under concurrent perturbations in evapotranspiration (ET) and imperviousness in the Upper Saint Johns River Basin.

\begin{tabular}{cccccccccccccc}
\hline Change in & \multicolumn{10}{c}{ Change in ET $(\%)$} \\
\cline { 2 - 14 } imperviousness (\%) & -30 & -25 & -20 & -15 & -10 & -5 & 0 & 5 & 10 & 15 & 20 & 25 & 30 \\
\hline-30 & -29 & -29 & -29 & -29 & -29 & -29 & -29 & -29 & -29 & -29 & -30 & -30 & -30 \\
-25 & -24 & -24 & -24 & -24 & -24 & -24 & -24 & -24 & -24 & -25 & -25 & -25 & -25 \\
-20 & -19 & -19 & -19 & -19 & -19 & -19 & -19 & -19 & -20 & -20 & -20 & -20 & -20 \\
-15 & -14 & -14 & -14 & -14 & -14 & -14 & -14 & -15 & -15 & -15 & -15 & -15 & -15 \\
-10 & -9 & -9 & -9 & -9 & -9 & -9 & -10 & -10 & -10 & -10 & -10 & -10 & -10 \\
-5 & -4 & -4 & -4 & -4 & -4 & -5 & -5 & -5 & -5 & -5 & -5 & -5 & -6 \\
0 & 1 & 1 & 1 & 1 & 0 & 0 & 0 & 0 & 0 & 0 & -1 & -1 & -1 \\
5 & 6 & 6 & 6 & 5 & 5 & 5 & 5 & 5 & 5 & 4 & 4 & 4 & 4 \\
10 & 11 & 11 & 11 & 10 & 10 & 10 & 10 & 9 & 9 & 9 & 9 & 9 & 9 \\
15 & 16 & 16 & 15 & 15 & 15 & 15 & 14 & 14 & 14 & 14 & 14 & 14 & 13 \\
20 & 21 & 21 & 20 & 20 & 20 & 20 & 19 & 19 & 19 & 19 & 18 & 18 & 18 \\
25 & 26 & 25 & 25 & 25 & 25 & 24 & 24 & 24 & 24 & 23 & 23 & 23 & 23 \\
30 & 31 & 30 & 30 & 30 & 29 & 29 & 29 & 29 & 28 & 28 & 28 & 28 & 27 \\
\hline
\end{tabular}

Note: Positive sign indicates increase, while negative indicates decrease.

Table 3.11: Percent changes of mean annual runoff under concurrent perturbations in evapotranspiration (ET) and imperviousness in the Ocklawaha River Basin.

\begin{tabular}{cccccccccccccc}
\hline Change in & \multicolumn{10}{c}{ Change in ET $(\%)$} \\
\cline { 2 - 14 } imperviousness (\%) & -30 & -25 & -20 & -15 & -10 & -5 & 0 & 5 & 10 & 15 & 20 & 25 & 30 \\
\hline-30 & -30 & -30 & -30 & -30 & -30 & -30 & -30 & -30 & -30 & -30 & -30 & -30 & -30 \\
-25 & -25 & -25 & -25 & -25 & -25 & -25 & -25 & -25 & -25 & -25 & -25 & -25 & -25 \\
-20 & -20 & -20 & -20 & -20 & -20 & -20 & -20 & -20 & -20 & -20 & -20 & -20 & -20 \\
-15 & -15 & -15 & -15 & -15 & -15 & -15 & -15 & -15 & -15 & -15 & -15 & -15 & -15 \\
-10 & -10 & -10 & -10 & -10 & -10 & -10 & -10 & -10 & -10 & -10 & -10 & -10 & -10 \\
-5 & -5 & -5 & -5 & -5 & -5 & -5 & -5 & -5 & -5 & -5 & -5 & -5 & -5 \\
0 & 0 & 0 & 0 & 0 & 0 & 0 & 0 & 0 & 0 & 0 & 0 & 0 & 0 \\
5 & 6 & 5 & 5 & 5 & 5 & 5 & 5 & 5 & 5 & 5 & 5 & 5 & 5 \\
10 & 11 & 10 & 10 & 10 & 10 & 10 & 10 & 10 & 10 & 10 & 10 & 10 & 10 \\
15 & 16 & 16 & 16 & 15 & 15 & 15 & 15 & 15 & 15 & 15 & 15 & 15 & 15 \\
20 & 21 & 21 & 21 & 20 & 20 & 20 & 20 & 20 & 20 & 20 & 20 & 20 & 20 \\
25 & 26 & 26 & 26 & 26 & 25 & 25 & 25 & 25 & 25 & 25 & 25 & 25 & 25 \\
30 & 31 & 31 & 31 & 31 & 30 & 30 & 30 & 30 & 30 & 30 & 30 & 30 & 30 \\
\hline
\end{tabular}

Note: Positive sign indicates increase, while negative indicates decrease. 
Table 3.12: Percent changes of mean annual runoff under concurrent perturbations in evapotranspiration (ET) and imperviousness in the Lower Saint Johns River Basin.

\begin{tabular}{cccccccccccccc}
\hline Change in & \multicolumn{10}{c}{ Change in ET $(\%)$} \\
\cline { 2 - 14 } imperviousness (\%) & -30 & -25 & -20 & -15 & -10 & -5 & 0 & 5 & 10 & 15 & 20 & 25 & 30 \\
\hline-30 & -10 & -13 & -15 & -17 & -19 & -21 & -23 & -25 & -26 & -28 & -29 & -31 & -32 \\
-25 & -6 & -9 & -11 & -13 & -15 & -17 & -19 & -21 & -23 & -24 & -25 & -27 & -28 \\
-20 & -2 & -5 & -7 & -9 & -11 & -13 & -15 & -17 & -19 & -20 & -22 & -23 & -24 \\
-15 & 2 & -1 & -4 & -6 & -8 & -10 & -12 & -13 & -15 & -16 & -18 & -19 & -21 \\
-10 & 5 & 2 & 0 & -2 & -4 & -6 & -8 & -9 & -11 & -13 & -14 & -16 & -17 \\
-5 & 9 & 6 & 4 & 2 & 0 & -2 & -4 & -6 & -7 & -9 & -10 & -12 & -13 \\
0 & 13 & 10 & 8 & 6 & 4 & 2 & 0 & -2 & -4 & -5 & -6 & -8 & -9 \\
5 & 16 & 14 & 11 & 9 & 7 & 5 & 3 & 2 & 0 & -1 & -3 & -4 & -6 \\
10 & 20 & 17 & 15 & 13 & 11 & 9 & 7 & 6 & 4 & 2 & 1 & 0 & -2 \\
15 & 23 & 21 & 18 & 17 & 15 & 13 & 11 & 10 & 8 & 6 & 5 & 3 & 2 \\
20 & 27 & 25 & 22 & 21 & 18 & 16 & 15 & 13 & 11 & 10 & 9 & 7 & 6 \\
25 & 31 & 28 & 26 & 24 & 22 & 20 & 18 & 17 & 15 & 13 & 12 & 11 & 9 \\
30 & 34 & 32 & 29 & 28 & 26 & 24 & 22 & 20 & 19 & 17 & 16 & 14 & 13 \\
\hline
\end{tabular}

Note: Positive sign indicates increase, while negative indicates decrease.

Table 3.13: Percent changes of mean annual runoff under concurrent perturbations in evapotranspiration (ET) and imperviousness in the Saint Johns River Basin.

\begin{tabular}{cccccccccccccc}
\hline Change in & \multicolumn{10}{c}{ Change in ET $(\%)$} \\
\cline { 2 - 14 } imperviousness (\%) & -30 & -25 & -20 & -15 & -10 & -5 & 0 & 5 & 10 & 15 & 20 & 25 & 30 \\
\hline-30 & -19 & -21 & -22 & -23 & -24 & -25 & -26 & -27 & -28 & -29 & -30 & -30 & -31 \\
-25 & -15 & -16 & -18 & -19 & -20 & -21 & -22 & -23 & -24 & -24 & -25 & -26 & -27 \\
-20 & -10 & -12 & -13 & -14 & -15 & -16 & -17 & -18 & -19 & -20 & -21 & -22 & -22 \\
-15 & -6 & -8 & -9 & -10 & -11 & -12 & -13 & -14 & -15 & -16 & -16 & -17 & -18 \\
-10 & -2 & -3 & -4 & -6 & -7 & -8 & -9 & -10 & -10 & -11 & -12 & -13 & -14 \\
-5 & 3 & 1 & 0 & -1 & -2 & -3 & -4 & -5 & -6 & -7 & -8 & -9 & -9 \\
0 & 7 & 5 & 4 & 3 & 2 & 1 & 0 & -1 & -2 & -3 & -4 & -4 & -5 \\
5 & 11 & 10 & 9 & 7 & 6 & 5 & 4 & 3 & 2 & 2 & 1 & 0 & -1 \\
10 & 15 & 14 & 13 & 12 & 11 & 10 & 9 & 8 & 7 & 6 & 5 & 4 & 3 \\
15 & 20 & 19 & 17 & 16 & 15 & 14 & 13 & 12 & 11 & 10 & 9 & 8 & 8 \\
20 & 24 & 23 & 21 & 20 & 19 & 18 & 17 & 16 & 15 & 14 & 14 & 13 & 12 \\
25 & 28 & 27 & 25 & 25 & 23 & 22 & 21 & 20 & 19 & 18 & 18 & 17 & 16 \\
30 & 33 & 31 & 30 & 29 & 28 & 26 & 26 & 25 & 24 & 23 & 22 & 21 & 20 \\
\hline
\end{tabular}

Note: Positive sign indicates increase, while negative indicates decrease. 


\subsubsection{Potential future runoff projections}

\subsubsection{Runoff projections under changes in climate}

In response to the climatic (rainfall and ET) projections of $20 \mathrm{GCMs}$, SWMM simulated ensemble mean future runoff depths indicated spatial mean 45 to $60 \mathrm{~mm}$ (per $\mathrm{m}^{2}$ basin area) increases in the 10-year mean annual storm runoff across the Saint Johns River Basin under different scenarios (Figure 3.7a), relative to the 2010s (Figure A3.4). The runoff increases were mainly governed by the corresponding projected ensemble mean increases in the 10-year mean annual rainfall of 224 to $350 \mathrm{~mm}$ (Figure A3.5a). Projected climatic changes resulted in higher (than other locations) runoff increases at and near major urban centers across the basin. For example the northern (e.g., Jacksonville), north-eastern (e.g., Gainesville), and the south-central (e.g., Orlando, Clermont) regions of the basin would experience 284 to $365 \mathrm{~mm}, 96$ to $128 \mathrm{~mm}$, and 89 to $152 \mathrm{~mm}$ (spatial mean) runoff increases (Figure 3.7a). Undeveloped lands in the northeastern, north-central, south-central, and southern parts of the basin, characterized by croplands, pasture, grasslands, and wetlands (Figure 3.1) would experience substantially lower spatial mean runoff increase of 30 to $42 \mathrm{~mm}$ albeit the substantial spatial mean runoff increases of 217 to $360 \mathrm{~mm}$. 


\section{0s-RCP $4.5 \quad$ 2080s-RCP $4.5 \quad$ 2050s-RCP $8.5 \quad$ 2080s-RCP 8.5}

(a) Climate

(b) Land cover
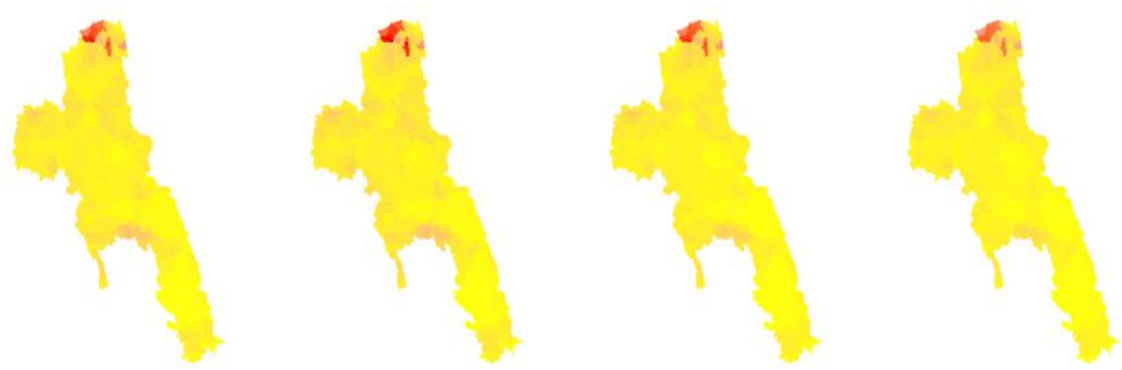

(c) Climate and land cover
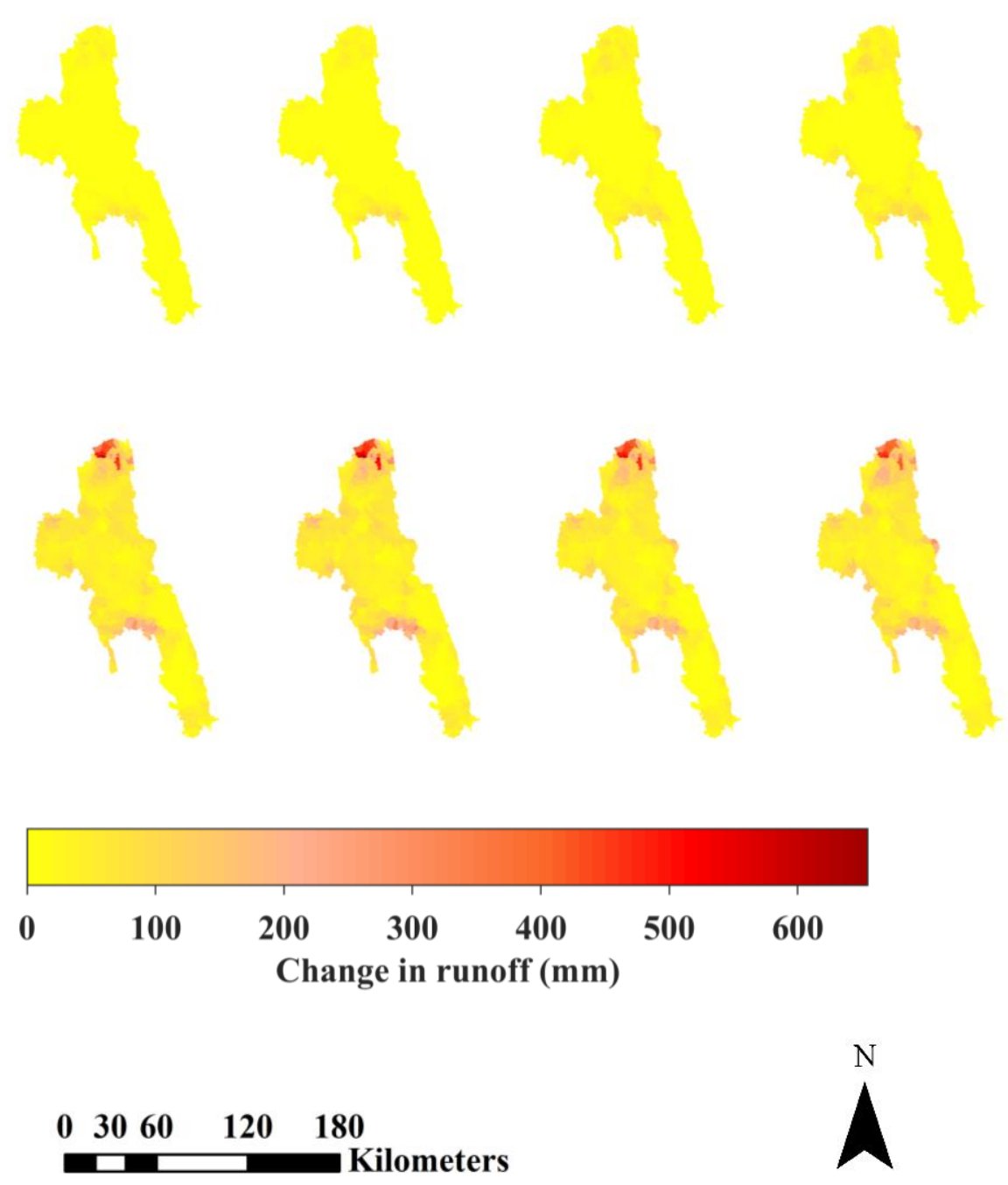

Figure 3.7: Spatial variation of the simulated changes in 10-year mean annual runoff depth due to the projected changes in (a) climate, (b) land cover, and (c) climate and land cover under different future scenarios in the Saint Johns River Basin. 
Based on the basin-wide ensemble mean runoff volume, we found higher relative changes in the 10-year mean runoffs for the dry season as well as the early and late wet season months, i.e., October-May (Figure 3.8a). 98 to 315\% increases in runoff were observed for these months across different future scenarios on account of the 29 to $70 \%$ ensemble mean increases in rainfall (Figure A3.6a). Under projected climatic changes, highest ensemble mean increase in mean annual basin-wide runoff volume was observed under the 2080s-RCP 4.5 scenario for the entire Saint Johns River Basin as well as its different subwatersheds (Table 3.14). About 37\% increase in basin-wide rainfall in the 2080s-RCP 4.5 (Table A3.3. in Appendix 3) primarily led to the $152 \%$ increase in basin total runoff volume. Basin runoff increases for 2050s-RCP 4.5, 2050s-RCP 8.5 and 2080s-RCP 8.5, were, respectively, 140\%, 124\%, and 114\%.

\subsubsection{Runoff projections under changes in land cover}

Much lower runoff increases were noted under projected land cover changes than under projected climatic changes. Spatial mean increases in 10-year mean annual runoff of 6 to $15 \mathrm{~mm}$ were observed across the Saint Johns River Basin under different future scenarios (Figure 3.7b) subject to 0.8 to 1.9 percentage points increases in imperviousness (Figure A3.5b). Urban centers in the northern (e.g., Jacksonville), north-eastern (e.g., Gainesville), and south-central (e.g., Orlando, Clermont) parts of the basin were projected to see higher runoff increase than other basin locations. Spatial mean 7 to 9 percentage points increases in imperviousness (figure A3.5b) at these basin areas would result in spatial mean 60 to $84 \mathrm{~mm}$ runoff increases under different future scenarios (Figure 3.7b). Unbuilt areas at the northeastern, north-central, south-central, and southern parts of the basin were projected to have nominal spatial mean imperviousness increases of 0.2 to 0.7 percentage points across different future scenarios; these basin locations would have low spatial mean runoff increases of 1 to $6 \mathrm{~mm}$ accordingly. 
(a) Climate
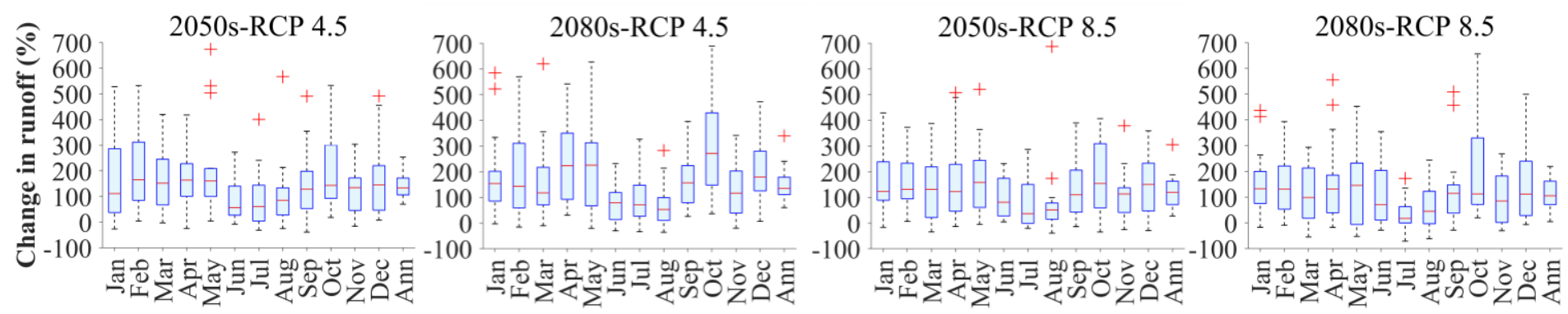

(b) Land

cover
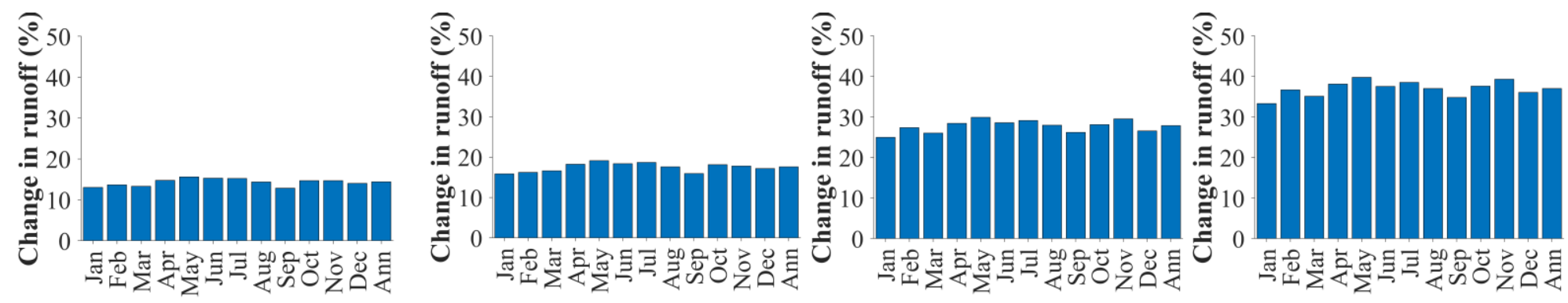

(c) Climate and land cover
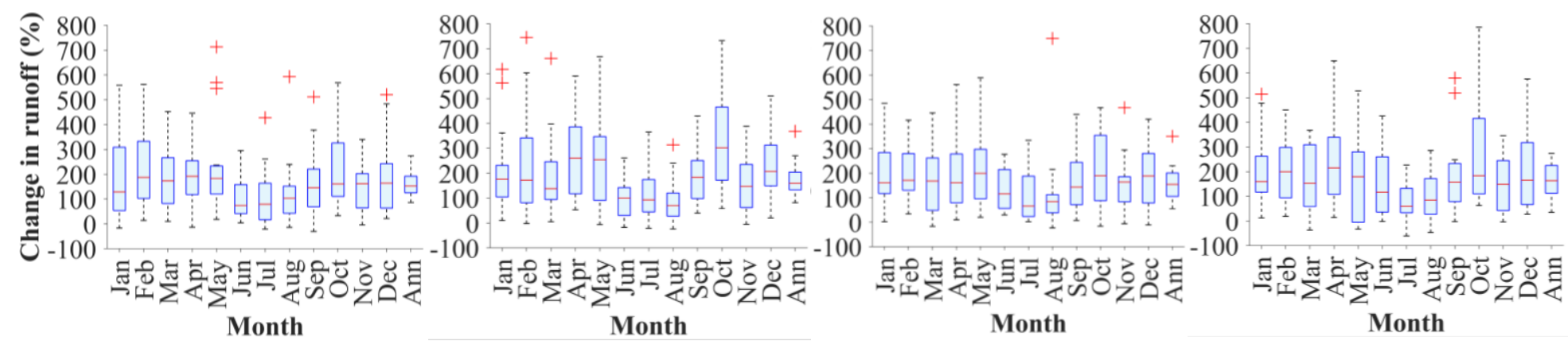

Figure 3.8: Percentage changes in 10-year mean monthly and annual runoff under the projected changes in (a) climate, (b) land cover, and (c) climate and land cover for different future scenarios in the Saint Johns River Basin. For (a) and (c), the box-whiskers represent variations in runoff change across the general circulation models (GCMs); the lower, intermediate, and upper horizontal lines in the boxes indicate 25th, 50th, and 75th percentiles; plus signs indicate extreme outliers. Jan: January; Feb: February; Mar: March; Apr: April; Jun: June; Jul: July; Aug: August; Sep: September; Oct: October; Nov: November; Dec: December; Ann: Annual. 
Table 3.14: Potential future changes in basin-average runoff volume for the Saint Johns River Basin and its subwatersheds, relative to the baseline period of 2010s, under different future scenarios.

\begin{tabular}{|c|c|c|c|c|c|}
\hline \multirow[b]{2}{*}{ Watershed } & \multirow[b]{2}{*}{ Variable } & \multicolumn{4}{|c|}{ Projected runoff changes $(\%)$} \\
\hline & & $\begin{array}{l}\text { 2050s- } \\
\text { RCP } 4.5\end{array}$ & $\begin{array}{l}\text { 2080s- } \\
\text { RCP } 4.5\end{array}$ & $\begin{array}{l}\text { 2050s- } \\
\text { RCP 8.5 }\end{array}$ & $\begin{array}{c}\text { 2080s- } \\
\text { RCP 8.5 }\end{array}$ \\
\hline Upper Saint & Climate & +142 & +145 & +108 & +97 \\
\hline \multirow{2}{*}{$\begin{array}{c}\text { Johns River } \\
\text { Basin }\end{array}$} & Land cover & +19 & +24 & +31 & +40 \\
\hline & Climate and land & +168 & +177 & +148 & +150 \\
\hline \multirow{3}{*}{$\begin{array}{l}\text { Ocklawaha } \\
\text { River Basin }\end{array}$} & Climate & +210 & +229 & +181 & +167 \\
\hline & Land cover & +19 & +25 & +38 & +54 \\
\hline & Climate and land & +235 & +264 & +230 & +243 \\
\hline \multirow{3}{*}{$\begin{array}{c}\text { Lower Saint } \\
\text { Johns River } \\
\text { Basin }\end{array}$} & Climate & +112 & +125 & +109 & +102 \\
\hline & Land cover & +10 & +11 & +22 & +29 \\
\hline & Climate and land & +126 & +141 & +137 & +140 \\
\hline \multirow{3}{*}{$\begin{array}{l}\text { Saint Johns } \\
\text { River Basin }\end{array}$} & Climate & +140 & +152 & +124 & +114 \\
\hline & Land cover & +14 & +18 & +28 & +37 \\
\hline & Climate and land & +160 & +176 & +159 & +164 \\
\hline
\end{tabular}

Note: Positive sign indicates increases.

Ensemble mean changes in basin-wide annual mean runoff volume under changing land cover outlined relatively nominal seasonal variation in runoff responses (Figure 3.8b). Higher relative changes in 10-year mean monthly runoffs were, generally, observed for October-May, and also for July. About 16 to $31 \%$ relative increases in basin-average imperviousness under different future scenarios (Table A3.3 in Appendix 3) resulted in higher (than other months) 13$40 \%$ runoff increases for October-May and July. Among the different future scenarios, maximum increase in mean annual basin runoff volume was noted for the 2080-RCP 8.5 scenario in the Saint Johns River Basin and its subwatersheds (Table 3.14). Under this scenario, the maximum relative increase in basin-average percent imperviousness of about $40 \%$ resulted in the highest runoff increase of $37 \%$, under changing land cover. Basin runoff increases for the other scenarios were as follows: $14 \%$ in 2050s-RCP4.5; $18 \%$ in 2080s-RCP 4.5; and 28\% in 2050s-RCP 8.5. 


\subsubsection{Runoff projections under concurrent changes in climate and land cover}

Under simultaneous projected changes in climate and land cover, relatively more widespread and higher spatial mean increases in storm runoff depth (63 to $70 \mathrm{~mm}$ per $\mathrm{m}^{2}$ basin area) were found in the Saint Johns River Basin as compared to that under the standalone climatic or land cover changes across all four scenarios (Figure 3.7c). The spatial patterns of runoff changes under simultaneously changing climate and land cover primarily represented that under individually changing climate (Figure 3.7a). Higher (than other locations) runoff increases at and near major urban centers across the basin were noted. The urban centers in the northern, north-eastern, and south-central regions of the basin (e.g., Jacksonville, Gainesville, Orlando, and Clermont), are expected to experience high spatial mean runoff increases of 192 to $262 \mathrm{~mm}$ subject to spatial mean 218 to $405 \mathrm{~mm}$ and 7 to 9 percentage points increases in, respectively, rainfall and imperviousness.

Under simultaneously changing climate and land cover, higher overall relative increases in ensemble mean monthly runoff were detected during October-May across the future scenarios (Figure 3.8c). 29 to $70 \%$ ensemble mean increases in rainfall (Figure A3.6a) together with 16 to $31 \%$ relative increases in basin-average imperviousness (Table A3.3) contributed to relative runoff increases of 149 to $346 \%$ in these months. Projected concurrent changes in climate and land cover in the Saint Johns River Basin led to high ensemble mean increases in mean annual basin runoff volume (Figure 3.8c; Table 3.14) under all future scenarios: 2050s-RCP 4.5 (160\%); 2080s-RC 4.5 (176\%); 2050s-RCP8.5 (159\%); and 2080s-RCP 8.5 (164\%). In terms of basinscale relative changes, 2080s-RCP 4.5 was apparently the most critical future runoff scenario for long term infrastructure design, construction, and maintenance related to runoff and flooding management. 


\subsection{Discussion}

\subsection{Runoff sensitivities and future runoff projections}

The sensitivity analyses results generally outlined notable seasonal variations of runoff responses due to individually changing climatic and land cover drivers in the Saint Johns River Basin. Higher monthly runoff sensitivities under individually changing rainfalls were found during the wet season months of August-October and dry season month of January. Under individually changing ET, higher monthly runoff sensitivities were observed for early and late wet season months of October and May and dry season months of December and February. Isolated changes in land cover led to higher monthly sensitivities of basin-scale runoffs during wet months of May, July, and October and dry month November. Runoff sensitivities to rainfall were higher than that to ET and imperviousness. Under -30 to $+30 \%$ changes in baseline rainfalls, -40 to $+50 \%$ changes in mean annual baseline runoff volume were noted (Figure 3.4d) in the Saint Johns River Basin. In comparison, -30 to $+30 \%$ changes in baseline ET and imperviousness, respectively, led to lower annual runoff changes of -5 to $+7 \%$ (Figure 3.5d) and 26 to $+26 \%$ (Figure 3.6d).

Potential future runoff scenarios in the Saint Johns River Basin suggested high relative runoff increases across the basin relative to the baseline period (Figure 3.7). Higher (than other locations) runoff increases were noted for the major urban centers and their neighboring areas in the basin. Potential relative basin runoff increases in future under simultaneously changing climate and land cover were higher during October-May (Figure 3.8c). Both the sensitivity analyses outcomes and future runoff scenarios for the Saint Johns River Basin indicated stronger influence of climatic (rainfall) changes on basin-wide runoff than land cover changes. Further, both the combined sensitivity analyses for basin-scale annual runoff (Table 3.2 to 3.13 ) and 
potential future runoff changes (Table 3.14) demonstrated nonlinear runoff responses under simultaneous changes in climatic and land cover drivers.

\subsubsection{Comparison of findings of the study with existing literature}

The overall findings of the current study on the Saint Johns River Basin of northeast Florida, primarily characterized by natural land uses, complement previous and current relevant research for different regions around the globe. For example, Abdul-Aziz and Al-Amin (2015) also found notable seasonal variation of historical runoffs for the year 2010 under changing climate, land use, and hydrology for the highly urbanized Miami River Basin (drainage area $\sim 175 \mathrm{~km}^{2}$ ) of southeast Florida. There are, however, some occasional differences between their findings and the findings for the Saint Johns River Basin. Abdul-Aziz and Al-Amin (2015) reported high runoff sensitivities to rainfall to rainfall during dry season months of November and December; findings for the Saint Johns River Basin outlined lower sensitivities of the 10-year baseline runoffs in the 2010s (2004-2013) to changing rainfall for these months. The contrast in the findings of the two studies may be attributed to the difference in spatial and temporal scale, land cover, and temporal rainfall distributions.

The runoff sensitivity analyses results as well as the potential future runoff scenarios outlined climate as the controlling driver of stormwater runoff in coastal-natural Saint Johns River Basin by the 2050s (2044-2053) and by the 2080s (2076-2085). Pan et al. (2017) also found changing climate to be more impactful on runoff changes than changing land use/cover during 2031-2050 for the Beijiang River basin in China. Similarly, Sinha et al. (2020) reported more predominant impact of climatic changes on runoff generation as compared to land cover changes for a river basin in India. Berghuijs et al. (2017) obtained higher sensitivity of runoff to changing rainfall than to changing ET globally, similar to findings on the Saint Johns River 
Basin. Wang et al. (2017) concluded that a 10\% decrease in precipitation may cause 9.4-17.4\% decreases in runoff across different catchments in China. Their findings are comparable to the $40 \%$ changes in runoff due to $-30 \%$ changes in rainfall in the Saint Johns River Basin. Bulti and Abebe (2020) found that a 22\% growth of the urban built-up area during 1995-2019 resulted in 12.9 and $6.9 \%$ increase in runoff depth in two sub-watersheds within the Adama city of Ethiopia. In comparison, a 30\% perturbation in baseline imperviousness of 2004-2013 resulted in 22 to $30 \%$ increases in mean annual runoff depth across different subwatersheds in the Saint Johns River Basin. The nonlinear runoff responses in the Saint Johns River Basin, for both baseline runoff sensitivities, and future projected runoffs are also corroborated by the existing hydrologic research (e.g., Abdul-Aziz and Al-Amin, 2015; Hovenga et al., 2016; Lamichhane and Shakya, 2019).

\subsubsection{Hydrologic and environmental implications}

The potential future changes in runoff regimes due to the projected climatic and land cover changes can have drastic hydrologic and environmental impacts for the urban centers as well as the undeveloped lands across the Saint Johns River Basin. Projected high runoff increases in future (Figure 3.7) implied potential pluvial flooding and water quality risks for the major urban centers (e.g., Jacksonville, Gainesville, Orlando) and their nearby locations. Anticipated high

increases in monthly and annual runoffs in future would probably contribute to year-long higher than average flow conditions in the open channel drainage systems in the basin. The nonlinear runoff response necessitated considering concurrent changes in climate and land cover, instead of considering individual changes in them, for design and upgradation of new and existing flood control infrastructures. High increases in future runoff from the urban and agricultural lands can bring increased nutrient loadings to the streams and other surface water bodies. The 
corresponding water quality problems can have detrimental impacts on the Saint Johns River as well as its tributaries and lakes. Potential algal bloom under nutrient (nitrogen and phosphorus) increases can interfere with life cycle of different aquatic species by blocking sunlight. The algal growth might also cause environmental pollutions by releasing harmful toxins.

\subsubsection{Study limitations, caveats, and uncertainties}

Insignificant changes in the drainage networks and stream geometric features were assumed during the sensitivity analyses and future runoff projections, which might not be applicable while considering potential changes in land cover. Historical hourly rainfall distributions were used for hourly disaggregation of the constructed future monthly rainfalls since GCMs do not provide appropriate representations of the hourly rainfall distributions. Projected changes in hourly rainfall as well as changes in stream network and their geometric properties can affect the runoff generation process - suggesting potential uncertainties in the estimated runoff scenarios.

Meanwhile, large-scale ocean-atmospheric phenomena such as El Niño-Southern

Oscillation (ENSO) often lead to seasonal climatic anomalies in northeast Florida (Misra and DiNapoli, 2013) which is accompanied by the impacts of tropical storms/hurricanes. The CMIP5 GCMs do not represent these phenomena in the climatic projections (Zhao et al., 2017; Lu et al., 2018), which can bring uncertainties into estimated runoff scenarios. Furthermore, differences in climatic projections of the 20 CMIP5 GCMs caused high uncertainties in the future runoffs; ensembled runoff estimations were considered accordingly. Potential uncertainties in the land cover projections is also likely to contribute to added uncertainties in the future runoff scenarios.

\subsection{Conclusions}

The current study investigated the individual as well as combined impacts of climatic and land cover changes on stormwater runoff regimes in coastal-natural environments, considering the 
Saint Johns River Basin of northeast Florida as the study area. Using U.S. EPA SWMM 5.1, a large-scale $\left(24928 \mathrm{~km}^{2}\right)$ mechanistic hydrologic model was developed for this basin. The model was calibrated and validated ( $\mathrm{NSE}=0.70$ to $0.82, \mathrm{RSR}=0.43$ to 0.55 ) with daily observed streamflows during the historical 10-year period of 2010s (2004-2013). The calibrated Saint Johns River Basin model was utilized to determine basin runoff responses under reference changes in climate (rainfall and ET) and land cover (imperviousness), and to perform comparative assessments of the historical and potential future stormwater runoff regimes as well. Basin-wide storm runoffs had notably different seasonal sensitivities to standalone reference perturbations (-30 to $+30 \%$, with $5 \%$ increments) in rainfall, ET, and imperviousness. The sensitivity results outlined substantially stronger influence of climatic (rainfall) changes on basin-wide runoff than land cover changes. Based on annual runoff sensitivities, rainfall had approximately 2 and 8 times stronger control on runoff than imperviousness and ET, respectively. Moreover, stronger nonlinear responses of runoff due to concurrent changes in climate and land cover were noted as compared to superposition of their individual effects.

Subject to climatic projections of the 20 CMIP5 GCMs and ICLUS land cover projections, the Saint Johns River Basin would experience high ensembled increases in 10-year mean annual storm runoff by 2050s (2044-2053) and 2080s (2076-2085), relative to the 2010s. Urban centers and their nearby areas in the northern (e.g., Jacksonville), north-eastern (e.g., Gainesville), and south-central (e.g., Orlando, and Clermont) regions of the basin are projected to undergo higher (than other locations) runoff increases across all of the future scenarios. Undeveloped lands at the northeastern, north-central, south-central, and southern parts of the basin, characterized by current land covers of croplands, pasture, grasslands, and wetlands, are 
expected to experience substantially lower runoff increases even though high rainfall increases are projected at these locations.

Based on the basin-scale ensembled runoff changes, the projected climatic changes would result in high increases (relative to 2010s) in annual storm runoff under the 2080s-RCP 4.5 (152\%), 2050s-RCP 4.5 (140\%), 2050s-RCP 8.5 (124\%), and 2080s-RCP 8.5 (114\%) scenarios. In comparison, the projected land cover changes would bring the following moderate runoff increases: 2080s-RCP 8.5 (37\%), 2050s-RCP 8.5 (28\%), 2080s-RCP 4.5 (18\%), and 2050s-RCP $4.5(14 \%)$. Under the projected simultaneous changes in climate and land cover, the annual storm runoff is projected to increase by $176 \%, 164 \%, 160 \%$, and $159 \%$ under 2080s-RCP 4.5, 2080sRCP 8.5, 2050s-RCP 4.5, and 2050s-RCP 8.5, respectively. Projected relative runoff increases in future under simultaneously changing climate and land cover were higher during October-May. Nearly similar projected seasonal variations in rainfall and runoff changes were observed. The future basin-scale runoff increases and the seasonal patterns of runoff changes emphasized the predominant climatic control on storm runoff in coastal-natural environments.

The study findings would aid in mitigating the impacts of climate and land cover changes in northeast Florida as well as coastal-natural environments for other global regions. The projected runoff increases across the Saint Johns River Basin by the 2050s and 2080s suggested the critical basin areas under potentially greater risks of pluvial flooding and impaired surface water quality. It would be required to adopt appropriate management strategies to reduce the influx of enhanced pollutant loads from urban and agricultural areas to Saint Johns River and its tributaries. The findings are particularly relevant in undeveloped areas in high latitudes as well as wet tropical and subtropical regions that are expected to experience increases in rainfall (IPCC, 2014a). 


\section{Acknowledgments}

The research was funded by a National Science Foundation (NSF) Critical Resilient

Interdependent Infrastructure Systems and Processes (CRISP 2.0) Award to Dr. Omar I. AbdulAziz (NSF CMMI Award \#1832680), and by the "Florida Public Hurricane Loss Model

Enhancements" project's freshwater flood modeling award to Dr. Omar I. Abdul-Aziz. The research on climate and land cover change impacts on stormwater runoff was exclusively funded by the NSF project. The findings and conclusions of this research are those of the authors, and do not necessarily reflect the views of NSF and the State of Florida or any of its sub-agencies. 


\section{Appendix 3}

Table A3.1: Streamflow stations used for calibrations and validations of the Saint Johns River Basin model.

\begin{tabular}{cccc}
\hline Station & Agency & Calibration period & Validation period \\
\hline $\begin{array}{c}\text { Saint Johns River near } \\
\text { Melbourne }\end{array}$ & USGS & $01 / 01 / 2004-12 / 31 / 2008$ & $01 / 01 / 2009-12 / 31 / 2013$ \\
$\begin{array}{c}\text { Saint Johns River near } \\
\text { DeLand }\end{array}$ & USGS & $01 / 01 / 2004-12 / 31 / 2008$ & $03 / 01 / 2009-12 / 31 / 2013$ \\
$\begin{array}{c}\text { Saint Johns River near } \\
\quad \text { Satsuma }\end{array}$ & USGS & $06 / 01 / 2004-12 / 31 / 2008$ & $01 / 01 / 2009-12 / 31 / 2013$ \\
$\begin{array}{c}\text { Saint Johns River near } \\
\text { Jacksonville }\end{array}$ & USGS & $02 / 01 / 2004-12 / 31 / 2008$ & $01 / 01 / 2009-12 / 31 / 2013$ \\
\hline
\end{tabular}

Note: SFMWD refers to South Florida Water Management District 
Table A3.2: List of the Coupled Model Intercomparison Project's fifth phase (CMIP5) general circulation models (GCMs) used for future projections of rainfall and potential evapotranspiration in the Saint Johns River Basin.

\begin{tabular}{|c|c|c|}
\hline Name & Agency & $\begin{array}{l}\text { Resolution } \\
\text { (Long. } \times \text { Lat.) }\end{array}$ \\
\hline bcc-csm1-1 & Beijing Climate Center, China Meteorological Administration & $2.8^{\circ} \times 2.8^{\circ}$ \\
\hline bcc-csm1-1-m & Beijing Climate Center, China Meteorological Administration & $1.12^{\circ} \times 1.12^{\circ}$ \\
\hline BNU-ESM & $\begin{array}{c}\text { College of Global Change and Earth System Science, Beijing } \\
\text { Normal University, China }\end{array}$ & $2.8^{\circ} \times 2.8^{\circ}$ \\
\hline CanESM2 & Canadian Centre for Climate Modeling and Analysis & $2.8^{\circ} \times 2.8^{\circ}$ \\
\hline CCSM4 & National Center of Atmospheric Research, USA & $1.25^{\circ} \times 0.94^{\circ}$ \\
\hline CNRM-CM5 & National Centre of Meteorological Research, France & $1.4^{\circ} \times 1.4^{\circ}$ \\
\hline CSIRO-Mk3-6-0 & $\begin{array}{c}\text { Commonwealth Scientific and Industrial Research } \\
\text { Organization/Queensland Climate Change Centre of } \\
\text { Excellence, Australia }\end{array}$ & $1.8^{\circ} \times 1.8^{\circ}$ \\
\hline GFDL-ESM2M & NOAA Geophysical Fluid Dynamics Laboratory, USA & $2.5^{\circ} \times 2.0^{\circ}$ \\
\hline GFDL-ESM2G & NOAA Geophysical Fluid Dynamics Laboratory, USA & $2.5^{\circ} \times 2.0^{\circ}$ \\
\hline HadGEM2-ES & Met Office Hadley Center, UK & $1.88^{\circ} \times 1.25^{\circ}$ \\
\hline HadGEM2-CC & Met Office Hadley Center, UK & $1.88^{\circ} \times 1.25^{\circ}$ \\
\hline inmem4 & Institute for Numerical Mathematics, Russia & $2.0^{\circ} \times 1.5^{\circ}$ \\
\hline IPSL-CM5A-LR & Institut Pierre Simon Laplace, France & $3.75^{\circ} \times 1.8^{\circ}$ \\
\hline IPSL-CM5A-MR & Institut Pierre Simon Laplace, France & $2.5^{\circ} \times 1.25^{\circ}$ \\
\hline IPSL-CM5B-LR & Institut Pierre Simon Laplace, France & $2.75^{\circ} \times 1.8^{\circ}$ \\
\hline MIROC5 & $\begin{array}{l}\text { Atmosphere and Ocean Research Institute (The University of } \\
\text { Tokyo), National Institute for Environmental Studies, and } \\
\text { Japan Agency for Marine-Earth Science and Technology }\end{array}$ & $1.4^{\circ} \times 1.4^{\circ}$ \\
\hline MIROC-ESM & $\begin{array}{l}\text { Japan Agency for Marine-Earth Science and Technology, } \\
\text { Atmosphere and Ocean Research Institute (The University of } \\
\text { Tokyo), and National Institute for Environmental Studies }\end{array}$ & $2.8^{\circ} \times 2.8^{\circ}$ \\
\hline $\begin{array}{l}\text { MIROC-ESM- } \\
\text { CHEM }\end{array}$ & $\begin{array}{l}\text { Japan Agency for Marine-Earth Science and Technology, } \\
\text { Atmosphere and Ocean Research Institute (The University of } \\
\text { Tokyo), and National Institute for Environmental Studies }\end{array}$ & $2.8^{\circ} \times 2.8^{\circ}$ \\
\hline MRI-CGCM3 & Meteorological Research Institute, Japan & $1.1^{\circ} \times 1.1^{\circ}$ \\
\hline NorESM1-M & Norwegian Climate Center, Norway & $2.5^{\circ} \times 1.9^{\circ}$ \\
\hline
\end{tabular}

Source: https://climate.northwestknowledge.net/MACA/GCMs.php; Note: Lat. and Long., respectively, refer to latitude and longitude. 
Table A3.3: Baseline and future basin-average percent changes in annual rainfall, evapotranspiration (ET), and imperviousness for the Saint Johns River Basin and its subwatersheds relative to the baseline period of 2010s.

\begin{tabular}{|c|c|c|c|c|c|c|}
\hline \multirow{2}{*}{ Watershed } & \multirow{2}{*}{ Variable } & \multirow{2}{*}{$\begin{array}{c}\text { Baseline } \\
2010 \mathrm{~s} \\
\text { values }\end{array}$} & \multicolumn{4}{|c|}{ Projected changes (\%) } \\
\hline & & & $\begin{array}{c}\text { 2050s- } \\
\text { RCP } 4.5\end{array}$ & $\begin{array}{l}\text { 2080s- } \\
\text { RCP } 4.5\end{array}$ & $\begin{array}{c}\text { 2050s- } \\
\text { RCP } 8.5\end{array}$ & $\begin{array}{l}\text { 2080s- } \\
\text { RCP } 8.5\end{array}$ \\
\hline \multirow{3}{*}{$\begin{array}{c}\text { Upper Saint } \\
\text { Johns River } \\
\text { Basin }\end{array}$} & Rainfall & $799.2 \mathrm{~mm}$ & +33.6 & +35.2 & +25.2 & +19.8 \\
\hline & ET & $3.6 \mathrm{~mm} /$ day & +3.8 & +5.4 & +5.9 & +11.2 \\
\hline & Imperviousness & $4.2 \%$ & +18.5 & +23.0 & +34.9 & +46.0 \\
\hline \multirow{3}{*}{$\begin{array}{l}\text { Ocklawaha } \\
\text { River Basin }\end{array}$} & Rainfall & $1077.4 \mathrm{~mm}$ & +34.3 & +38.6 & +29.4 & +24.5 \\
\hline & ET & $3.6 \mathrm{~mm} /$ day & +3.8 & +5.4 & +5.9 & +11.2 \\
\hline & Imperviousness & $2.6 \%$ & +18.1 & +23.3 & +37.1 & +52.9 \\
\hline \multirow{3}{*}{$\begin{array}{c}\text { Lower Saint } \\
\text { Johns River } \\
\text { Basin } \\
\end{array}$} & Rainfall & $1082.2 \mathrm{~mm}$ & +32.6 & +36.7 & +31.2 & +27.0 \\
\hline & ET & $3.6 \mathrm{~mm} /$ day & +3.8 & +5.4 & +5.9 & +11.2 \\
\hline & Imperviousness & $7.1 \%$ & +13.8 & +14.6 & +24.8 & +31.3 \\
\hline \multirow{3}{*}{$\begin{array}{l}\text { Saint Johns } \\
\text { River Basin }\end{array}$} & Rainfall & $953.3 \mathrm{~mm}$ & +33.5 & +36.7 & +28.4 & +23.5 \\
\hline & ET & $3.6 \mathrm{~mm} /$ day & +3.8 & +5.4 & +5.9 & +11.2 \\
\hline & Imperviousness & $4.6 \%$ & +16.3 & +19.3 & +30.7 & +40.4 \\
\hline
\end{tabular}

Note: Positive sign indicates increases.

Table A3.4: Sensitivity coefficients of runoff to changes in rainfall in the Upper Saint Johns River Basin.

\begin{tabular}{ccccccccccccc}
\hline \multirow{2}{*}{ Month } & \multicolumn{10}{c}{ Change in rainfall (\%) } \\
\cline { 2 - 14 } & -30 & -25 & -20 & -15 & -10 & -5 & 5 & 10 & 15 & 20 & 25 & 30 \\
\hline January & 1.18 & 1.18 & 1.19 & 1.19 & 1.18 & 1.19 & 1.24 & 1.23 & 1.24 & 1.26 & 1.27 & 1.31 \\
February & 1.20 & 1.19 & 1.20 & 1.21 & 1.19 & 1.20 & 1.30 & 1.27 & 1.27 & 1.29 & 1.31 & 1.34 \\
March & 1.16 & 1.16 & 1.16 & 1.17 & 1.16 & 1.17 & 1.22 & 1.20 & 1.20 & 1.21 & 1.22 & 1.24 \\
April & 1.20 & 1.21 & 1.22 & 1.23 & 1.23 & 1.25 & 1.32 & 1.32 & 1.34 & 1.37 & 1.39 & 1.43 \\
May & 1.18 & 1.19 & 1.21 & 1.22 & 1.22 & 1.23 & 1.29 & 1.29 & 1.29 & 1.29 & 1.30 & 1.31 \\
June & 1.15 & 1.15 & 1.16 & 1.16 & 1.16 & 1.17 & 1.21 & 1.21 & 1.21 & 1.23 & 1.24 & 1.26 \\
July & 1.27 & 1.29 & 1.31 & 1.34 & 1.35 & 1.37 & 1.44 & 1.46 & 1.48 & 1.51 & 1.53 & 1.56 \\
August & 1.22 & 1.23 & 1.26 & 1.28 & 1.30 & 1.32 & 1.36 & 1.41 & 1.45 & 1.50 & 1.54 & 1.59 \\
September & 1.22 & 1.23 & 1.25 & 1.26 & 1.26 & 1.27 & 1.31 & 1.31 & 1.33 & 1.35 & 1.38 & 1.41 \\
October & 1.19 & 1.20 & 1.21 & 1.23 & 1.25 & 1.27 & 1.34 & 1.36 & 1.38 & 1.42 & 1.44 & 1.47 \\
November & 1.36 & 1.38 & 1.42 & 1.44 & 1.45 & 1.47 & 1.62 & 1.62 & 1.64 & 1.66 & 1.66 & 1.69 \\
December & 1.19 & 1.18 & 1.19 & 1.19 & 1.17 & 1.17 & 1.28 & 1.28 & 1.31 & 1.38 & 1.42 & 1.45 \\
Annual & 1.21 & 1.22 & 1.23 & 1.24 & 1.25 & 1.27 & 1.32 & 1.33 & 1.35 & 1.38 & 1.40 & 1.43 \\
\hline & & & & & & & & & & & &
\end{tabular}


Table A3.5: Sensitivity coefficients of runoff to changes in rainfall in the Ocklawaha River Basin.

\begin{tabular}{ccccccccccccc}
\hline \multirow{2}{*}{ Month } & \multicolumn{10}{c}{ Change in rainfall (\%) } \\
\cline { 2 - 13 } & -30 & -25 & -20 & -15 & -10 & -5 & 5 & 10 & 15 & 20 & 25 & 30 \\
\hline January & 1.12 & 1.12 & 1.13 & 1.13 & 1.13 & 1.12 & 1.15 & 1.14 & 1.15 & 1.16 & 1.18 & 1.20 \\
February & 1.19 & 1.20 & 1.22 & 1.24 & 1.25 & 1.26 & 1.24 & 1.28 & 1.32 & 1.36 & 1.40 & 1.43 \\
March & 1.11 & 1.12 & 1.12 & 1.13 & 1.13 & 1.13 & 1.18 & 1.18 & 1.21 & 1.22 & 1.26 & 1.28 \\
April & 1.12 & 1.12 & 1.13 & 1.13 & 1.13 & 1.12 & 1.16 & 1.16 & 1.16 & 1.16 & 1.17 & 1.18 \\
May & 1.15 & 1.16 & 1.18 & 1.18 & 1.19 & 1.19 & 1.26 & 1.28 & 1.30 & 1.31 & 1.33 & 1.36 \\
June & 1.21 & 1.24 & 1.29 & 1.33 & 1.39 & 1.43 & 1.54 & 1.57 & 1.62 & 1.64 & 1.67 & 1.72 \\
July & 1.17 & 1.18 & 1.20 & 1.22 & 1.24 & 1.27 & 1.38 & 1.42 & 1.47 & 1.54 & 1.61 & 1.65 \\
August & 1.11 & 1.11 & 1.11 & 1.12 & 1.12 & 1.12 & 1.17 & 1.18 & 1.21 & 1.24 & 1.28 & 1.33 \\
September & 1.39 & 1.44 & 1.48 & 1.50 & 1.50 & 1.48 & 1.56 & 1.59 & 1.64 & 1.67 & 1.74 & 1.81 \\
October & 1.14 & 1.15 & 1.16 & 1.17 & 1.18 & 1.18 & 1.24 & 1.19 & 1.23 & 1.24 & 1.25 & 1.29 \\
November & 1.17 & 1.18 & 1.18 & 1.18 & 1.18 & 1.15 & 1.22 & 1.20 & 1.22 & 1.21 & 1.22 & 1.22 \\
December & 1.13 & 1.13 & 1.14 & 1.13 & 1.13 & 1.12 & 1.18 & 1.18 & 1.19 & 1.22 & 1.26 & 1.30 \\
Annual & 1.18 & 1.20 & 1.21 & 1.23 & 1.25 & 1.25 & 1.32 & 1.34 & 1.37 & 1.40 & 1.43 & 1.47 \\
\hline
\end{tabular}

Table A3.6: Sensitivity coefficients of runoff to changes in rainfall in the Lower Saint Johns River Basin.

\begin{tabular}{cccccccccccccc}
\hline \multirow{2}{*}{ Month } & \multicolumn{10}{c}{ Change in rainfall (\%) } \\
\cline { 2 - 14 } & -30 & -25 & -20 & -15 & -10 & -5 & 5 & 10 & 15 & 20 & 25 & 30 \\
\hline January & 1.54 & 1.57 & 1.64 & 1.61 & 1.68 & 1.66 & 1.66 & 1.70 & 1.85 & 1.83 & 1.87 & 1.94 \\
February & 1.53 & 1.58 & 1.63 & 1.67 & 1.63 & 1.60 & 1.68 & 1.56 & 1.67 & 1.70 & 1.79 & 1.80 \\
March & 1.51 & 1.54 & 1.58 & 1.64 & 1.61 & 1.64 & 1.65 & 1.68 & 1.70 & 1.74 & 1.75 & 1.81 \\
April & 1.46 & 1.53 & 1.56 & 1.47 & 1.51 & 1.48 & 1.33 & 1.48 & 1.70 & 1.58 & 1.69 & 1.83 \\
May & 1.44 & 1.51 & 1.54 & 1.55 & 1.60 & 1.64 & 1.62 & 1.68 & 1.77 & 1.72 & 1.70 & 1.76 \\
June & 1.41 & 1.44 & 1.48 & 1.53 & 1.54 & 1.48 & 1.53 & 1.74 & 1.73 & 1.72 & 1.80 & 1.85 \\
July & 1.38 & 1.42 & 1.46 & 1.52 & 1.55 & 1.63 & 1.64 & 1.76 & 1.74 & 1.73 & 1.74 & 1.86 \\
August & 1.47 & 1.53 & 1.57 & 1.58 & 1.59 & 1.56 & 1.65 & 1.79 & 1.83 & 1.89 & 1.96 & 2.08 \\
September & 1.60 & 1.68 & 1.69 & 1.74 & 1.76 & 1.75 & 1.78 & 1.79 & 1.72 & 1.79 & 1.78 & 1.90 \\
October & 1.57 & 1.60 & 1.66 & 1.79 & 2.02 & 2.07 & 2.00 & 1.88 & 1.94 & 1.94 & 1.92 & 1.99 \\
November & 1.34 & 1.39 & 1.47 & 1.46 & 1.49 & 1.63 & 1.23 & 1.33 & 1.42 & 1.48 & 1.54 & 1.60 \\
December & 1.45 & 1.51 & 1.57 & 1.53 & 1.48 & 1.62 & 1.57 & 1.76 & 1.69 & 1.64 & 1.67 & 1.76 \\
Annual & 1.47 & 1.53 & 1.57 & 1.60 & 1.62 & 1.63 & 1.64 & 1.72 & 1.75 & 1.76 & 1.80 & 1.88 \\
\hline
\end{tabular}


Table A3.7: Sensitivity coefficients of runoff to changes in rainfall in the Saint Johns River Basin.

\begin{tabular}{ccccccccccccc}
\hline \multirow{2}{*}{ Month } & \multicolumn{10}{c}{ Change in rainfall (\%) } \\
\cline { 2 - 14 } & -30 & -25 & -20 & -15 & -10 & -5 & 5 & 10 & 15 & 20 & 25 & 30 \\
\hline January & 1.39 & 1.41 & 1.46 & 1.43 & 1.48 & 1.47 & 1.49 & 1.50 & 1.60 & 1.59 & 1.62 & 1.68 \\
February & 1.39 & 1.42 & 1.45 & 1.48 & 1.46 & 1.44 & 1.50 & 1.44 & 1.51 & 1.54 & 1.61 & 1.63 \\
March & 1.33 & 1.35 & 1.37 & 1.41 & 1.39 & 1.41 & 1.44 & 1.45 & 1.46 & 1.49 & 1.51 & 1.55 \\
April & 1.31 & 1.35 & 1.37 & 1.33 & 1.35 & 1.34 & 1.29 & 1.36 & 1.49 & 1.43 & 1.50 & 1.58 \\
May & 1.31 & 1.35 & 1.37 & 1.38 & 1.41 & 1.44 & 1.46 & 1.49 & 1.54 & 1.52 & 1.51 & 1.55 \\
June & 1.30 & 1.32 & 1.35 & 1.39 & 1.41 & 1.39 & 1.45 & 1.57 & 1.57 & 1.57 & 1.63 & 1.66 \\
July & 1.29 & 1.32 & 1.35 & 1.39 & 1.41 & 1.46 & 1.52 & 1.58 & 1.59 & 1.62 & 1.64 & 1.71 \\
August & 1.32 & 1.36 & 1.38 & 1.40 & 1.41 & 1.40 & 1.47 & 1.56 & 1.59 & 1.64 & 1.70 & 1.78 \\
September & 1.45 & 1.50 & 1.52 & 1.55 & 1.56 & 1.56 & 1.60 & 1.61 & 1.59 & 1.64 & 1.66 & 1.74 \\
October & 1.36 & 1.38 & 1.42 & 1.49 & 1.60 & 1.63 & 1.64 & 1.58 & 1.62 & 1.63 & 1.63 & 1.69 \\
November & 1.31 & 1.35 & 1.40 & 1.40 & 1.41 & 1.50 & 1.33 & 1.38 & 1.44 & 1.48 & 1.51 & 1.55 \\
December & 1.33 & 1.37 & 1.41 & 1.39 & 1.35 & 1.44 & 1.44 & 1.55 & 1.52 & 1.51 & 1.54 & 1.61 \\
Annual & 1.34 & 1.37 & 1.40 & 1.42 & 1.44 & 1.45 & 1.49 & 1.53 & 1.56 & 1.58 & 1.61 & 1.67 \\
\hline
\end{tabular}

Table A3.8: Baseline (2010s) 10-year mean monthly rainfalls for the Saint Johns River Basin and its subwatersheds.

\begin{tabular}{ccccc}
\hline \multirow{2}{*}{ Month } & \multicolumn{4}{c}{ Rainfall (mm) } \\
\cline { 2 - 5 } & $\begin{array}{c}\text { Upper Saint Johns } \\
\text { River Basin }\end{array}$ & $\begin{array}{c}\text { Ocklawaha River } \\
\text { Basin }\end{array}$ & $\begin{array}{c}\text { Lower Saint Johns } \\
\text { River Basin }\end{array}$ & $\begin{array}{c}\text { Saint Johns River } \\
\text { Basin }\end{array}$ \\
\hline January & 32 & 64 & 60 & 48 \\
February & 35 & 78 & 72 & 57 \\
March & 45 & 77 & 58 & 57 \\
April & 37 & 57 & 51 & 46 \\
May & 57 & 77 & 94 & 73 \\
June & 115 & 165 & 171 & 144 \\
July & 106 & 148 & 132 & 125 \\
August & 131 & 152 & 158 & 145 \\
September & 103 & 102 & 118 & 107 \\
October & 79 & 69 & 69 & 73 \\
November & 27 & 32 & 36 & 47 \\
December & 32 & 55 & 63 & 47 \\
\hline
\end{tabular}


Table A3.9: Spatio-temporally averaged number of monthly rainfall events for the Saint Johns River Basin and its subwatersheds in the 10-year baseline period (2010s).

\begin{tabular}{ccccc}
\hline \multirow{2}{*}{ Month } & \multicolumn{4}{c}{ Number of rainfall events } \\
\cline { 2 - 5 } & $\begin{array}{c}\text { Upper Saint Johns } \\
\text { River Basin }\end{array}$ & $\begin{array}{c}\text { Ocklawaha River } \\
\text { Basin }\end{array}$ & $\begin{array}{c}\text { Lower Saint Johns } \\
\text { River Basin }\end{array}$ & $\begin{array}{c}\text { Saint Johns River } \\
\text { Basin }\end{array}$ \\
\hline January & 13 & 11 & 13 & 13 \\
February & 12 & 11 & 15 & 13 \\
March & 12 & 11 & 12 & 12 \\
April & 10 & 9 & 10 & 10 \\
May & 14 & 11 & 13 & 13 \\
June & 26 & 25 & 24 & 25 \\
July & 26 & 24 & 22 & 25 \\
August & 27 & 24 & 26 & 26 \\
September & 24 & 17 & 23 & 16 \\
October & 18 & 13 & 16 & 11 \\
November & 13 & 8 & 11 & 13 \\
December & 14 & 10 & 13 & \\
\hline
\end{tabular}

Table A3.10: Baseline (2010s) 10-year mean monthly potential evapotranspiration (ET) for the Saint Johns River Basin.

\begin{tabular}{c|c}
\hline Month & ET (mm/day) \\
\hline January & 1.4 \\
February & 2.0 \\
March & 3.3 \\
April & 4.6 \\
May & 5.3 \\
June & 5.4 \\
July & 5.4 \\
August & 5.0 \\
September & 4.2 \\
October & 3.0 \\
November & 1.8 \\
December & 1.2 \\
\hline
\end{tabular}


Table A3.11: Baseline (2010s) 10-year mean monthly runoff volumes for the Saint Johns River Basin and its subwatersheds.

\begin{tabular}{ccccc}
\hline \multirow{2}{*}{ Month } & \multicolumn{4}{c}{ Runoff $\left(\right.$ million $\left.\mathrm{m}^{3}\right)$} \\
\cline { 2 - 5 } & $\begin{array}{c}\text { Upper Saint Johns } \\
\text { River Basin }\end{array}$ & $\begin{array}{c}\text { Ocklawaha River } \\
\text { Basin }\end{array}$ & $\begin{array}{c}\text { Lower Saint Johns } \\
\text { River Basin }\end{array}$ & $\begin{array}{c}\text { Saint Johns River } \\
\text { Basin }\end{array}$ \\
\hline January & 9 & 11 & 33 & 53 \\
February & 10 & 14 & 33 & 56 \\
March & 14 & 14 & 31 & 59 \\
April & 11 & 10 & 23 & 45 \\
May & 21 & 15 & 41 & 78 \\
June & 41 & 33 & 85 & 158 \\
July & 38 & 29 & 56 & 123 \\
August & 46 & 29 & 76 & 151 \\
September & 34 & 23 & 61 & 119 \\
October & 24 & 13 & 35 & 26 \\
November & 7 & 5 & 14 & 46 \\
December & 8 & 9 & 29 & \\
\hline
\end{tabular}

Table A3.12: Sensitivity coefficients of runoff to changes in ET in the Upper Saint Johns River Basin.

\begin{tabular}{ccccccccccccc}
\hline \multirow{2}{*}{ Month } & \multicolumn{10}{c}{ Change in ET (\%) } \\
\cline { 2 - 12 } & -30 & -25 & -20 & -15 & -10 & -5 & 5 & 10 & 15 & 20 & 25 & 30 \\
\hline January & -0.02 & -0.02 & -0.02 & -0.02 & -0.02 & -0.02 & -0.02 & -0.02 & -0.02 & -0.02 & -0.02 \\
February & -0.03 & -0.03 & -0.03 & -0.03 & -0.03 & -0.03 & -0.03 & -0.03 & -0.03 & -0.03 & -0.03 & -0.03 \\
March & -0.03 & -0.03 & -0.03 & -0.03 & -0.03 & -0.03 & -0.03 & -0.03 & -0.03 & -0.03 & -0.03 & -0.03 \\
April & -0.05 & -0.04 & -0.04 & -0.04 & -0.05 & -0.04 & -0.04 & -0.04 & -0.04 & -0.04 & -0.04 & -0.03 \\
May & -0.04 & -0.04 & -0.04 & -0.04 & -0.04 & -0.04 & -0.04 & -0.04 & -0.03 & -0.03 & -0.03 & -0.03 \\
June & -0.04 & -0.04 & -0.04 & -0.04 & -0.04 & -0.04 & -0.04 & -0.04 & -0.04 & -0.04 & -0.03 & -0.03 \\
July & -0.04 & -0.04 & -0.04 & -0.03 & -0.03 & -0.03 & -0.03 & -0.03 & -0.03 & -0.03 & -0.03 & -0.03 \\
August & -0.04 & -0.04 & -0.03 & -0.03 & -0.03 & -0.03 & -0.03 & -0.03 & -0.03 & -0.03 & -0.03 & -0.03 \\
September & -0.04 & -0.04 & -0.03 & -0.03 & -0.03 & -0.03 & -0.03 & -0.03 & -0.03 & -0.03 & -0.03 & -0.03 \\
October & -0.03 & -0.03 & -0.03 & -0.03 & -0.03 & -0.03 & -0.03 & -0.03 & -0.03 & -0.03 & -0.03 & -0.03 \\
November & -0.04 & -0.04 & -0.04 & -0.04 & -0.04 & -0.04 & -0.03 & -0.03 & -0.03 & -0.03 & -0.03 & -0.03 \\
December & -0.02 & -0.02 & -0.02 & -0.02 & -0.02 & -0.02 & -0.02 & -0.02 & -0.02 & -0.02 & -0.02 & -0.02 \\
Annual & -0.04 & -0.04 & -0.04 & -0.03 & -0.03 & -0.03 & -0.03 & -0.03 & -0.03 & -0.03 & -0.03 & -0.03 \\
\hline
\end{tabular}


Table A3.13: Sensitivity coefficients of runoff to changes in ET in the Ocklawaha River Basin.

\begin{tabular}{|c|c|c|c|c|c|c|c|c|c|c|c|c|}
\hline \multirow{2}{*}{ Month } & \multicolumn{12}{|c|}{ Change in ET $(\%)$} \\
\hline & -30 & -25 & -20 & -15 & -10 & -5 & 5 & 10 & 15 & 20 & 25 & 30 \\
\hline $\mathrm{Ja}$ & -0.01 & .01 & 0.01 & 0.01 & 0.01 & -0.01 & -0.01 & -0.01 & -0.01 & -0.01 & -0.01 & -0.01 \\
\hline Fel & 01 & 01 & 01 & .01 & .01 & -0.01 & -0.01 & 0.01 & 0.01 & 0.01 & 0.01 & -0.01 \\
\hline Mar & -0.01 & -0.01 & -0.01 & -0.01 & -0.01 & -0.01 & -0.01 & -0.01 & -0.01 & -0.01 & -0.01 & -0.01 \\
\hline & -0.01 & -0.01 & -0.02 & -0.02 & -0.02 & -0.02 & -0.01 & -0.01 & -0.01 & -0.01 & -0.01 & -0.01 \\
\hline & -0.01 & -0.01 & -0.01 & -0.01 & -0.01 & -0.01 & -0.01 & -0.01 & -0.01 & -0.01 & -0.01 & -0.01 \\
\hline $\mathrm{Ju}$ & -0.02 & -0.02 & -0.02 & -0.01 & -0.01 & -0.01 & -0.01 & -0.01 & -0.01 & -0.01 & -0.01 & -0.01 \\
\hline $\mathrm{Ju}$ & -0.02 & -0.02 & -0.02 & -0.02 & -0.02 & -0.02 & -0.01 & -0.01 & -0.01 & -0.01 & -0.01 & -0.01 \\
\hline & -0.02 & -0.02 & -0.01 & -0.02 & -0.01 & -0.01 & -0.01 & -0.01 & -0.01 & -0.01 & -0.01 & -0.01 \\
\hline Sept & -0.01 & -0.01 & -0.01 & -0.01 & -0.01 & -0.01 & -0.02 & -0.01 & -0.01 & -0.01 & -0.01 & -0.01 \\
\hline Octo & -0.01 & -0.01 & -0.01 & -0.01 & -0.01 & -0.01 & -0.01 & -0.01 & -0.01 & -0.01 & -0.01 & -0.01 \\
\hline & -0.01 & -0.01 & -0.01 & -0.01 & -0.01 & -0.01 & -0.01 & -0.01 & -0.01 & -0.01 & -0.01 & -0.01 \\
\hline December & -0.01 & -0.01 & -0.01 & -0.01 & -0.01 & -0.01 & -0.01 & -0.01 & -0.01 & -0.01 & -0.01 & -0.01 \\
\hline Annual & -0.01 & -0.01 & -0.01 & -0.01 & -0.01 & -0.01 & -0.01 & -0.01 & -0.01 & -0.01 & -0.01 & -0.01 \\
\hline
\end{tabular}

Table A3.14: Sensitivity coefficients of runoff to changes in ET in the Lower Saint Johns River Basin.

\begin{tabular}{ccccccccccccc}
\hline \multirow{2}{*}{ Month } & \multicolumn{10}{c}{ Change in ET (\%) } \\
\cline { 2 - 13 } & -30 & -25 & -20 & -15 & -10 & -5 & 5 & 10 & 15 & 20 & 25 & 30 \\
\hline January & -0.37 & -0.33 & -0.30 & -0.28 & -0.25 & -0.39 & -0.20 & -0.35 & -0.28 & -0.23 & -0.22 & -0.25 \\
February & -0.42 & -0.37 & -0.38 & -0.32 & -0.30 & -0.37 & -0.29 & -0.38 & -0.37 & -0.38 & -0.34 & -0.31 \\
March & -0.22 & -0.23 & -0.21 & -0.16 & -0.15 & -0.18 & -0.10 & -0.13 & -0.18 & -0.17 & -0.17 & -0.16 \\
April & -0.35 & -0.27 & -0.26 & -0.27 & -0.18 & -0.12 & -0.30 & -0.30 & -0.31 & -0.28 & -0.31 & -0.36 \\
May & -0.41 & -0.43 & -0.45 & -0.46 & -0.39 & -0.36 & -0.38 & -0.41 & -0.35 & -0.33 & -0.37 & -0.38 \\
June & -0.47 & -0.42 & -0.40 & -0.44 & -0.37 & -0.06 & -0.27 & -0.46 & -0.34 & -0.36 & -0.35 & -0.28 \\
July & -0.47 & -0.43 & -0.39 & -0.46 & -0.42 & -0.31 & -0.43 & -0.40 & -0.34 & -0.35 & -0.32 & -0.31 \\
August & -0.47 & -0.47 & -0.42 & -0.38 & -0.35 & -0.36 & -0.34 & -0.34 & -0.32 & -0.33 & -0.33 & -0.32 \\
September & -0.42 & -0.39 & -0.36 & -0.35 & -0.37 & -0.41 & -0.33 & -0.35 & -0.30 & -0.31 & -0.31 & -0.32 \\
October & -0.41 & -0.46 & -0.44 & -0.46 & -0.53 & -0.58 & -0.59 & -0.58 & -0.49 & -0.42 & -0.37 & -0.34 \\
November & -0.28 & -0.27 & -0.29 & -0.22 & -0.17 & -0.12 & -0.33 & -0.39 & -0.39 & -0.32 & -0.31 & -0.23 \\
December & -0.44 & -0.42 & -0.45 & -0.44 & -0.53 & -0.44 & -0.30 & -0.34 & -0.35 & -0.32 & -0.35 & -0.36 \\
Annual & -0.42 & -0.39 & -0.38 & -0.38 & -0.35 & -0.31 & -0.33 & -0.38 & -0.33 & -0.32 & -0.32 & -0.30 \\
\hline
\end{tabular}


Table A3.15: Sensitivity coefficients of runoff to changes in ET in the Saint Johns River Basin.

\begin{tabular}{ccccccccccccc}
\hline \multirow{2}{*}{ Month } & \multicolumn{10}{c}{ Change in ET (\%) } \\
\cline { 2 - 12 } & -30 & -25 & -20 & -15 & -10 & -5 & 5 & 10 & 15 & 20 & 25 & 30 \\
\hline January & -0.21 & -0.19 & -0.18 & -0.16 & -0.24 & -0.13 & -0.22 & -0.18 & -0.14 & -0.14 & -0.16 \\
February & -0.25 & -0.22 & -0.23 & -0.19 & -0.18 & -0.22 & -0.18 & -0.23 & -0.22 & -0.22 & -0.20 & -0.19 \\
March & -0.13 & -0.13 & -0.12 & -0.09 & -0.09 & -0.10 & -0.06 & -0.08 & -0.10 & -0.10 & -0.10 & -0.09 \\
April & -0.19 & -0.15 & -0.15 & -0.15 & -0.11 & -0.08 & -0.17 & -0.17 & -0.17 & -0.15 & -0.17 & -0.20 \\
May & -0.23 & -0.24 & -0.25 & -0.25 & -0.22 & -0.20 & -0.21 & -0.23 & -0.20 & -0.18 & -0.20 & -0.21 \\
June & -0.26 & -0.24 & -0.23 & -0.25 & -0.21 & -0.05 & -0.15 & -0.26 & -0.19 & -0.20 & -0.20 & -0.16 \\
July & -0.23 & -0.21 & -0.19 & -0.22 & -0.21 & -0.16 & -0.21 & -0.19 & -0.17 & -0.17 & -0.16 & -0.15 \\
August & -0.25 & -0.25 & -0.22 & -0.20 & -0.19 & -0.19 & -0.18 & -0.18 & -0.17 & -0.17 & -0.18 & -0.17 \\
September & -0.23 & -0.21 & -0.20 & -0.19 & -0.20 & -0.22 & -0.18 & -0.19 & -0.16 & -0.17 & -0.17 & -0.17 \\
October & -0.21 & -0.23 & -0.22 & -0.23 & -0.27 & -0.29 & -0.29 & -0.29 & -0.25 & -0.21 & -0.19 & -0.17 \\
November & -0.16 & -0.16 & -0.17 & -0.13 & -0.10 & -0.08 & -0.19 & -0.22 & -0.22 & -0.18 & -0.17 & -0.13 \\
December & -0.27 & -0.26 & -0.28 & -0.28 & -0.33 & -0.28 & -0.19 & -0.21 & -0.22 & -0.20 & -0.22 & -0.22 \\
Annual & -0.23 & -0.22 & -0.21 & -0.21 & -0.20 & -0.17 & -0.18 & -0.21 & -0.18 & -0.18 & -0.18 & -0.17 \\
\hline
\end{tabular}

Table A3.16: Sensitivity coefficients of runoff to changes in imperviousness in the Upper Saint Johns River Basin.

\begin{tabular}{crrrrrrrrrrrr}
\hline \multirow{2}{*}{ Month } & \multicolumn{10}{c}{ Change in imperviousness (\%) } \\
\cline { 2 - 13 } & -30 & -25 & -20 & -15 & -10 & -5 & 5 & 10 & 15 & 20 & 25 & 30 \\
\hline January & 1.04 & 1.04 & 1.04 & 1.04 & 1.02 & 1.02 & 1.05 & 1.04 & 1.04 & 1.04 & 1.03 & 1.03 \\
February & 1.04 & 1.04 & 1.04 & 1.04 & 1.02 & 1.02 & 1.09 & 1.05 & 1.05 & 1.05 & 1.04 & 1.04 \\
March & 1.02 & 1.01 & 1.01 & 1.01 & 1.00 & 1.01 & 1.04 & 1.01 & 1.01 & 1.01 & 1.00 & 1.01 \\
April & 0.99 & 0.98 & 0.98 & 0.97 & 0.97 & 0.97 & 1.01 & 0.99 & 0.98 & 0.98 & 0.98 & 0.98 \\
May & 0.98 & 0.98 & 0.98 & 0.97 & 0.96 & 0.96 & 0.99 & 0.97 & 0.97 & 0.97 & 0.96 & 0.96 \\
June & 0.99 & 0.98 & 0.98 & 0.98 & 0.97 & 0.97 & 0.99 & 0.98 & 0.98 & 0.98 & 0.97 & 0.97 \\
July & 0.93 & 0.92 & 0.92 & 0.92 & 0.91 & 0.91 & 0.93 & 0.92 & 0.91 & 0.91 & 0.91 & 0.91 \\
August & 0.94 & 0.94 & 0.94 & 0.94 & 0.93 & 0.93 & 0.95 & 0.93 & 0.93 & 0.93 & 0.93 & 0.92 \\
September & 0.96 & 0.96 & 0.96 & 0.96 & 0.95 & 0.95 & 0.96 & 0.95 & 0.95 & 0.95 & 0.95 & 0.95 \\
October & 0.98 & 0.98 & 0.98 & 0.98 & 0.97 & 0.97 & 0.99 & 0.98 & 0.98 & 0.98 & 0.97 & 0.97 \\
November & 0.95 & 0.95 & 0.95 & 0.95 & 0.92 & 0.92 & 0.99 & 0.96 & 0.95 & 0.95 & 0.95 & 0.95 \\
December & 1.05 & 1.05 & 1.05 & 1.05 & 1.02 & 1.02 & 1.09 & 1.06 & 1.06 & 1.06 & 1.06 & 1.06 \\
Annual & 0.97 & 0.97 & 0.97 & 0.97 & 0.96 & 0.96 & 0.98 & 0.97 & 0.96 & 0.96 & 0.96 & 0.96 \\
\hline
\end{tabular}


Table A3.17: Sensitivity coefficients of runoff to changes in imperviousness in the Ocklawaha River Basin.

\begin{tabular}{|c|c|c|c|c|c|c|c|c|c|c|c|c|}
\hline \multirow{2}{*}{ Month } & \multicolumn{12}{|c|}{ Change in imperviousness (\%) } \\
\hline & -30 & -25 & -20 & -15 & -10 & $\begin{array}{l}-5 \\
\end{array}$ & 5 & 10 & 15 & 20 & 25 & 30 \\
\hline January & 1.06 & 1.06 & 1.06 & 1.07 & 1.07 & 1.06 & 1.08 & 1.07 & 1.07 & 1.07 & 1.07 & 1.07 \\
\hline February & 1.02 & 1.02 & 1.03 & 1.02 & 1.03 & 1.02 & 1.05 & 1.04 & 1.04 & 1.04 & 1.04 & 1.03 \\
\hline March & 1.04 & 1.05 & 1.05 & 1.04 & 1.04 & 1.03 & 1.07 & 1.05 & 1.06 & 1.05 & 1.05 & 1.05 \\
\hline April & 1.03 & 1.04 & 1.03 & 1.03 & 1.03 & 1.02 & 1.07 & 1.05 & 1.05 & 1.05 & 1.05 & 1.05 \\
\hline May & 1.02 & 1.02 & 1.02 & 1.02 & 1.02 & 1.01 & 1.03 & 1.02 & 1.02 & 1.02 & 1.02 & 1.02 \\
\hline June & 0.98 & 0.98 & 0.98 & 0.98 & 0.98 & 0.97 & 0.99 & 0.98 & 0.99 & 0.98 & 0.98 & 0.98 \\
\hline July & 1.00 & 1.00 & 1.00 & 0.99 & 1.00 & 0.99 & 1.01 & 1.00 & 1.00 & 0.99 & 0.99 & 0.99 \\
\hline August & 1.03 & 1.03 & 1.03 & 1.02 & 1.03 & 1.02 & 1.03 & 1.03 & 1.03 & 1.02 & 1.02 & 1.02 \\
\hline September & 0.89 & 0.90 & 0.89 & 0.89 & 0.89 & 0.89 & 0.91 & 0.90 & 0.90 & 0.89 & 0.89 & 0.89 \\
\hline October & 1.03 & 1.03 & 1.03 & 1.03 & 1.03 & 1.02 & 1.06 & 1.04 & 1.04 & 1.04 & 1.04 & 1.03 \\
\hline November & 1.05 & 1.06 & 1.06 & 1.06 & 1.06 & 1.03 & 1.09 & 1.08 & 1.09 & 1.08 & 1.08 & 1.08 \\
\hline December & 1.06 & 1.07 & 1.07 & 1.07 & 1.06 & 1.04 & 1.10 & 1.08 & 1.09 & 1.09 & 1.09 & 1.08 \\
\hline Annual & 1.00 & 1.01 & 1.01 & 1.00 & 1.00 & 1.00 & 1.02 & 1.01 & 1.01 & 1.01 & 1.01 & 1.01 \\
\hline
\end{tabular}

Table A3.18: Sensitivity coefficients of runoff to changes in imperviousness in the Lower Saint Johns River Basin.

\begin{tabular}{ccccccccccccc}
\hline \multirow{2}{*}{ Month } & \multicolumn{10}{c}{ Change in imperviousness (\%) } \\
\cline { 2 - 14 } & -30 & -25 & -20 & -15 & -10 & -5 & 5 & 10 & 15 & 20 & 25 & 30 \\
\hline January & 0.63 & 0.63 & 0.62 & 0.63 & 0.64 & 0.62 & 0.66 & 0.65 & 0.61 & 0.59 & 0.61 & 0.62 \\
February & 0.76 & 0.76 & 0.76 & 0.77 & 0.77 & 0.75 & 0.73 & 0.75 & 0.74 & 0.70 & 0.73 & 0.73 \\
March & 0.59 & 0.57 & 0.56 & 0.61 & 0.56 & 0.57 & 0.55 & 0.56 & 0.58 & 0.56 & 0.57 & 0.57 \\
April & 0.78 & 0.76 & 0.77 & 0.77 & 0.75 & 0.76 & 0.73 & 0.75 & 0.72 & 0.74 & 0.73 & 0.73 \\
May & 0.79 & 0.77 & 0.80 & 0.82 & 0.91 & 0.76 & 0.81 & 0.81 & 0.84 & 0.82 & 0.82 & 0.82 \\
June & 0.80 & 0.79 & 0.77 & 0.80 & 0.79 & 1.09 & 0.59 & 0.76 & 0.70 & 0.79 & 0.80 & 0.76 \\
July & 0.85 & 0.85 & 0.85 & 0.87 & 0.86 & 0.83 & 0.77 & 0.81 & 0.80 & 0.82 & 0.83 & 0.83 \\
August & 0.75 & 0.75 & 0.75 & 0.76 & 0.75 & 0.77 & 0.64 & 0.72 & 0.72 & 0.71 & 0.72 & 0.72 \\
September & 0.72 & 0.68 & 0.69 & 0.67 & 0.70 & 0.68 & 0.63 & 0.68 & 0.58 & 0.66 & 0.67 & 0.67 \\
October & 0.79 & 0.76 & 0.78 & 0.82 & 0.77 & 0.73 & 0.78 & 0.77 & 0.75 & 0.72 & 0.73 & 0.74 \\
November & 0.92 & 0.93 & 0.92 & 0.93 & 0.92 & 0.88 & 0.89 & 0.88 & 0.87 & 0.85 & 0.87 & 0.89 \\
December & 0.76 & 0.77 & 0.77 & 0.85 & 0.75 & 0.77 & 0.72 & 0.80 & 0.71 & 0.69 & 0.71 & 0.71 \\
Annual & 0.76 & 0.75 & 0.75 & 0.77 & 0.76 & 0.79 & 0.68 & 0.74 & 0.71 & 0.73 & 0.74 & 0.73 \\
\hline
\end{tabular}


Table A3.19: Sensitivity coefficients of runoff to changes in imperviousness in the Saint Johns River Basin.

\begin{tabular}{ccccccccccccc}
\hline \multirow{2}{*}{ Month } & \multicolumn{10}{c}{ Change in imperviousness (\%) } \\
\cline { 2 - 13 } & -30 & -25 & -20 & -15 & -10 & -5 & 5 & 10 & 15 & 20 & 25 & 30 \\
\hline January & 0.79 & 0.79 & 0.78 & 0.79 & 0.79 & 0.78 & 0.81 & 0.80 & 0.78 & 0.77 & 0.78 & 0.78 \\
February & 0.88 & 0.87 & 0.87 & 0.88 & 0.88 & 0.86 & 0.87 & 0.88 & 0.87 & 0.85 & 0.86 & 0.86 \\
March & 0.80 & 0.79 & 0.78 & 0.80 & 0.78 & 0.79 & 0.79 & 0.78 & 0.79 & 0.78 & 0.79 & 0.79 \\
April & 0.89 & 0.88 & 0.89 & 0.88 & 0.87 & 0.88 & 0.88 & 0.88 & 0.87 & 0.87 & 0.87 & 0.87 \\
May & 0.89 & 0.88 & 0.89 & 0.90 & 0.95 & 0.87 & 0.90 & 0.90 & 0.91 & 0.90 & 0.90 & 0.90 \\
June & 0.89 & 0.88 & 0.87 & 0.89 & 0.88 & 1.03 & 0.78 & 0.87 & 0.83 & 0.88 & 0.88 & 0.86 \\
July & 0.91 & 0.91 & 0.91 & 0.92 & 0.91 & 0.89 & 0.88 & 0.89 & 0.88 & 0.89 & 0.89 & 0.89 \\
August & 0.87 & 0.86 & 0.86 & 0.86 & 0.86 & 0.86 & 0.81 & 0.85 & 0.85 & 0.84 & 0.84 & 0.84 \\
September & 0.83 & 0.80 & 0.81 & 0.80 & 0.81 & 0.80 & 0.78 & 0.80 & 0.75 & 0.79 & 0.79 & 0.79 \\
October & 0.90 & 0.89 & 0.89 & 0.91 & 0.89 & 0.86 & 0.90 & 0.89 & 0.88 & 0.87 & 0.87 & 0.88 \\
November & 0.96 & 0.96 & 0.96 & 0.96 & 0.95 & 0.92 & 0.96 & 0.94 & 0.94 & 0.92 & 0.93 & 0.94 \\
December & 0.88 & 0.88 & 0.88 & 0.93 & 0.87 & 0.87 & 0.87 & 0.91 & 0.85 & 0.84 & 0.85 & 0.85 \\
Annual & 0.87 & 0.86 & 0.86 & 0.87 & 0.87 & 0.88 & 0.84 & 0.86 & 0.84 & 0.85 & 0.85 & 0.85 \\
\hline
\end{tabular}




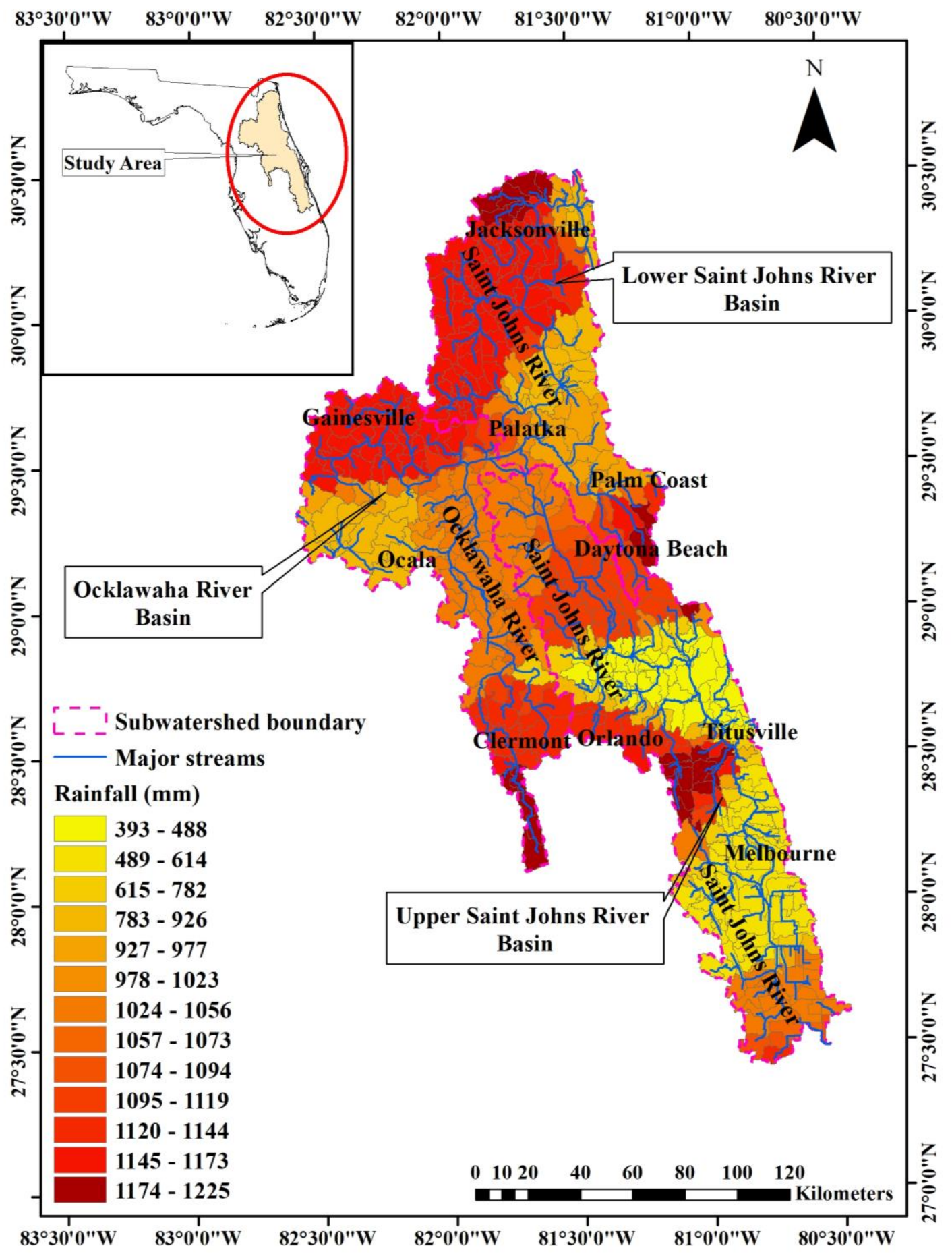

Figure A3.1: Spatial variation of observed 10-year mean annual rainfall in the Saint Johns River Basin for 2004-2013 (2010s). The inset showing location of the study area in the state of Florida is not drawn to the map-scale. 


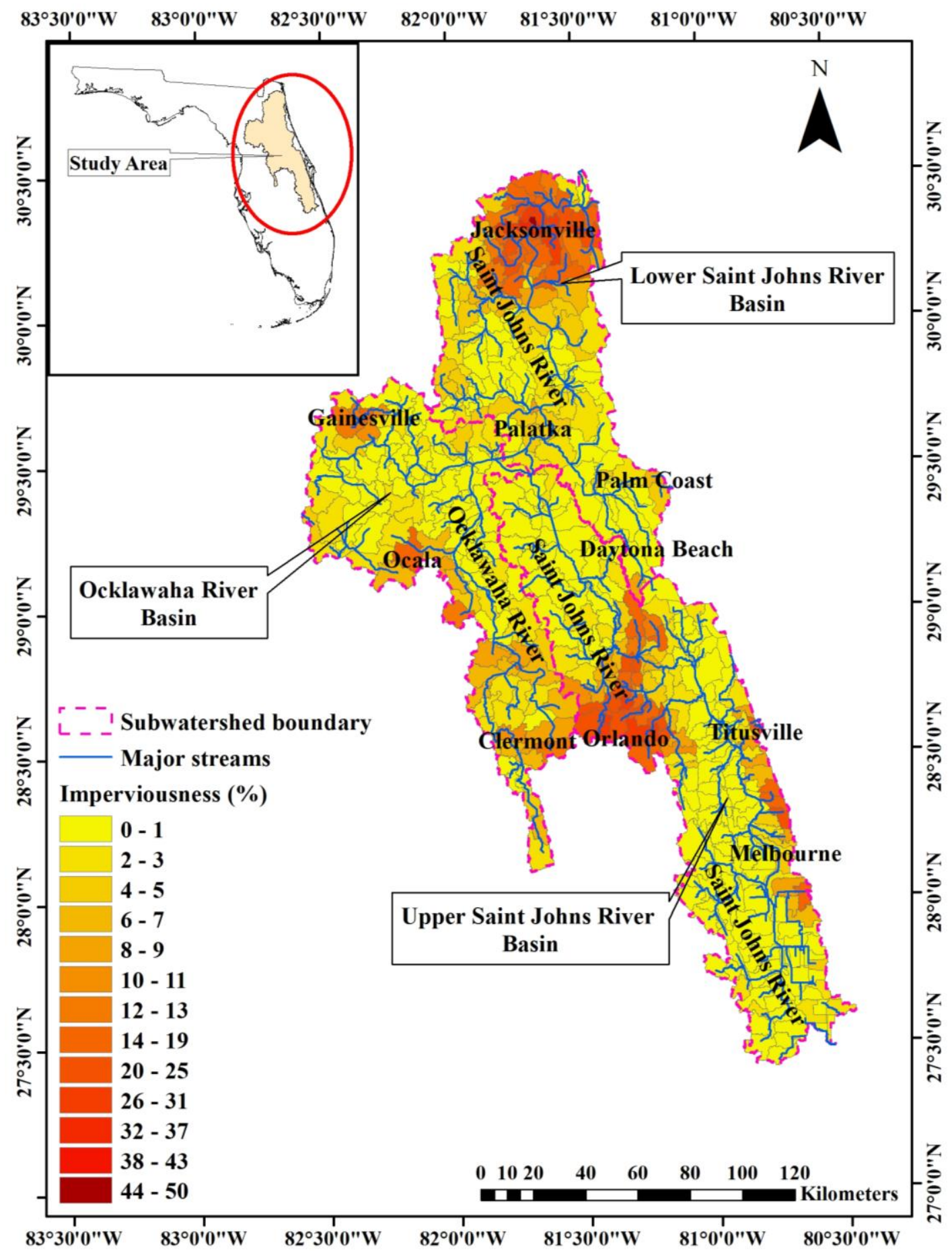

Figure A3.2: Spatial variation of imperviousness in the Saint Johns River Basin for 2004-2013 (2010s). The inset showing location of the study area in the state of Florida is not drawn to the map-scale. 


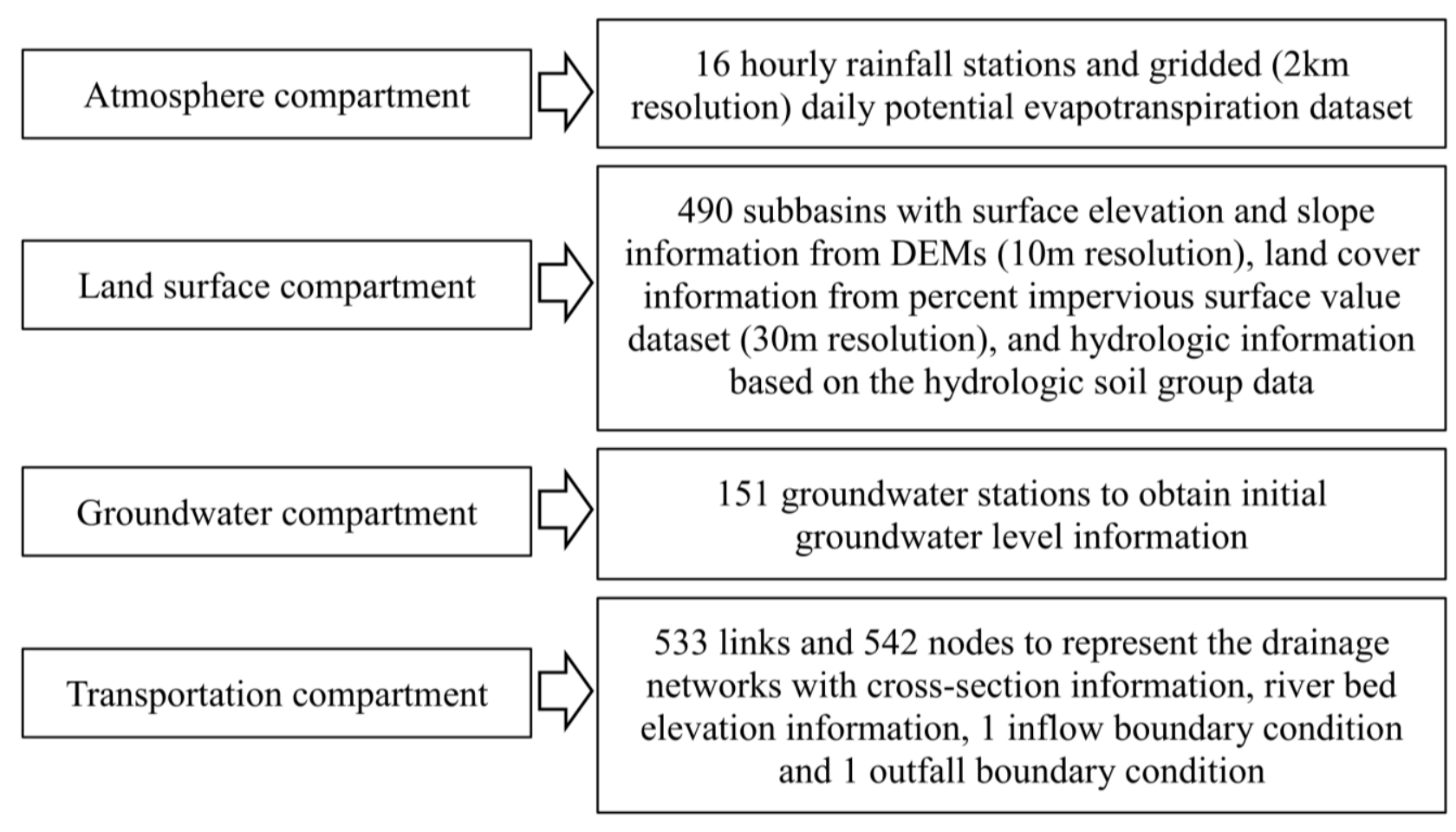

Figure A3.3: Summary of SWMM developments for the Saint Johns River Basin. 


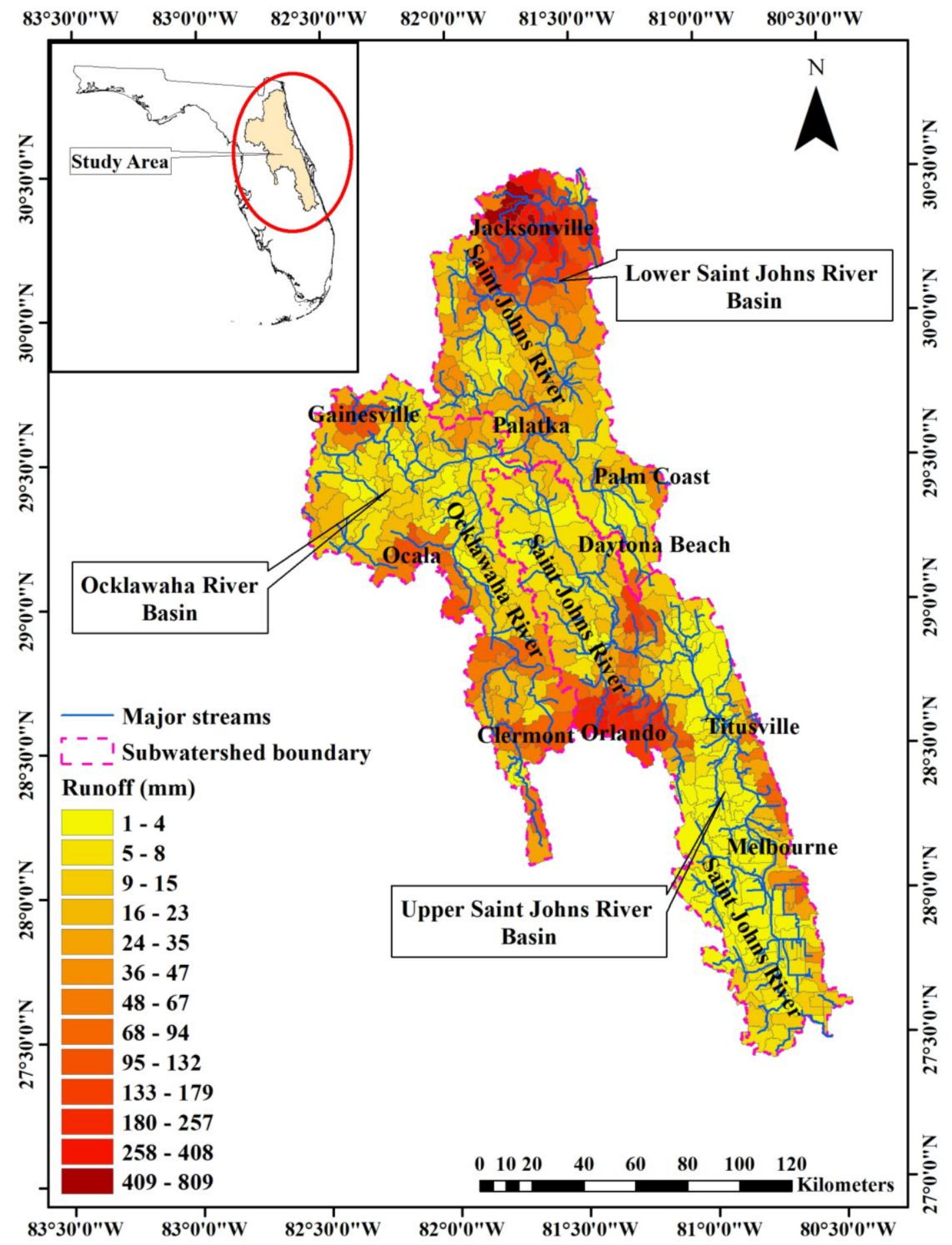

Figure A3.4: Spatial variation of model simulated subbasin-scale 10-year mean annual runoff in the Saint Johns River Basin for 2004-2013 (2010s). The inset showing location of the study area in the state of Florida is not drawn to the map-scale. 
(a) Rainfall
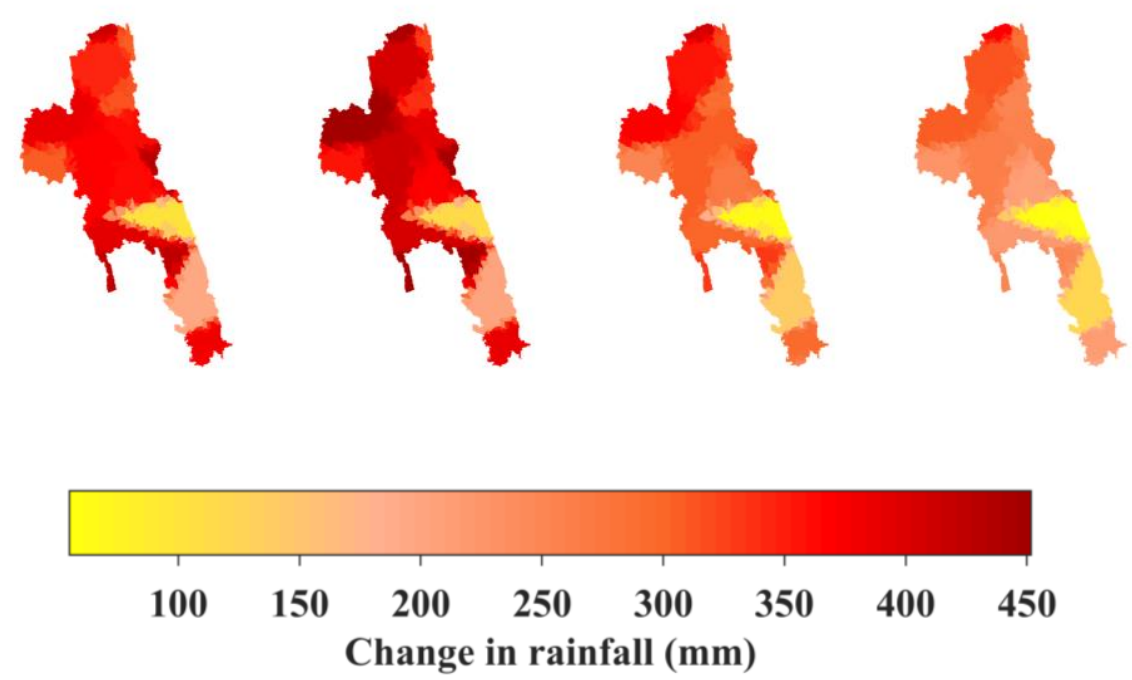

(b) Imperviousness
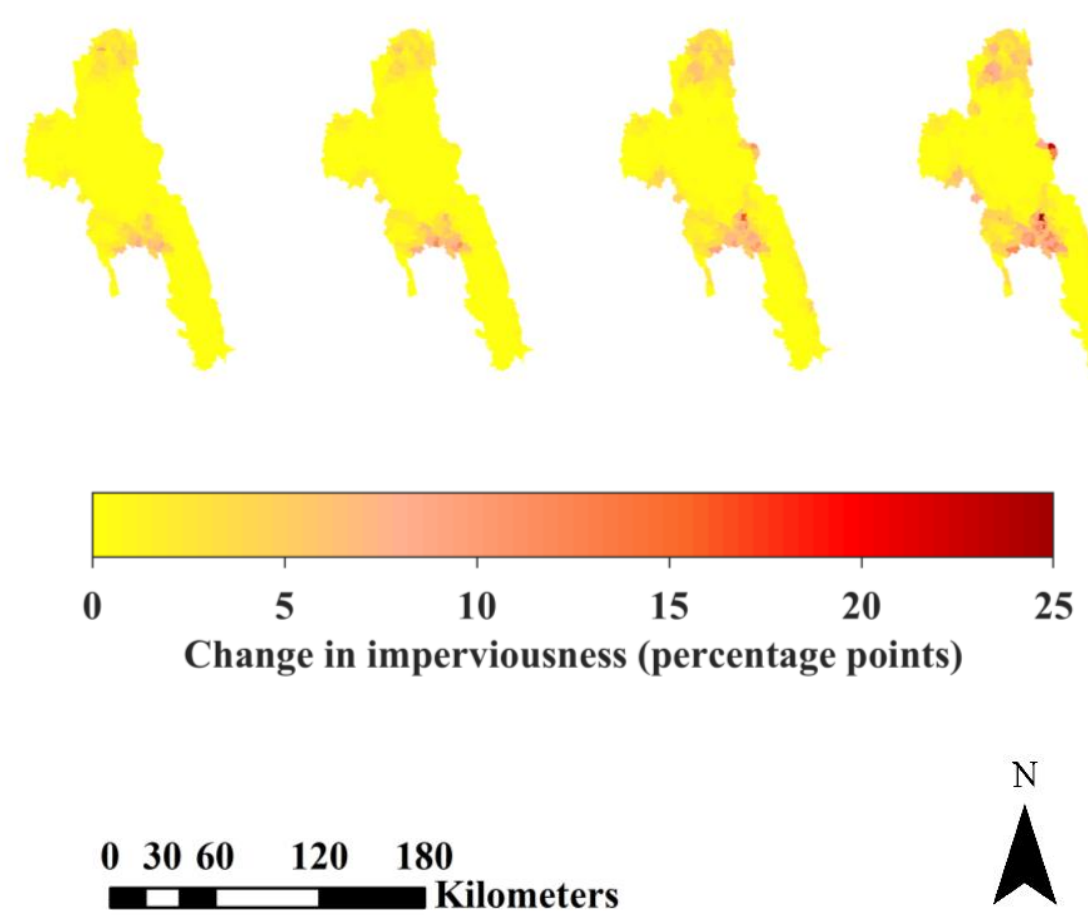

Figure A3.5: Spatial variation of (a) changes in 10-year mean annual rainfall depth based on ensemble mean rainfall projections of the 20 general circulation models (GCMs), and (b) percentage points change in 10-year mean imperviousness under different future scenarios in the Saint Johns River Basin. 
(a)

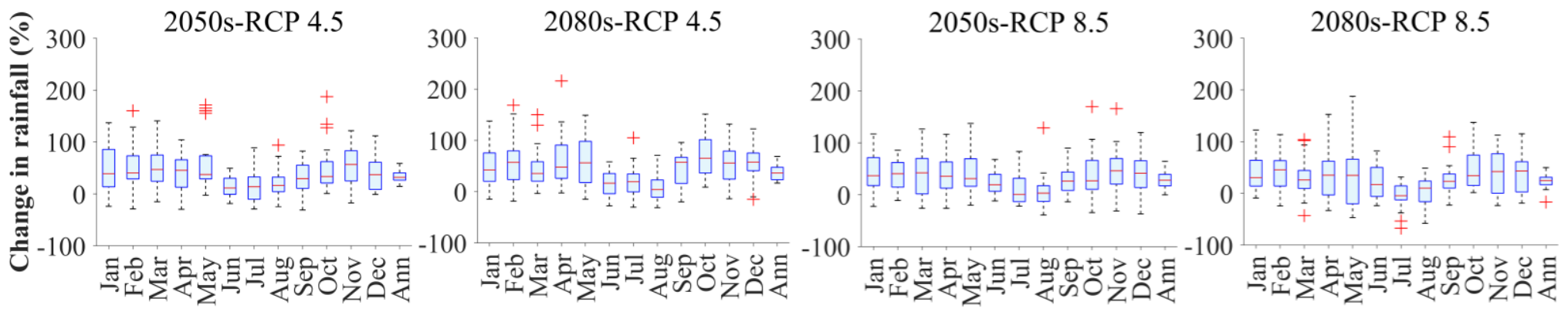

(b)

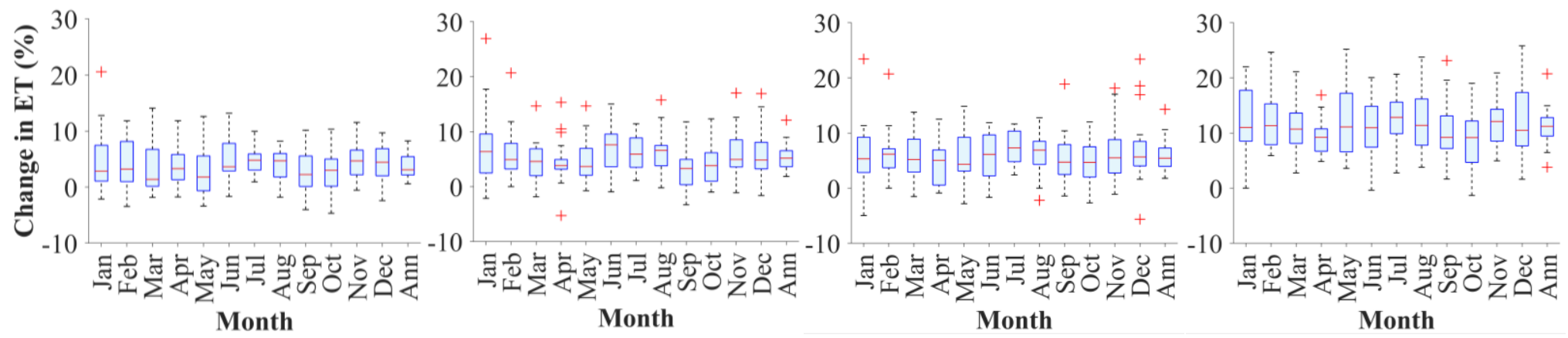

Figure A3.6: Percentage changes in 10-year mean monthly and annual (a) rainfall and (b) evapotranspiration (ET) across the general circulation models (GCMs) for different future scenarios in the Saint Johns River Basin. The lower, intermediate, and upper horizontal lines in the boxes indicate $25^{\text {th }}, 50^{\text {th }}$, and $75^{\text {th }}$ percentiles, respectively; plus signs indicate extreme outliers. Jan: January; Feb: February; Mar: March; Apr: April; Jun: June; Jul: July; Aug: August; Sep: September; Oct: October; Nov: November; Dec: December; Ann: Annual. 


\title{
Chapter 4: Potential changes in extreme runoffs under changing climate, land cover, and sea level in coastal-urban environments
}

\begin{abstract}
Individual and combined impacts of changing climate, land cover, and sea level on extreme runoffs were evaluated, considering the Southeast Coasts Basin of Florida a prototype of thriving coastal-urban environments across the globe. A large-scale $\left(7117 \mathrm{~km}^{2}\right)$ mechanistic hydrologic model was developed for the basin using U.S. Environmental Protection Agency (U.S. EPA)'s Storm Water Management Model (SWMM) 5.1. The model was calibrated and validated (NashSutcliffe Efficiency $=0.74$ to 0.92 ) with observed daily streamflow records for 2004-2013. Significance and direction of trends in annual maximum rainfall and sea level regimes of 1-7 day durations were then assessed for the historical 2000s (1964-2013). Statistically insignificant ( $p$ value $\leq 0.05$ ) decreasing trends, overall, for rainfall and significant increasing trends for sea level were detected. The 1-7 day stationary design rainfalls and non-stationary design sea levels of varying return periods $(2,5,10,25,50$, and 100 year) were then estimated for 2010. Design rainfalls and sea levels for 2010 ranged from 92 to $489 \mathrm{~mm}$ and -0.014 to $0.271 \mathrm{~m}$ NAVD 88, respectively. Design rainfalls and sea levels in 2050 and 2080 were computed based on the climatic and sea level rise (SLR) projections under the Representative Concentration Pathways (RCP) 4.5 and 8.5 scenarios. The estimated historical and future design rainfalls and sea levels together with the land cover information were used as inputs to the calibrated SWMM model to estimate extreme runoffs in 2010, 2050, and 2080. Higher (than other locations) future extreme runoff increases were expected at and near major urban centers in the basin, relative to 2010 . Potential shifts in basin-wide runoff volume indicated stronger control of climate on extreme runoff regimes in the Southeast Coasts Basin. Subject to simultaneously changing climate, land
\end{abstract}


cover, and sea level, basin-wide extreme runoff volume would increase by 63 to $145 \%, 46$ to $125 \%, 48$ to $122 \%$, and 52 to $121 \%$, respectively, under the 2080-RCP 8.5, 2050-RCP 4.5, 2050-

RCP 8.5, and 2080-RCP 4.5 scenarios. The higher relative runoff increases demonstrated 2080RCP 8.5 as the most critical future scenario in the Southeast Coasts Basin in terms of elevated extreme runoff and pluvial flooding risks. The study offers valuable insights for stormwater management, ecosystem protection, and resilience enhancement for southeast Florida and other coastal-urban environments around the world.

\subsection{Introduction}

Increased greenhouse gas emissions from human activities such as land cover change, fossil fuel burning, waste management, etc. (Tian et al., 2016) lead to global warming which is generally associated with higher intensity and frequency of extreme rainfalls (Molnar et al., 2015; Myhre et al., 2019). Potential increases in flooding risks are expected due to the heavier and more frequent rainfalls. Assuming current level of adaptation to climatic changes, most part of the world would be under both near term (2030-2040) and long term (2080-2100) medium to high flooding risks due to extreme rainfall (IPCC, 2014a). Global urban centers, apparently, would be subject to higher flooding risks because of the increasing impervious surfaces and loss of natural drainage systems. Coastal metropolitan areas are even more vulnerable to flooding from groundwater inundation (GWI) on account of sea level rise (SLR). SLR would reduce subsurface storage of stormwater by raising groundwater table (GWT), which would, in turn, increase coastal flooding potential under extreme rainfall events (Sukop et al., 2018). Given that 55\% of the world's population currently reside in urban areas and this percentage is projected to rise to $68 \%$ by 2050 (Nations, 2018), it is essential to evaluate potential extreme rainfall induced flooding risks in urban areas under changing climate, land cover, and sea level. 
Much research has examined the association of changing climate and land cover with runoff extremes and flooding for different regions across the globe (e.g., Guimares Nobre et al., 2017; Yin et al., 2018; Zhang et al., 2018). Mechanistic (i.e., process-based) rainfall-runoff models have been extensively applied in this regard to simulate the rapid increases in stormwater runoff and flooding potential under extreme rainfall events. Further, this type of models have been implemented to evaluate changes in extreme runoff and flooding risks based on future climatic and land cover projections, and also, by sensitivity analyses. Ali et al. (2019) used the Noah-MP land surface hydrological model (Niu et al., 2011) to evaluate changes in potential flooding risks in future across the Indian subcontinent. The authors outlined more rapid anticipated increases in multi-day flooding events in future than that in daily flooding events under increasing extreme rainfall events; they also found higher potential flooding increases for 2060-2099 than that during 2020-2059. Gori et al. (2019) used the Vflo hydrologic model (Vieux, 2016), together with HEC-RAS hydraulic model (Brunner and CEIWR-HEC, 2016), to report considerable expansions in 100-year floodplain across the Cypress Creek watershed at Houston, Texas, USA due to potential land developments in 2050. Jothityangkoon et al. (2013) used a rainfall-runoff modeling framework proposed by Jothityangkoon and Sivapalan (2003) to investigate the impacts of climate and land use change on probable maximum flood (PMF) at the Upper Ping River catchment in northern Thailand. They found notable increases in PMF under a $5 \%$ increase in probable maximum precipitation (PMP) depth and a 30\% deforestation.

The issue of flooding risks due to SLR driven GWI is still an emergent topic in existing literature. Rotzoll and Fletcher (2013) adopted a 1-dimensional steady state analytical solution approach to find that a $1 \mathrm{~m}$ SLR would inundate significant area of a heavily urbanized coastal zone in Honolulu, Hawaii, USA. Hoover et al. (2017) added $1 \mathrm{~m}$ and $2 \mathrm{~m}$ SLR projections to 
groundwater levels (GWL) across different parts of coastal California, USA and concluded that the northern California coastal plains would be more vulnerable to potential GWI flooding. Habel et al. (2017) applied a 3-dimensional numerical method to simulate GWI driven by SLR for the Waikiki area of Honolulu, Hawaii, USA. They reported potential GWI for a substantial part within the study area due to an approximately $1 \mathrm{~m}$ SLR.

The existing literature does not provide sufficient insight into the potential hydrologic impacts of changing climatic extremes, land cover, and sea level for rapid-growing coastal-urban environments. Detailed assessments of the potential detrimental outcomes of these changes would be a prime requisite to minimize vulnerabilities of the local community and economy. Southeast Florida of USA is an epitome of booming coastal built environments with many top growing urban centers in the country. This area represents very complex hydrologic settings due to regular human interventions and developments since the $20^{\text {th }}$ century (Hughes and White, 2016). Heavy rainfall during recurring hurricanes and tropical storms together with SLR put the highly urbanized southeast Florida under massive pluvial, i.e., rainfall-driven flooding (Falconer et al., 2009; Carter et al., 2015; Rosenzweig et al., 2018) risks. In a recent study on southeast Florida, Sukop et al. (2018) denoted GWT rise from heavy rainfall events as a key contributor to flooding in Arch Creek basin of the northern Miami-Dade County under existing conditions. Their findings also suggested frequent GWL related flooding by 2060 for the relatively lowlying areas of the study basin under a projected SLR of $0.61 \mathrm{~m}$ and increased rainfall. Further comprehensive research exploring interrelations of runoff extreme with its prime drivers across the entire southeast Florida would be vital.

The objective of this study is to investigate the individual as well as combined impacts of changes in extreme rainfall, land cover, and sea level on runoff extremes in thriving coastal- 
urban environments. Selecting the Southeast Coasts Basin of Florida as the study area, a largescale mechanistic rainfall-runoff model, using U.S. Environmental Protection Agency (U.S. EPA) Storm Water Management Model (SWMM) 5.1 (Rossman, 2015), is developed. The model is calibrated and validated with historical streamflows at 6 major streams across the basin. Historical runoff extremes are then computed using design rainfalls and sea levels estimated for 1-7 day durations with varying return periods $(2,5,10,25,50$, and 100-year). Finally, future runoff extremes are computed based on climatic, land cover, and sea level projections in order to identify basin areas with intensified pluvial flooding and environmental pollution risks.

\subsection{Materials and methods}

\subsubsection{Study area}

The Florida Southeast Coasts Basin, which has an area of approximately $7117 \mathrm{~km}^{2}$ (Figure 4.1), primarily represents built-up land uses/cover, i.e., residential, commercial, and industrial areas. Western (especially northwestern) and southern parts of the basin are, however, characterized by croplands, pasture lands, and wetlands. Cities like Miami, Doral, Hialeah, Hollywood, Fort Lauderdale, Boca Raton, and West Palm Beach are the major highly urbanized population centers in the Southeast Coasts Basin. The basin also contains growing cities such as Homestead, Sunrise, Jupiter, Port St. Lucie, and Fort Pierce. 


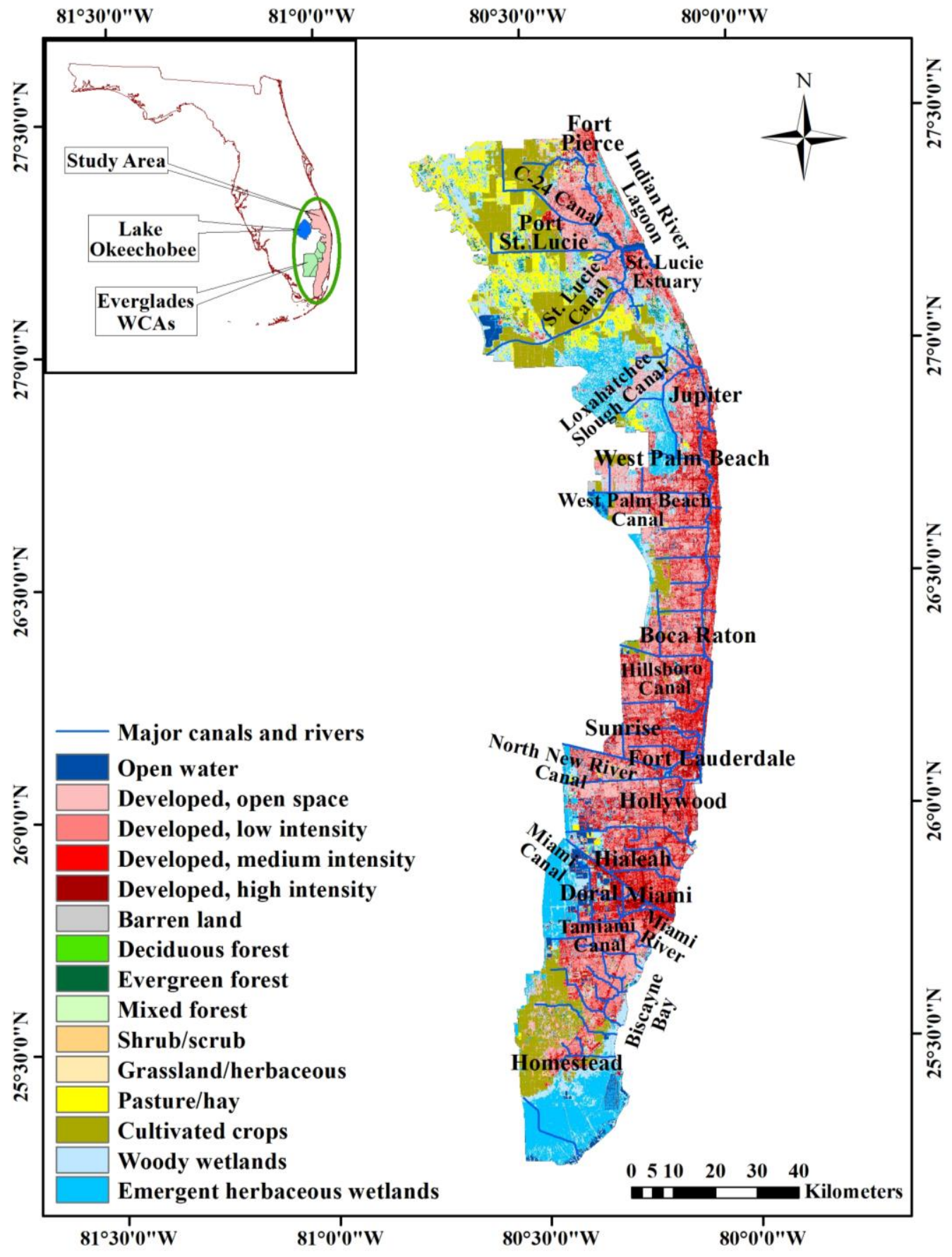

Figure 4.1: Major canals, rivers, and land cover types in the Southeast Coasts Basin. The inset showing the location of the study area, Lake Okeechobee, and the Everglades WaterConservation Areas (WCAs) in the state of Florida is not drawn to the map-scale. 
Most of the streams that drain the Southeast Coasts Basin originate from Lake Okeechobee (the largest freshwater lake in Florida), and pass through the Everglades Water Conservation Areas (WCAs) before entering the basin. Tamiami Canal (also known as the C4 canal), Miami River (C6 canal), North New River Canal, Hillsboro Canal, West Palm Beach Canal, and St. Lucie River are some of the major streams across the basin. In order to mitigate flooding and prevent salinity intrusion, these rivers and canals are managed by control structures. The streams in the Southeast Coasts Basin generally flow into the estuarine water bodies (e.g., St. Lucie Estuary, Indian River Lagoon, and Biscayne Bay) before they reach the Atlantic Ocean.

The basin is characterized by different climate zones (ORNL DAAC, 2017) as per the Köppen-Geiger climate classification (Kottek et al., 2006; Rubel et al., 2017). Humid subtropical climate with highly varying rainfall over the year is observed in places such as Port St. Lucie in the northeastern part of the basin. Other northeastern basin locations (e.g., Jupiter) undergo tropical rainforest climate receiving approximately uniformly distributed rainfall throughout the year. Meanwhile, tropical climate characterized by a relatively long monsoon season and a short dry season is generally found over the middle Southeast Coasts Basin (from West Palm Beach to Miami). The lower southern part of the basin (e.g., Homestead) is subject to tropical savannah climate experiencing longer dry seasons than that in tropical monsoon climate.

\subsubsection{Data sets for model development}

The extent of the Southeast Coasts Basin was defined using the hydrological unit code (HUC8; ID: 03090206), of the U.S. Geological Survey (USGS) (USGS, 2016a); isolated areas and barrier islands (e.g., Miami Beach, Key Biscayne) were not considered in this regard. Topographical variations across the basin were represented using digital elevation model (DEM) of 1/3 arcsecond (approximately 10m) resolution given by the National Elevation Dataset (NED) (USGS, 
2016b). Percent imperviousness dataset of 30m resolution found from the National Land Cover Database (NLCD) (Fry et al., 2011; Homer et al., 2015) were used to account for different types of land cover. Hydrologic soil groups in the soil survey geographic database (SSURGO; USDANRCS, 2015) together with guidelines of the National Engineering Handbook (USDA-NRCS, 2009) and Rawls et al. (1983) were used to define soil types over the basin.

Observed streamflow records during 2004-13 for different streams across the basin were collected from the national water information system (USGS, 2017) and the environmental database of South Florida Water Management District (SFWMD) named DBHYDRO (SFWMD, 2017). Historical streamflow at 14 locations were used to constitute upstream boundary conditions in the Southeast Coasts Basin model (Figure 4.2; Table A4.1 in Appendix 4). Hourly water levels at the National Oceanic and Atmospheric Administration (NOAA)'s tidal station 8723214 in Virginia Key, Biscayne Bay were incorporated as the downstream boundary conditions for the Miami River. Hourly downstream boundary conditions were not available at outlet of the other major streams. The 6 streamflow stations where the model was to be calibrated and validated represented control structures; features (e.g., number of gates, gate width and height, crest elevation, etc.) and real time gate opening timeseries of these control structures were collected from DBHYDRO. Stream cross section and bed elevation information for the rivers can canals were collected from SFWMD datasets and technical report (see Section 2.2.2 in Chapter 2 for details). 


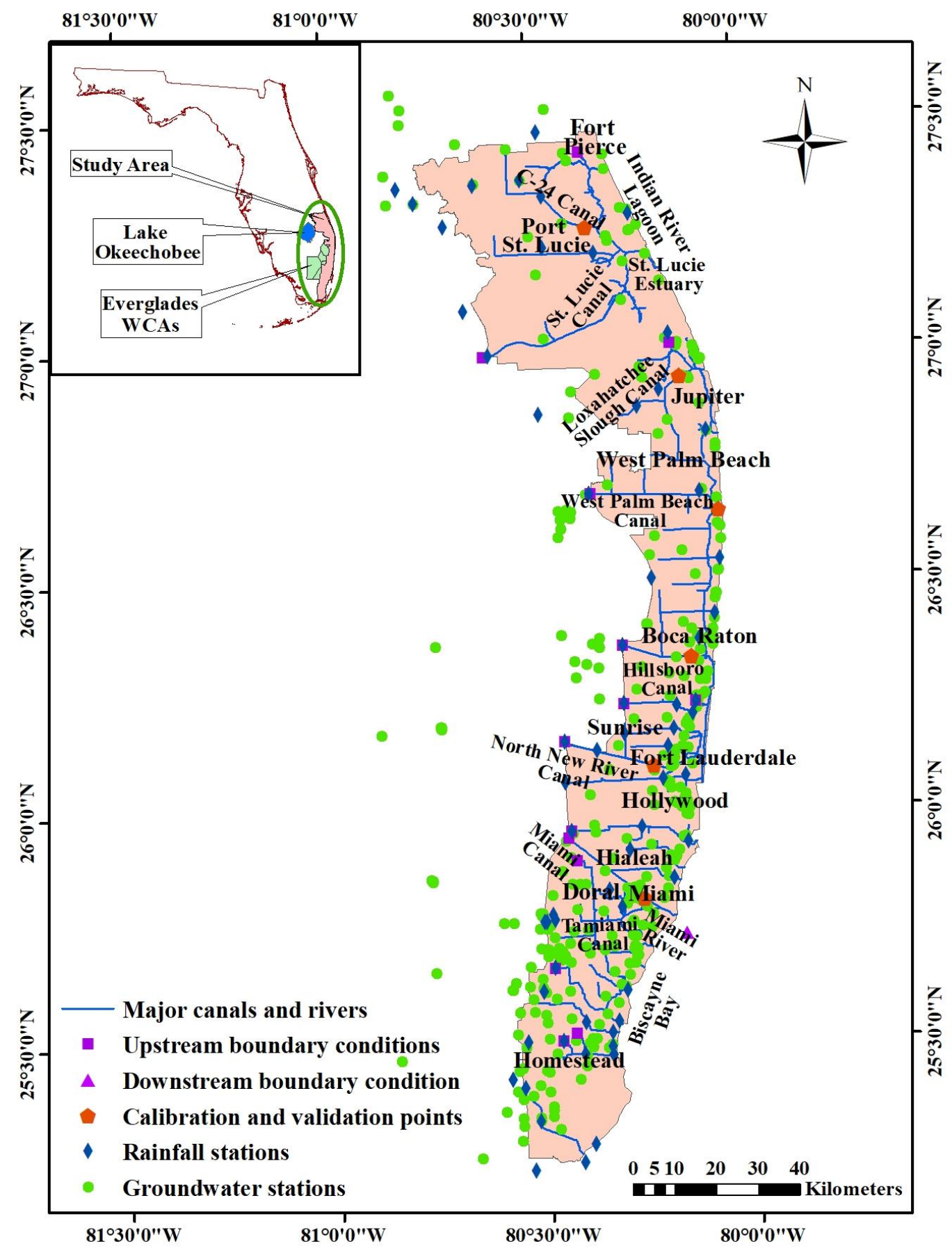

Figure 4.2: Locations of boundary conditions, model calibrations and validation points, rainfall gauging stations, and groundwater monitoring stations used in the Southeast Coasts Basin model. The inset showing the location of the study area, Lake Okeechobee, and the Everglades Water Conservation Areas (WCAs) in the state of Florida is not drawn to the map-scale. 
Hourly rainfall data during 2004-2013 for 71 stations within and in close proximity of the basin (Figure 4.2), collected from DBHYDRO and NOAA's National Climatic Data Center (NCDC) database, were included in the model. Monthly average evapotranspiration (ET) rates ( $\mathrm{mm} /$ day) computed based on satellite-based gridded $(2 \mathrm{~km})$ USGS daily potential ET dataset (USGS, 2016c) for 2004-2013 were also incorporated accordingly. Observed groundwater level (GWL) data for 410 stations from SFWMD, Everglades National Park (ENP), and USGS stations were utilized to represent the hyporheic exchanges in the Southeast Coasts Basin.

\subsubsection{Development of the mechanistic rainfall-runoff model using EPA SWMM 5.1}

The U.S. EPA SWMM 5.1 is a mechanistic rainfall-runoff model that parameterizes and dynamically integrates different components of urban and natural hydrology, hydroclimatological forcing variables, and land cover properties (Rossman, 2015). At first, Arc Hydro (Maidment and Morehouse, 2002) for ESRI ArcGIS 10.2 was used to split the large-scale Southeast Coasts Basin into smaller subbasins, and to develop link (stream)-node (junction) network draining those subbasins based on the $10 \mathrm{~m}$ DEMs. The developed subbasins and linknode networks were later modified for appropriate representation of the complex hydrologic settings of southeast Florida (see Text A2.1 in Appendix 2 for details), which resulted in 333 subbasins, 434 links, and 436 nodes. Table 4.1 summarizes the major variables and parameters for the Southeast Coasts Basin model. Underground sewers and catch-basins were not considered in the model assuming they would drain into the rivers and canals.

Hourly rainfall records for 2004-2013 from the 71 stations (Figure 4.2) were distributed among the subbasins (Figure A4.1) by means of Thiessen Polygons (see Text A2.2 in Appendix 2). Since, the potential ET rates ( $\mathrm{mm} /$ day) showed low spatial variability with coefficient of variation $=1.56$ to $8.8 \%$ for different months, spatially averaged monthly potential ET rates were 
used in the model. Dry season observed GWL (on or around 01/01/2004) were used as initial GWL (see Text A2.3 and A2.4 in Appendix 2) which would be dynamically updated by dint of groundwater mass balance and hyporheic exchanges (Rossman, 2016).

Table 4.1: Variables and calibrated parameters of the Southeast Coasts Basin model for simulation during 2004-2013.

\begin{tabular}{ll}
\hline Variables and Parameters & Range \\
\hline Climate & \\
Rainfall (mm/hr) & 0 to 181.10 \\
Potential evapotranspiration (mm/day) & 1.74 to 5.44 \\
Overland flow & \\
Characteristic width (m) & 171.27 to 42806.45 \\
Imperviousness (\%) & 0.01 to 75.60 \\
Slope (\%) & 0.01 to 3.21 \\
Overland roughness coefficient (Manning's n) for impervious subarea & 0.01 to 0.019 \\
Overland roughness coefficient (Manning's n) for pervious subarea & 0.017 to 0.20 \\
Depression storage depth for impervious subarea (mm) & 1.27 to 2.54 \\
Depression storage depth for pervious subarea (mm) & 2.54 to 7.62 \\
Infiltration and groundwater flow & \\
Initial suction head (mm) & 88.37 to 109 \\
Saturated hydraulic conductivity (mm/hr) & 3 to 170.40 \\
Initial moisture deficit & \\
Soil porosity & 0.02 to 0.25 \\
Field capacity & 0.43 to 0.49 \\
Permanent wilting point & 0.06 to 0.19 \\
Lower evaporation depth ${ }^{\mathrm{b}}$ (m) & 0.024 to 0.085 \\
Initial groundwater elevation (m NAVD 88) & 0.25 to 3.5 \\
Unsaturated zone moisture content & -3.5 to 7.84 \\
Groundwater flow coefficient, A1 & 0.24 to 0.41 \\
Groundwater flow exponent, B1 & 0.001 to 0.041 \\
Surface water flow coefficient, A2 & 1 \\
Surface water flow exponent, B2 & 0.01 to 0.0106 \\
Surface water-ground water exchange coefficient, A3 & 1 \\
Streamflow & -0.0002 to 0 \\
Channel roughness (Manning's n) & \\
\hline Nots: & 0.02 to 0.04 \\
\hline
\end{tabular}

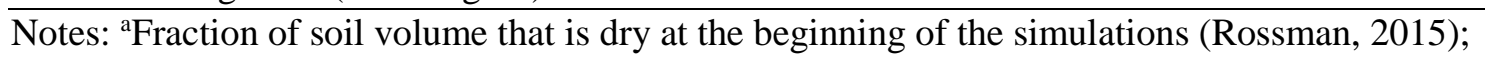

${ }^{b}$ maximum depth below the surface at which evapotranspiration can take place from the lower saturated zone (Rossman, 2015). 
Subbasin characteristic widths were computed based on their shapes and length of the corresponding draining channels (see text A2.5 in Appendix 2). The 'percent developed imperviousness' raster dataset of NLCD 2006 and NLCD 2011 (Fry et al., 2011; Homer et al., 2015) were used to compute temporally averaged percent imperviousness (Figure A4.2) for model simulation during 2004-2013. 10 meter DEM was used on the Arc Hydro platform to obtain slope of the subbasins. Initial estimations of subbasin overland roughness coefficients and depression storage depths were found from the SWMM Reference Manual (Rossman, 2016) and SWMM User's Manual (Rossman, 2015). Initial Green-Ampt infiltration parameters and aquifer values were estimated based on subbasin soil type and recommended values from the SWMM Reference Manual (Rossman, 2016). 14 upstream boundary conditions and 1 downstream boundary condition (Figure 4.2; Table A4.1) were used in the model to represent the influence of external water bodies (Lake Okeechobee and Everglades WCAs) and ocean tides, respectively. The overall model structure for the Southeast Coasts Basin is depicted in Figure A4.3.

The Southeast Coasts Basin SWMM model was run for continuous simulation during 2004-2013 at hourly reporting time-step, and calibrated and validated at 6 different major streams (Figure 4.3; Table A4.2) during 01/01/2004-12/31/2008 and 01/01/2009-12/31/2013, respectively. Parameters that were adjusted to calibrate the model (Table 4.1) were subbasin characteristic width and overland roughness coefficients (Manning's n), Green-Ampt infiltration parameters, aquifer parameters, surface water-ground water exchange coefficients (A1, A2, A3), and channel roughness coefficient (Manning's n). Realistic simulated GWLs were ensured by restricting their lower limits in close proximity of the initial GWLs. Model performance evaluation was made based on the Nash-Sutcliffe Efficiency (NSE) (Nash and Sutcliffe, 1970) and the ratio of the root-mean-square error to the standard deviation of observations (RSR) (see 
Text A2.6 in Appendix 2). Effective NSE and RSR values were estimated through excluding zero streamflow records in both the observed and simulated time-series to avoid the impact of control structure gate closing (see Section 2.2.3 in Chapter 2).

\subsubsection{Climatic, land cover, and sea level datasets for extreme runoff computations}

There were 8 long-term hourly NOAA-NCDC rainfall stations within and around the Southeast Coasts Basin (Figure 4.3); these rainfall observations were used for historical design rainfall estimations during 1964-2013, defined as the historical baseline period of 2000s. For stations with no recorded rainfalls in certain year/years, rainfalls for immediate years prior to 1964 were taken into account. The two NOAA stations 084091 and 084095 (about $5 \mathrm{~km}$ apart) at Homestead, had hourly rainfall records for 1942-1992 and 1995-2013, respectively. Since they were quite close to each other, rainfall records for the two stations were combined to produce the 50-year dataset (merged ID: 084091-084095) during or around 1964-2013. Downscaled rainfall projections given by the 20 Coupled Model Intercomparison Project's fifth phase (CMIP5) general circulation models (GCMs) (see Table A4.3 in Appendix 4) from the multivariate adaptive constructed analogs (MACA) dataset (Abatzoglou and Brown, 2012) were used to estimate future extreme rainfalls and stormwater runoffs. Historical climatic simulations and future climatic projections from MACA were available for, 1950-2005 and 2006-2099, respectively, under the Representative Concentration Pathways (RCP) 4.5 and 8.5 scenario (IPCC, 2014b). The daily MACA-GCM rainfalls for the 2000s, as well as for the future 50-year periods of 2050s (2025-2074) and 2080s (2050-2099) at the nearest MACA grid were extracted for the 8 observed rainfall stations (Figure 4.3). Monthly modeled historical and future potential ET, computed using the Penman-Monteith method (Allen et al., 1998), were also collected at all 
MACA grids within the basin extent to compute the corresponding spatial mean monthly potential ET rates.

Existing literature (e.g., Teutschbein and Seibert, 2012, Chen et al., 2013) corroborate GCM's lack of ability in representing hourly and daily rainfall variability appropriately. Biascorrected future projections of 50-year annual maximum 1-7 day total rainfall depths at each station were, therefore, computed by means of the delta change factor methodology (Teutschbein and Seibert, 2012; Chen et al., 2013). Ratios of GCM-projected future annual rainfall maxima ( $\left.A_{f u t, p r o j}\right)$ over GCM-simulated historical annual rainfall maxima $\left(A_{\text {hist,sim }}\right)$ were estimated to represent the relative changes in annual rainfall maximas between the historical 2000s and the future 2050s or 2080s. For each rainfall duration, 50 such ratio values for the 50 -year period were obtained. Outlier annual maxima ratios, identified as values beyond the range with a lower boundary of $Q_{1}-1.5 * I Q R$ and an upper boundary of $Q_{3}+1.5 * I Q R\left(Q_{1}=25^{\text {th }}\right.$ percentile; $Q_{3}$ $=75^{\text {th }}$ percentile; $\left.I Q R=Q_{3}-Q_{1}\right)($ Tukey, 1977), were replaced with the closest lower or upper boundary values. Bias-corrected future annual rainfall maxima $\left(A_{f u t, r e c}\right)$ for a year was finally produced by multiplying the observed historical annual rainfall maxima $\left(A_{\text {hist }, o b s}\right)$ for the 2000s with the corresponding adjusted delta change ratio value $\left(A_{f u t, p r o j} / A_{\text {hist,sim }}\right)$. 


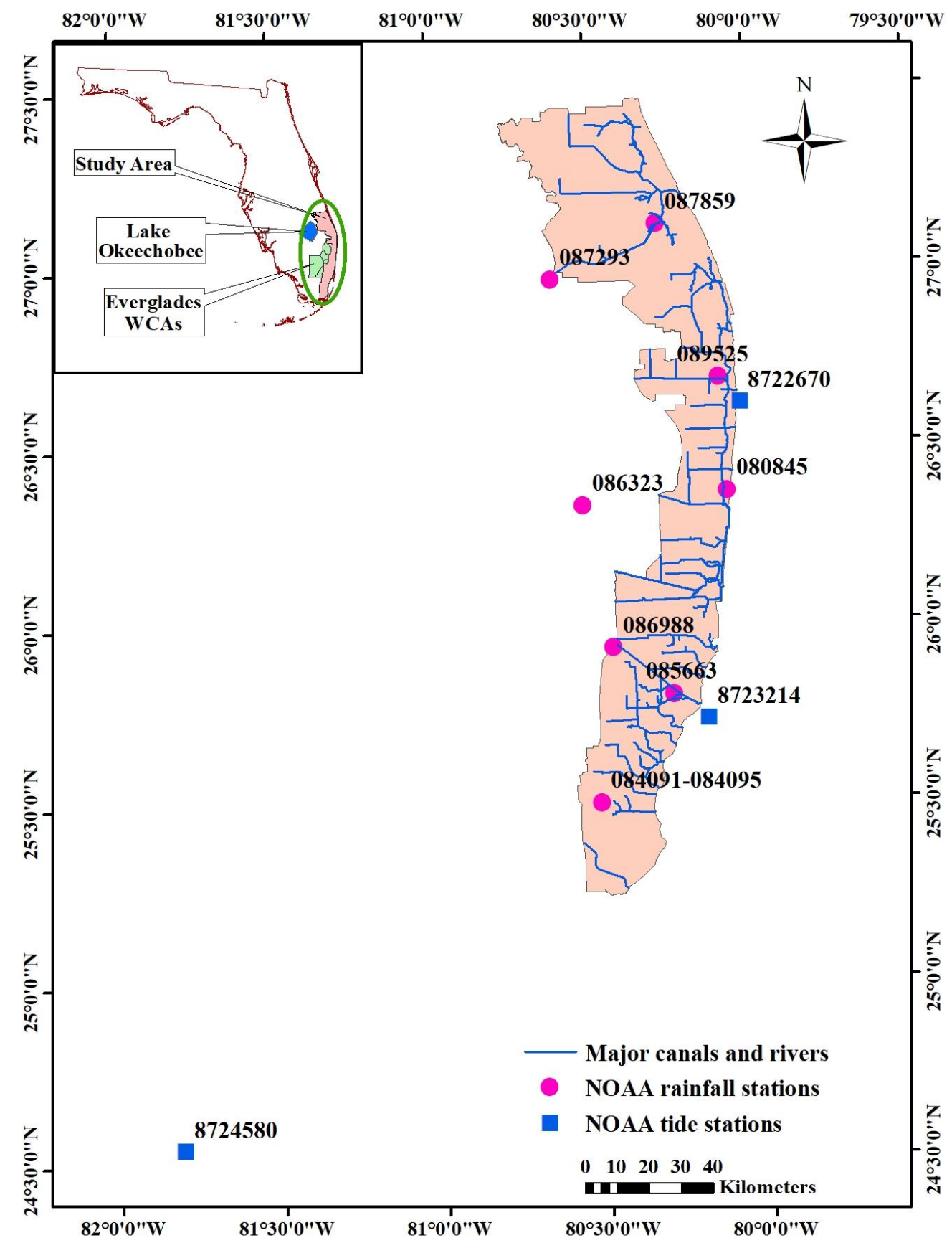

Figure 4.3: Locations of rainfall and tide stations used for extreme rain and sea level estimations in the Southeast Coasts Basin. The numbers beside the station locations indicate station IDs assigned by NOAA. The NOAA tide station 8724580 was used to develop the 50-year annual maximum water levels at tide station 8723214 and 8722670. The inset showing the location of the study area, Lake Okeechobee, and the Everglades Water Conservation Areas (WCAs) in the state of Florida is not drawn to the map-scale. 
Future monthly ET projections were also obtained using the monthly delta change ratios (50 ratio values for each month). Integrated Climate and Land-Use Scenarios (ICLUS) imperviousness projections (U.S. EPA, 2010) for the Special Report on Emissions Scenarios (SRES) (Nakicenovic et al., 2000) A1 and B1 were used to represent potential future land cover changes in the basin. SRES A1FI and B1 scenario is similar to RCP 8.5 and 4.5, respectively, with respect to atmospheric $\mathrm{CO}_{2}$ concentrations, global radiative forcing, and global mean temperature (Van Vuuren and Carter, 2014). Reconstructed future percent imperviousness $\left(I_{f u t, r e c}\right)$ for a subbasin was estimated by multiplying the imperviousness relative change ratio, $I_{\text {fut }, \text { proj }} / I_{\text {hist }, \text { sim }}\left(I_{\text {fut }, \text { proj }}=\right.$ projected future imperviousness on 2050 or $2080 ; I_{\text {hist }, \text { sim }}=$ simulated historical imperviousness on 2010) with the observed historical (i.e., NLCD) imperviousness on the 2010s ( $I_{\text {hist,obs }}$ ) (see Section 2.2.4 in Chapter 2). Projected future changes in imperviousness and ET are reported in Table A4.4.

The two NOAA tide stations to be used for extreme water level computations, 8723214 and 8722670 (Figure 4.3), had continuous observed hourly water level records for 19 years and 3 years, respectively, during the baseline 2000s. NOAA station 8724580 (at Key West) was the nearest tide station with 50-year hourly water level records during 1964-2013. 50-year annual maximum 1-7 day mean water levels at station 8723214 and 8722670 were, therefore, estimated by performing linear regression between their observed water level annual maximums of different durations with that at station 8724580 for the respective overlapping years. The coefficient of determination, $R^{2}$ for regression of water level maximas between 8723214 and 8724580 ranged between 0.83 to 0.88 for 1-7 day duration; range of $R^{2}$ values for regression between 8722670 and 8724580 was 0.71 to 0.80 . Potential future sea level projections were formed based on the SLR scenarios on 2050 and 2080 for southeast Florida (SFRCCC Sea Level 
Rise Work Group, 2020; Sweet et al., 2017a; Sweet et al., 2017b), with respect to 2010. Intermediate SLR scenario representing midpoint of the likely range under RCP 4.5 and intermedia-high SLR scenario corresponding to midpoint of the likely range under RCP 8.5 for the NOAA tide station 8724580 were used (Table A4.5 in Appendix 4).

\subsubsection{Analyses of trends in rainfall and sea level}

Significance of monotonic (i.e., increasing or decreasing) trends in annual maximum total rainfall depths and mean water levels were assessed based on the non-parametric Mann-Kendall test (Mann, 1945; Kendall, 1938; Kendall, 1976) (see Text A4.1. in Appendix 4). This test has been widely used (e.g., Martinez et al., 2012; Irizarry-Ortiz et al., 2013; Sayemuzzaman and Jha, 2014; Gavrilov et al., 2018; Pirnia et al., 2019; Mahjabin and Abdul-Aziz, 2020) to estimate local or at-site trend significance for different hydro-meteorological datasets. 5\% statistical significance level, i.e., $95 \%$ certainty in the alternative hypothesis that the dataset had a monotonic trend, was considered for the Mann-Kendall test. Meanwhile, Theil-Sen approach, also known as Sen slope estimator, (Theil, 1950; Sen, 1968) (see Text A4.2) was used to estimate magnitude of trends in annual maximum rainfall and water level. This is also a nonparametric method which has been frequently used for robust prediction of trend slope by different studies (e.g., Irizarry-Ortiz et al., 2013; Sayemuzzaman et al., 2013; Hanel et al., 2016; Hadi and Tombul, 2018; Mahjabin and Abdul-Aziz, 2020).

\subsubsection{Estimations of historical and future extreme rainfall, sea level, and runoff}

This study intended to estimate 1-7 day extreme rainfalls and water levels with varying return periods of 2, 5, 10, 25, 50, and 100-year using extreme value probability distributions adopting the block maxima approach. During the initial analyses phase, different extreme value distributions, i.e., the generalized extreme value (GEV), Weibull, and Fréchet produced 
inconsistent rainfall depth-duration-frequency (DDF) curves, i.e., lower rainfall depth for higher duration storms under a particular return period were observed. The Gumbel extreme value distribution performed better in this concern, and therefore, was used in this study for design rainfall and sea level estimations on the year 2010, 2050, and 2080. Gumbel is a two-parameter (location and scale; see Text A4.3 in Appendix 4 for details) distribution that can be used to model probability distribution of both maximum and minimum. It has been widely implemented in literature (e.g., Hirabayashi et al., 2013; Vidal, 2014; Bhagat, 2017; Mahdi and Mohamedmeki, 2020) on different hydro-meteorological random variables. Non-stationary Gumbel distributions, considering trends in the location parameter, were fitted to the datasets (see Text A4.3 in Appendix 4) when Mann-Kendall test suggested significant monotonic trends; stationary Gumbel distributions were fitted otherwise. For a few stations, the inconsistent design rainfall depth-duration relationships were still present. Power law equations $\left(Y=a X^{b}\right.$ where $Y=$ rainfall depth; $X=$ event duration; $a=$ constant; and $b=$ exponent) were fitted to the design rainfall depth-duration datasets, under a certain return period, to correct the inconsistent design rainfall values. The power-law fittings were performed during both design rainfall and sea level estimations in history and future for all stations, in order to maintain consistency in approach.

The power-law corrected event total design rainfalls and event mean design water levels, for a particular duration, were distributed to hourly values based on the observed historical hourly distributions. 50 hourly distributions corresponding to the 50 annual maximum values in the 2000s were averaged to produce the representative hourly distribution for a particular event duration. The representative hourly rainfall and sea level distribution under an event duration was used for hourly disaggregation of historical design rainfalls and water levels, respectively, for all return periods. 
Since GCMs do not perform well in representing observed rainfall variability for smaller (than monthly) temporal scales (Zhang, 2013; Langousis et al., 2016), the historical hourly rainfall distributions, under a particular event duration, were used for disaggregation of future design rainfalls. Historical and future hourly design rainfalls were distributed among the subbasins based on the Thiessen Polygons (see Text A2.2 in Appendix 2). Since SLR projections were available for the NOAA station 8724580 only (Section 4.2.4), they were added to the historical hourly design water levels at NOAA station 8723214 and 8722670 to obtain the corresponding future hourly design water levels, assuming similar potential future changes in sea level. The design water levels at station 8723214 and 8722670 were assigned to nearest outlet node at the Miami River and the West Palm Beach Canal, respectively. For the remaining stream outlets in the basin, design water levels for either the Miami River or the West Palm Beach Canal outlet (whichever was closer) were used while adjusting for the respective differences in stream bed elevation. The estimated extreme rainfalls, extreme sea levels, and observed ET in 2010 together with imperviousness in 2010s (2004-2013) were used for SWMM simulations of extreme runoffs on hourly reporting time-step across the Southeast Coasts Basin. Future extreme runoffs in 2050 and 2080 under RCP 4.5 and 8.5 were computed based on the reconstructed future projections of extreme rainfall, ET, and imperviousness along with the estimated future extreme sea levels.

\subsection{Results}

\subsubsection{Model calibrations and validations}

In calibration and validation of Southeast Coasts Basin model during 2004-2013, range of NSE values were from 0.74 to 0.92 (Figure 4.4) among the 6 stations; RSR values varied from 0.28 to 0.51. These performance evaluation statistics for different stations over the basin (Figure 4.2) 
corroborated good to very good performance of the model (Moriasi et al., 2007). The calibrated and validated model was, therefore, appropriate to be used for evaluation of historical and future extreme runoff scenarios.

\subsubsection{Historical trends and design values for rainfall and sea level}

Mann-Kendall test results for annual maximum 1-7 day total rainfall depths outlined lack of monotonic trend at 5\% statistical significance level for most $(75 \%)$ stations for the historical 2000s (Table 4.2). For station 086988 (Figure 4.3), significant decreasing trends with Sen's slope values ranging between -1.49 to $-0.77 \mathrm{~mm}$ /year were observed for $1,3,4,5,6$, and 7-day duration. For station 086323, significant decreasing trend with slope of $-1.29 \mathrm{~mm} /$ year was observed for 7-day rainfall maxima only. In case of sea level, on the other hand, significant increasing trends for all durations were witnessed (Table 4.3) for both of the stations considered in this study (Figure 4.3). Sen's slope values for ranged from 3.55 to $4.14 \mathrm{~mm} /$ year for these two sea level stations. Significant sea level trends at these two stations are indicators of considerable historical SLR experienced in the Southeast Coasts Basin. 

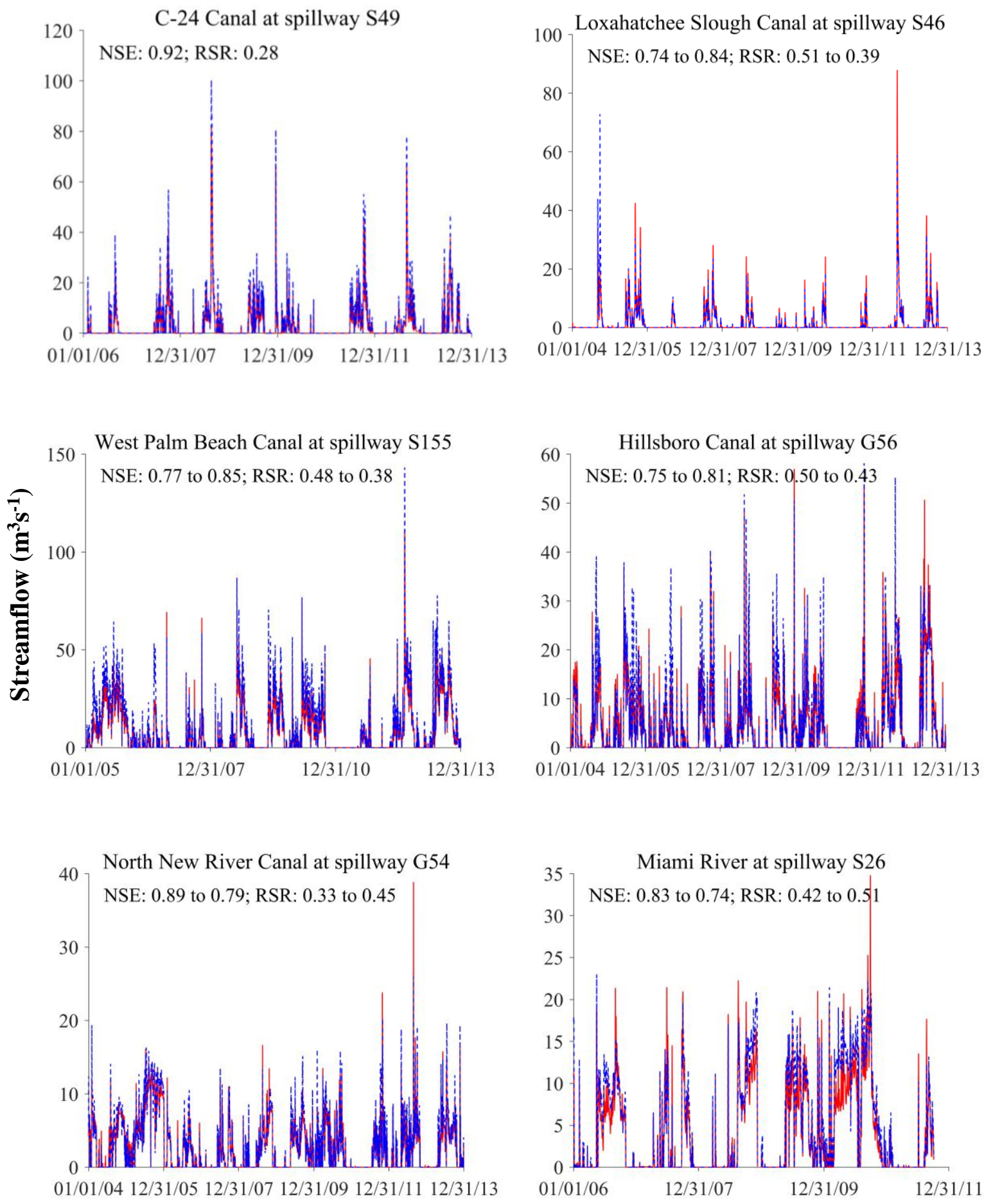

Month/Day/Year

----Observed — Predicted

Figure 4.4: Model calibration and validation plots with historical daily streamflow for the Southeast Coasts Basin. 01/01/05 refers to January 01, 2005. Calibration and validation periods are, respectively, $01 / 01 / 2006$ to $12 / 31 / 2008$ and $01 / 01 / 2009$ to $12 / 31 / 2013$ for the C-24 Canal; 
01/01/2005 to 12/31/2008 and 01/01/2009 to 12/31/2013 for the West Palm Beach Canal; and 01/01/2006 to 12/09/2008 and 01/01/2009 to 10/03/2011 for the Miami River. For the remaining streams, calibration and validation periods are $01 / 01 / 2004$ to $12 / 31 / 2008$ and $01 / 01 / 2009$ to $112 / 31 / 2013$, respectively.

Based on the trend analyses outcomes, stationary design rainfall and non-stationary design sea level estimations were performed for 2010. The power law fitting corrected $\left(R^{2}\right.$ ranged from 0.911 to 0.999 among the rainfall stations, and from 0.998 to 0.999 among the sea level stations) design rainfall and sea level values (Table 4.4, 4.5, and 4.6) outlined a wide range of extreme rainfall and sea level regimes. Overall higher (than other stations) 1-7 day design rainfall depths for different return periods were generally observed for station 080845 at Boca Raton (127 to $489 \mathrm{~mm}$ ), station 085663 at Miami (126 to $438 \mathrm{~mm}$ ), and station 086988 near Hialeah (107 to $449 \mathrm{~mm}$ ) (Figure 4.3; Table 4.4). Station 086323 and 087293 had lower 1-7 day design rainfalls of 92 to $428 \mathrm{~mm}$, and 102 to $313 \mathrm{~mm}$, respectively. Spatial mean design rainfall for the entire basin ranged from 122 to $429 \mathrm{~mm}$ (Table 4.5). Meanwhile, among the two tide stations (Figure 4.3), higher 1-7 day design water levels ranging from 0.003 to $0.271 \mathrm{~m}$ NAVD 88 were observed for station 8723214 near the Miami River outlet under different return periods (Table 4.6). 
Table 4.2: Sen's slope values (mm/year) for annual maximum event total rainfall depths for different durations during 1964-2013 in the Southeast Coasts Basin. Numbers in the parentheses indicate $p$-values of the Mann-Kendall test. $p>0.05$ and $p \leq 0.05$ indicates absence and presence of monotonic trend, respectively, at 5\% statistical significance level.

\begin{tabular}{cccccccc}
\hline \multirow{2}{*}{ Station ID } & \multicolumn{7}{c}{ Sen's slope values, $\beta(\mathrm{mm} /$ year $)$} \\
\cline { 2 - 7 } & 1-day & 2-day & 3-day & 4-day & 5-day & 6-day & 7-day \\
\hline 087859 & $-0.42(0.33)$ & $-0.53(0.20)$ & $-0.58(0.24)$ & $-0.88(0.20)$ & $-0.84(0.07)$ & $-1.13(0.06)$ & $-1.17(0.07)$ \\
087293 & $-0.52(0.14)$ & $-0.62(0.08)$ & $-0.73(0.08)$ & $-0.73(0.09)$ & $-0.62(0.24)$ & $-0.74(0.08)$ & $-0.63(0.07)$ \\
089525 & $0.72(0.13)$ & $0.68(0.23)$ & $0.78(0.13)$ & $0.67(0.22)$ & $0.55(0.26)$ & $0.59(0.14)$ & $0.61(0.29)$ \\
080845 & $-0.52(0.17)$ & $-0.35(0.55)$ & $-0.28(0.52)$ & $-0.39(0.59)$ & $-0.23(0.74)$ & $-0.29(0.51)$ & $-0.20(0.78)$ \\
086323 & $-0.74(0.05)$ & $-0.79(0.10)$ & $-0.95(0.07)$ & $-0.91(0.08)$ & $-0.94(0.05)$ & $-1.02(0.10)$ & $-1.29(0)$ \\
086988 & $-0.77(0)$ & $-1.02(0.06)$ & $-1.20(0.02)$ & $-1.22(0.01)$ & $-1.35(0.01)$ & $-1.49(0.01)$ & $-1.42(0.02)$ \\
085663 & $0.08(0.91)$ & $-0.11(0.93)$ & $-0.07(0.74)$ & $0.06(0.90)$ & $0.20(0.69)$ & $0.27(0.60)$ & $0.30(0.66)$ \\
$084091-$ & $-0.63(0.25)$ & $-0.64(0.09)$ & $-0.69(0.09)$ & $-0.85(0.11)$ & $-0.89(0.12)$ & $-0.99(0.12)$ & $-1.09(0.10)$ \\
084095 & & & & & & &
\end{tabular}

Table 4.3: Sen's slope values (mm/year) for annual maximum event mean sea levels for different durations during 1964-2013 in the Southeast Coasts Basin. Numbers in the parentheses indicate $p$-values of the Mann-Kendall test. $p>0.05$ and $p \leq 0.05$ indicates absence and presence of monotonic trend, respectively, at $5 \%$ statistical significance level.

\begin{tabular}{cccccccc}
\hline \multirow{2}{*}{ Station ID } & \multicolumn{7}{c}{ Sen's slope values, $\beta(\mathrm{mm} /$ year) } \\
\cline { 2 - 8 } & 1-day & 2-day & 3-day & 4-day & 5-day & 6-day & 7-day \\
\hline 8722670 & $3.94(0)$ & $3.80(0)$ & $3.83(0)$ & $3.89(0)$ & $3.97(0)$ & $4.05(0)$ & $4.14(0)$ \\
8723214 & $3.70(0)$ & $3.55(0)$ & $3.55(0)$ & $3.59(0)$ & $3.65(0)$ & $3.72(0)$ & $3.80(0)$ \\
\hline
\end{tabular}


Table 4.4: Historical design rainfall $(\mathrm{mm})$ in 2010 for different stations in the Southeast Coasts Basin under varying durations and return periods.

\begin{tabular}{|c|c|c|c|c|c|c|c|c|}
\hline \multirow{2}{*}{$\begin{array}{c}\text { Station } \\
\text { ID }\end{array}$} & \multirow{2}{*}{$\begin{array}{l}\text { Return } \\
\text { period }\end{array}$} & \multicolumn{7}{|c|}{ Design rainfall $(\mathrm{mm})$} \\
\hline & & 1-day & 2-day & 3-day & 4-day & 5-day & 6-day & 7-day \\
\hline \multirow{6}{*}{087859} & 2-year & 117 & 137 & 151 & 161 & 169 & 176 & 183 \\
\hline & 5-year & 158 & 182 & 198 & 210 & 220 & 228 & 235 \\
\hline & 10-year & 185 & 211 & 229 & 242 & 253 & 262 & 270 \\
\hline & 25-year & 219 & 249 & 268 & 283 & 295 & 306 & 314 \\
\hline & 50-year & 244 & 276 & 298 & 314 & 327 & 338 & 347 \\
\hline & 100-year & 269 & 304 & 327 & 344 & 358 & 369 & 380 \\
\hline \multirow{6}{*}{087293} & 2-year & 102 & 117 & 127 & 135 & 141 & 146 & 151 \\
\hline & 5 -year & 133 & 152 & 165 & 174 & 182 & 188 & 194 \\
\hline & 10-year & 154 & 175 & 190 & 200 & 209 & 216 & 223 \\
\hline & 25-year & 180 & 205 & 221 & 233 & 243 & 252 & 259 \\
\hline & 50-year & 199 & 227 & 244 & 258 & 269 & 278 & 286 \\
\hline & 100-year & 219 & 248 & 267 & 282 & 294 & 304 & 313 \\
\hline \multirow{6}{*}{089525} & 2-year & 136 & 158 & 173 & 185 & 194 & 202 & 209 \\
\hline & 5 -year & 180 & 206 & 224 & 237 & 247 & 256 & 264 \\
\hline & 10-year & 210 & 238 & 257 & 271 & 282 & 292 & 301 \\
\hline & 25-year & 247 & 279 & 299 & 314 & 327 & 337 & 347 \\
\hline & 50-year & 275 & 308 & 330 & 347 & 360 & 371 & 381 \\
\hline & 100 -year & 302 & 338 & 361 & 379 & 393 & 404 & 415 \\
\hline \multirow{6}{*}{080845} & 2-year & 127 & 148 & 162 & 173 & 181 & 189 & 195 \\
\hline & 5 -year & 186 & 214 & 232 & 245 & 256 & 266 & 274 \\
\hline & 10-year & 226 & 257 & 278 & 293 & 306 & 317 & 326 \\
\hline & 25-year & 276 & 312 & 336 & 354 & 369 & 381 & 392 \\
\hline & 50-year & 313 & 353 & 380 & 399 & 415 & 429 & 441 \\
\hline & 100-year & 349 & 394 & 422 & 444 & 461 & 476 & 489 \\
\hline \multirow{6}{*}{086323} & 2-year & 92 & 113 & 128 & 140 & 149 & 158 & 165 \\
\hline & 5-year & 133 & 163 & 184 & 200 & 213 & 225 & 236 \\
\hline & 10-year & 160 & 196 & 220 & 240 & 256 & 270 & 282 \\
\hline & 25-year & 194 & 237 & 267 & 290 & 309 & 326 & 341 \\
\hline & 50-year & 219 & 268 & 301 & 327 & 349 & 368 & 385 \\
\hline & 100-year & 244 & 298 & 335 & 364 & 388 & 409 & 428 \\
\hline \multirow{6}{*}{086988} & 2-year & 107 & 130 & 145 & 157 & 166 & 175 & 182 \\
\hline & 5-year & 155 & 185 & 205 & 220 & 233 & 244 & 254 \\
\hline & 10-year & 186 & 221 & 244 & 262 & 277 & 290 & 301 \\
\hline & 25-year & 226 & 267 & 294 & 315 & 333 & 347 & 360 \\
\hline & 50-year & 256 & 301 & 331 & 355 & 374 & 390 & 405 \\
\hline & 100-year & 285 & 335 & 368 & 394 & 415 & 433 & 449 \\
\hline \multirow{6}{*}{085663} & 2-year & 126 & 150 & 166 & 178 & 189 & 198 & 205 \\
\hline & 5-year & 173 & 202 & 222 & 236 & 248 & 259 & 268 \\
\hline & 10-year & 205 & 237 & 258 & 275 & 288 & 299 & 309 \\
\hline & 25-year & 245 & 281 & 305 & 323 & 338 & 350 & 361 \\
\hline & 50-year & 275 & 314 & 340 & 359 & 375 & 388 & 400 \\
\hline & 100-year & 305 & 347 & 374 & 394 & 411 & 425 & 438 \\
\hline \multirow{6}{*}{$\begin{array}{c}084091- \\
084095\end{array}$} & 2-year & 110 & 133 & 148 & 160 & 170 & 178 & 186 \\
\hline & 5-year & 152 & 181 & 201 & 217 & 230 & 241 & 250 \\
\hline & 10-year & 179 & 214 & 237 & 255 & 269 & 282 & 293 \\
\hline & 25-year & 214 & 254 & 281 & 302 & 320 & 334 & 348 \\
\hline & 50-year & 240 & 284 & 314 & 338 & 357 & 373 & 388 \\
\hline & 100-year & 265 & 314 & 347 & 373 & 394 & 412 & 428 \\
\hline
\end{tabular}


Table 4.5: Historical basin-average design rainfall (mm) in 2010 in the Southeast Coasts Basin under varying durations and return periods.

\begin{tabular}{cccccccc}
\hline Return & \multicolumn{7}{c}{ Design rainfall $(\mathrm{mm})$} \\
\cline { 2 - 8 } period & 1-day & 2-day & 3-day & 4-day & 5-day & 6-day & 7-day \\
\hline 2-year & 122 & 144 & 158 & 170 & 179 & 187 & 194 \\
5-year & 169 & 196 & 214 & 228 & 239 & 248 & 257 \\
10-year & 200 & 231 & 251 & 266 & 279 & 289 & 299 \\
25-year & 240 & 274 & 297 & 315 & 329 & 341 & 351 \\
50-year & 269 & 307 & 332 & 351 & 366 & 379 & 390 \\
100-year & 298 & 339 & 366 & 386 & 403 & 417 & 429 \\
\hline
\end{tabular}

Table 4.6: Historical design sea level (m NAVD 88) in 2010 for different stations in the Southeast Coasts Basin under varying durations and return periods.

\begin{tabular}{ccccccccc}
\hline Station & Return & \multicolumn{7}{c}{ Design sea level (m NAVD 88) } \\
\cline { 3 - 9 } ID & period & 1-day & 2-day & 3-day & 4-day & 5-day & 6-day & 7-day \\
\hline \multirow{8}{*}{8722670} & 2-year & 0.045 & 0.024 & 0.011 & 0.003 & -0.004 & -0.009 & -0.014 \\
& 5-year & 0.104 & 0.079 & 0.065 & 0.055 & 0.047 & 0.041 & 0.036 \\
& 10-year & 0.144 & 0.116 & 0.101 & 0.090 & 0.081 & 0.074 & 0.069 \\
& 25-year & 0.193 & 0.163 & 0.146 & 0.134 & 0.124 & 0.117 & 0.110 \\
& 50-year & 0.230 & 0.198 & 0.179 & 0.166 & 0.156 & 0.148 & 0.141 \\
& 100-year & 0.267 & 0.232 & 0.212 & 0.198 & 0.188 & 0.179 & 0.172 \\
\hline \multirow{8}{*}{8723214} & 2-year & 0.063 & 0.041 & 0.028 & 0.019 & 0.013 & 0.007 & 0.003 \\
& 5-year & 0.118 & 0.093 & 0.078 & 0.068 & 0.060 & 0.054 & 0.048 \\
& 10-year & 0.155 & 0.127 & 0.111 & 0.100 & 0.091 & 0.084 & 0.078 \\
& 25-year & 0.202 & 0.171 & 0.153 & 0.140 & 0.131 & 0.123 & 0.117 \\
& 50-year & 0.237 & 0.203 & 0.184 & 0.171 & 0.160 & 0.152 & 0.145 \\
& 100-year & 0.271 & 0.235 & 0.215 & 0.200 & 0.189 & 0.180 & 0.173 \\
\hline
\end{tabular}

\subsubsection{Extreme runoffs in 2010}

For the 100-year design rainfall events (the maximum probable extreme rainfalls considered in this study) of 1-7 day durations in 2010, subbasin level accumulated rainfall depths (Figure A4.4 in Appendix 4) varied from 219 to $489 \mathrm{~mm}$ across the Southeast Coasts Basin. Higher (than other locations) rainfall depths of 288 to $489 \mathrm{~mm}$ were observed at Boca Raton, Fort Lauderdale, Sunrise, and Hollywood areas. Subbasin level accumulated 1-7 day extreme runoff depths under 100-year rainfalls and sea levels (Figure A4.5) varied from 0.1 to $441 \mathrm{~mm}$. On account of the discernible stronger control of extreme rainfall in extreme runoff generation than ET, the 1-7 day 
extreme runoffs in 2010 were mainly regulated by the 1-7 day extreme rainfalls, and also by the 1-7 day extreme sea levels. The spatial variations in the runoff extremes were primarily governed by the spatial variation in imperviousness in the 2010s (representative of imperviousness on 2010) (Figure A4.2). Various urbanized basin locations, characterized by 32 to $76 \%$ imperviousness, encountered higher runoff depths in 2010. For instance, the north-central (e.g., West Palm Beach, Boca Raton), central (e.g., Sunrise, Fort Lauderdale, Hollywood), and the south-central (e.g., Hialeah, Miami, Doral) basin regions experienced 90 to $407 \mathrm{~mm}, 133$ to 441 $\mathrm{mm}$, and 202 to $358 \mathrm{~mm}$ runoff depths, respectively under 100-year rainfalls and sea levels with 1-7 day durations (Figure A4.5). Locations at the northern, western, and southern parts of the basin experienced relatively lower 1-7 day runoff depths ranging from 4 to $99 \mathrm{~mm}$. Low to moderate imperviousness of 1 to $18 \%$, on account of the croplands, pasture lands, grasslands, and wetlands mainly contributed to low runoff depths at these basin locations. Basin-scale 1-7 day runoff volume extremes in 2010 ranged from 148 to 646 million $\mathrm{m}^{3}$ under different return periods (Table 4.7). Since the maximum runoff volume was obtained under the 7-day 100-year rainfalls and sea levels, potential future spatial variation in runoff responses were assessed considering potential changes in 7-day 100-year rainfalls and sea levels.

Table 4.7: Historical basin total runoff volume extreme (million $\mathrm{m}^{3}$ ) in 2010 in the Southeast Coasts Basin under extreme rainfalls and sea levels of varying durations and return periods.

\begin{tabular}{cccccccc}
\hline Return & \multicolumn{7}{c}{ Runoff extreme $\left(\right.$ million $\left.\mathrm{m}^{3}\right)$} \\
\cline { 2 - 7 } period & 1-day & 2-day & 3-day & 4-day & 5-day & 6-day & 7-day \\
\hline 2-year & 148 & 176 & 194 & 208 & 220 & 230 & 239 \\
5-year & 215 & 244 & 267 & 286 & 302 & 316 & 328 \\
10-year & 267 & 292 & 320 & 343 & 362 & 379 & 394 \\
25-year & 346 & 363 & 395 & 422 & 445 & 466 & 484 \\
50-year & 415 & 422 & 456 & 485 & 512 & 537 & 559 \\
100-year & 494 & 487 & 523 & 555 & 588 & 619 & 646 \\
\hline
\end{tabular}




\subsubsection{Extreme future runoffs under standalone changes in individual drivers}

\subsubsection{Under standalone changes in climate}

High ensemble mean increases in runoff extremes (on spatial mean, 124 to $145 \mathrm{~mm}$ per $\mathrm{m}^{2}$ basin area) across different future scenarios were observed (Figure 4.5a) in regards to the 7-day 100year extreme rainfall together with ET projections from the 20 GCMs. The corresponding high ensemble mean increases in rainfall extremes ranged from 197 to $223 \mathrm{~mm}$ (on spatial mean, per $\mathrm{m}^{2}$ basin area) (Figure A4.6a). Different urban centers spreading from the north-central to the south-central parts of the basin (e.g., West Palm Beach, Fort Lauderdale, Miami) would experience a more notable higher (than other basin locations) spatial mean runoff increases of 177 to $208 \mathrm{~mm}$ due to the spatial mean 187 to $220 \mathrm{~mm}$ rainfall increases. Majority of the northern, western, and southern parts of the basin, with croplands, pasture lands, grasslands, and wetlands as the dominant land cover types, had relatively lower spatial mean increases in runoff extremes ranging from 45 to $58 \mathrm{~mm}$ in spite of the high spatial mean increases in rainfall extremes of 187 to $212 \mathrm{~mm}$. The highest spatial mean runoff increase of $145 \mathrm{~mm}$ was found for the 2080-RCP 8.5 scenario (Figure 4.5a), with respect to 2010, due to the corresponding maximum spatial mean rainfall increase (Figure A4.6a).

Increases in 1-7 day accumulated ensemble mean runoff volumes of different return periods, in regards to climatic changes, ranged from 12 to $109 \%$ (Figure 4.6a), with respect to runoffs in 2010 . These runoff increases were governed by the projected 11 to $52 \%$ increases in extreme rainfalls (Figure A4.7) and 4.7 to $7.9 \%$ increases in ET (Table A4.4). Higher runoff increases of 14 to $109 \%$ resulted for the $2080-\mathrm{RCP} 8.5$ scenario in response to the corresponding greater increases in rainfall events of different durations and return periods. Runoff increases of 14 to $106 \%, 12$ to $98 \%$, and 12 to $93 \%$ were observed for the $2050-\mathrm{RCP} 4.5,2050-\mathrm{RCP} 8.5$, and 
2080-RCP 4.5 scenario, respectively. Relative increases in runoff extremes intensified with increases in return periods of the rainfall events. Since the greater return period (i.e., less frequent) rainfall events were associated with significantly higher rainfall depths, they contributed to extremely rapid soil saturations, and the consequent, substantially higher increases in runoff extremes. Mixed trends for increase in basin runoff extremes with increase in rainfall event durations were witnessed across different return periods. The largest climatic-change driven increase in basin-scale runoff extreme volume of $109 \%$ was found for the 7 -day event with 100-year return period under the 2080-RCP 8.5 scenario.

\subsubsection{Under standalone changes in land cover}

As compared to impact of climatic changes for a 7-day 100-year event (Figure 4.5a), basin average 7 to 10 percentage points increases in imperviousness (Figure A4.6b) contributed to much lower spatial mean runoff increases ( 21 to $31 \mathrm{~mm}$ per $\mathrm{m}^{2}$ basin area; Figure $4.5 \mathrm{~b}$ ) across the two RCP scenarios in 2050 and 2080. Spatial mean 11 to 15 percentage points increases in imperviousness at different urban centers in the northeast (e.g., Fort Pierce, Port St. Lucie, Jupiter), north-central (e.g., West Palm Beach, Boca Raton), and south-central (e.g., Doral, Hialeah, Miami, Homestead) parts of the basin generated spatial mean 9 to $34 \mathrm{~mm}$ increases in runoff extremes under different future scenarios. Croplands, pasture lands, grasslands, and wetlands at the northern, western, and southern parts of the basin are projected to undergo spatial mean 11 to 21 percentage points increases in imperviousness due to the potential conversion to more impervious land covers — resulting spatial mean projected 45 to $87 \mathrm{~mm}$ runoff increases. The 2080-RCP 8.5 scenario gave the highest spatial mean runoff increase of $31 \mathrm{~mm}$ because of the maximum spatial mean increases in imperviousness across the basin (Figure A4.6b). 
(d) Climate
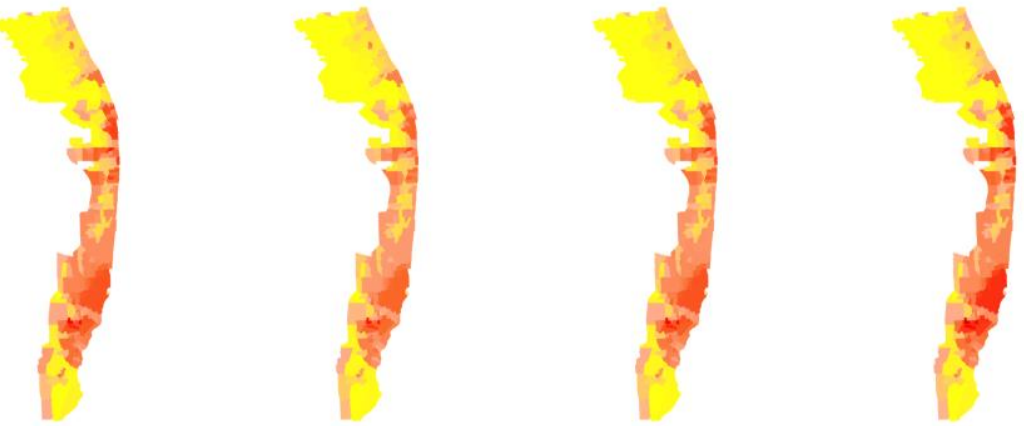

(c) Land cover
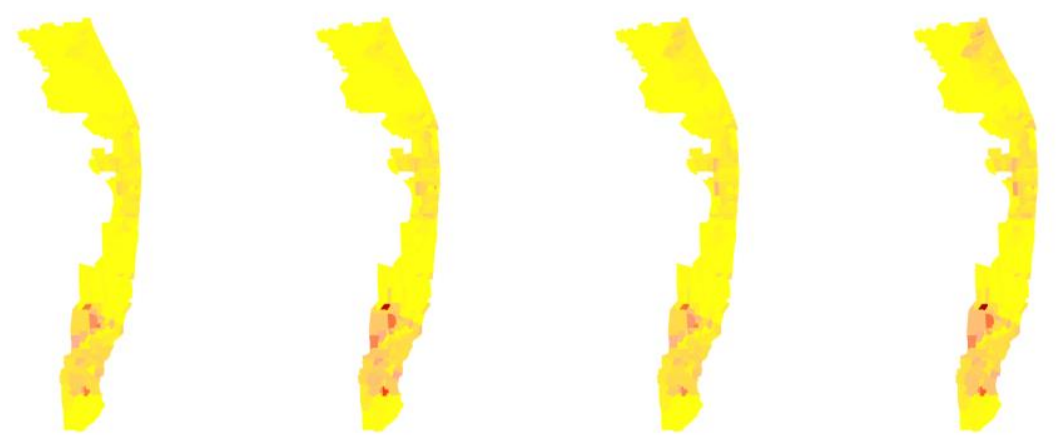

(b) Sea level
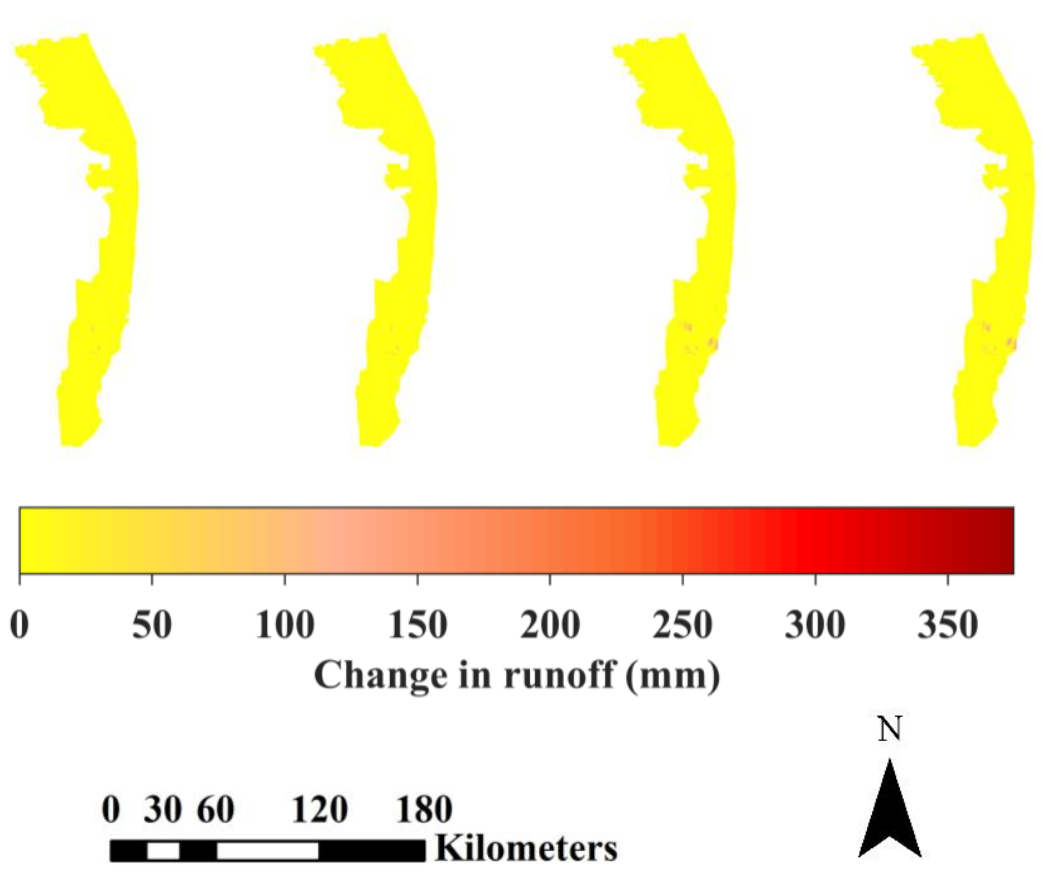

$250 \quad 300 \quad 350$

\section{m)}

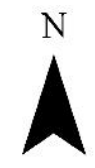

Figure 4.5: Spatial variation of the predicted changes in 7-day total runoff depth due to the projected standalone changes in (a) climate (100-year rainfall together with ET), (b) land cover, and (c) 100-year sea level under different future scenarios in the Southeast Coasts Basin. 
(a)

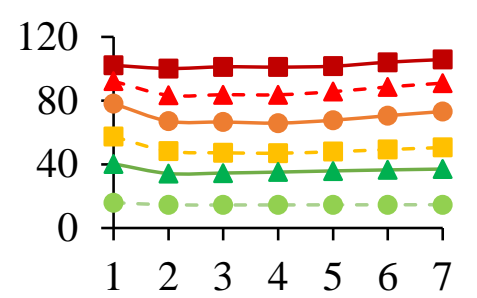

(b)

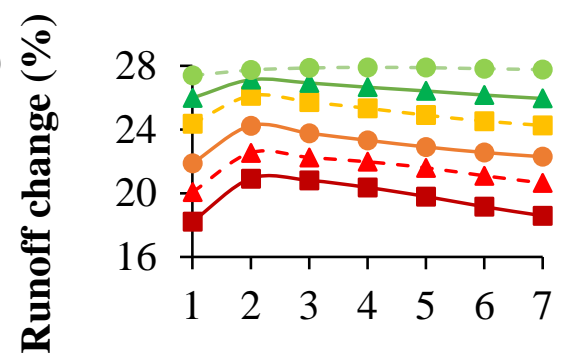

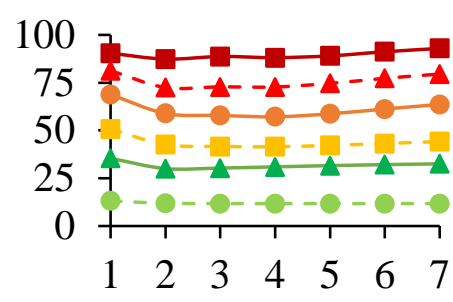
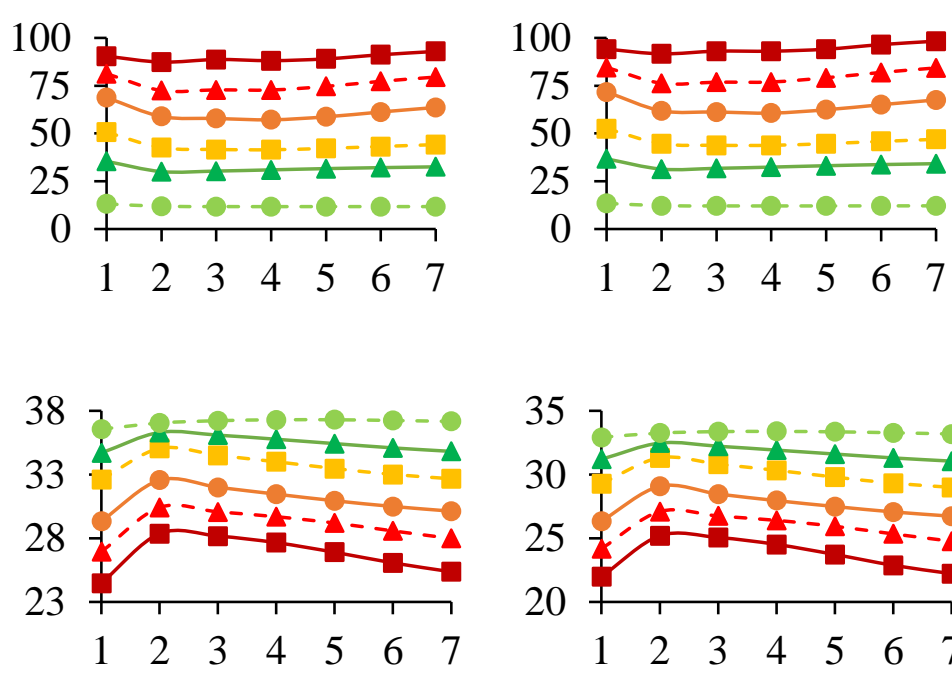
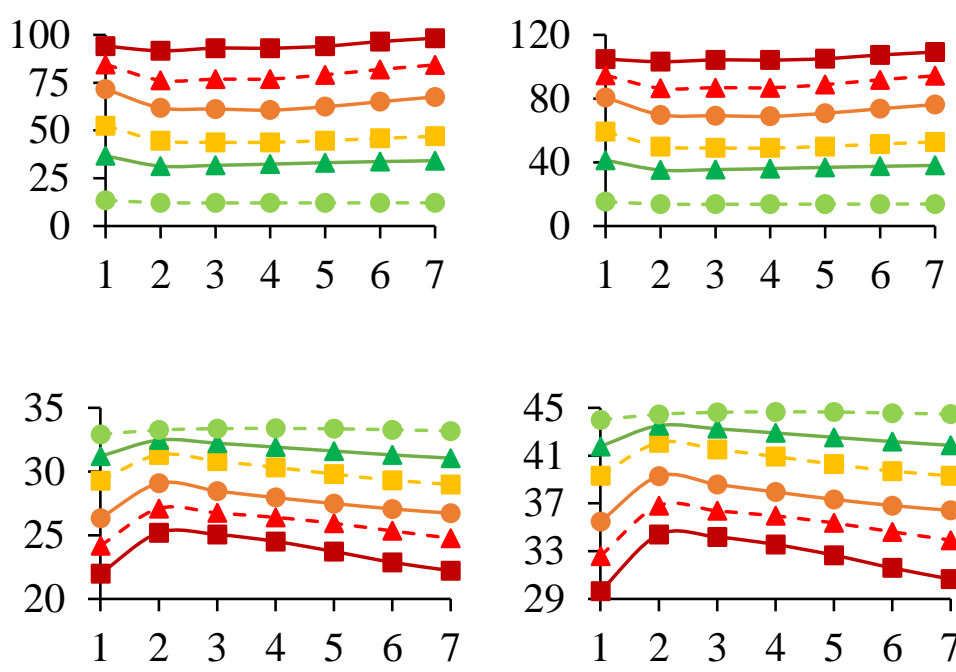

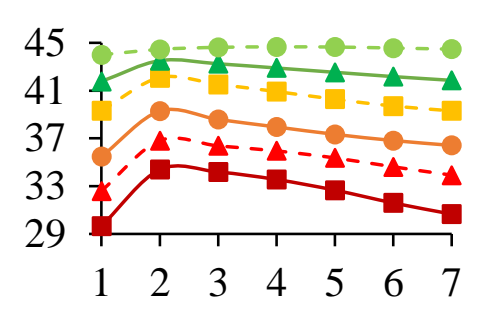

(c)

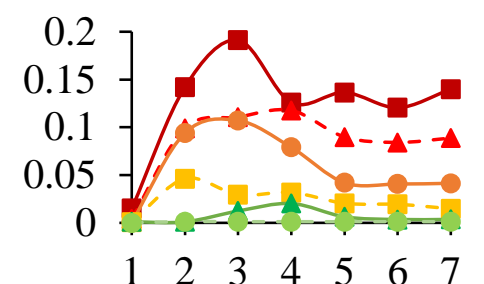

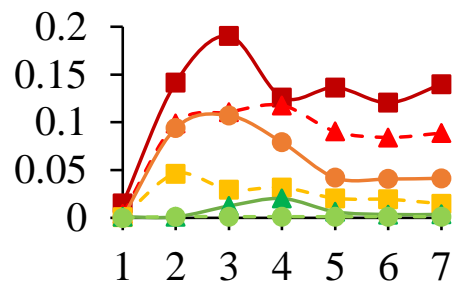
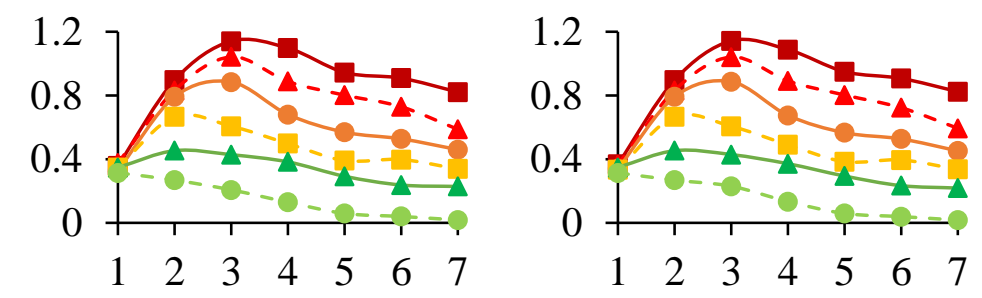

\section{Duration (day)}

$$
-\bullet-2 \text {-year } \longrightarrow 5 \text {-year }-\varpi-10 \text {-year } \rightarrow 25 \text {-year }-\star-50 \text {-year } \rightarrow-100 \text {-year }
$$

Figure 4.6: Percentage changes in 1-7 day total runoff due to the projected standalone changes in (a) climate (rainfall of varying return periods and ET), (b) land cover, and (c) sea level of varying return periods under different future scenarios in the Southeast Coasts Basin. 
The basin-scale runoff volume changes under changing land cover were much lower than that under changing climate. Potential future standalone changes in land cover across the Southeast Coasts Basin, while keeping the rainfall extremes in 2010 unchanged, led to 18 to $45 \%$ relative increases in basin-scale extreme runoff volumes of different durations and return periods (Figure 4.6b). Higher runoff increases of 30 to $45 \%$ were found for the 2080-RCP 8.5 scenario because of the corresponding highest potential increase in basin-average imperviousness (Table A4.4 in Appendix 4). Runoff increases in the 2080-RCP 4.5, 2050-RCP 8.5, and 2050-RCP 4.5 were, respectively, 24 to $37 \%, 22$ to $33 \%$, and 18 to $28 \%$. Runoff increases under changing land cover attenuated with increases in return period of rainfall events in 2010. Meanwhile, in case of the 2-year return period event, runoff increases intensified with increases in event duration up to 4-day; the relative runoff increases decreased thereafter. For the higher return period events, relative runoff increases intensified when even durations were increased up to 2-day; runoff increases decreased for the following higher durations. These extreme runoff responses suggested greater influence of land cover on runoff generation under extreme rainfall events of lower depths than that under extreme rainfall events of higher depths in coastal-urban environments. The maximum land cover-change driven increase in basin-scale extreme runoff volume of $45 \%$ resulted for the 4-day event with 2-year return period under the 2080-RCP 8.5 scenario (Figure 4.6b).

\subsubsection{Under standalone changes in sea level}

In comparison to climatic and land cover changes, (Figure 4.5a, b), 0.38 to $1.14 \mathrm{~m}$ projected SLR across the Southeast Coasts Basin (Table A4.5) gave significantly lower spatial mean 0.4 to 1.8 $\mathrm{mm}$ increases in 7-day runoff (Figure 4.5c). Almost 97\% area of the basin did not experience any runoff increases from the potential SLR. Urban centers in the north-central (e.g., West Palm 
Beach, Boca Raton), central (e.g., Sunrise, Fort Lauderdale, Hollywood), and south-central (e.g., Doral, Hialeah, Miami) parts of the basin had spatial mean 7 to $31 \mathrm{~mm}$ increases in runoff extremes under different future scenarios. Close proximity of GWL to ground surface at these basin regions, with depth to event-average GWL from ground surface varying from 0.60 to 0.73 $\mathrm{m}$ (spatial mean), might have resulted in the runoff increases under the potential SLR. The 2080RCP 8.5 scenario gave the highest spatial mean runoff increase of $1.8 \mathrm{~mm}$ on account of the maximum projected SLR among the other scenarios (Table A4.5).

Projected standalone changes in sea level, in comparison to that in climate and land cover, gave nominal changes in basin-scale extreme runoff volume for different durations and return periods under all future scenarios: 2080-RCP 8.5 (0.02 to $1.14 \%), 2050-\mathrm{RCP} 8.5$ (0.02 to 1.14\%), 2080-RCP 8.5 (0 to $0.19 \%$ ), and 2080-RCP 4.5 (0 to $0.19 \%$ ) (Figure 4.6c). The two RCP 8.5 scenarios had comparatively higher runoff increases because of the higher projected SLR. The much lower increases in runoff extremes under changing sea level than that under changing climate, as it were also observed in case of changing land cover, reiterated the dominant role of climate, i.e., rainfall in extreme runoff generations in the coastal-urban Southeast Coasts Basin. Overall, runoff increases under changing sea level intensified with increases in event return periods for rainfall and sea level. Increase in basin runoff extremes with increase in rainfall and sea level event durations showed mixed trends across different return periods with drop in runoff increases, generally, for the higher duration events. The overall decreasing nature of basin runoff increases for higher duration events indicates diminishing impact of SLR induced GWT rise in accelerating soil saturation and runoff generation when the soil is already at or near saturation due to the more sustained rainfalls. The highest sea level- 
change induced increase in basin-scale extreme runoff volume of $1.14 \%$ was found for the 3 -day, 100-year return period event under the 2080-RCP 8.5 scenario (Figure 4.6c).

\subsubsection{Extreme future runoffs under concurrent changes in two major drivers}

\subsubsection{Under concurrent changes in climate and land cover}

Combined changes in climate and land cover led to more widespread and greater ensemble mean increases in 7-day 100-year runoff extremes of 147 to $173 \mathrm{~mm}$ (on spatial mean, per $\mathrm{m}^{2}$ of basin area) under different future scenarios (Figure 4.7a) than isolated impacts of climatic (Figure 4.5a) and land cover (Figure 4.5b) changes. Urban centers across a more distinguishable spatial extent from the south-central to the north-central Southeast Coasts Basin (e.g., West Palm Beach, Fort Lauderdale, Miami) are projected to go through 187 to $220 \mathrm{~mm}$ spatial mean rainfall increases and 6 to 9 percentage points spatial mean imperviousness increases. These cities would consequently have very high 195 to $228 \mathrm{~m}$ runoff increases for different future scenarios. The northern, western, and southern regions of the basin, characterized by croplands, pasture lands, grasslands, and wetlands, at the northern, western, and southern regions of the basin would experience projected high increases in both rainfall extremes (187 to $212 \mathrm{~mm}$ ) and imperviousness (11 to 21 percentage points). As a result, notable increases in spatial mean extreme runoff volume of 111 to $160 \mathrm{~mm}$ are expected at these natural basin locations. Overall, the spatial patterns of potential extreme runoff increases in different scenarios due to climaticland cover changes (Figure 4.7a) reflected that due to the climatic changes (Figure 4.5a). Maximum projected spatial mean rainfall and imperviousness increases of $223 \mathrm{~mm}$ and 10 percentage points, respectively, in the 2080-RCP 8.5 scenario (Figure A4.6a, b), produced the corresponding highest spatial mean runoff increase of $173 \mathrm{~mm}$ among the different future scenarios. 


\section{0-RCP $4.5 \quad$ 2080-RCP $4.5 \quad$ 2050-RCP $8.5 \quad$ 2080-RCP 8.5}

(a) Climate and land cover
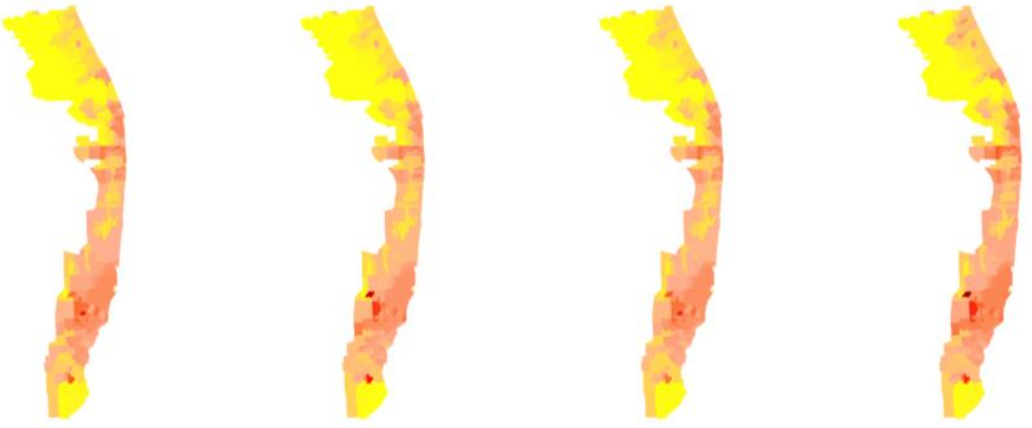

(b) Climate and sea level
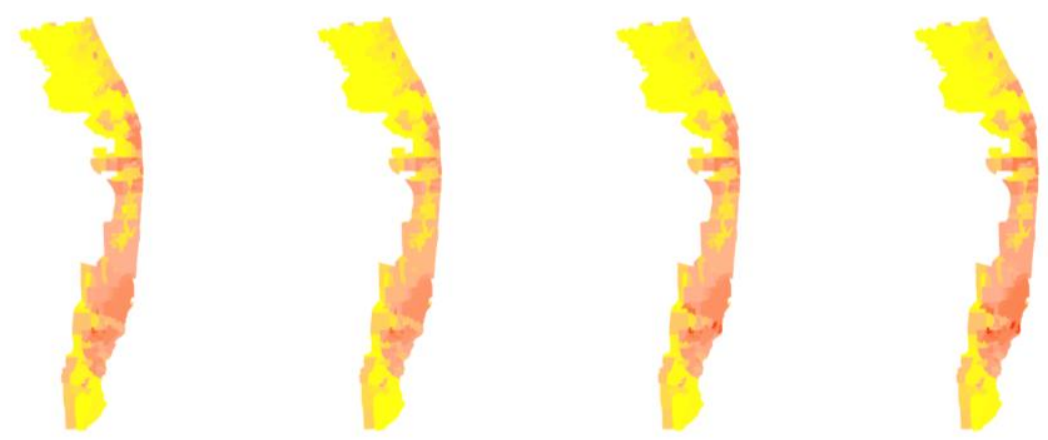

(c) Land cover and sea level

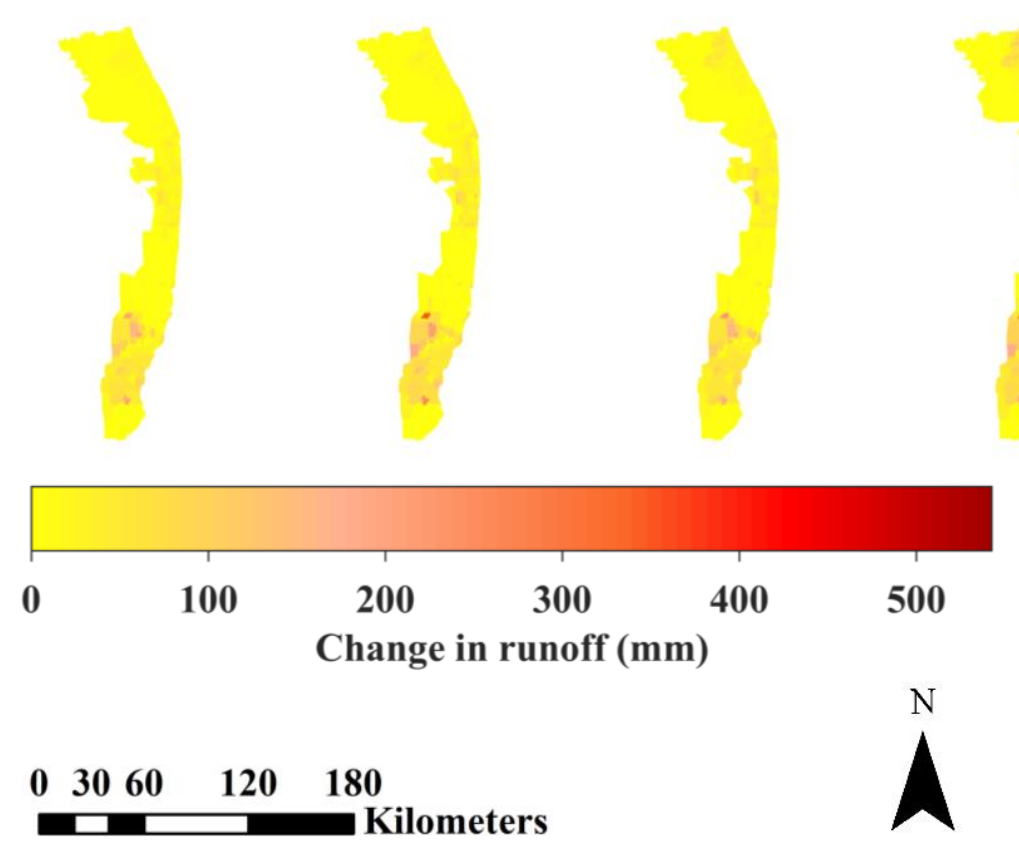

Figure 4.7: Spatial variation of the predicted changes in 7-day total runoff depth due to the projected simultaneous changes in (a) climate (100-year rainfall together with ET) and land cover, (b) climate and 100-year sea level, and (c) land cover and 100-year sea level under different future scenarios in the Southeast Coasts Basin. 
Subject to simultaneous potential changes in climate and land cover, basin-scale 1-7 day extreme runoff volumes would increase by 63 to $144 \%, 46$ to $125 \%, 48$ to $121 \%$, and 52 to $121 \%$ on the 2080-RCP8.5, 2050-RCP 4.5, 2050-RCP 8.5, and 2080-RCP 4.5 scenario (Figure 4.8a), respectively. Higher increases in rainfall (Figure A4.7) and highest increase in basinaverage imperviousness (Table A4.4) caused higher runoff increases in the 2080-RCP 8.5 than the other scenarios. Climate-land cover driven runoff increases intensified with increases in return period. With increasing event duration, it had mixed trends across different return periods. Maximum increase in basin-scale extreme runoff volume of $144 \%$, driven by climatic-land cover changes took place under the 2080-RCP 8.5 scenario for a 2-day 100-year event (Figure 4.8a).

\subsubsection{Under concurrent changes in climate and sea level}

Concurrently changing climate and sea level produced spatial mean 125 to $149 \mathrm{~mm}$ increases in ensemble mean extreme runoff for the 7-day 100-year event (Figure 4.7b). The runoff increases were mainly governed by the spatial mean 197 to $223 \mathrm{~mm}$ increases in ensemble mean rainfall (Figure A4.6a). The spatial pattern of climatic-sea level change induced runoff increases was quite similar to that of climatic-change driven runoff increases (Figure 4.5a), which can be attributed to no runoff increases from SLR at almost 97\% basin locations (Figure 4.5c). Urban centers at the central (e.g., Fort Lauderdale) and the south-central (e.g., Doral, Hialeah, Miami) parts of the basin are projected to have 191 to $285 \mathrm{~mm}$ spatial mean increases in the runoff extremes under different future scenarios due to simultaneously changing climate and sea level. Highest spatial mean runoff increase of $149 \mathrm{~mm}$ resulted in the 2080-RCP 8.5 scenario because of the corresponding maximum spatial mean rainfall increase (Figure A4.6a) and SLR (Table A4.5). 
2050-RCP 4.5

(a)

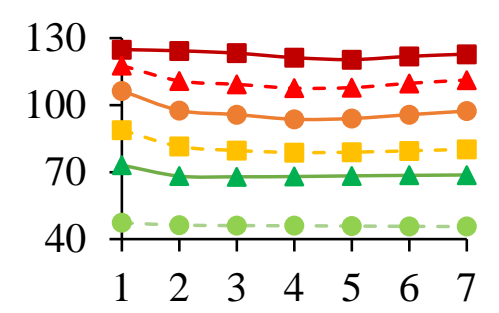

(b)

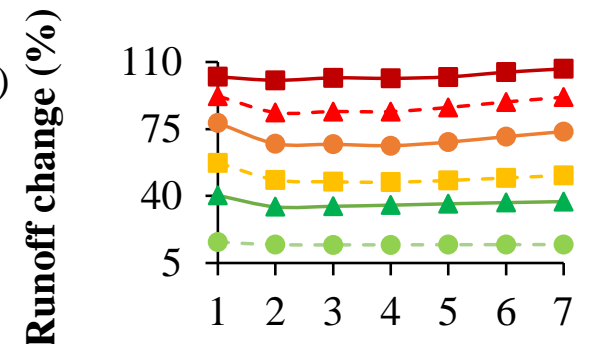

(c)

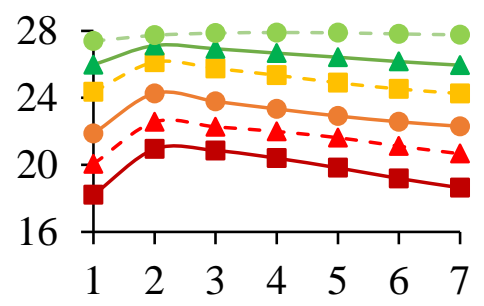

2080-RCP 4.5
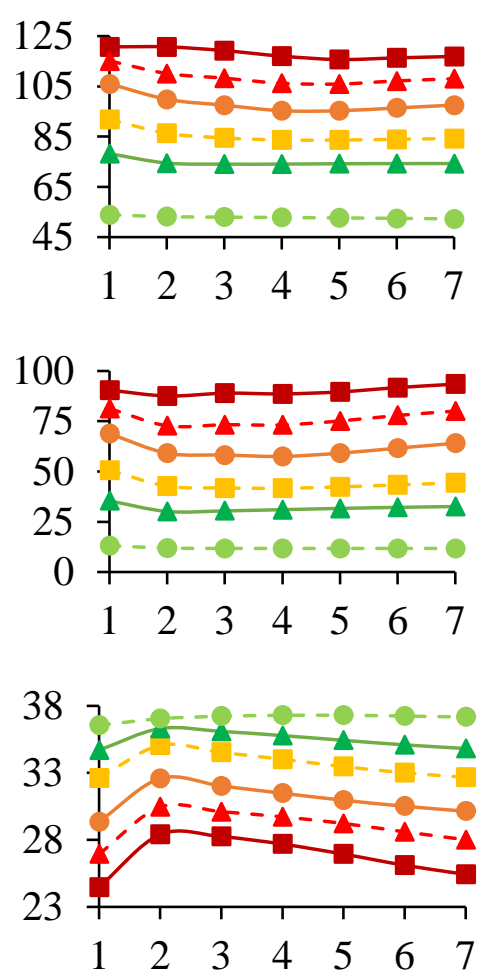

2050-RCP 8.5
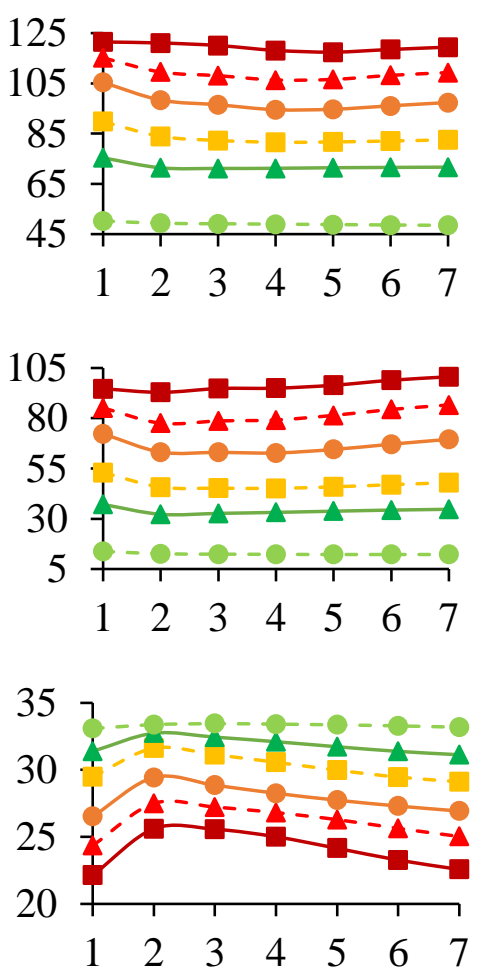

2080-RCP 8.5
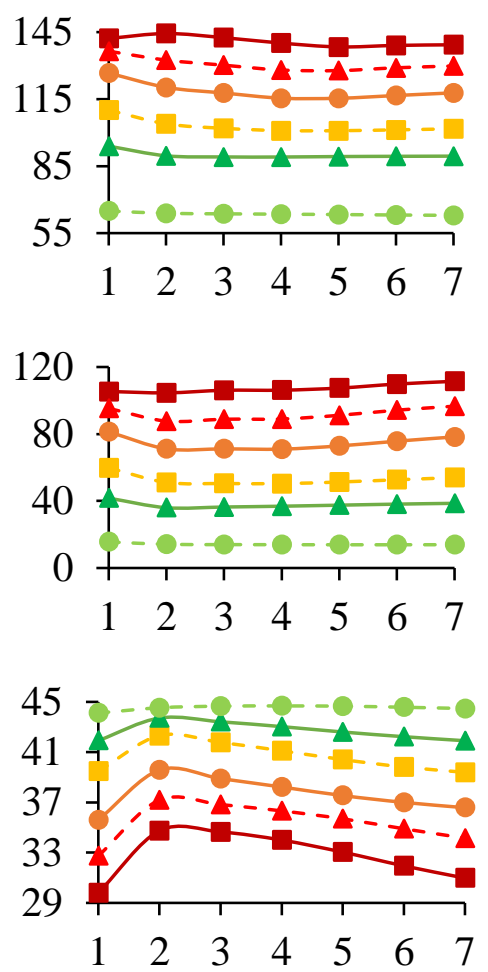

\section{Duration (day)}

$$
-\bullet-2 \text {-year } \longrightarrow 5 \text {-year }-\varpi-10 \text {-year } \longrightarrow 25 \text {-year }-\star-50 \text {-year } \rightarrow-100 \text {-year }
$$

Figure 4.8: Percentage changes in 1-7 day total runoff due to the projected simultaneous changes in (a) climate (rainfall of varying return periods and ET) and land cover, (b) climate and sea level of varying return periods, and (c) land cover and sea level of varying return periods under different future scenarios in the Southeast Coasts Basin. 
Concurrent changes in climate and sea level brought increases in basin-scale runoff volume extremes of 14 to $111 \%, 14$ to $106 \%, 12$ to $101 \%$, and 12 to $93 \%$, respectively, in the 2080-RCP 8.5, 2050-RCP 4.5, 2050-RCP 8.5, and 2080-RCP 4.5 (Figure 4.8b). Higher runoff increases were found in the 2080-RCP 8.5 scenario, in comparison to the other scenarios in regards to the higher projected rainfall increases (Figure A4.7) and the highest projected SLR (Table A4.4). Similar to isolated climatic change, combined climatic-sea level change driven basin-scale runoff volume increases had upward trends with increasing return periods and mixed trends with increasing event durations. Highest runoff volume increase of $111 \%$ from combined climatic and sea level changes took place for the 7-day 100-year event in the 2080-RCP 8.5 (Figure 4.8b).

\subsubsection{Under concurrent changes in land cover and sea level}

Simultaneous potential changes in land cover and sea level produced 21 to $32 \mathrm{~mm}$ spatial mean increases in 7-day 100-year runoff across different scenarios (Figure 4.7c), which were substantially lower than the runoff changes due to climatic-land cover and climatic-sea level changes (Figure 4.7a, b). Because of lack of SLR impact at majority of the basin locations (Figure 4.5c), the spatial pattern of runoff increases under concurrently changing land cover and sea level primarily followed that under individually changing land cover (Figure $4.5 \mathrm{~b}$ ). Central (e.g., Fort Lauderdale) and the south-central (e.g., Doral, Hialeah, Miami) basin locations would be under projected to have 61 to $97 \mathrm{~mm}$ spatial mean runoff increases across different future scenarios mostly due to the spatial mean potential 14 to 19 percentage points increase in imperviousness (Figure A4.6b). The maximum projected spatial mean 10 percentage points increase in imperviousness and projected SLR of $1.14 \mathrm{~m}$ (Table A4.5) resulted in the highest spatial mean runoff increase of $32 \mathrm{~mm}$ in the 2080-RCP 8.5 . 
Under the combined land cover-sea level changes, relatively low increases in basin-scale runoff volume extremes were observed under all scenarios: 2080-RCP 8.5 (30 to 45\%), 2080RCP 4.5 (24 to 37\%), 2050-RCP 8.5 (22 to 33\%), and 2050-RCP 4.5 (18 to 28\%) (Figure 4.8c). Maximum projected increase in basin-average imperviousness (Table A4.4) together with maximum projected SLR (Table A4.5) in the 2080-RCP 8.5 contributed to the subsequent highest relative increase in basin runoff volume of $45 \%$. Basin runoff increases from concurrently changing land cover and sea level showed downward trends with increasing event return periods, and initial upward trends followed by later downward trends with increasing event durations, as it were also observed in case of individually changing land cover (Figure 4.6b). Due to combined changes in land cover and sea level, maximum relative increase in basin runoff volume of $45 \%$ occurred for the 4-day 2-year event in 2080-RCP 8.5.

\subsubsection{Extreme future runoffs under concurrent changes in all major drivers}

When projected changes in climate, land cover, and sea level were superimposed, spatial mean increases in 7-day runoff of 148 to $175 \mathrm{~mm}$ across the four future scenarios were found (Figure 4.9), relative to runoffs in 2010. Since the potential SLR produced runoff increases at a very few basin locations (Figure 4.5c), spatial variation in runoff increases from changes in all three drivers was almost similar to that from the combined changes in climate and land cover (Figure 4.7a). The central to south-central stretch of the basin are expected to experience potential high rainfall increases (Figure A4.6a), moderate to high increases in imperviousness (Figure A4.6b), and high SLR (Table A4.5). Therefore, moderate to high spatial mean runoff increases of 156 to $189 \mathrm{~mm}$ and 279 to $363 \mathrm{~mm}$ are projected for the central (e.g., Fort Lauderdale) and the southcentral (e.g., Doral, Hialeah, Miami) basin locations under simultaneous changes in all these drivers. Since maximum increases in rainfall, imperviousness, and sea level are anticipated in the 
2080-RCP 8.5, this scenario gave the maximum potential spatial mean runoff increase of 175 $\mathrm{mm}$.

Concurrent projected changes in climate, land cover, and sea level gave relative increases in basin-scale runoff volume of 63 to $145 \%, 46$ to $125 \%, 48$ to $122 \%$, and 52 to $121 \%$ under the 2080-RCP 8.5, 2050-RCP 4.5, 2050-RCP 8.5, and 2080-RCP 4.5 scenario (Figure 4.10), respectively. Subject to simultaneous changes in all major drivers, increases in basin-scale extreme runoff volume intensified with increases in event return period. With increasing even durations, runoff increases demonstrated mixed trends. Maximum relative increase in basin runoff volume of $145 \%$ under combined climate-land cover-sea level changes was noted in the 2080-RCP 8.5 for a 2-day 100-year event. Highest basin runoff volume increase was observed for the 2080-RCP 8.5 on account of the corresponding maximum potential increase in rainfall (Figure A4.7), imperviousness (Table A4.5), and sea level (Table A4.5). Based on the potential basin-wide runoff volume increases (Figure 4.10), 2050-RCP 4.5 and 2080-RCP 8.5 are the most critical near-term and long-term future scenarios in the Southeast Coasts Basin in terms of vulnerability assessment of major infrastructures under potential extreme runoff and flooding risks. 

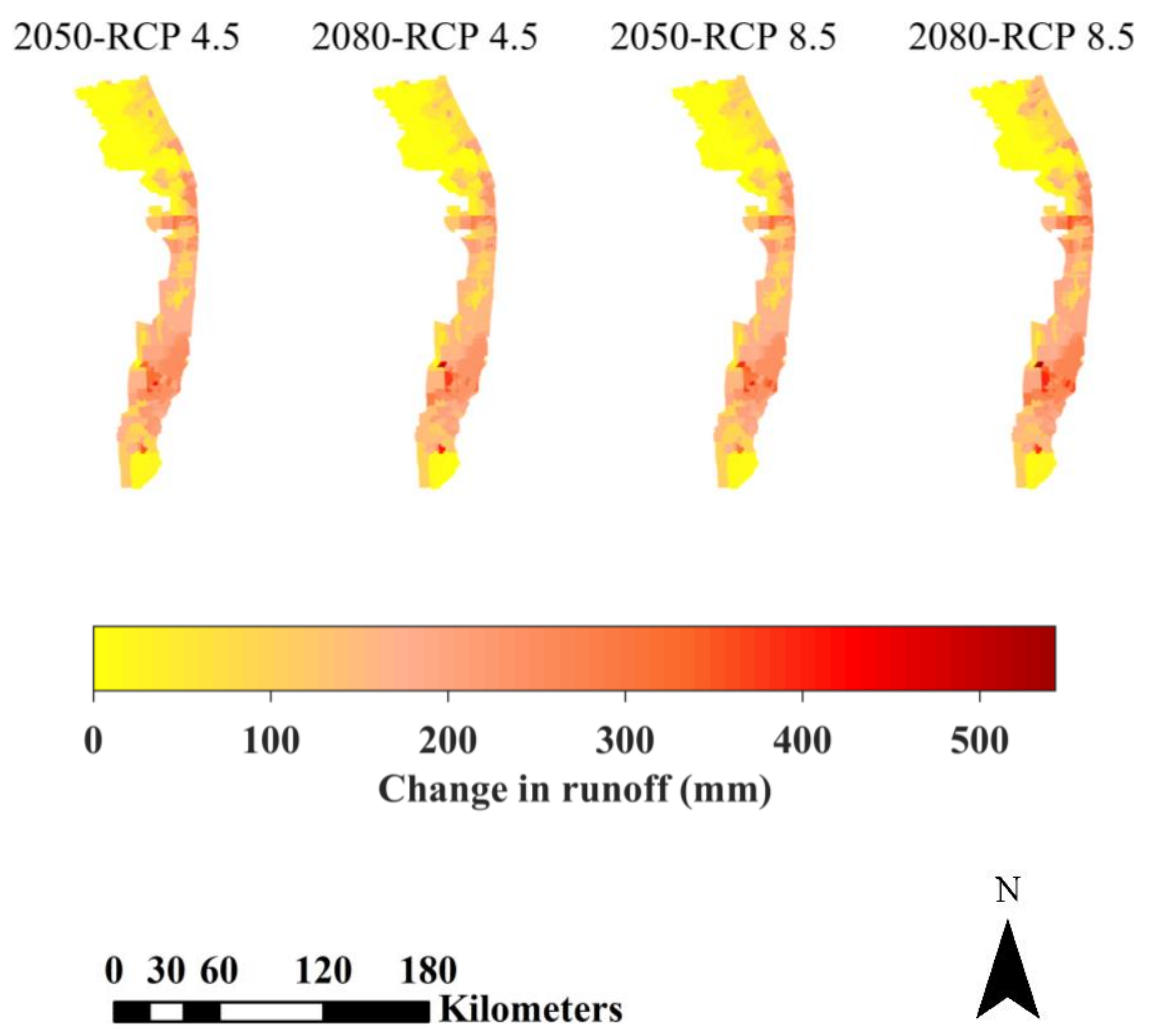

Figure 4.9: Spatial variation of the predicted changes 7-day total runoff depth due to the projected simultaneous changes in climate (100-year rainfall together with ET), land cover, and 100-year sea level in the Southeast Coasts Basin. 
2050-RCP 4.5

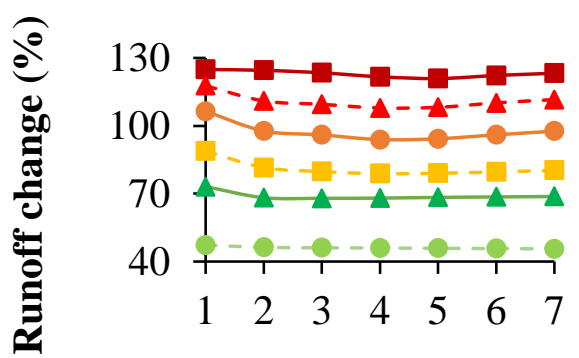

2080-RCP 4.5

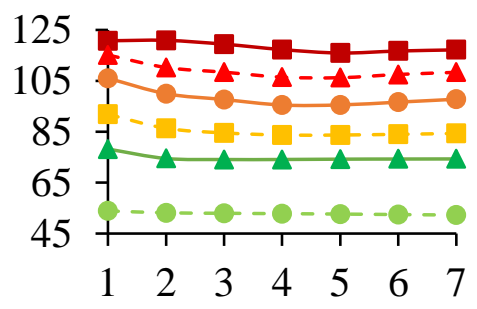

2050-RCP 8.5

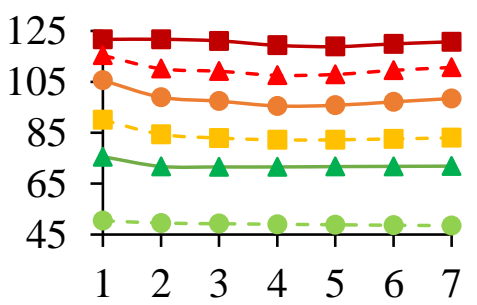

2080-RCP 8.5

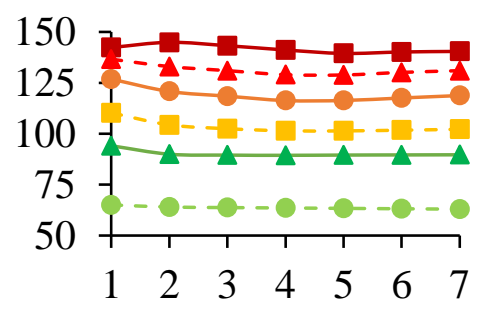

\section{Duration (day)}

$$
-\bullet \text { - 2-year } \rightarrow-5 \text {-year }-"-10 \text {-year } \rightarrow-25 \text {-year }-\star-50 \text {-year } \rightarrow-100 \text {-year }
$$

Figure 4.10: Percentage changes in 1-7 day total runoff due to the projected simultaneous changes in climate (rainfall of varying return periods and ET), land cover, and sea level of varying return periods under different future scenarios in the Southeast Coasts Basin. 


\subsection{Discussion}

\subsubsection{Historical and future scenarios of extreme rainfall, sea level, and runoff scenarios}

Most (75\%) of the long-term rainfall stations in the Southeast Coasts Basin (Figure 4.3) did not have monotonic trends in 1-7 day maximum annual rainfalls for 1964-2013 at 5\% statistical significance level (Table 4.2). Except for 2-day duration, station 086988 represented significant decreasing trends for all other event durations; station 086323 had significant decreasing trend for 7-day maximum annual rainfall only. Both of the tide stations in this study, however, had significant increasing trends in 1-7 day maximum annual water level for 1964-2013 (Table 4.3). Estimated stationary design rainfalls and non-stationary water levels, as suggested by the trend analyses outcomes, in 2010 ranged from 92 to $489 \mathrm{~mm}$ (Table 4.4) and -0.014 to 0.271 m NAVD 88 (Table 4.6) across different stations, event durations, and return periods. Basin-wide extreme runoff volume in 2010 varied from 148 to 646 million $\mathrm{m}^{3}$ across different event durations and return periods (Table 4.7).

Under isolated potential changes in climate (rainfall and ET) and land cover, higher (than other locations) runoff increases at and around the major urban centers (e.g., Fort Pierce, Port St. Lucie, Jupiter, West Palm Beach, Boca Raton, Sunrise, Fort Lauderdale, Hollywood, Doral, Hialeah, Miami, and Homestead) across the basin were noted (Figure 4.5a, b). Much of the northern, western, and southern parts of the basin, currently characterized by croplands, pasture, grasslands, and wetlands, were also projected to experience notable runoff increases owing to the potential land development activities. Individual changes in sea level did not bring any runoff increases in most (97\%) parts of the basin (Figure 4.5c) except for a few urban centers where GWLs were in close proximity to ground surface. Concurrent 'two at a time' (more notably in case of 'climatic-land cover' changes) and 'three at a time' changes in the drivers produced 
greater and more widespread increases in runoff across the Southeast Coasts Basin (Figure 4.7; Figure 4.9). The spatial patterns of potential runoff increases under the combined 'climatic-land cover' and 'climatic-land cover-sea level' changes, generally, corresponded to that under the isolated climatic changes (Figure 4.5a).

Future extreme basin-wide runoff volume in the Southeast Coasts Basin can increase from 12 up to $109 \%$ (Figure 4.6a), relative to runoff volume in 2010, across different scenarios, event durations, and return periods in response to potential climatic changes. For individual changes in land cover and sea level, respectively, the basin-wide runoff increases ranged from 18 to $45 \%$ and 0 to $1.14 \%$ (Figure $4.6 \mathrm{~b}, \mathrm{c}$ ) — denoting climate (primarily rainfall) as the controlling driver of future extreme runoff generation. Under concurrently changing climate, land cover, and sea level, higher relative increases in basin-wide extreme runoff volume of 63 to $145 \%$ were found for the 2080-RCP 8.5 (Figure 4.10) — making it the most critical future scenario for extreme runoff and pluvial flooding risks.

Except for land cover, future relative increases in basin-scale extreme runoff volume, due to individual changes in drivers, intensified with increases in event return periods (Figure 4.6a). Runoff increases under individually changing rainfall showed mixed trends with increases in event duration. In contrast, runoff increases under individual changes in both land cover and sea level demonstrated overall decreasing trends with event duration increases (Figure 4.6b, c), which were particularly true for the higher durations — suggesting diminishing impacts of land cover change and SLR on runoff when the soil is at or near saturation due to sustained rainfalls. 


\subsubsection{Comparison of study findings with existing literature}

The findings of this study are in general agreements with existing relevant research on Florida and different regions across the globe. For example, Mahjabin and Abdul-Aziz (2020) reported locally significant $(p$-value $\leq 0.10)$ increasing trends in 4-7 day annual maximum rainfalls for 6\% (1 out of 18) of different stations across Florida during 1960-2010. In the current study, locally significant ( $p$-value $\leq 0.05$ ) decreasing trends in 1-6 day (except for 2-day) and 7-day annual maximum rainfalls were found, respectively, for 13\% (1 out of 8 ) and 25\% (2 out of 8) of different stations across southeast Florida during 1964-2013 (Table 4.2). The differences in trend direction can be attributed to difference in the gauging stations across the two studies where locally significant trends were found. Furthermore, Irizarry-Ortiz et al. (2013) reported, for 19502008, statistically significant decreasing trends in 2-3 day maximum rainfalls for 6\% (2 out of 32) of different stations across Florida at 5\% significance level. Further, they found significant decreasing trends in 5 and 7-day maximum rainfalls for 3\% (1 out of 32) of stations. Their findings are comparable to the statistically significant decreasing trends in annual maximum rainfalls found for northeast Florida (Table 4.2). The reported decreasing trends might be due to the general decrease in wet season rainfall in Florida, as reported by Irizarry-Ortiz et al. (2013) during 1950-2008. The current study demonstrated significant increasing trends in sea level at both of the tide stations during 1964-2013. The upward sea level trends were evidence of the consistent SLR in south Florida which has been corroborated by the recent studies (e.g., Wdowinski et al., 2016; Valle-Levinson et al., 2017; Domingues et al., 2018; Jones et al., 2019).

Based on the potential future extreme runoff scenarios (Figure 4.5 and 4.6), it was evident that potential climatic (i.e., rainfall) changes would be the dominant driver of changing extreme runoff regimes and pluvial flooding risks, as compared to potential land cover changes 
and SLR in the Southeast Coasts Basin by both the middle and end of the 21 st century.

Skougaard Kaspersen et al. (2017) also reported greater relative importance of climatic change than urban development for increased exposure to 50 and 100-year pluvial floodings during 2081-2100 in four European cities: Odense, Denmark; Vienna, Austria; Strasbourg, France; and Nice, France. Similarly, Khan et al. (2019) found climatic changes to be more impactful than urbanization on extreme runoffs during 2016-2035 for different study basins in Maryland, USA.

Siddique and Palmer (2020) concluded that with respect to the base period of 1960-1999, 25-50\% and over 50\% increases in 100-year 1-day precipitation during 2021-2060 and 20602099, respectively, would increase 100-year 1-day streamflow in the Merrimack river of Massachusetts, USA up to $13.7 \%$ and $20.6 \%$. In comparison, in the Florida Southeast Coasts Basin, up to $102 \%$ and $105 \%$ increase in basin-wide 1-day 100-year runoff volume (with respect to the baseline 2010) in the year 2050 and 2080 were found, respectively (Figure 4.6a), for the corresponding rainfall increases up to $45 \%$ and $46 \%$ (Figure A4.7). Accelerated runoff responses due widespread impervious cover throughout the basin contributed to the very high relative runoff increases for southeast Florida in response to the potential climatic changes. Zope et al. (2016) reported a $4.45 \%$ increase in 100 -year runoff volume for a $74.84 \%$ increase in the built up area between 1966 and 2009 for the Oshiwara River Basin of Mumbai, India. In comparison, for a potential $35.6 \%$ increase in basin-average imperviousness in 2080 under RCP 8.5 (Table A4.4), 30 to $34 \%$ increases in 100-year runoffs of 1-7 day durations were found in the Southeast Coasts Basin (Figure 4.6b).

\subsubsection{Potential implications for hydrologic and environmental impact management}

Projected changes in runoff extremes in the Southeast Coasts Basin may adversely affect its hydrologic and environmental sustainability. Potential high increases in runoff extremes around 
major urban centers across the Basin (e.g., West Palm Beach, Boca Raton, Fort Lauderdale, Hollywood, Miami, Doral) under changing climate, land cover, and sea level (Figure 4.9) indicates risks of pluvial flooding and impaired surface water quality. The additional extreme runoff volume might overwhelm the drainage and flood control system in southeast Florida if they don't go through continued improvements for adapting to both near and far-term adverse impacts of changes in the major drivers. It was seen that potential land cover changes would cause higher runoff volume increases for more recurring (i.e., lower return period) rainfall events in the Southeast Coasts Basin. Many cross drainage facilities (permanent culverts, bridgeculverts) and bridges in roadways of Florida are designed considering 10 and 25-year floods (FDOT, 2020). The anticipated persistent urbanizations and developments in Southeast Florida, therefore, might cause increased flooding risks for its roadways and severely damage its transportation infrastructure accordingly.

Increased extreme runoff volume from the Southeast Coasts Basin would bring additional nutrient loadings to different estuarine water bodies such as the Indian River Lagoon, St. Lucie Estuary, and Biscayne Bay, etc., which can endanger many of its marine species. Apart from the high nutrient loading, the freshwater influx is also characterized by high turbidity and low salinity. These may cause bleaching and death of the coral reefs in the estuaries (e.g., St. Lucie Estuary; see Lapointe et al., 2012). In many cases, however, water quality and biodiversity in these adjacent estuarine waterbodies (e.g., Biscayne Bay) would recover from the detrimental impacts of extreme events in a few months (Wachnicka et al., 2020).

\subsubsection{Limitations and caveats of the study and uncertainties}

Impacts of potential changes in upstream streamflow boundary conditions, to reflect the influence of streams originating from outside of the basin (mostly from Lake Okeechobee), were 
not considered in this study to construct the future extreme future runoff projections. During the preliminary analyses, sensitivities of basin-wide 7-day 100-year extreme runoff volume of the Southeast Coasts Basin in 2010 to changing upstream boundary condition were evaluated. The sensitivity scenarios were designed based on the potential future ensemble mean relative changes in extreme rainfalls projected by the CMIP5 GCMs assuming similar relative changes in the streamflow in 2010. With respect to 2010, basin-average rainfall in the Southeast Coasts Basin is projected to increase from 11 to $52 \%$ in 2050 and 2080 across the two RCP scenarios, different event durations and return periods (Figure A4.7). The upstream streamflows in 2010 were perturbed from 10 to $50 \%$, with an increment of $10 \%$ accordingly. The perturbations gave very nominal relative changes in basin-wide 7-day 100 -year extreme runoff volume of 0.01 to $0.03 \%$. The future extreme runoff scenarios were therefore estimated based on the projected changes in climate (rainfall, ET), land cover (imperviousness), and sea level.

The large-scale Southeast Coasts Basin has plenty of local management structures such as street inlets, underground sewers, and catch-basins. Those were not incorporated in the model assuming that surface runoff would eventually reach to the canals and rivers. No significant changes in the drainage networks and stream geometric features between the historical and future period were assumed while estimating the future extreme runoffs. Average of the hourly rainfall distributions corresponding to the 50-year annual maximum rainfall and water level values, for a particular event duration, was used to disaggregate their historical as well future design values. The historical hourly rainfall distributions were used for hourly disaggregation of the future design rainfalls since GCMs do not represent observed hourly rainfall distributions satisfactorily. Historical hourly sea level distributions were used to for hourly disaggregation of future design seas levels since relative SLR projections were available in terms of overall increase in water 
surface elevation only. Since, design sea level estimations were available at outlet of two streams only: the West Palm Beach Canal and the Miami River, they were assigned to outlet of the other streams (while considering the differences in stream bed elevation) based on proximity due to the corresponding limited availability of the long-term hourly sea level data. These can be reckoned as caveats of the current study since potential future changes in hourly rainfalls and sea levels, drainage networks, and management structures are likely to impact the physical processes related to extreme runoff generation.

Different large-scale ocean-atmospheric phenomena such as El Niño-Southern Oscillation (ENSO), Pacific Decadal Oscillation (PDO), Atlantic Multi-decadal Oscillation (AMO), North Atlantic Oscillation (NAO), Arctic Oscillation (AO), sea-breeze convection, and tropical storms/hurricanes frequently contribute to seasonal climatic anomalies in southeast Florida (Obeysekera et al., 2011; Abdul-Aziz and Al-Amin, 2015). These phenomena are not well addressed by the CMIP5 GCMs (Zhao et al., 2017; Lu et al., 2018), which can bring uncertainties into their climatic projections and affect the design rainfall estimations. Furthermore, differences in climatic projections of the 20 CMIP5 GCMs led to high uncertainties in the estimated future runoff extremes, which necessitated considering the ensembled projected runoffs. The possible uncertainties in the land cover and SLR projections are also to be considered during decision-making based on the runoff projections.

\subsection{Conclusions}

This study investigated the shifts in extreme runoff regimes in response to potential climatic (rainfall and ET), land cover (imperviousness), and sea level changes in complex coastal-urban environments, considering the Florida Southeast Coasts Basin as the study area. A large-scale $\left(7117 \mathrm{~km}^{2}\right)$ mechanistic hydrologic model, using U.S. EPA SWMM 5.1, was developed for the 
basin. The Southeast Coasts Basin model was calibrated and validated (NSE $=0.74$ to 0.92 , RSR $=0.28$ to 0.51$)$ with daily observed streamflow of 2004-2013. Significance $(p$-value $\leq 0.05)$ and direction of monotonic trends in annual maximum rainfalls and sea levels of 1-7 day durations were then evaluated for the historical 50-year period of the 2000s (1964-2013) by means of the non-parametric Mann-Kendall test and the Theil-Sen slope estimator. Locally significant decreasing trends in 1-6 day (except for 2-day) and 7-day historical annual maximum rainfalls, respectively, were found for $13 \%$ and $25 \%$ of the 8 rainfall stations across the basin. None of the remaining rainfall stations represented significant trends.

Based on the trend analyses outcomes, stationary 1-7 day design rainfall estimations with varying return periods $(2,5,10,25,50$, and 100 year) for the historical as well as future periods were performed using the Gumbel extreme value distribution. Design rainfalls in 2010, representing the 2000s, ranged from 92 (for a 1-day 2-year event) up to $489 \mathrm{~mm}$ (for a 7-day 100-year event) across the rainfall stations. Future design rainfalls were estimated for two 50year periods: the 2050s (2025-2074) and the 2080s (2050-2099) under RCP 4.5 and 8.5 using the rainfall projections from the 20 CMIP5 GCMs. For both of the tide stations used in this study, locally significant increasing trends in 1-7 day historical annual maximum sea levels were noted. Therefore, non-stationary design sea levels were estimated in the 2000s using the non-stationary Gumbel extreme value distribution considering trend in its location parameter. Design sea levels in 2010 ranged from -0.014 (for a 7-day 2-year event) up to $0.271 \mathrm{~m}$ NAVD 88 (for a 1-day 100year event) across the tide stations. Future design sea level estimations in the 2050s and the 2080s were found using the SFRCCC SLR projections for southeast Florida. The calibrated and validated Southeast Coasts Basin model was then used to compute runoff extremes in the year 2010, 2050, and 2080, representing the 2000s, 2050s, and 2080s, respectively. Extreme rainfalls 
and sea levels in 2050 and 2080 along with the CMIP5 ET projections and land cover projections from the EPA ICLUS dataset were used for computing the future runoff extremes under both standalone and concurrent changes in climate, land cover, and sea level.

The ensembled runoff projections for the Southeast Coasts Basin suggested high increases in runoff extremes in 2050 and 2080, relative to 2010 for many major urban centers and their nearby areas. Except for land cover, future relative increases in the basin-scale extreme runoff volume intensified with increases in return periods for individually changing drivers. Under standalone changes in climate, higher relative runoff increases were found as compared to that in land cover and sea level. Isolated climatic changes led to 14 to $109 \%, 14$ to $106 \%, 12$ to $98 \%$, and 12 to $93 \%$ increases in 1-7 day extreme runoff volumes of different return periods in the 2080-RCP 8.5 , 2050-RCP 4.5, 2050-RCP 8.5 , and 2080-RCP 4.5 scenario, respectively. Projected SLR for the Southeast Coasts Basin represents nominal influence on the extreme runoff regimes. The basin-scale runoff increases under individual changes in the drivers outlined overall dominance of climate on runoff extremes in complex coastal-urban environments.

In case of combined changes in climate and land cover, basin runoff increases of 63 to $144 \%, 46$ to $125 \%, 48$ to $121 \%$, and 52 to $121 \%$ were observed in the $2080-\mathrm{RCP} 8.5,2050-\mathrm{RCP}$ 4.5, 2050-RCP 8.5, and 2080-RCP 4.5 scenario, respectively. Concurrently changing climate and land cover brought about higher relative increases in basin runoff as compared to other combinations of concurrently changing drivers. Changes in extreme runoff volume in the basin under concurrent changes in climate, land cover, and sea level were 63 to $145 \%, 46$ to $125 \%, 48$ to $122 \%$, and 52 to $121 \%$, respectively, under the $2080-\mathrm{RCP} 8.5,2050-\mathrm{RCP} 4.5,2050-\mathrm{RCP} 8.5$, and 2080-RCP 4.5 scenario. Higher potential increases in rainfall, imperviousness, and sea level than the other future scenarios contributed to higher relative increases in basin-wide extreme 
runoff volume in the 2080-RCP 8.5 - making it the most critical future scenario for extreme runoff and flooding risk management.

The study findings have crucial local as well as global implications for mitigating the adverse impacts of changing extreme events and land cover. Runoff projections in 2050 and 2080 outlined critical areas in southeast Florida under risks of pluvial flooding and impaired surface water quality. Projected high increases in basin runoff necessitates improvements and enhancements of the existing drainage infrastructures. It would also be vital to manage the freshwater influx and nutrient loadings from the Southeast Coasts Basin, following hurricanes and other extreme events, into the downstream estuarine waterbodies to protect their biota. The study findings and their significance would be relevant for urbanizing areas with likelihoods of rainfall increases which are located in the high latitudes, and in the wet tropical and subtropical environments (IPCC, 2014a). Therefore, this study can offer valuable insights for stormwater management, ecosystem protection, and resilience enhancement for coastal-urban environments across the globe.

\section{Acknowledgments}

This research was funded by a National Science Foundation (NSF) Critical Resilient Interdependent Infrastructure Systems and Processes (CRISP 2.0) Award to Dr. Omar I. AbdulAziz (NSF CMMI Award \#1832680), and by the "Florida Public Hurricane Loss Model

Enhancements" project's freshwater flood modeling award to Dr. Omar I. Abdul-Aziz. The research on climate, land cover, and sea level change impacts on runoff extremes was exclusively funded by the NSF project. The findings and conclusions of this research are those of the authors, and do not necessarily reflect the views of NSF and the State of Florida or any of its sub-agencies. 


\section{Appendix 4}

\section{Text A4.1: Mann-Kendall test for determination of trend significance}

Following (Novotny and Stefan, 2007), the Mann-Kendall test statistics, $S$ is calculated as follows:

$S=\sum_{i=1}^{n-1} \sum_{j=i+1}^{n} \operatorname{Sgn}\left(X_{j}-X_{i}\right)$

where $n$ is the total number of data points in the time-series, $X_{i}$ and $X_{j}$ are successive data values for time $t_{i}$ and $t_{j}(j>i)$, respectively, and sgn is the sign function which can be expressed as:

$\operatorname{sgn}\left(X_{j}-X_{i}\right)=\left\{\begin{array}{c}+1, \text { when }\left(X_{j}-X_{i}\right)>0 \\ 0, \text { when }\left(X_{j}-X_{i}\right)=0 \\ -1, \text { when }\left(X_{j}-X_{i}\right)<0\end{array}\right.$

The concerned null hypothesis, $H_{o}$, is there is no trend or serial correlation in the data set $(S=0)$, i.e., the data points $\left(X_{1}, X_{2}, \ldots \ldots, X_{n}\right)$ are independent and identically distributed. The alternative hypothesis, is there is a monotonic trend in the dataset $(S \neq 0)$, i.e., the $X_{i}$ and $X_{j}$ do not have identical distribution for all $i, j \leq n$ and $i \neq j$.

\section{Text A4.2: Theil-Sen approach for estimation of trend slope}

In the Theil-Sen approach, the trend slope is computed as the median of all pairwise slopes. For a time-series with $n$ number of data points, there can be a total $n(n-1) / 2$ pairs of slopes for all $j>i$. Magnitude of the trend slope, $\beta$ is estimated as follows (Novotny and Stefan, 2007):

$\beta=\operatorname{Median}\left\{\frac{X_{j}-X_{i}}{j-i}\right\}$

where $X_{i}$ and $X_{j}$ are successive data values for time $t_{i}$ and $t_{j}(j>i)$, respectively. 
Text A4.3: Gumbel distribution for stationary and non-stationary extreme value analyses

Following Pérez-Rodríguez et al (2009), probability density function (pdf) of the Gumbel distribution for a stationary extreme value analyses can be expressed as:

$f(x ; \zeta, \beta)=\frac{1}{\beta} \exp \left[-\frac{x-\zeta}{\beta}-\exp \left(-\frac{x-\zeta}{\beta}\right)\right], x, \zeta \in \mathrm{R}, \beta>0$

where $\zeta$ is the location parameter and $\beta$ is the scale parameter.

In case of a non-stationary analyses, a linear trend was considered in the location parameter as follows:

$\beta(t)=C_{1}+C_{2} t$

Where $t$ is time, and $C_{1}$ and $C_{2}$ is intercept and slope of the linear trend, respectively. 
Table A4.1: Streamflow stations used for constructing model inflow boundary conditions in the Florida Southeast Coasts Basin.

\begin{tabular}{llll}
\hline Station ID & Stream name & Data frequency & Agency \\
\hline S38_C & Cypress Creek Canal & Instantaneous & SFWMD \\
G57_S & Pompano Canal & Instantaneous & SFWMD \\
S34_C & North New River Canal & Instantaneous & SFWMD \\
Kitching & Kitching Creek & Daily & SFWMD \\
272524080221800 & Fivemile Creek & Daily & USGS \\
S308.DS & St. Lucie Canal & Daily & SFWMD \\
02287395 & Miami Canal & Daily & USGS \\
S30_C & Snake Creek Canal & Instantaneous & SFWMD \\
S338_C & Black Creek Canal & Instantaneous & SFWMD \\
2287497 & Snapper Creek Extension Canal & Daily & USGS \\
S167_S & Mowry Canal & Instantaneous & SFWMD \\
S166_S & C-103N Canal & Instantaneous & SFWMD \\
S5AE_C & West Palm Beach Canal & Instantaneous & SFWMD \\
S39_S & Hillsboro Canal & Instantaneous & SFWMD \\
\hline
\end{tabular}

Note: SFMWD refers to South Florida Water Management District

Table A4.2: Streamflow stations used for model calibrations and validations in the Florida Southeast Coasts Basin.

\begin{tabular}{cccccc}
\hline Station & $\begin{array}{c}\text { Type of control } \\
\text { structure }\end{array}$ & Canal/Stream & Agency & $\begin{array}{c}\text { Calibration } \\
\text { period }\end{array}$ & $\begin{array}{c}\text { Validation } \\
\text { period }\end{array}$ \\
\hline S49 & Gated spillway & C-24 Canal & SFWMD & $01 / 01 / 2006-$ & $01 / 01 / 2009-$ \\
& & & & $12 / 31 / 2008$ & $12 / 31 / 2011$ \\
S46 & Gated spillway & Loxahatchee & SFWMD & $01 / 01 / 2004-$ & $01 / 01 / 2008-$ \\
& & Slough Canal & & $12 / 31 / 2007$ & $12 / 31 / 2011$ \\
S155 & Gated spillway & West Palm & SFWMD & $01 / 01 / 2005-$ & $01 / 01 / 2009-$ \\
& & Beach Canal & & $12 / 31 / 2008$ & $12 / 31 / 2011$ \\
G56 & \multirow{2}{*}{ Gated spillway } & Hillsboro & SFWMD & $01 / 01 / 2004-$ & $01 / 01 / 2008-$ \\
& & Canal & & $12 / 31 / 2007$ & $12 / 31 / 2011$ \\
G54 & \multirow{2}{*}{ Gated spillway } & North New & SFWMD & $01 / 01 / 2006-$ & $01 / 01 / 2009-$ \\
& & River Canal & & $03 / 31 / 2008$ & $12 / 31 / 2011$ \\
S26 & \multirow{2}{*}{ Gated spillway } & Miami River & SFWMD & $01 / 01 / 2006-$ & $01 / 01 / 2009-$ \\
& & & & $12 / 31 / 2008$ & $12 / 31 / 2011$ \\
\hline
\end{tabular}

Note: SFMWD refers to South Florida Water Management District 
Table A4.3: List of the Coupled Model Intercomparison Project's fifth phase (CMIP5) general circulation models (GCMs) used for future projections of rainfall and potential evapotranspiration in the Southeast Coasts Basin.

\begin{tabular}{|c|c|c|}
\hline Name & Agency & $\begin{array}{l}\text { Resolution } \\
\text { (Long. } \times \text { Lat.) }\end{array}$ \\
\hline bcc-csm1-1 & Beijing Climate Center, China Meteorological Administration & $2.8^{\circ} \times 2.8^{\circ}$ \\
\hline bcc-csm1-1-m & Beijing Climate Center, China Meteorological Administration & $1.12^{\circ} \times 1.12^{\circ}$ \\
\hline BNU-ESM & $\begin{array}{c}\text { College of Global Change and Earth System Science, Beijing } \\
\text { Normal University, China }\end{array}$ & $2.8^{\circ} \times 2.8^{\circ}$ \\
\hline CanESM2 & Canadian Centre for Climate Modeling and Analysis & $2.8^{\circ} \times 2.8^{\circ}$ \\
\hline CCSM4 & National Center of Atmospheric Research, USA & $1.25^{\circ} \times 0.94^{\circ}$ \\
\hline CNRM-CM5 & National Centre of Meteorological Research, France & $1.4^{\circ} \times 1.4^{\circ}$ \\
\hline CSIRO-Mk3-6-0 & $\begin{array}{c}\text { Commonwealth Scientific and Industrial Research } \\
\text { Organization/Queensland Climate Change Centre of } \\
\text { Excellence, Australia }\end{array}$ & $1.8^{\circ} \times 1.8^{\circ}$ \\
\hline GFDL-ESM2M & NOAA Geophysical Fluid Dynamics Laboratory, USA & $2.5^{\circ} \times 2.0^{\circ}$ \\
\hline GFDL-ESM2G & NOAA Geophysical Fluid Dynamics Laboratory, USA & $2.5^{\circ} \times 2.0^{\circ}$ \\
\hline HadGEM2-ES & Met Office Hadley Center, UK & $1.88^{\circ} \times 1.25^{\circ}$ \\
\hline HadGEM2-CC & Met Office Hadley Center, UK & $1.88^{\circ} \times 1.25^{\circ}$ \\
\hline inmem 4 & Institute for Numerical Mathematics, Russia & $2.0^{\circ} \times 1.5^{\circ}$ \\
\hline IPSL-CM5A-LR & Institut Pierre Simon Laplace, France & $3.75^{\circ} \times 1.8^{\circ}$ \\
\hline IPSL-CM5A-MR & Institut Pierre Simon Laplace, France & $2.5^{\circ} \times 1.25^{\circ}$ \\
\hline IPSL-CM5B-LR & Institut Pierre Simon Laplace, France & $2.75^{\circ} \times 1.8^{\circ}$ \\
\hline MIROC5 & $\begin{array}{l}\text { Atmosphere and Ocean Research Institute (The University of } \\
\text { Tokyo), National Institute for Environmental Studies,and } \\
\text { Japan Agency for Marine-Earth Science and Technology }\end{array}$ & $1.4^{\circ} \times 1.4^{\circ}$ \\
\hline MIROC-ESM & $\begin{array}{l}\text { Japan Agency for Marine-Earth Science and Technology, } \\
\text { Atmosphere and Ocean Research Institute (The University of } \\
\text { Tokyo), and National Institute for Environmental Studies }\end{array}$ & $2.8^{\circ} \times 2.8^{\circ}$ \\
\hline $\begin{array}{l}\text { MIROC-ESM- } \\
\text { CHEM }\end{array}$ & $\begin{array}{l}\text { Japan Agency for Marine-Earth Science and Technology, } \\
\text { Atmosphere and Ocean Research Institute (The University of } \\
\text { Tokyo), and National Institute for Environmental Studies }\end{array}$ & $2.8^{\circ} \times 2.8^{\circ}$ \\
\hline MRI-CGCM3 & Meteorological Research Institute, Japan & $1.1^{\circ} \times 1.1^{\circ}$ \\
\hline NorESM1-M & Norwegian Climate Center, Norway & $2.5^{\circ} \times 1.9^{\circ}$ \\
\hline
\end{tabular}

Source: https://climate.northwestknowledge.net/MACA/GCMs.php; Note: Lat. and Long., respectively, refer to latitude and longitude. 
Table A4.4: Baseline values and future basin-average percent changes in evapotranspiration (ET), and imperviousness for the Florida Southeast Coasts Basin relative to the baseline year of 2010.

\begin{tabular}{cccccc}
\hline \multirow{2}{*}{ Variable } & \multirow{2}{*}{$\begin{array}{c}\text { Baseline 2010 } \\
\text { values }\end{array}$} & \multicolumn{4}{c}{ Projected changes (\%) } \\
\cline { 2 - 6 } & & 2050-RCP 4.5 & 2080-RCP 4.5 & 2050-RCP 8.5 & 2080-RCP 8.5 \\
\hline ET & $3.8 \mathrm{~mm} /$ day & +4.7 & +5.1 & +5.9 & +7.9 \\
Imperviousness & $27.1 \%$ & +24.7 & +30.5 & +28.3 & +35.6 \\
\hline
\end{tabular}

Note: Positive sign indicates increases.

Table A4.5: Sea level rise (SLR) (m) projections, relative to 2010, for the NOAA tide station 8724580 at Key West used for future extreme runoff estimations in the Southeast Coasts Basin.

\begin{tabular}{ccc}
\hline \multirow{2}{*}{ Year } & \multicolumn{2}{c}{ SLR $(\mathrm{m})$} \\
\cline { 2 - 3 } & RCP 4.5 & RCP 8.5 \\
\hline 2050 & 0.38 & 0.49 \\
2080 & 0.83 & 1.14 \\
\hline
\end{tabular}




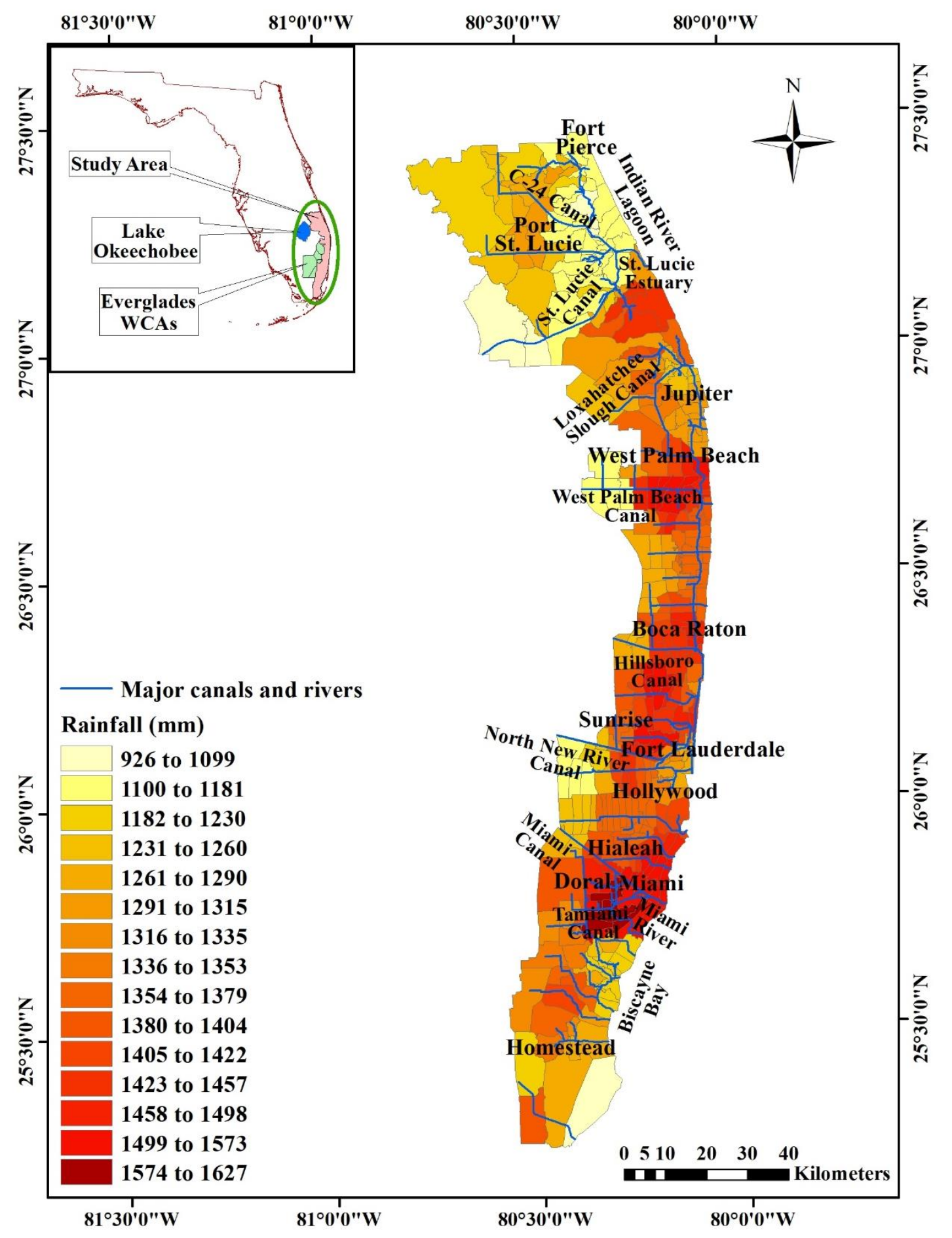

Figure A4.1: Spatial variation of observed 10-year mean annual rainfall in the Southeast Coasts Basin for 2004-2013 (2010s). The inset showing the location of the study area, Lake Okeechobee, and the Everglades Water Conservation Areas (WCAs) in the state of Florida is not drawn to the map-scale. 


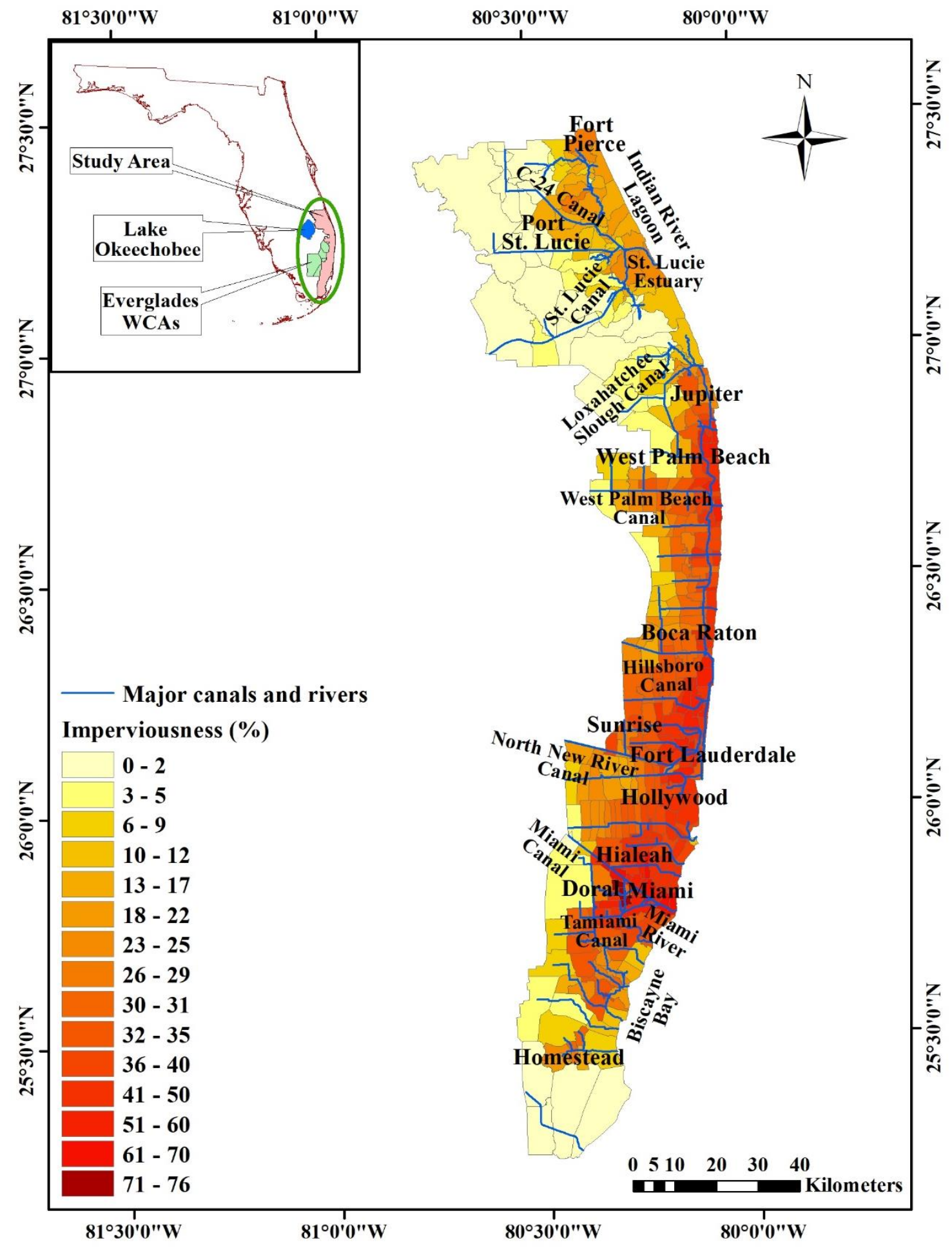

Figure A4.2: Spatial variation of imperviousness in the Southeast Coasts Basin. The inset showing the location of the study area, Lake Okeechobee, and the Everglades Water Conservation Areas (WCAs) in the state of Florida is not drawn to the map-scale. 


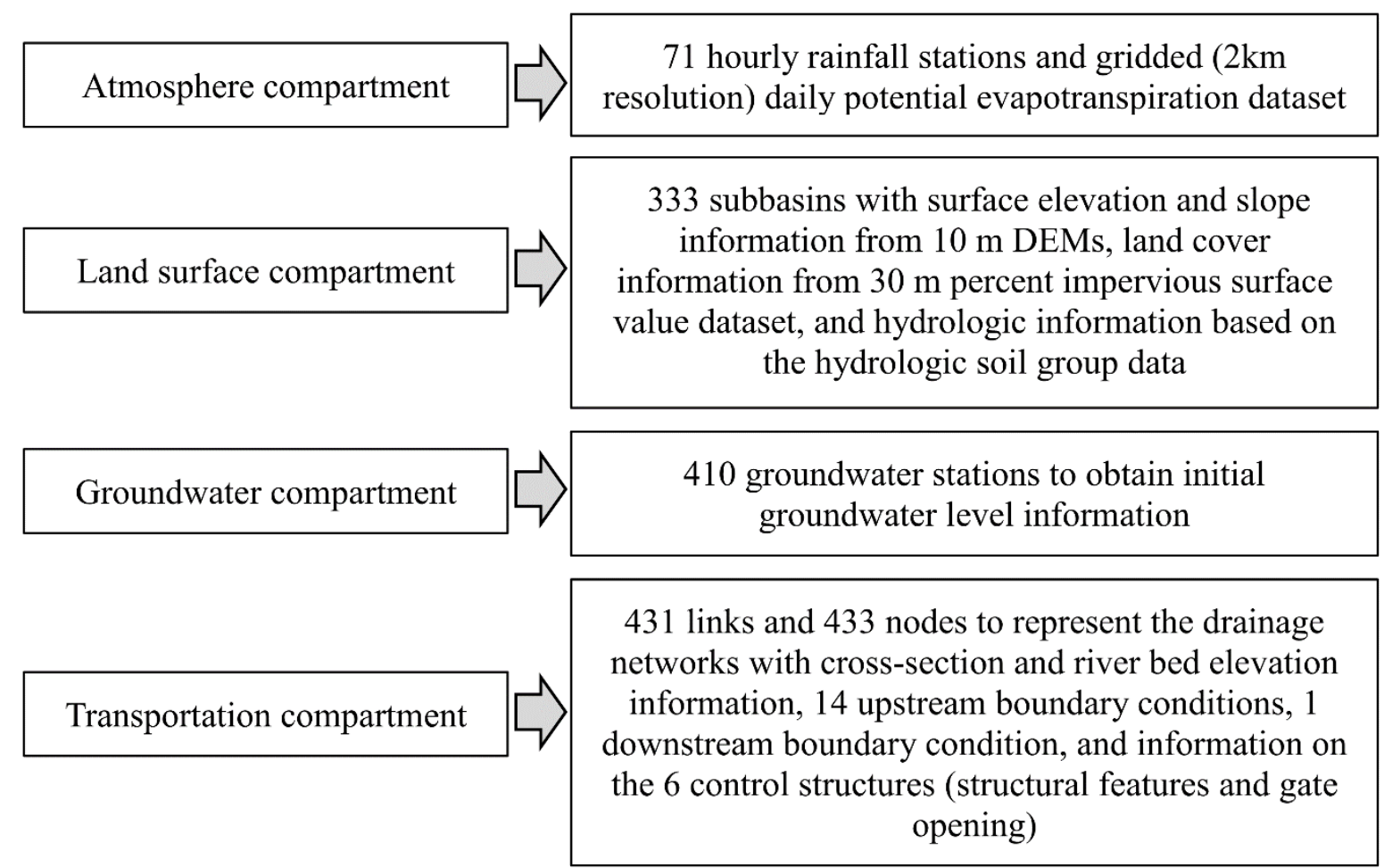

Figure A4.3: Summary of SWMM developments for the Southeast Coasts Basin. 

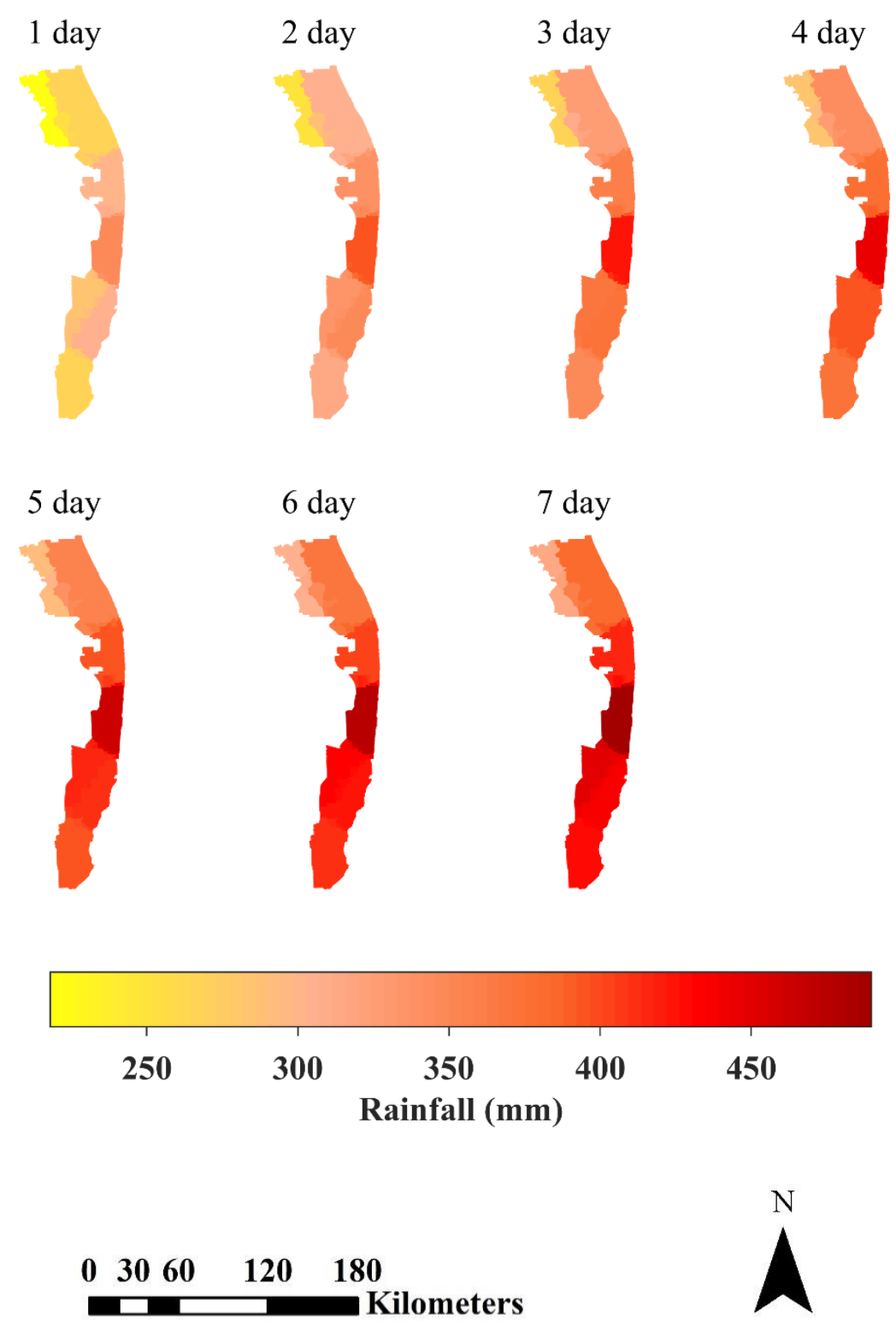

Figure A4.4: Spatial variation of accumulated rainfall depth for the 100-year event with varying durations on 2010 in the Southeast Coasts Basin. 

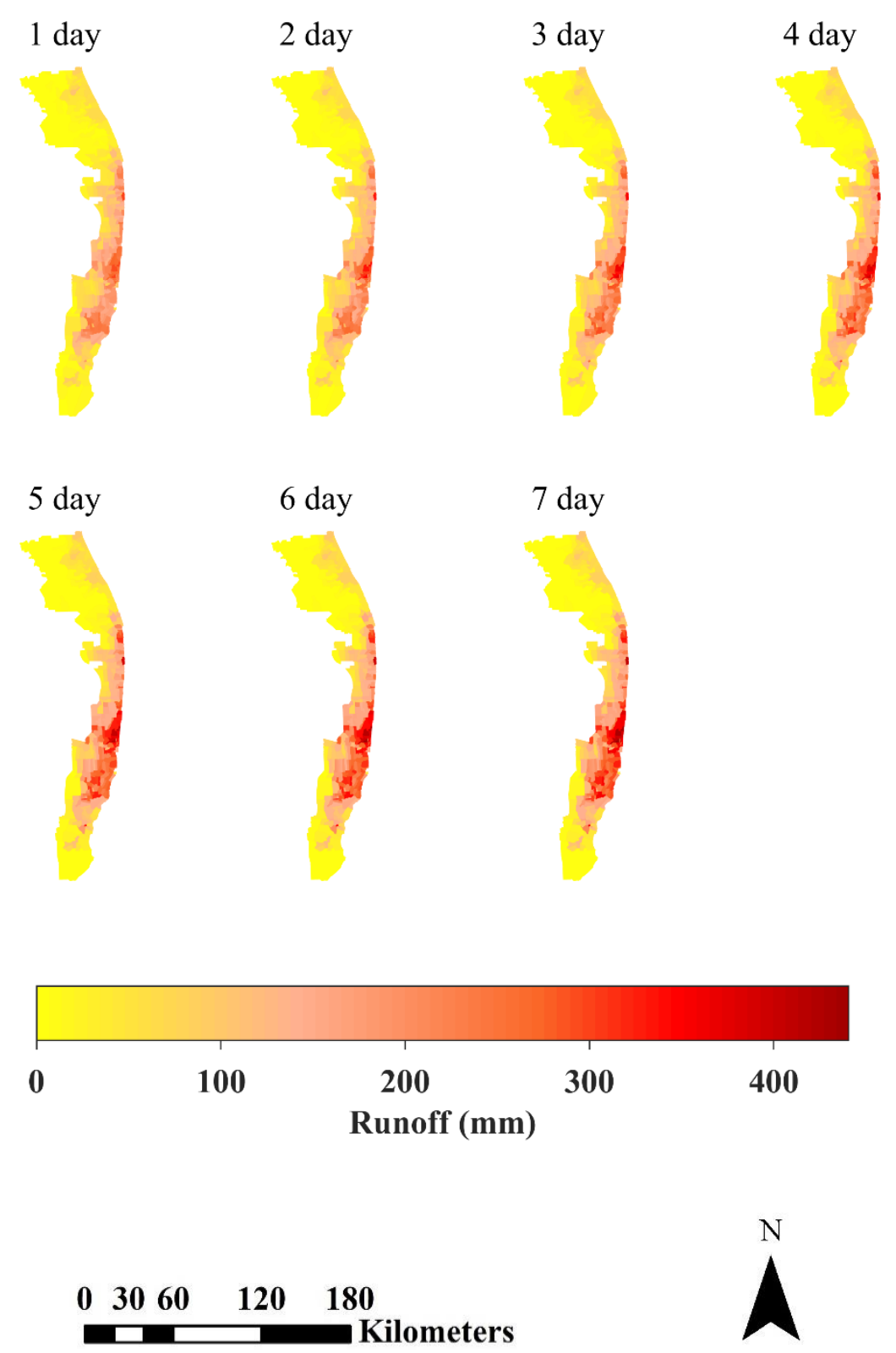

Figure A4.5: Spatial variation of accumulated runoff depth on 2010 in the Southeast Coasts Basin due to 100-year rainfall and sea level events with varying durations. 
(e) Rainfall
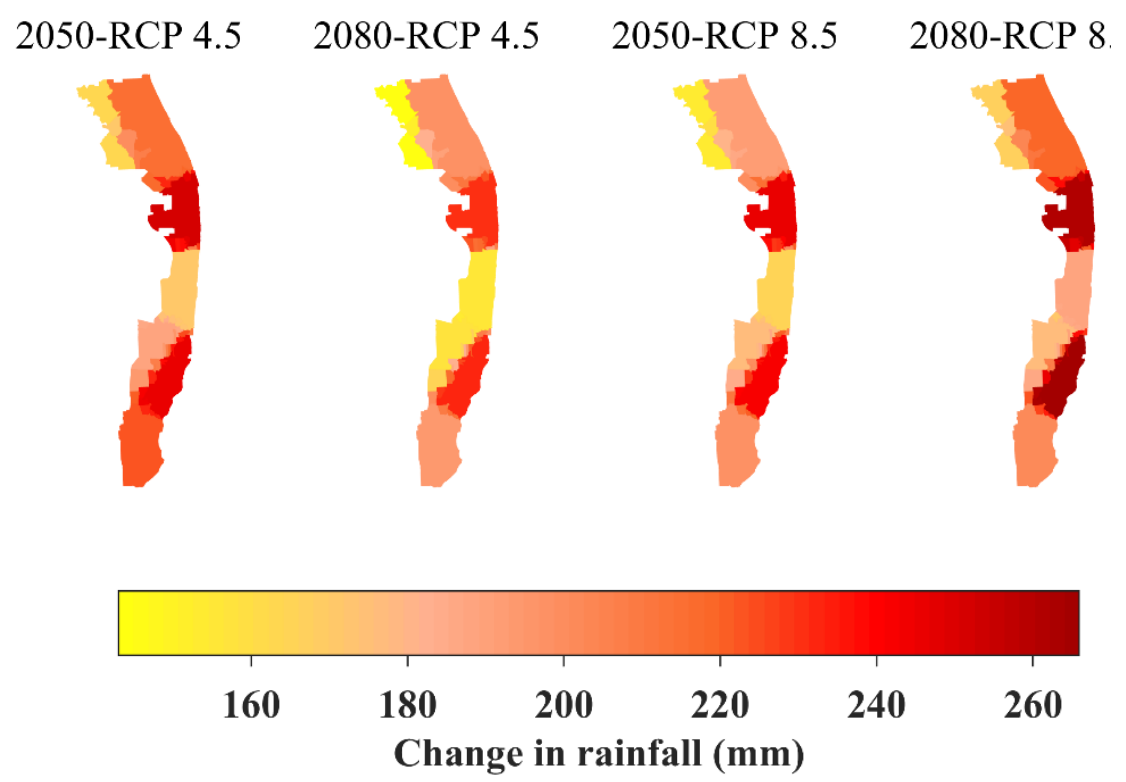

(b) Imperviousness

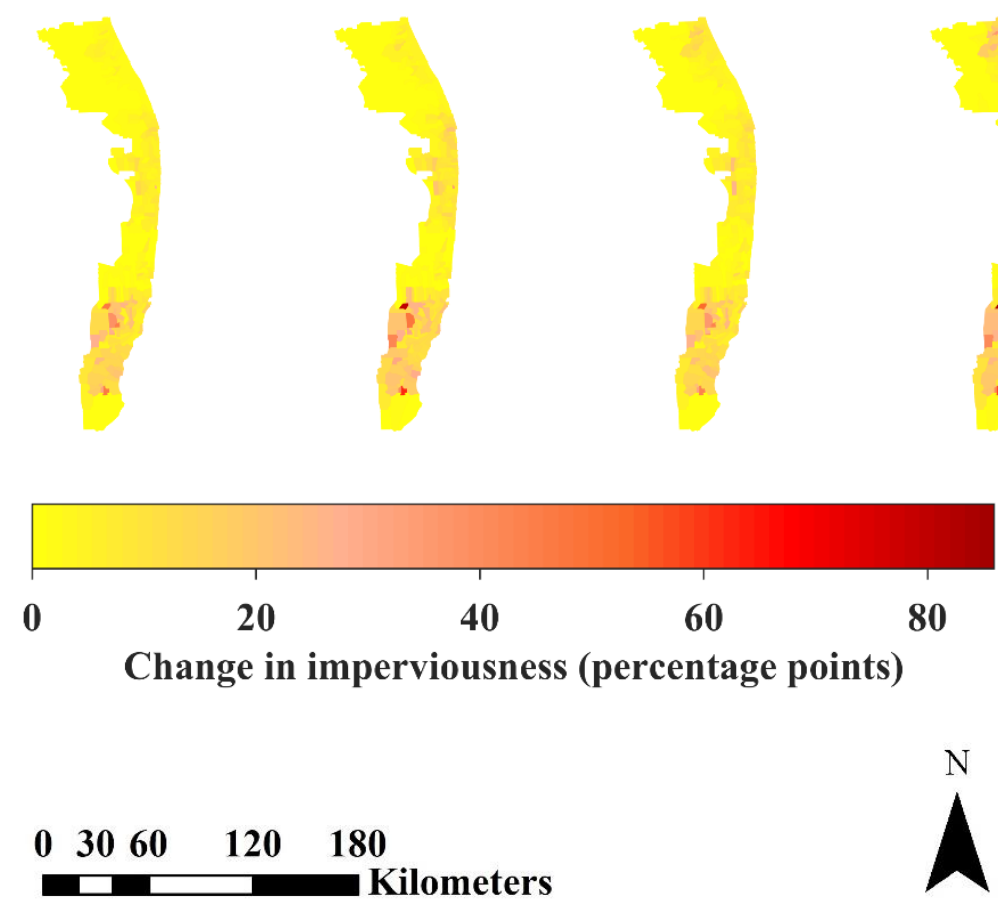

Figure A4.6: Spatial variation of (a) changes in 7-day accumulated rainfall depth for 100-year return period based on ensemble mean design rainfall projections from the 20 general circulation models (GCMs), and (b) percentage points change imperviousness under different future scenarios in the Southeast Coasts Basin. 

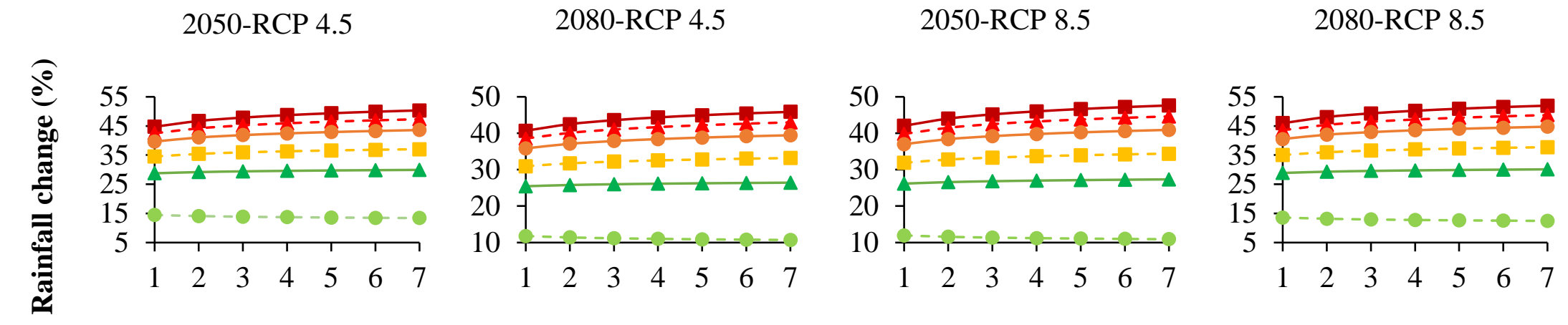

\section{Duration (day)}

$$
-\bullet \text { - 2-year } \longrightarrow \text { - 5-year }-"-10 \text {-year } \longrightarrow 25 \text {-year }-\star-50 \text {-year } \rightarrow-100 \text {-year }
$$

Figure A4.7: Projected percentage changes in 1-7 day total rainfall of varying return periods under different future scenarios in the Southeast Coasts Basin. 


\title{
Chapter 5: Impacts of changing climate, land cover, and sea level on extreme runoffs in coastal-natural environments
}

\begin{abstract}
This study determined individual and synergistic impacts of changing climate, land cover, and sea level on coastal-natural extreme runoffs. A large-scale $\left(24928 \mathrm{~km}^{2}\right)$ mechanistic hydrologic model was developed for the Saint Johns River Basin of northeast Florida considering the study area using U.S. EPA SWMM 5.1. The Saint Johns River Basin model was calibrated and validated with observed daily streamflows during 2004-2013 (Nash-Sutcliffe Efficiency $=0.70$ to 0.82 ). Significance and direction of trends in annual maximum rainfalls and sea levels of 1-7 day durations for the historical 2000s (1964-2013) were assessed thereafter. Overall, statistically insignificant ( $p$-value $\leq 0.05$ ) increasing trends in rainfall and significant increasing trends in sea level were detected. 1-7 day stationary design rainfalls and non-stationary design sea levels of varying return periods $(2,5,10,25,50$, and 100 year) in 2010 were computed accordingly. In 2010, design rainfalls ranged from 87 to $430 \mathrm{~mm}$; range of design sea levels was 0.14 to $0.44 \mathrm{~m}$ NAVD 88. Future design rainfalls and sea levels in 2050 and 2080 were estimated using the climatic and sea level rise (SLR) projections under the Representative Concentration Pathways (RCP) 4.5 and 8.5 scenarios. The design rainfalls and sea levels along with the land cover information in 2010, 2050, and 2080 were used to estimate the extreme runoffs implementing the calibrated SWMM model. Major and growing urban centers and their neighboring regions across the Saint Johns River Basin would experience high future extreme runoff increases, relative to 2010. Basin-scale runoff volume changes suggested dominance of climate in extreme runoff generation. Under concurrent changes in climate, land cover, and sea level, potential increases in extreme runoff volume in the basin would be 58 to $132 \%$, 46 to $113 \%, 32$ to $96 \%$, and 34 to $95 \%$
\end{abstract}


for the 2080-RCP $8.5,2050-\mathrm{RCP} 8.5,2050-\mathrm{RCP} 4.5$, and 2080-RCP 4.5 scenario, respectively. In light of the higher relative runoff increases than other scenarios, 2080-RCP 8.5 appeared as the most critical future scenario for extreme runoff and pluvial flooding risk management in the Saint Johns River Basin. The study findings would be beneficial for pluvial flooding management and ecosystem protection for northeast Florida and other coastal-natural environments across the globe.

\subsection{Introduction}

Global warming, primarily due to anthropogenic activities (Swain et al., 2020), generally brings about higher intensity and frequency of extreme rainfalls (Fischer and Knutti, 2016; Papalexiou and Montanari, 2019), followed by potential elevated flooding risks. IPCC (2014a) predicts both near and long-term medium to high flooding risks due to extreme rainfall for most part of the world if current level of adaptation to climatic changes prevails. Meanwhile, potential land cover changes can substantially alter the hydrologic responses of watersheds and can jeopardize sustainability of the ecosystems. Coastal environments, on top of these, are subject to flooding risks due to sea level rise (SLR) induced groundwater inundation (GWI) (Sukop et al., 2018). Accordingly, it would be pivotal to evaluate potential extreme rainfall induced flooding risks in coastal-natural environments under changing climate, land cover, and sea level in order to protect their biodiversity and ecosystems.

The controls of changing climate and land cover over runoff extremes and flooding have been extensively studied by existing literature addressing watersheds around the world (e.g., Jena et al., 2014; Rahmani et al., 2016; Vemula et al., 2019). Mechanistic (i.e., process-based) rainfall-runoff models have been widely used in many relevant studies to predict watershed responses under extreme rainfall events. Further, application of mechanistic models for future 
predictions of extreme runoff and flooding, by taking account of projected climatic and land cover changes, is also prevalent. Yuan et al. (2018) used the Xinanjiang hydrologic model (Zhao et al., 1995) to investigate the future changes in flooding under projected extreme rainfall in the Jinsha River Basin of China. They found notable changes in extreme flood under 20 and 50-year return period during 2020-2050, relative to the baseline 1961-1990, accordingly. Siddique et al. (2020) examined impacts of the potential future climatic changes on 100-year flood in the Commonwealth of Massachusetts, USA implementing the National Oceanic and Atmospheric Administration (NOAA)'s Hydrology Laboratory-Research Distributed Hydrologic Model (HLRDHM) (Koren et al., 2004). For December-January and March-May, respectively, prominent increases and decreases in 100-year floods in 2021-2060 and 2060-2099 were reported by the authors, with respect to 1981-2016. Using the WetSpa model (Wang et al., 1996), Kohnová et al. (2019) evaluated impacts of potential future climatic and land use changes across difference catchments of Slovakia. They outlined notable future decreases in annual maximum design daily runoff for October-March by end of the $21^{\text {st }}$ century, in reference to 1981-2010, for their study area.

GWI due to SLR, and the corresponding flooding risks, is a less explored field of knowledge. The first few studies in this regard have been conducted for Hawaii, USA. Rotzoll and Fletcher (2013) adopted a 1-dimensional steady state analytical solution approach to report submergence of substantial amount of land across a heavily urbanized coastal region of Honolulu in Hawaii under a $1 \mathrm{~m}$ SLR. Habel et al. (2017) simulated GWI under potential SLR using a 3dimensional numerical method for the Waikiki area of Honolulu in Hawaii. Their findings indicated potential GWI for majority of the study area subject to an approximately $1 \mathrm{~m}$ SLR. In a more recent study, Sukop et al. (2018) investigated GWI induced flooding problems in Arch 
Creek basin of southeast Florida, USA. They concluded that a projected SLR of $0.61 \mathrm{~m}$ by 2060, accompanied by increased rainfalls, would bring about frequent flooding due to rising GWT across the relatively low-lying areas of the study basin.

The existing literature does not offer much knowledge on the hydrologic impacts of potential changes in climatic extremes, land cover, and sea level for coastal-natural environments. It would be essential to perform a detailed investigation of the adverse outcomes of these changes to minimize vulnerabilities of the coastal ecosystem, community, and economy. Northeast Florida of USA is a prototype of complex coastal-natural hydrologic settings. The prevailing changes in climate and land cover (Jagtap et al., 2002; Volk et al., 2017) are expected to influence its hydrologic responses to extreme events, which has not been investigated yet. Therefore, it would be vital to perform a comprehensive assessment of changes in extreme stormwater runoff regimes across northeast Florida under the anticipated changes in climate, land cover, and sea level.

This study aims to examine the individual and synergistic impacts of changes in climate, land cover, and sea level on runoff extremes in complex coastal-natural environments. The Saint Johns River Basin of northeast Florida, a prototype of such environments, is regarded as the study area. A large-scale mechanistic rainfall-runoff model is developed for the basin using the U.S. Environmental Protection Agency (U.S. EPA) Storm Water Management Model (SWMM) 5.1 (Rossman, 2015); the model is calibrated and validated with observed historical streamflows. Historical runoff extremes are then computed using design rainfalls and sea levels of 1-7 day durations with varying return periods $(2,5,10,25,50$, and 100-year). Finally, future runoff extremes are computed by taking the climatic, land cover, and sea level projections as inputs to the Saint Johns River Basin model. The potential future changes in extreme runoff would outline 
basin areas with elevated risks of pluvial flooding, i.e., rainfall-driven flooding (Falconer et al., 2009; Carter et al., 2015; Rosenzweig et al., 2018) and environmental pollution.

\subsection{Materials and methods}

\subsubsection{Study area}

The Saint Johns River Basin drains an area of approximately $24928 \mathrm{~km}^{2}$ (Figure 5.1). Croplands, evergreen forests, pasture lands, grasslands, and wetlands constitute the dominant land uses/cover in the basin. However, some sporadic footprints of low to medium levels of urbanization are noted across the Saint Johns River Basin as well. Jacksonville, Gainesville, and Orlando represent the major urban centers in the basin. Ocala, Palatka, Palm Coast, Daytona Beach, Clermont, Titusville, and Melbourne are the emergent urban centers. The Saint Johns River Basin represents three subwatersheds: the Upper Saint Johns River Basin $\left(10427 \mathrm{~km}^{2}\right)$, the Ocklawaha River Basin $\left(7224 \mathrm{~km}^{2}\right)$, and the Lower Saint Johns River Basin $\left(7277 \mathrm{~km}^{2}\right)$. The Saint Johns River, the longest river in Florida, drains the Upper and Lower Saint Johns River Basin. The river originates from the south of Melbourne and drains through Jacksonville prior to reaching the Atlantic Ocean. The Ocklawaha River Basin is drained by the Ocklawaha River, which is the largest tributary of the Saint Johns River. According to the Köppen-Geiger climate classification (Kottek et al., 2006; Rubel et al., 2017), the Saint Johns River Basin represents humid subtropical climate. The basin, accordingly, experiences high seasonal variations in rainfalls throughput the year (ORNL DAAC, 2017). 


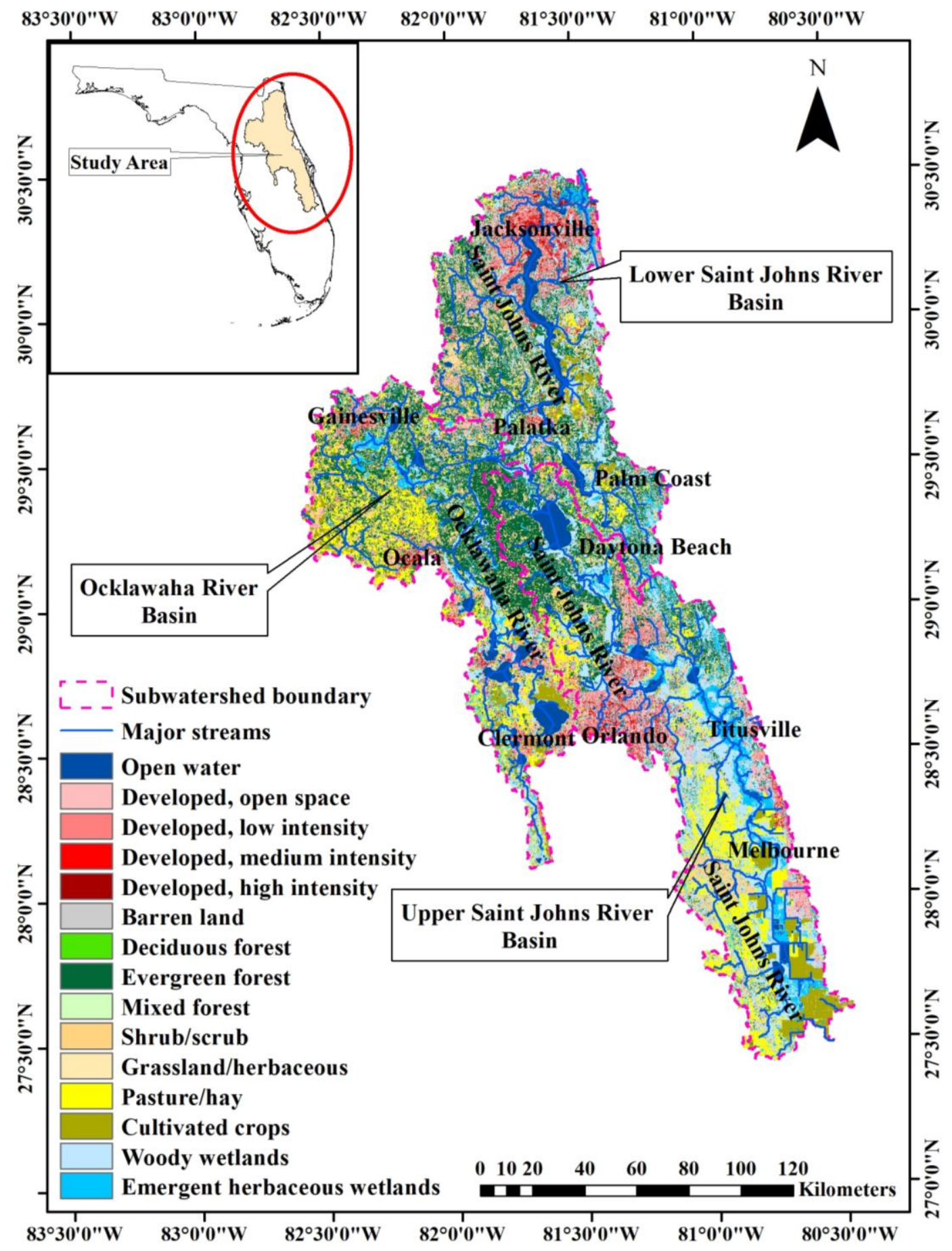

Figure 5.1: Subwatersheds, major streams, and land cover types in the Saint Johns River Basin. The inset showing location of the study area in the state of Florida is not drawn to the map-scale. 


\subsubsection{Data sets for model development}

Extent of the Saint Johns River Basin was defined based on the third-level hydrological unit code (HUC6; ID: 030801) obtained from the U.S. Geological Survey (USGS) (USGS, 2016a).

Topographical variation across the basin was incorporated based on the digital elevation models (DEMs) of 1/3 arc-second (approximately $10 \mathrm{~m}$ ) resolution; the DEMs were collected from the National Elevation Dataset (NED) (USGS, 2016b). Percent imperviousness data of $30 \mathrm{~m}$ resolution data for 2006 and 2011 were collected from the National Land Cover Database (NLCD) (Fry et al., 2011; Homer et al., 2015) in order to represent the spatial variation in land cover. Subbasin soil types were determined following the hydrologic soil groups from the soil survey geographic database (SSURGO; USDA-NRCS, 2015) and the guidelines provided by the National Engineering Handbook (USDA-NRCS, 2009) and Rawls et al. (1983).

Observed volumetric streamflow rate during 2004-2013, at different stations along the Saint Johns River, were collected from the national water information system of USGS (USGS, 2018). These streamflow records were used for calibration of the Saint Johns River Basin model (Table A5.1 in Appendix 5). Streamflow records during 2004-2013 for the Ocklawaha River at Rodman Dam (downstream of Lake Ocklawaha), also collected from USGS, were used as the inflow boundary conditions in the model (Figure 5.2). Hourly observed water levels for the National Oceanic and Atmospheric Administration (NOAA)'s tidal station at Mayport Bar Pilots Dock (ID: 8720218) during 2004-2013 were incorporated as the outfall boundary conditions at the mouth of the Saint Johns River. Outfall boundary conditions for the other streams across the basin were not available. Surveyed stream geometry information (cross section and bed elevation) for the Saint Johns River as well as its branches and tributaries were acquired from the Saint Johns River Water Management District (SJRWMD). 


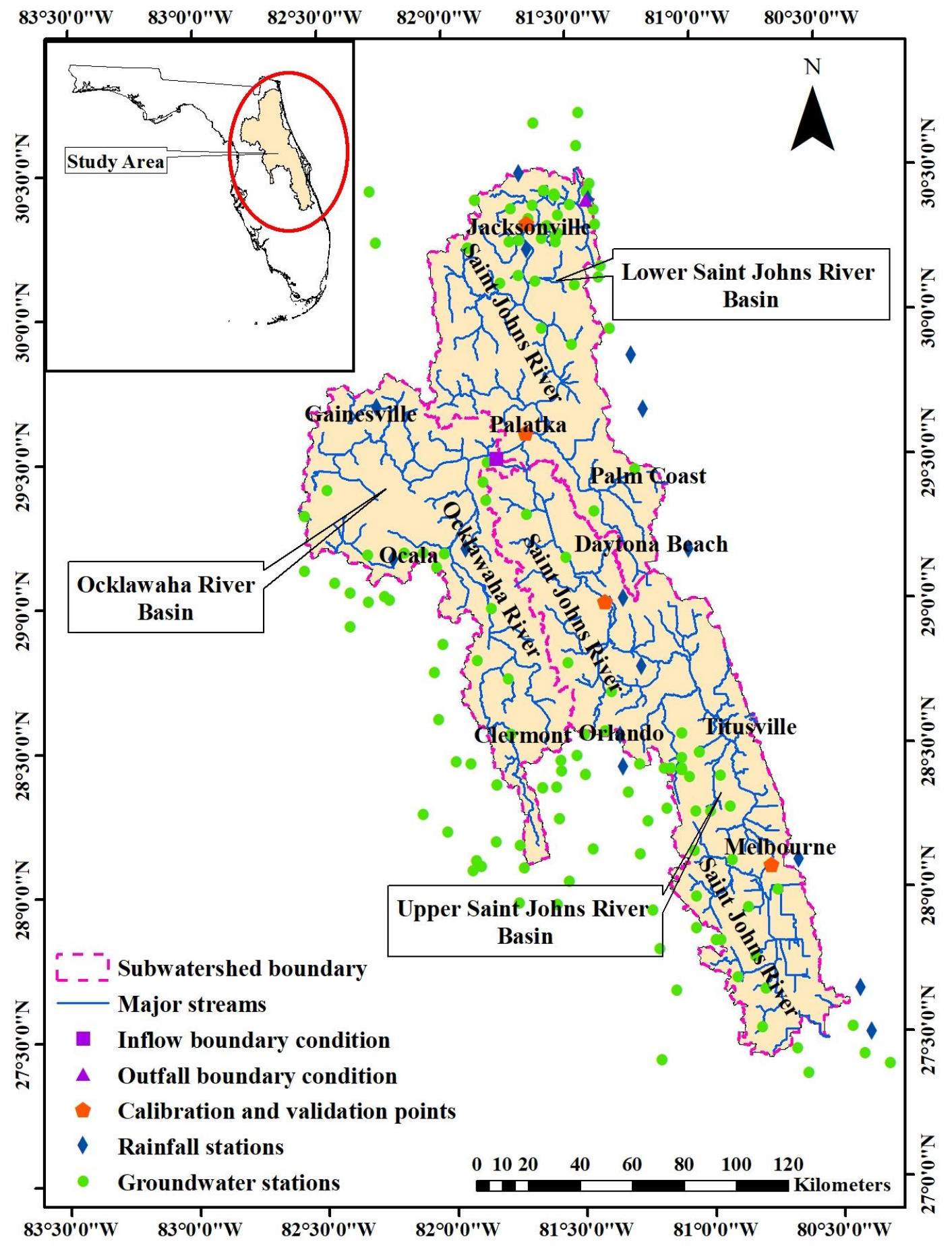

Figure 5.2: Locations of boundary conditions, model calibrations and validation points, rainfall gauging stations, and groundwater monitoring stations used in the Saint Johns River Basin model. The inset showing location of the study area in the state of Florida is not drawn to the map-scale. 
Observed hourly rainfalls for 2004-2013 at 16 stations (Figure 5.2) were used to account for the spatiotemporal rainfall variability across the Saint Johns River Basin. Rainfall data for 13 of these stations were obtained from NOAA's National Centers for Environmental Information (NCEI) database. For the remaining 3 stations, rainfall data were obtained from NOAA's National Climatic Data Center (NCDC) database. Satellite-based $2 \mathrm{~km}$ daily potential evapotranspiration (ET) datasets during 2004-2013 were collected from USGS (USGS, 2016c).

Observed groundwater level (GWL) data at 151 stations within and around the basin (Figure 5.2) were obtained from USGS to parameterize the hyporheic exchanges.

\subsubsection{Development of the mechanistic hydrologic model using EPA SWMM 5.1}

SWMM 5.1 is a mechanistic rainfall-runoff model developed by the U.S. EPA. It parameterizes and dynamically integrates different components of urban and natural hydrology, hydroclimatological forcing variables, and land cover features (Rossman, 2015). Based on the $10 \mathrm{~m}$ DEMs, the Saint Johns River Basin was split into smaller subbasins and link (stream)-node (junction) networks were developed using Arc Hydro (Maidment and Morehouse, 2002) for ESRI ArcGIS 10.2. Subbasin characteristic widths were estimated based on their shapes and length of the channels which drain them (see text A2.5 in Appendix 2). Thiessen Polygons developed for the 16 rainfall stations (Figure 5.2) were used (see Text A2.2 in Appendix 2) to assign hourly 2004-2103 rainfalls to different subbasins (Figure A5.1 in Appendix 5). Because of the low spatial variability in monthly mean potential ET rates ( $\mathrm{mm} /$ day; coefficient of variation of 2.93 to $13.72 \%$ ), spatially averaged monthly mean potential ET rates were used as inputs to the model. Observed dry season GWL on or around 01/01/2004 were used as initial GWL (see Text A2.3 and A2.4 in Appendix 2); SWMM dynamically updates GWL for the following time 
steps through groundwater mass balance and hyporheic exchanges (Rossman, 2016). Table 5.1 summarizes the major variables and parameters for the Saint Johns River Basin model.

The NLCD 'percent developed imperviousness' raster dataset for 2006 and 2011 were used to estimate temporally averaged historical percent imperviousness of the subbasins (Figure A5.2) for simulation during 2004-2013. The 10 meter DEM was used to obtain subbasin slopes through ArcHydro. Initial estimations of subbasin overland roughness coefficient and depression storage depth were made with regards to SWMM Reference Manual (Rossman, 2016) and SWMM User's Manual (Rossman, 2015). Initial values of Green-Ampt infiltration parameters and aquifer properties were computed based on the SWMM Reference Manual (Rossman, 2016), depending on the soil types. 1 inflow boundary condition and 1 outfall boundary condition (Figure 5.2) were used in the model to represent the influence of Lake Ocklawaha and the Atlantic ocean tides, respectively. The overall model structure is depicted in Figure A5.3.

The Saint Johns River Basin model was run for continuous hourly simulations during 2004-2013. The model was calibrated and validated, respectively, at 4 streamflow stations along the Saint Johns River (Figure 5.2; Table A5.1) during 01/01/2004-12/31/2008 and 01/01/200912/31/2013. Major parameters that were adjusted during model calibration (Table 5.1) were characteristic widths, overland roughness coefficients (Manning's n), Green-Ampt infiltration parameters, aquifer parameters, ground water flow coefficient (A1) and exponent (B1), and channel roughness coefficient (Manning's n). Realistic patterns in simulated GWLs were ensured by confining their lower limits within close proximity of the initial GWLs. Model performance was evaluated based on the Nash-Sutcliffe Efficiency (NSE) (Nash and Sutcliffe, 1970) and the ratio of the root-mean-square error to the standard deviation of observations (RSR; see Text A2.6 in Appendix 2). 
Table 5.1: Model variables and calibrated parameters during 2004-2013 for the Saint Johns River Basin.

\begin{tabular}{ll}
\hline Variables and Parameters & Range \\
\hline Climate & \\
Rainfall* (mm/hr) & 0 to 253.24 \\
Potential evapotranspiration* (mm/day) & 1.24 to 5.42 \\
Overland flow & \\
Characteristic width (m) & 1238.04 to 65012.12 \\
Imperviousness* (\%) & 0.0001 to 49.5274 \\
Slope (\%) & 0.0001 to 5.0715 \\
Overland roughness coefficient (Manning's n) for impervious subarea & 0.01 to 0.019 \\
Overland roughness coefficient (Manning's n) for pervious subarea & 0.017 to 0.20 \\
Depression storage depth for impervious subarea (mm) & 1.27 to 2.54 \\
Depression storage depth for pervious subarea (mm) & 2.54 to 7.62 \\
Infiltration and groundwater flow & \\
Initial suction head (mm) & 131.01 to 148.73 \\
Saturated hydraulic conductivity (mm/hr) & 3.16 to 108.25 \\
Initial moisture deficit ${ }^{\mathrm{a}}$ & 0.265 to 0.280 \\
Soil porosity & 0.38 to 0.40 \\
Field capacity & 0.168 to 0.234 \\
Permanent wilting point & 0.090 to 0.095 \\
Lower evaporation depth ${ }^{\mathrm{b}}$ (m) & 1 to 5 \\
Initial groundwater elevation (m NAVD 88) & -11.28 to 47.11 \\
Unsaturated zone moisture content & 0.100 to 0.135 \\
Groundwater flow coefficient, A1 & 0.015 to 0.05 \\
Groundwater flow exponent, B1 & 1.1 to 1.5 \\
Streamflow & \\
Channel roughness (Manning's n) & 0.01 to 0.09 \\
\hline Notes: Fracion of soil volum
\end{tabular}

Notes: ${ }^{\text {F}}$ Fraction of soil volume that is dry at the beginning of the simulations (Rossman, 2015); ${ }^{\mathrm{b}}$ maximum depth below the surface at which evapotranspiration can take place from the lower saturated zone (Rossman, 2015); *variables or parameters used for sensitivity analyses.

\subsubsection{Climatic, land cover, and sea level datasets for impact assessments}

Observed historical hourly rainfalls for 9 long-term hourly NOAA-NCDC rainfall stations

(Figure 5.3) were used to compute design rainfalls during 1964-2013 (defined as the baseline 2000s) in the Saint Johns River Basin. Some stations had no recorded rainfalls for certain year/years during the 2000s; rainfall records for immediate years prior to 1964 were taken into account accordingly. Downscaled daily rainfall projections provided by the 20 Coupled Model 
Intercomparison Project's fifth phase (CMIP5) general circulation models (GCMs) (see Table A5.2 in Appendix 5) were collected from the multivariate adaptive constructed analogs (MACA) dataset (Abatzoglou and Brown, 2012) to compute future extreme rainfalls and runoffs. MACA gave historical climatic simulations and future climatic projections for 1950-2005 and 20062099, respectively, under the Representative Concentration Pathways (RCP) 4.5 and 8.5 scenario (IPCC, 2014b). Daily MACA rainfalls for the 2000s, as well as for the future 50-year periods of 2050s (2025-2074) and 2080s (2050-2099) were obtained for the MACA grids closest to the 9 observed rainfall stations (Figure 5.3). Monthly modeled historical and future potential ET were also extracted at all MACA grids falling within extent of the Saint Johns River Basin; these monthly ETs were computed using the Penman-Monteith method (Allen et al., 1998).

Since GCMs do not to perform satisfactorily in representing hourly and daily rainfall variabilities (Teutschbein and Seibert, 2012, Chen et al., 2013), bias-corrected future projections of 50-year annual maximum 1-7 day total rainfalls at each station were estimated using the delta change factor methodology (Teutschbein and Seibert, 2012; Chen et al., 2013; see section 4.2.4 in Chapter 4). 50 ratios of GCM-projected future annual maximum rainfall over GCM-simulated historical annual maximum rainfall $\left(A_{f u t, p r o j} / A_{\text {hist,sim }}\right)$, representing the relative rainfall changes between the historical and future 50-year periods, were first computed. Outlier ratios, identified as ratio values either below the lower boundary of $Q_{1}-1.5 * I Q R$ or above the upper boundary of $Q_{3}+1.5 * I Q R\left(Q_{1}=25^{\text {th }}\right.$ percentile; $Q_{3}=75^{\text {th }}$ percentile; $\left.I Q R=Q_{3}-Q_{1}\right)$ (Tukey, 1977), were replaced with the closest boundary value. Bias-corrected future annual maximum rainfall $\left(A_{f u t, r e c}\right)$ was finally produced by multiplying the observed historical annual maximum rainfall $\left(A_{\text {hist,obs }}\right)$ in the 2000s with the corresponding adjusted delta change ratio value. 


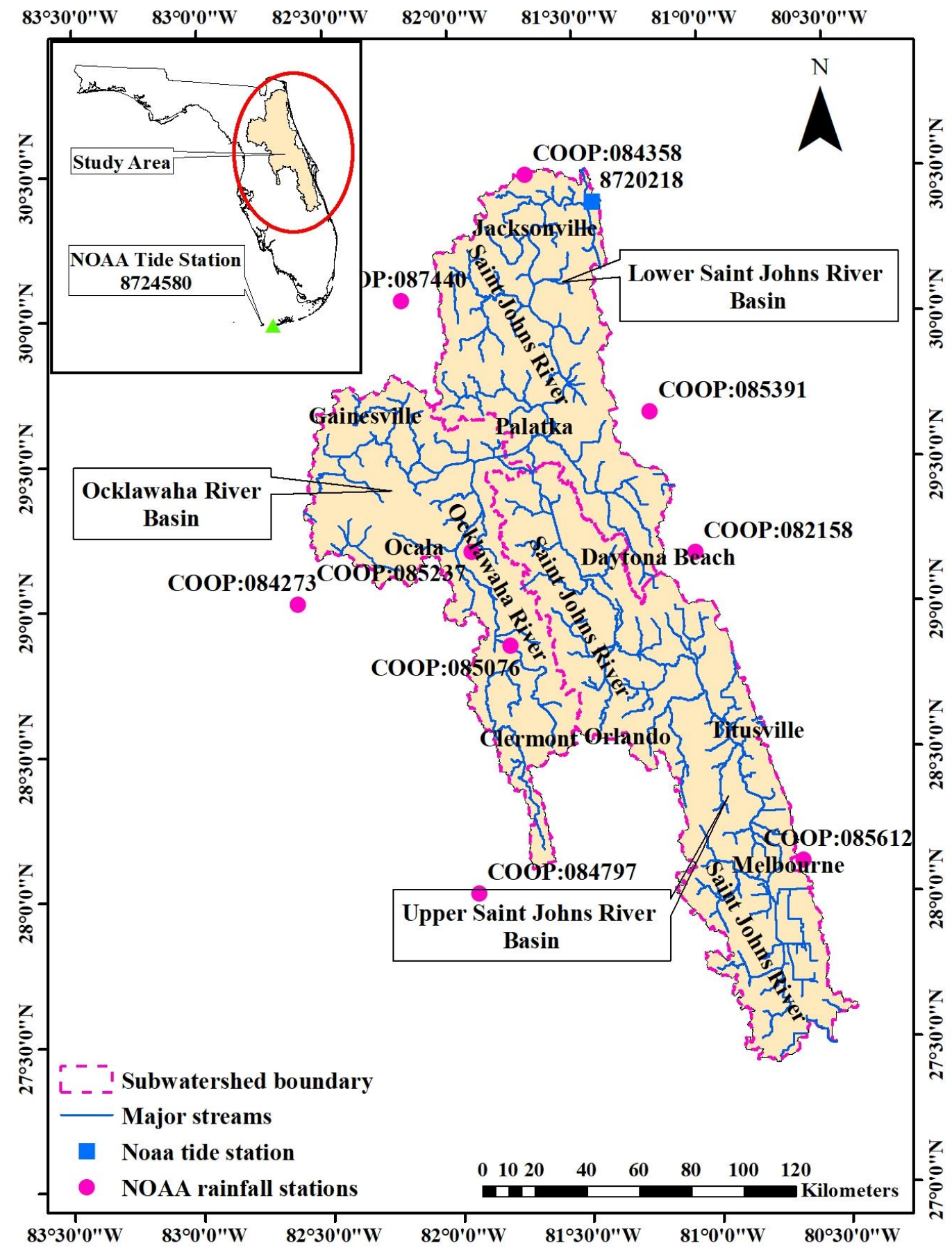

Figure 5.3: Locations of rainfall and tide stations used for extreme rain and sea level estimations in the Saint Johns River Basin. The numbers beside the station locations indicate station IDs assigned by NOAA. The inset shows location of the study area in the state of Florida and the NOAA tide station 8724580 which was used to develop the 50-year annual maximum water levels at tide station 8720218. Inset is not drawn to the map-scale. 
Future monthly ET projections were also reconstructed using the delta change factor approach while producing 50 ratio values for each month. In order to represent potential future land cover changes in the Saint Johns River Basin, Integrated Climate and Land-Use Scenarios (ICLUS) imperviousness projections (U.S. EPA, 2010) were collected for the Special Report on Emissions Scenarios (SRES) (Nakicenovic et al., 2000) A1 and B1. In terms of atmospheric $\mathrm{CO}_{2}$ concentrations, global radiative forcing, and global mean temperature, SRES A1FI and B1 is similar to RCP 8.5 and 4.5, respectively (Van Vuuren and Carter, 2014). Reconstructed future percent imperviousness $\left(I_{f u t, r e c}\right)$ for a subbasin was found by multiplying the ratio of projected future imperviousness in 2050 or 2080 over simulated historical imperviousness in 2010 $\left(I_{\text {fut }, \text { proj }} / I_{\text {hist,sim }}\right)$ with the observed historical imperviousness on the 2010s $\left(I_{\text {hist,obs }}\right)$ (Figure A5.2). Table A5.3 in Appendix 5 summarizes the projected future changes in ET and imperviousness in the Saint Johns River Basin.

The NOAA tide station 8720218 (Figure 5.3) had continuous observed hourly water level records for 13 years 1964-2013. Tide station at Key West (NOAA ID: 8724580) was the nearest station which had continuous hourly water level records for 1964-2013. Therefore, 50-year annual maximum 1-7 day mean water levels at tide station 8720218 were estimated through linear regressions between its observed annual maximum water levels of different durations with that at station 8724580 for the overlapping 13 years. The coefficient of determination, $R^{2}$ for the regressions between 8720218 and 8724580 ranged from 0.47 to 0.62 for 1-7 day durations. Future sea levels were estimated based on the projected SLR in 2050 and 2080, with respect to 2010, for southeast Florida (SFRCCC Sea Level Rise Work Group, 2020; Sweet et al., 2017a; Sweet et al., 2017b) at station 8724580 . 


\subsubsection{Analyses of rainfall and sea level trends}

Non-parametric Mann-Kendall test (Mann, 1945; Kendall, 1938; Kendall, 1976) was performed to determine significance of monotonic (i.e., increasing or decreasing) trends in annual maximum total rainfall depths and mean water levels (see Text A4.1). Mann-Kendall test has been widely used (e.g., Gavrilov et al., 2018; Pirnia et al., 2019; Mahjabin and Abdul-Aziz, 2020) for determination of local, i.e., at-site trend significance for different hydro-meteorological datasets. In the current study, 5\% statistical significance level for the Mann-Kendall test was considered, which means $95 \%$ certainty in the alternative hypothesis that the dataset had a monotonic trend was desired. The non-parametric Theil-Sen approach, also known as Sen slope estimator, (Theil, 1950; Sen, 1968) (see Text A4.2) was employed to compute magnitude of trends in annual maximum rainfall and water level. Theil-Sen approach has been extensively used in literature (e.g., Hanel et al., 2016; Hadi and Tombul, 2018; Mahjabin and Abdul-Aziz, 2020) as a robust prediction tool for trend slopes.

\subsubsection{Estimations of historical and future extreme rainfall, sea level, and runoff}

In the current study, Gumbel extreme value probability distribution was used, adopting the block maxima approach, to compute 1-7 day extreme rainfall and water level of varying return periods $(2,5,10,25,50$, and 100-year). Gumbel is a two-parameter (i.e., location and scale; see Text A4.3) distribution that has been widely applied (e.g., Bhagat, 2017; Mahdi and Mohamedmeki, 2020) on different hydro-meteorological random variables. Gumbel was chosen since unlike the other extreme value distributions (generalized extreme value, Weibull, and Fréchet), it did not produce inconsistent rainfall depth-duration-frequency (DDF) curves under a particular return period, i.e., lower rainfall depth for higher duration storms, during the initial analyses. Nonstationary Gumbel distributions were fitted to the datasets, considering trends in the location 
parameter, (see Text A4.3 in Appendix 4) when statistically significant monotonic trends were indicated by the Mann-Kendall test; stationary Gumbel distributions were fitted otherwise. In case of the occasional inconsistent design rainfall depth-duration relationship issues under a particular return period, power law equations $\left(Y=a X^{b}\right.$ where $Y=$ rainfall depth; $X=$ event duration; $a=$ constant; and $b=$ exponent) were fitted. In order to maintain consistency, the power-law fittings were performed for estimation of both historical and future design rainfall sea level.

The power-law corrected total design rainfalls and mean design water levels for an event were distributed to hourly values based on the observed historical hourly distributions. Average of the 50 hourly distributions corresponding to the 50 annual maximum values in the 2000 s was computed to have a representative hourly distribution for a particular event duration. The representative hourly distribution of rainfall and sea level, respectively, for an event duration was used for hourly disaggregation of historical design rainfalls and water levels for all return periods in the Saint Johns River Basin.

For hourly disaggregation of future design rainfalls of a certain event duration, the corresponding historical hourly rainfall distributions were used since observed hourly and daily rainfall variabilities are not reproduced satisfactorily by the GCMs (Zhang, 2013; Langousis et al., 2016). Thiessen Polygons were used for assigning the historical and future hourly design rainfalls to the subbasins (see Text A2.2). Meanwhile, relative SLR projections were available for the NOAA station 8724580 only (Section 5.2.4). Therefore, future hourly design water level values at NOAA station 8720218 were found by adding the SLR projections of station 8724580 to its historical hourly design water levels. Historical and future design water levels at station 8720218 were assigned to all stream outlets in the Saint Johns River Basin while taking the 
corresponding differences in stream bed elevation into account. SWMM simulations of runoff extremes in 2010 were then performed on hourly reporting time-step taking the extreme rainfalls, extreme sea levels, and observed ET in 2010 as well as imperviousness in 2010s (2004-2013) as inputs. Using the reconstructed future projections of extreme rainfall, ET, and imperviousness together with the estimated future extreme sea levels in 2050 and 2080 under both RCP 4.5 and 8.5 scenarios, future extreme runoffs across the Saint Johns River Basin were computed.

\subsection{Results}

\subsubsection{Model calibrations and validations}

Range of NSE values for the calibrated and validated Saint Johns River Basin model during 2004-2013 was from 0.70 to 0.82 (Figure 5.4) across the 4 stations; RSR values varied from 0.43 to 0.55 . These statistics for different stations along the Saint Johns River (Figure 5.2) indicated good to very good predictive performance of the model (Moriasi et al., 2007), and suitability of the developed model for estimating future extreme runoffs in the Saint Johns River Basin.

\subsubsection{Historical trends in rainfall and sea level and their design values}

Outcomes of The Mann-Kendall test demonstrated absence of monotonic trend in annual maximum 1-7 day total rainfall depths during the historical 2000s for most (78\%) stations (Table 5.2) in the Saint Johns River Basin at 5\% statistical significance level. In case of station 084797 (Figure 5.3), significant increasing trends with Sen's slope values ranging between 0.49 to 0.90 $\mathrm{mm} /$ year were observed for 1, 2, and 6-day duration. Significant increasing trend with Sen's slope of $0.81 \mathrm{~mm} /$ year for 7-day duration only was noted for station 085076 . In case of the tide station 8720218, significant increasing trends in sea level with Sen's slope values ranging from 4.1 to $4.5 \mathrm{~mm} /$ year were observed for all durations (Table 5.3). 

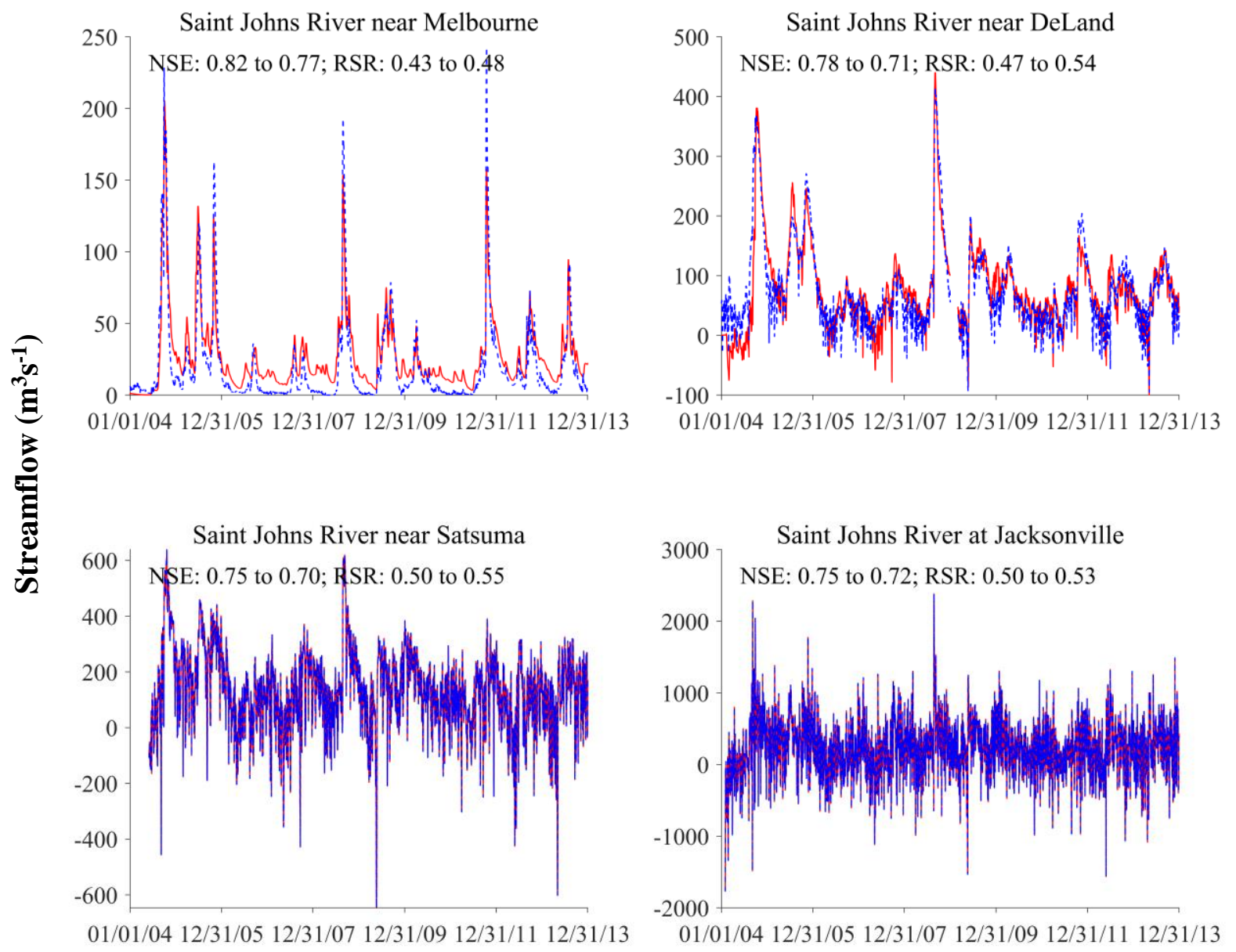

\section{Month/Day/Year}

Figure 5.4: Plots of model calibrations and validations with historical daily streamflow for the Saint Johns River Basin. 01/01/04 refers to January 01, 2004. Calibration and validation periods are, respectively, 01/01/2004 to 12/31/2008 and 01/01/2009 to 12/31/2013 for Saint Johns River near Melbourne; 01/01/2004 to 12/31/2008 and 03/01/2009 to 12/31/2013 for Saint Johns River near DeLand; 06/01/2004 to 12/31/2008 and 01/01/2009 to 12/31/2013 for Saint Johns River near Satsuma; and 02/01/2004 to 12/31/2008 and 01/01/2009 to 12/31/2013 for Saint Johns River near Jacksonville. 
Table 5.2: Sen's slope values (mm/year) for annual maximum event total rainfall depths for different durations during 1964-2013 in the Saint Johns River Basin. Numbers in the parentheses indicate $p$-values of the Mann-Kendall test. $p>0.05$ and $p \leq 0.05$ indicates absence and presence of monotonic trend, respectively, at 5\% statistical significance level.

\begin{tabular}{cccccccc}
\hline \multirow{2}{*}{ Station ID } & \multicolumn{7}{c}{ Sen's slope values, $\beta$ (mm/year) } \\
\cline { 2 - 7 } & 1-day & 2-day & 3-day & 4-day & 5-day & 6-day & 7-day \\
\hline 082158 & $0.06(0.81)$ & $-0.25(0.55)$ & $-0.16(0.66)$ & $0.1(0.81)$ & $0.27(0.61)$ & $0.41(0.33)$ & $0.55(0.25)$ \\
084273 & $0(0.95)$ & $-0.34(0.47)$ & $0(0.92)$ & $0.27(0.49)$ & $0.46(0.27)$ & $0.33(0.55)$ & $0.51(0.2)$ \\
084358 & $-0.34(0.48)$ & $-0.15(0.85)$ & $0.16(0.66)$ & $0.11(0.76)$ & $0.08(0.83)$ & $0.29(0.64)$ & $0.24(0.69)$ \\
087440 & $-0.06(0.83)$ & $-0.21(0.5)$ & $-0.2(0.66)$ & $-0.32(0.12)$ & $-0.29(0.48)$ & $-0.34(0.48)$ & $-0.37(0.48)$ \\
084797 & $0.49(0.01)$ & $0.64(0.04)$ & $0.63(0.13)$ & $0.63(0.21)$ & $0.73(0.1)$ & $0.9(0)$ & $0.72(0.09)$ \\
085612 & $0.6(0.21)$ & $0.64(0.28)$ & $0.56(0.22)$ & $0.45(0.32)$ & $0.48(0.32)$ & $0.33(0.52)$ & $0.26(0.69)$ \\
085076 & $0.37(0.34)$ & $0.36(0.28)$ & $0.4(0.34)$ & $0.59(0.09)$ & $0.76(0.05)$ & $0.76(0.07)$ & $0.81(0.01)$ \\
085237 & $-0.06(0.37)$ & $0(1)$ & $0.04(0.83)$ & $-0.17(0.71)$ & $-0.13(0.85)$ & $0(0.97)$ & $-0.21(0.47)$ \\
085391 & $0.48(0.23)$ & $0.62(0.17)$ & $0.83(0.06)$ & $0.48(0.3)$ & $0.42(0.4)$ & $0.52(0.17)$ & $0.51(0.16)$ \\
\hline
\end{tabular}

Table 5.3: Sen's slope values (mm/year) for annual maximum event mean sea levels for different durations during 1964-2013 in the Saint Johns River Basin. Numbers in the parentheses indicate $p$-values of the Mann-Kendall test. $p>0.05$ and $p \leq 0.05$ indicates absence and presence of monotonic trend, respectively, at 5\% statistical significance level.

\begin{tabular}{cccccccc}
\hline \multirow{2}{*}{ Station ID } & \multicolumn{7}{c}{ Sen's slope values, $\beta$ (mm/year) } \\
\cline { 2 - 8 } & 1-day & 2-day & 3-day & 4-day & 5-day & 6-day & 7-day \\
\hline 8720218 & $4.25(0)$ & $4.1(0)$ & $4.12(0)$ & $4.18(0)$ & $4.27(0)$ & $4.37(0)$ & $4.49(0)$ \\
\hline
\end{tabular}


Following the Mann-Kendall test results, stationary design rainfalls and non-stationary design sea levels were estimated in 2010. The power law fitting corrected $\left(R^{2}\right.$ ranged from 0.971 to 0.999 among the rainfall stations, and from 0.966 to 0.999 for the tide station 8720218 ) design rainfalls and sea levels (Table 5.4, 5.5, and 5.6) demonstrated a wide range of extreme rainfall and sea level regimes for the Saint Johns River Basin. Station 084358 (at Jacksonville) and 085237 (near Ocala) (Figure 5.3) represented higher (than other stations) 1-7 day design rainfall depths under different return periods ranging from 114 to $430 \mathrm{~mm}$ and 94 to $354 \mathrm{~mm}$, respectively (Table 5.4). Lower design rainfall depths of 87 to $315 \mathrm{~mm}$ and 96 to $286 \mathrm{~mm}$ were observed for station 084797 and 085076 , respectively. Spatial mean design rainfall for the entire basin ranged from 100 to $343 \mathrm{~mm}$ (Table 5.5). 1-7 day design sea levels under different return periods at tide station 8720218 ranged from 0.14 to 0.44 m NAVD 88 (Table 5.6).

\subsubsection{Extreme historical runoffs in 2010}

In case of the 100-year design rainfalls (the maximum probable extreme rainfalls considered in this study) in 2010 for 1-7 day durations, subbasin level accumulated rainfall depths across the Saint Johns River Basin (Figure A5.4 in Appendix 5) varied from 168 to $430 \mathrm{~mm}$. Notably higher (than other locations) rainfall depths of 210 to $430 \mathrm{~mm}$ were observed at and around Jacksonville. Subbasin level 1-7 day extreme runoffs ranging from 0.01 to $404 \mathrm{~mm}$ (Figure A5.5) were mainly governed by the 100-year rainfalls (given the perceivable dominance of extreme rainfall over ET in extreme runoff generation) and 100-year sea levels. Higher (than other locations) runoffs were generally found at various urban and peri-urban basin locations and their nearby areas characterized by 5 to $50 \%$ imperviousness. For example, extreme runoffs of 11 to $404 \mathrm{~mm}, 190$ to $310 \mathrm{~mm}, 12$ to $87 \mathrm{~mm}$, and 178 to $335 \mathrm{~mm}$ were found at the northern (e.g., Jacksonville), north-central (e.g., Palm Coast), south-central (e.g., Orlando and Clermont), and 
southern (e.g., Titusville and Melbourne) basin regions, respectively. Substantially lower 1-7 day runoffs of 0.01 to $21 \mathrm{~mm}$ were observed for vast majority of the unbuilt areas (croplands, pasture lands, grasslands, forests, and wetlands) spreading across the northern, northeastern, northcentral, south-central, and southern basin regions representing low baseline imperviousness of 0.01 to $3.5 \%$. Conversely, a few unbuilt areas at the southern basin regions experienced high 1-7 day extreme runoffs of 77 to $250 \mathrm{~mm}$ probably because the receiving streams reached to their full capacity and the rapidly rising GWT caused GWI. Basin-scale 1-7 day extreme runoffs in 2010 ranged from 118 to 466 million $\mathrm{m}^{3}$ (Table 5.7). The highest runoff volume was observed for the 7-day 100-year rainfalls and sea levels. The spatial variation in future runoff responses were, therefore, evaluated under potential changes in 7-day 100-year rainfalls and sea levels.

\subsubsection{Extreme future runoffs under standalone changes in individual drivers}

\subsubsection{Under standalone changes in climate}

Ensemble mean increases in runoff extremes in the Saint Johns River Basin were 12 to $14 \mathrm{~mm}$ (on spatial mean, per $\mathrm{m}^{2}$ basin area; Figure 5.5a) in regards to the 7-day 100-year extreme rainfall together with ET projections from the $20 \mathrm{GCMs}$ under different future scenarios. The moderate runoff increases albeit the corresponding high ensemble mean increases in rainfall extremes of 179 to $202 \mathrm{~mm}$ (on spatial mean, per $\mathrm{m}^{2}$ basin area; Figure A5.6a) can be attributed to the prevalent natural landscapes across the basin (basin-average imperviousness of $4.6 \%$ in the 2010s; Figure A5.2). Major as well as growing urban centers in the northern, north-central, south-central, and southern basin regions (e.g., Jacksonville, Palm Coast, Orlando, Clermont, Titusville, and Melbourne) and their nearby areas represented high spatial mean runoff increases ranging from 55 to $64 \mathrm{~mm}$. The high runoff increases at these basin locations were mostly due to high spatial mean rainfall increases of 193 to $221 \mathrm{~mm}$. 
Table 5.4: Historical design rainfall (mm) in 2010 for different stations in the Saint Johns River Basin under varying durations and return periods.

\begin{tabular}{|c|c|c|c|c|c|c|c|c|}
\hline \multirow{2}{*}{ Station ID } & \multirow{2}{*}{$\begin{array}{l}\text { Return } \\
\text { period }\end{array}$} & \multicolumn{7}{|c|}{ Design rainfall $(\mathrm{mm})$} \\
\hline & & 1-day & 2-day & 3-day & 4-day & 5-day & 6-day & 7-day \\
\hline \multirow{6}{*}{082158} & 2-year & 102 & 119 & 130 & 139 & 146 & 152 & 157 \\
\hline & 5-year & 137 & 158 & 172 & 183 & 192 & 199 & 206 \\
\hline & 10-year & 159 & 184 & 200 & 212 & 222 & 230 & 238 \\
\hline & 25-year & 188 & 216 & 235 & 249 & 260 & 270 & 279 \\
\hline & 50-year & 209 & 241 & 261 & 276 & 289 & 300 & 309 \\
\hline & 100-year & 231 & 265 & 287 & 303 & 317 & 329 & 339 \\
\hline \multirow{6}{*}{084273} & 2-year & 110 & 128 & 141 & 150 & 158 & 165 & 170 \\
\hline & 5-year & 147 & 171 & 188 & 200 & 210 & 219 & 227 \\
\hline & 10-year & 171 & 200 & 219 & 233 & 245 & 255 & 264 \\
\hline & 25-year & 202 & 236 & 258 & 275 & 289 & 301 & 312 \\
\hline & 50-year & 225 & 263 & 287 & 306 & 322 & 335 & 347 \\
\hline & 100-year & 248 & 289 & 316 & 337 & 354 & 369 & 382 \\
\hline \multirow{6}{*}{084358} & 2-year & 114 & 134 & 147 & 157 & 166 & 173 & 179 \\
\hline & 5-year & 154 & 182 & 201 & 215 & 227 & 237 & 246 \\
\hline & 10 -year & 181 & 214 & 237 & 254 & 268 & 280 & 291 \\
\hline & 25-year & 215 & 255 & 282 & 302 & 320 & 334 & 347 \\
\hline & 50-year & 240 & 285 & 315 & 338 & 358 & 374 & 389 \\
\hline & 100-year & 265 & 315 & 348 & 374 & 396 & 414 & 430 \\
\hline \multirow{6}{*}{087440} & 2-year & 89 & 104 & 114 & 122 & 128 & 133 & 138 \\
\hline & 5-year & 122 & 142 & 155 & 165 & 173 & 180 & 186 \\
\hline & 10 -year & 143 & 166 & 182 & 193 & 203 & 211 & 218 \\
\hline & 25-year & 170 & 198 & 216 & 229 & 241 & 250 & 259 \\
\hline & 50-year & 190 & 221 & 241 & 256 & 269 & 279 & 289 \\
\hline & 100-year & 210 & 244 & 266 & 283 & 297 & 308 & 319 \\
\hline \multirow{6}{*}{084797} & 2-year & 87 & 105 & 117 & 127 & 135 & 142 & 148 \\
\hline & 5-year & 109 & 133 & 150 & 164 & 175 & 184 & 193 \\
\hline & 10 -year & 123 & 152 & 172 & 188 & 201 & 212 & 223 \\
\hline & 25-year & 141 & 176 & 199 & 218 & 234 & 248 & 260 \\
\hline & 50-year & 155 & 193 & 220 & 241 & 259 & 274 & 288 \\
\hline & 100-year & 168 & 210 & 240 & 263 & 283 & 300 & 315 \\
\hline \multirow{6}{*}{085612} & 2-year & 107 & 123 & 133 & 140 & 147 & 152 & 157 \\
\hline & 5-year & 146 & 166 & 178 & 188 & 196 & 202 & 208 \\
\hline & 10-year & 172 & 194 & 208 & 219 & 228 & 235 & 242 \\
\hline & 25-year & 205 & 230 & 246 & 259 & 269 & 277 & 284 \\
\hline & 50-year & 229 & 257 & 275 & 288 & 299 & 308 & 316 \\
\hline & 100 -year & 253 & 283 & 303 & 317 & 329 & 339 & 347 \\
\hline \multirow{6}{*}{085076} & 2-year & 96 & 111 & 121 & 128 & 134 & 140 & 144 \\
\hline & 5-year & 124 & 142 & 154 & 163 & 170 & 177 & 182 \\
\hline & 10-year & 143 & 163 & 176 & 186 & 194 & 201 & 207 \\
\hline & 25-year & 166 & 189 & 204 & 215 & 224 & 232 & 239 \\
\hline & 50-year & 184 & 209 & 225 & 237 & 247 & 255 & 262 \\
\hline & 100-year & 201 & 228 & 245 & 258 & 269 & 278 & 286 \\
\hline \multirow{6}{*}{085237} & 2-year & 94 & 111 & 122 & 131 & 138 & 144 & 149 \\
\hline & 5-year & 132 & 154 & 169 & 180 & 189 & 197 & 204 \\
\hline & 10 -year & 157 & 183 & 200 & 213 & 224 & 233 & 240 \\
\hline & 25-year & 189 & 220 & 239 & 254 & 267 & 277 & 286 \\
\hline & 50-year & 213 & 247 & 268 & 285 & 299 & 310 & 321 \\
\hline & 100-year & 237 & 273 & 297 & 316 & 331 & 343 & 354 \\
\hline \multirow{6}{*}{085391} & 2-year & 97 & 114 & 125 & 134 & 141 & 147 & 152 \\
\hline & 5-year & 132 & 154 & 168 & 179 & 188 & 195 & 202 \\
\hline & 10-year & 155 & 180 & 196 & 208 & 219 & 227 & 235 \\
\hline & 25-year & 184 & 213 & 232 & 246 & 258 & 268 & 277 \\
\hline & 50-year & 206 & 237 & 258 & 274 & 287 & 298 & 308 \\
\hline & 100 -year & 227 & 262 & 284 & 301 & 316 & 328 & 338 \\
\hline
\end{tabular}


Table 5.5: Historical basin-average design rainfall (mm) in 2010 in the Saint Johns River basin under varying durations and return periods.

\begin{tabular}{cccccccc}
\hline Return & \multicolumn{7}{c}{ Design rainfall $(\mathrm{mm})$} \\
\cline { 2 - 7 } period & 1-day & 2-day & 3-day & 4-day & 5-day & 6-day & 7-day \\
\hline 2-year & 100 & 136 & 159 & 189 & 211 & 233 & 117 \\
5-year & 157 & 184 & 217 & 242 & 267 & 127 & 171 \\
10-year & 200 & 236 & 263 & 289 & 136 & 181 & 212 \\
25-year & 250 & 278 & 306 & 142 & 190 & 222 & 261 \\
50-year & 291 & 320 & 148 & 198 & 230 & 271 & 302 \\
100-year & 332 & 153 & 204 & 238 & 280 & 311 & 343 \\
\hline
\end{tabular}

Table 5.6: Historical design sea level (m NAVD 88) in 2010 at NOAA station 8720218 in the Saint Johns River basin under varying durations and return periods.

\begin{tabular}{ccccccccc}
\hline Station & Return & \multicolumn{7}{c}{ Design sea level (m NAVD 88) } \\
\cline { 3 - 9 } ID & period & 1-day & 2-day & 3-day & 4-day & 5-day & 6-day & 7-day \\
\hline \multirow{4}{*}{8720218} & 2-year & 0.20 & 0.17 & 0.16 & 0.15 & 0.15 & 0.14 & 0.14 \\
& 5-year & 0.26 & 0.23 & 0.22 & 0.21 & 0.20 & 0.20 & 0.19 \\
& 10-year & 0.30 & 0.27 & 0.26 & 0.25 & 0.24 & 0.23 & 0.23 \\
& 25-year & 0.36 & 0.33 & 0.31 & 0.29 & 0.28 & 0.28 & 0.27 \\
& 50-year & 0.40 & 0.36 & 0.34 & 0.33 & 0.32 & 0.31 & 0.30 \\
& 100-year & 0.44 & 0.40 & 0.38 & 0.36 & 0.35 & 0.34 & 0.34 \\
\hline
\end{tabular}

Table 5.7: Historical basin total runoff volume extreme (million $\mathrm{m}^{3}$ ) in 2010 in the Saint Johns River basin under extreme rainfalls and sea levels of varying durations and return periods.

\begin{tabular}{cccccccc}
\hline Return & \multicolumn{7}{c}{ Runoff extreme $\left(\right.$ million $\left.\mathrm{m}^{3}\right)$} \\
\cline { 2 - 7 } period & 1-day & 2-day & 3-day & 4-day & 5-day & 6-day & 7-day \\
\hline 2-year & 118 & 165 & 197 & 239 & 272 & 305 & 141 \\
5-year & 196 & 233 & 282 & 320 & 357 & 157 & 217 \\
10-year & 257 & 309 & 349 & 389 & 169 & 232 & 276 \\
25-year & 331 & 372 & 414 & 178 & 245 & 290 & 347 \\
50-year & 390 & 433 & 185 & 255 & 302 & 361 & 406 \\
100-year & 450 & 193 & 264 & 312 & 374 & 420 & 466 \\
\hline
\end{tabular}


(h) Climate
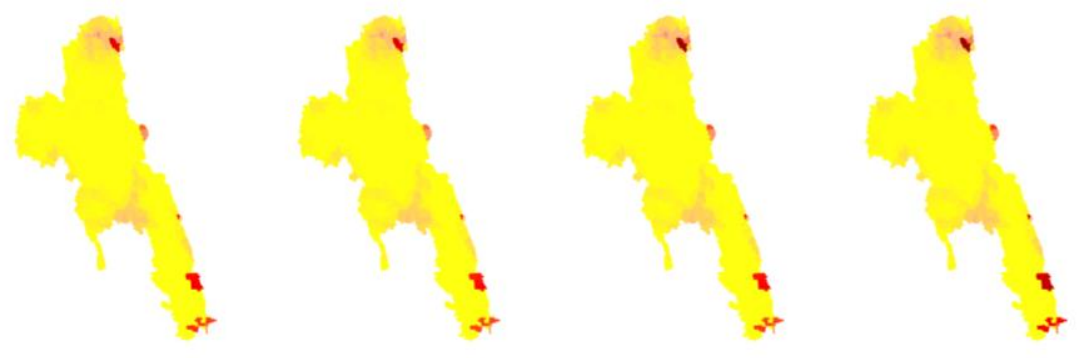

(g) Land cover

(f) Sea level
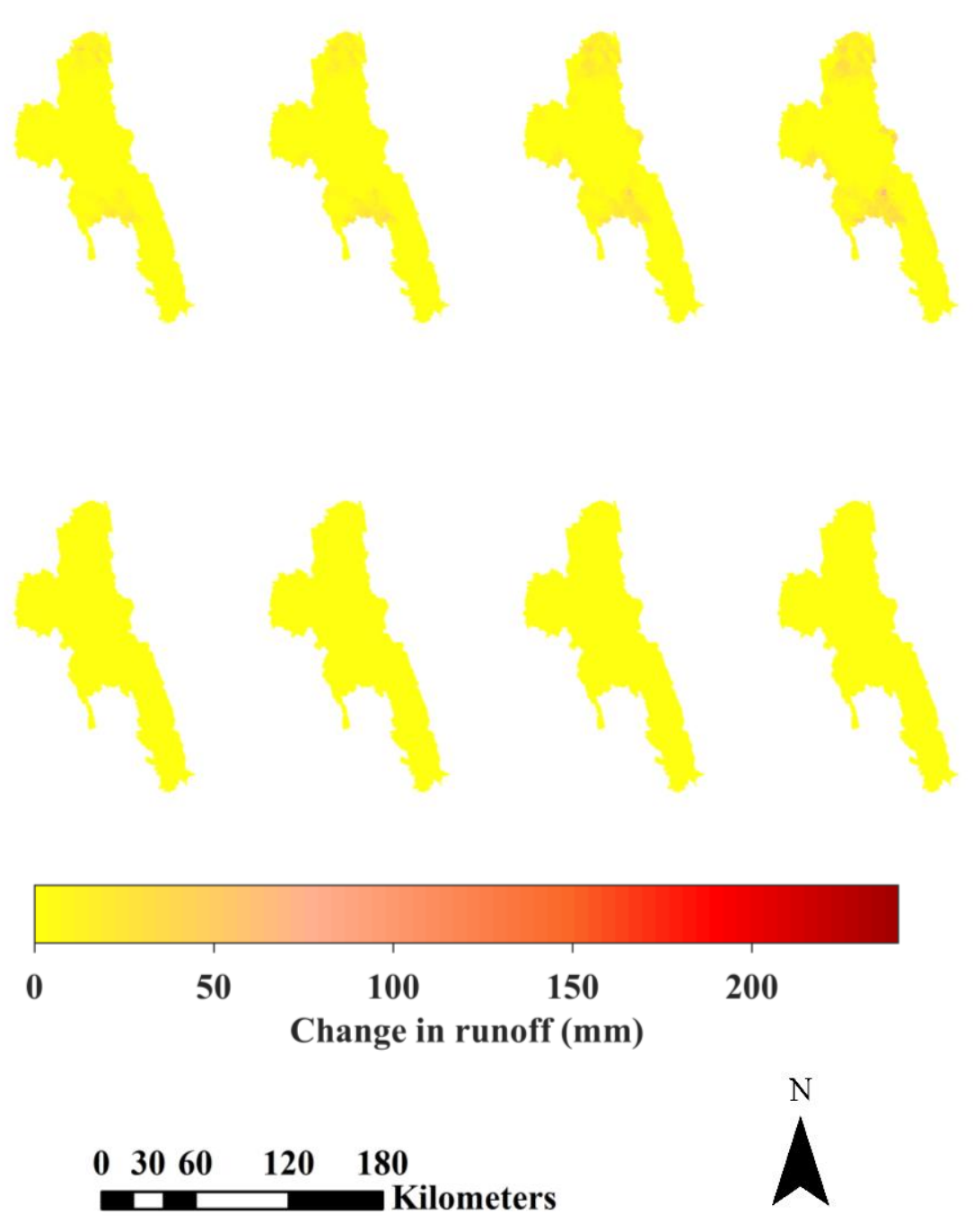

Figure 5.5: Spatial variation of the predicted changes in 7-day total runoff depth due to the projected standalone changes in (a) climate (100-year rainfall together with ET), (b) land cover, and (c) 100-year sea level under different future scenarios in the Saint Johns River Basin. 
Undeveloped lands at the southern part of the basin (Figure 5.5a) experienced very high spatial mean runoff increases of 155 to $184 \mathrm{~mm}$ under spatial mean rainfall increases of 183 to $216 \mathrm{~mm}$. Congestion of the drainage system together with GWI likely led to the higher (than other basin locations) runoff increases at these unbuilt areas. Most unbuilt locations (e.g., at the northern, northeastern, north-central, south-central, and southern parts of the basin), however, had very low spatial mean runoff increases of 1.1 to $1.3 \mathrm{~mm}$ regardless of the high potential rainfall increases of 175 to $196 \mathrm{~mm}$. Maximum spatial mean extreme runoff increase of $14 \mathrm{~mm}$ was noted for the 2080-RCP 8.5 scenario, with respect to 2010, on account of the corresponding maximum spatial mean increase in extreme rainfall of $202 \mathrm{~mm}$ (Figure A5.6a in Appendix 5).

With respect to 2010, increases in basin-wide 1-7 day ensemble mean runoff volume, under projected climatic changes, ranged from 17 to $87 \%$ across different return periods and future scenarios (Figure 5.6a). These runoff volume increases were regulated by the anticipated 16 to $59 \%$ ensemble mean increases in basin-average extreme rainfall (Figure A5.7) and 4 to $11 \%$ ensemble mean increases in basin-average ET (Table A5.3). Despite the maximum projected increase in ET of 11\%, higher rainfall increases of 18 to 59\% contributed to higher runoff increases of 21 to $87 \%$ in the 2080-RCP 8.5 scenario. Under the 2050-RCP 8.5, 2050RCP 4.5, and 2080-RCP 4.5 scenario, runoff increases of 18 to $80 \%, 18$ to $79 \%$, and 17 to $74 \%$ were noted, respectively. Intensified runoff increases with increasing return periods of the rainfall events were observed, since higher rainfall depths in higher return period events brought more rapid soil saturation and greater relative increases in runoff extremes, accordingly. Runoff increases showed overall decreasing trends with increasing rainfall event duration (Figure 5.6a). Maximum relative increase in basin-wide extreme runoff volume, under climatic changes, of $87 \%$ was observed in the 2080 -RCP 8.5 scenario due to the 7 -day 100 -year rainfall event. 
(a)

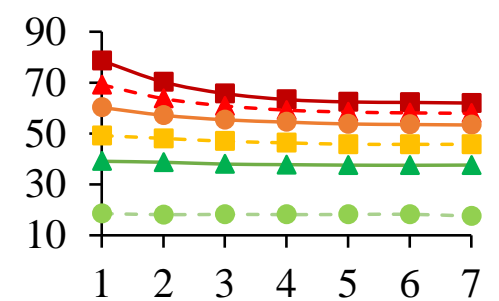

(b)

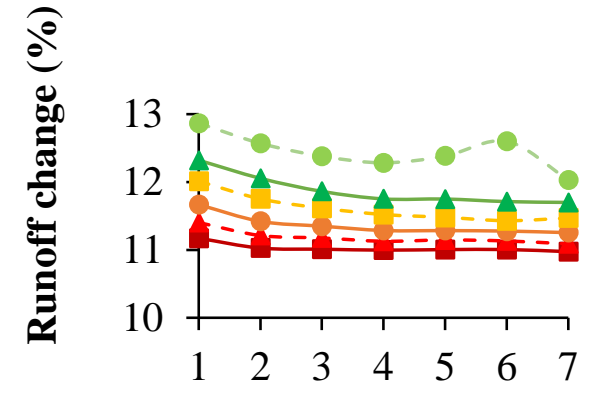

(c)

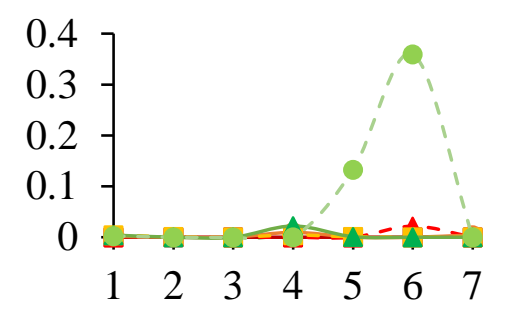

2080-RCP 4.5
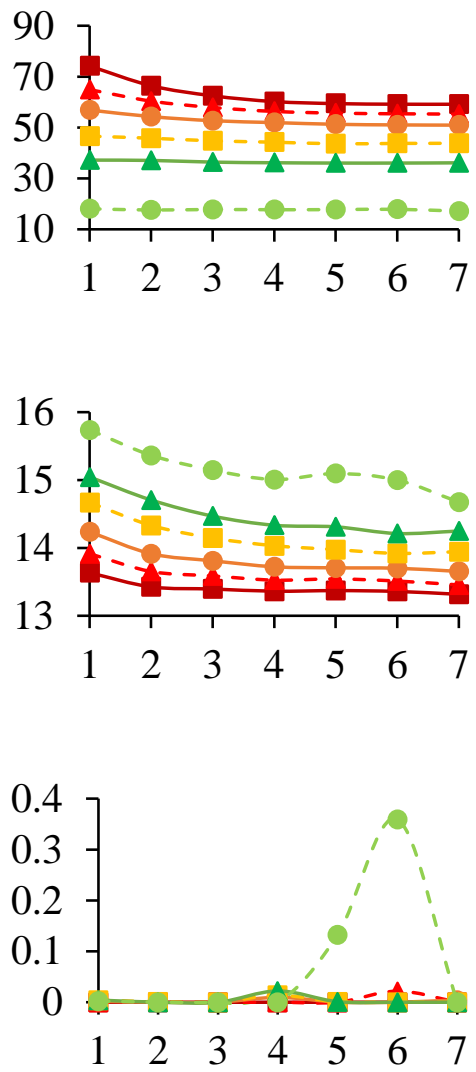

2050-RCP 8.5
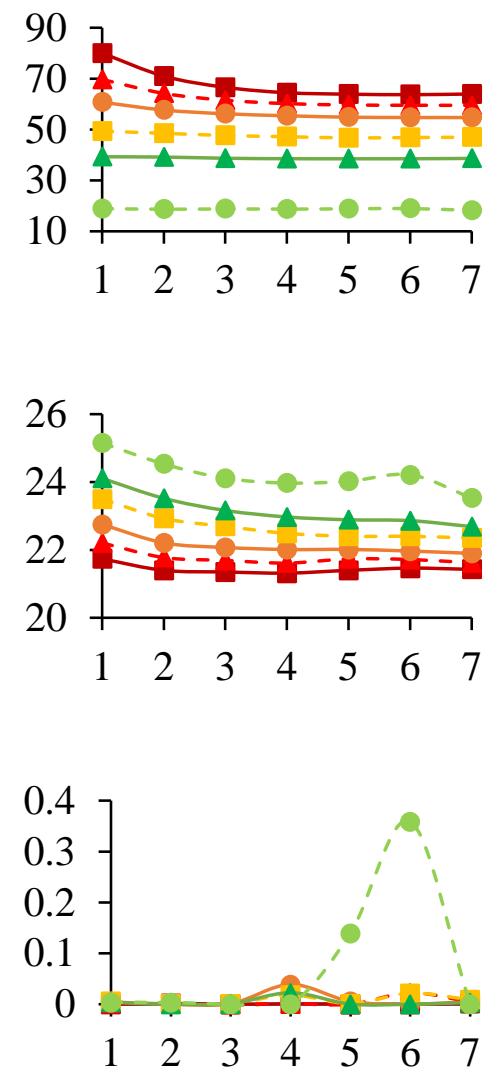

2080-RCP 8.5
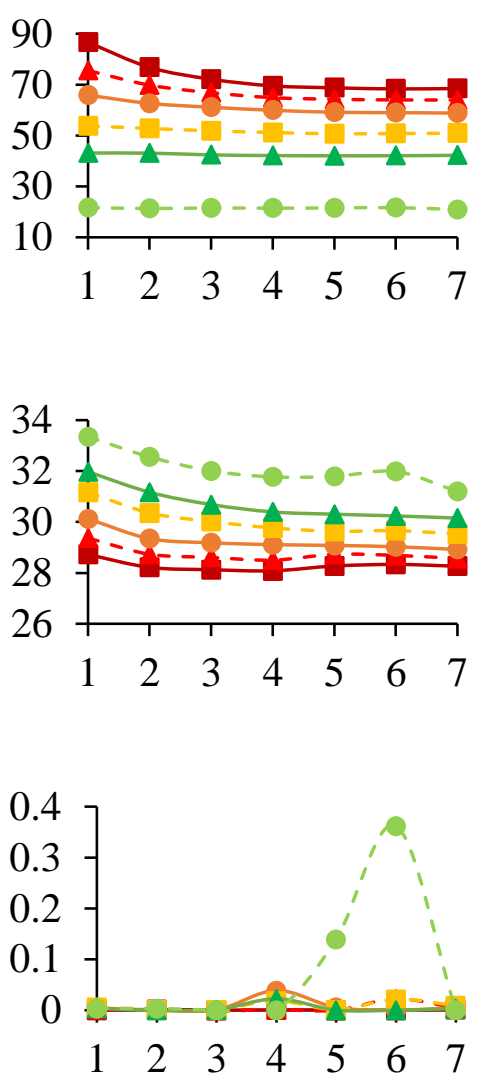

Duration (day)

$$
-\bullet-2 \text {-year } ₫ 5 \text {-year }-\square-10 \text {-year } \longrightarrow 25 \text {-year }-\star-50 \text {-year } \rightarrow-100 \text {-year }
$$

Figure 5.6: Percentage changes in 1-7 day total runoff due to the projected standalone changes in (a) climate (rainfall of varying return periods and ET), (b) land cover, and (c) sea level of varying return periods under different future scenarios in the Saint Johns River Basin. 


\subsubsection{Under standalone changes in land cover}

Very low spatial mean imperviousness increases across different future scenarios ranging from 0.75 to 1.9 percentage points (Figure A5.6b) generated nominal spatial mean 3 to $6 \mathrm{~mm}$ increases in extreme runoffs (Figure 5.5b) in the Saint Johns River Basin while keeping the 7-day 100-year rainfalls and sea levels in the 2010 unchanged. Primary and developing urban centers along with their neighboring places in the northern (e.g., Jacksonville), north-central (e.g., Palm Coast), south-central (e.g., Orlando and Clermont), and southern (e.g., Titusville and Melbourne) parts of the basin were anticipated to have spatial mean 13 to $25 \mathrm{~mm}$ increases in extreme runoff (Figure 5.5b). The corresponding projected spatial mean increases in imperviousness were 4 to 8 percentage points (Figure A5.6b). Undeveloped areas at the northern, northeastern, north-central, south-central, and southern parts of the basin, representing croplands, pasture lands, grasslands, forests, and wetlands in 2010, were projected to experience spatial mean 0.1 to 0.3 percentage point increases in imperviousness under different future scenarios. The consequent low spatial mean increases in extreme runoffs ranged from 0.3 to $1.1 \mathrm{~mm}$. Among the four future scenarios, 2080-RCP 8.5 represented the maximum spatial mean runoff increase of $6 \mathrm{~mm}$ (Figure 5.5b) in response to the maximum spatial mean increase in imperviousness (Figure A5.6b).

Isolated changes in land cover led to much lower changes in basin-scale extreme runoff volume (Figure 5.6b) as compared to that in climate. Potential 16-40\% increases in basin average imperviousness (Table A5.3) across different future scenarios generated 11 to 33\% increases in 1-7 day extreme runoff volumes under different return periods. 28 to $33 \%, 21$ to $25 \%, 13$ to $16 \%$, and 11 to $13 \%$ runoff increases were noted, respectively, for the 2080-RCP 8.5, 2050-RCP 8.5, 2080-RCP 4.5, and 2050-RCP 4.5 scenario (Figure 5.6b). Higher runoff increases were observed for the 2080-RCP 8.5 scenario due to the corresponding maximum potential increase in 
basin average imperviousness (Table A5.3). The relative runoff increases under changing land cover attenuated with increasing return period of the rainfall event in 2010. With increasing event duration, runoff increases demonstrated overall decreasing trends. These coastal-natural watershed responses indicated stronger impact of potential land cover changes on extreme runoffs under extreme rainfall events of lower depths than that under extreme rainfall events of higher depths. In case of extreme runoffs under 1-day 2-year rainfall events, highest increase in basin-wide extreme runoff volume of $33 \%$ was found in the 2080-RCP 8.5 scenario.

\subsubsection{Under standalone changes in sea level}

Individual sea level changes mostly (for around $99 \%$ basin locations) produced no runoff changes across the Saint Johns River Basin (Figure 5.5c). While keeping the 7-day 100-year rainfalls and land cover in the 2010 unchanged, potential 0.38 to $1.14 \mathrm{~m}$ SLR (Table A5.4) in 7day 100-year sea level produced minimal spatial mean runoff increases of 0.01 to $0.1 \mathrm{~m}$ for a very few locations in the northern and southern parts of the basin. The apparent insubstantial impact of potential sea level changes on watershed hydrologic response might be attributed to spatial mean 4 to $4.1 \mathrm{~m}$ depth to event-average GWL from the ground surface in the Saint Johns River Basin.

Standalone changes in 1-7 day sea level produced minimal changes in basin-wide extreme runoff volume across different future scenarios and event return periods. All of the future scenarios, i.e., 2050-RCP 4.5, 2080-RCP 4.5, 2050-RCP 8.5, and 2080-RCP 8.5 represented similar insubstantial increases in basin runoff volume of 0 to $0.4 \%$ under the potential SLR projections(Table A5.4). The much lower increases in runoff extremes given by changing sea level as compared changing climate, similar to changing land cover, reaffirmed the dominant role of climate (i.e., rainfall) in generating extreme runoff in the coastal-natural 
northeast Florida. No definite trends in runoff increases with increasing duration and return period of extreme rainfalls and sea levels were noted. Maximum potential increase in basin-scale extreme runoff volume of $0.4 \%$ was found for the 6-day 2-year return period event across all future scenarios.

\subsubsection{Extreme future runoffs under concurrent changes in two major drivers}

\subsubsection{Under concurrent changes in climate and land cover}

Concurrently changing climate and land cover represented slightly more widespread and notably greater runoff increases (Figure 5.7a) as compared to individually changing climate and land cover. Subject to simultaneous spatial mean 179 to $202 \mathrm{~mm}$ increases in 7-day 100-year extreme rainfall and spatial mean 0.75 to 1.9 percentage points increase in imperviousness (Figure A5.6a, $\mathrm{b}$ in Appendix 5), spatial mean increases in 7-day extreme runoff ranged from 17 to $24 \mathrm{~mm}$ across the Saint Johns River Basin. The spatial patterns of potential increases in extreme runoff due to concurrently changing climate and land cover (Figure 5.7a) generally demonstrated similarities to those due to individually changing climate (Figure 5.5a). Locations at and around the major and growing urban centers in the northern (e.g., Jacksonville), north-central (e.g., Palm Coast), south-central (e.g., Orlando and Clermont), and southern (e.g., Titusville, and Melbourne) parts of the basin outlined spatial mean 78 to $104 \mathrm{~mm}$ increase in 7-day extreme runoff across different future scenarios. Runoff increases for these urban centers and their neighboring areas were caused by concurrent spatial mean 193 to $221 \mathrm{~mm}$ increases in 7-day 100 -year extreme rainfall (Figure A5.6a) and 4 to 8 percentage points increases in imperviousness (Figure A5.6b). The 2080-RCP 8.5 scenario represented the maximum spatial mean 7-day extreme runoff increase of $24 \mathrm{~mm}$ (Figure 5.7a) commensurate with the highest spatial mean increase in 7-day 100-year extreme rainfall and imperviousness. 


\section{0-RCP $4.5 \quad 2080-R C P 4.5 \quad 2050-R C P ~ 8.5 \quad 2080-R C P ~ 8.5$}

(a) Climate and land cover
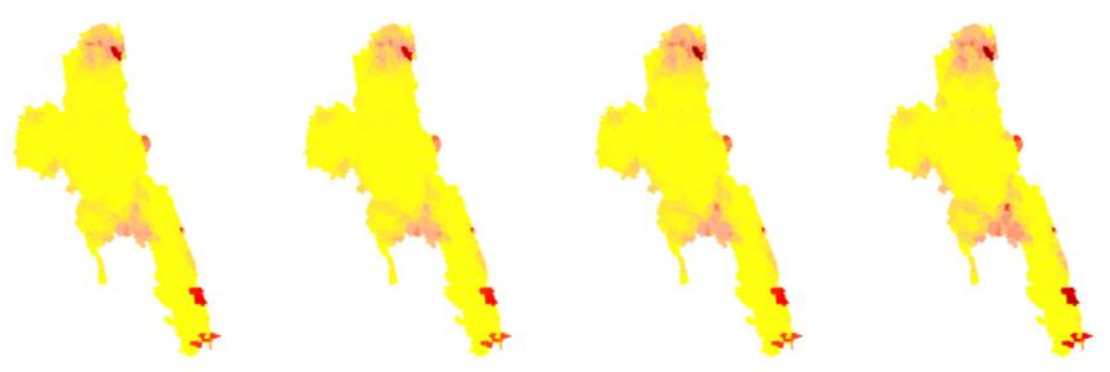

(b) Climate and sea level
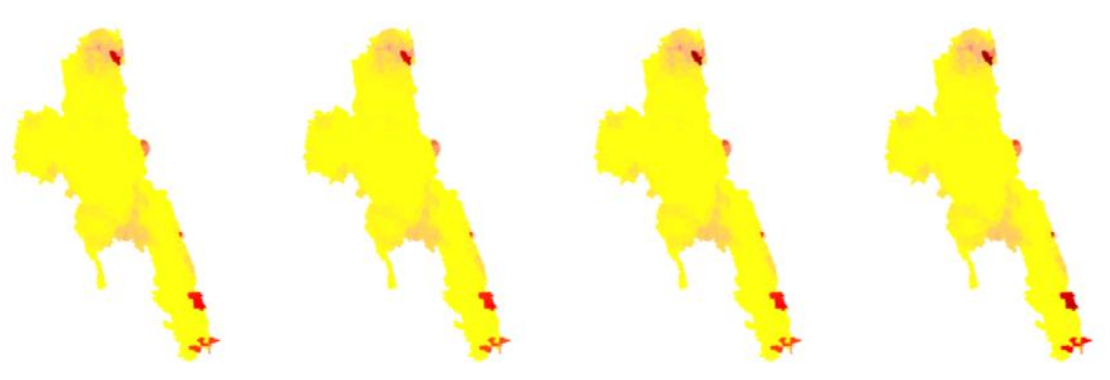

(c) Land cover and sea level
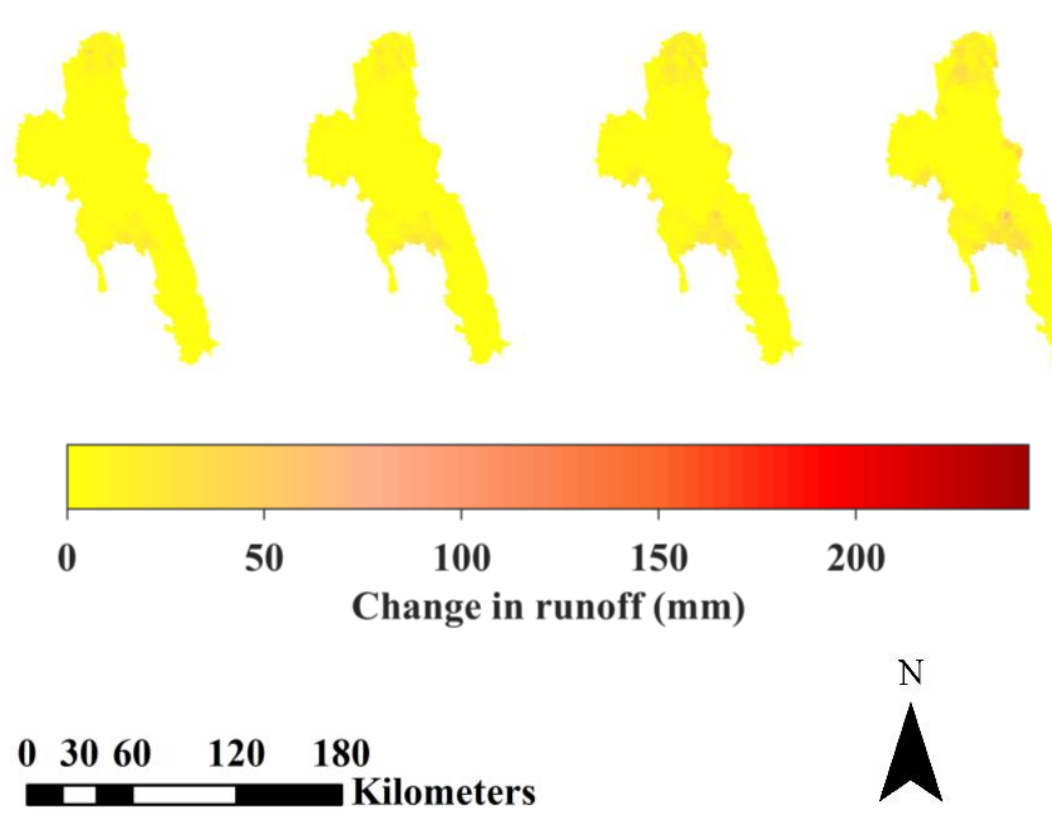

Figure 5.7: Spatial variation of the predicted changes in 7-day total runoff depth due to the projected simultaneous changes in (a) climate (100-year rainfall together with ET) and land 
cover, (b) climate and 100-year sea level, and (c) land cover and 100-year sea level under different future scenarios in the Saint Johns River Basin.

Simultaneous projected changes in climate and land cover in the Saint Johns River Basin contributed to basin-scale 1-7 day extreme runoff volume increases of 58 to $132 \%, 46$ to $113 \%$, 34 to $95 \%$, and 32 to $96 \%$ on the 2080-RCP8.5, 2050-RCP 8.5, 2080-RCP 4.5, and 2050-RCP 4.5 scenario (Figure 5.8a), respectively. 2080-RCP 8.5 represented higher runoff increases because of the higher potential increases in extreme rainfalls (Figure A5.7) together with the maximum potential increase in basin-average imperviousness (Table A5.3). Similar patterns for variations in basin-scale extreme runoff volume responses under simultaneously changing climate and land cover (Figure 5.8a) were noted as compared to that under individually changing climate (Figure 5.6a). Runoff changes under combined changes in climate and land cover increased with increases in return period of the extreme rainfall events; overall decreasing trends were observed with increasing even durations. Maximum potential increase in basin-wide extreme runoff volume of $132 \%$, under simultaneously changing climate and land cover, was found for the 1-day 100-year rainfall event in the 2080-RCP 8.5. 
(a)
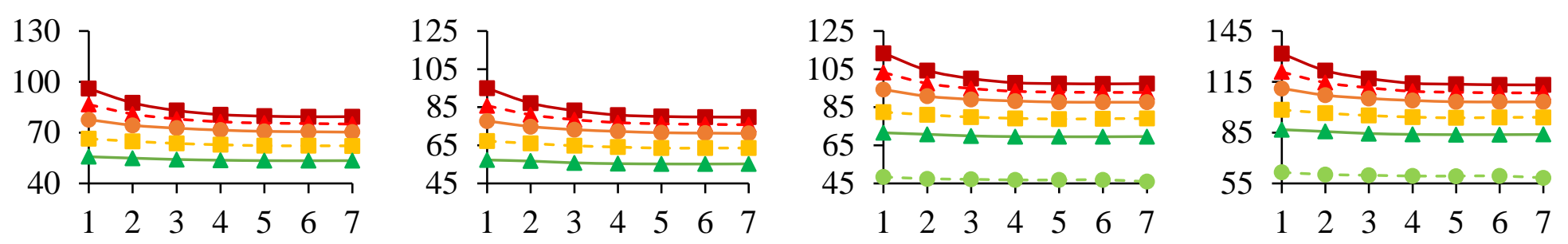

(b)
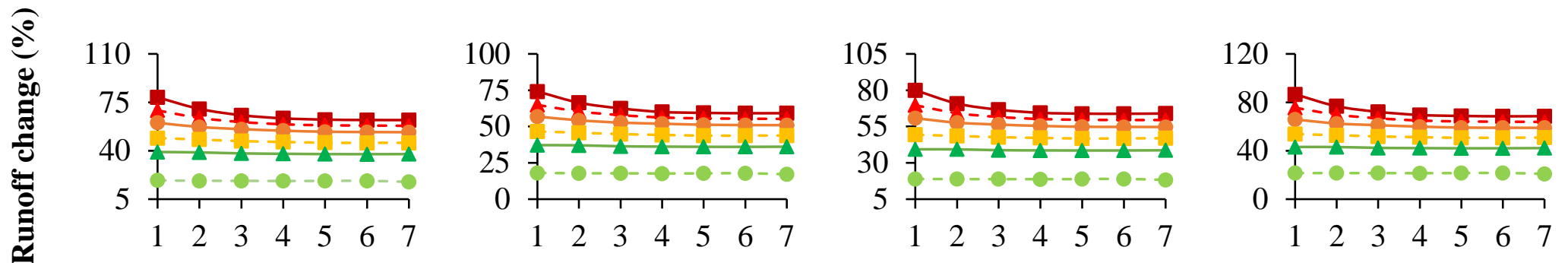

(c)
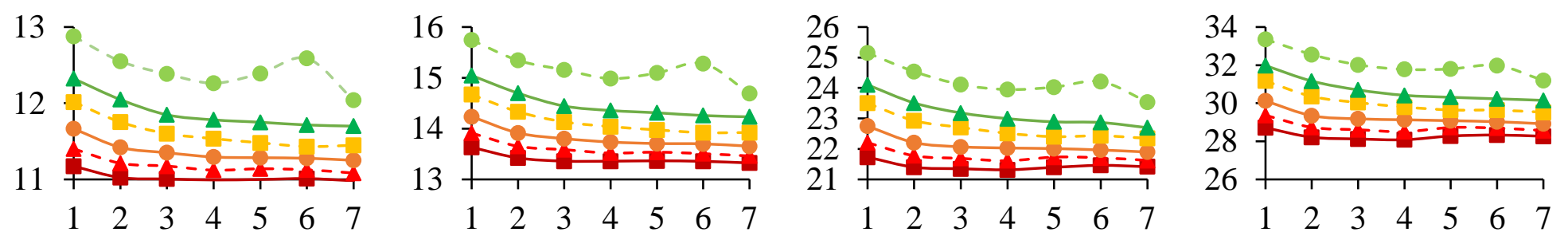

\section{Duration (day)}

$$
-\bullet \text { - 2-year } \longrightarrow \text { - 5-year }-\Perp-10 \text {-year } \longrightarrow 25 \text {-year }-\star-50 \text {-year } \rightarrow-100 \text {-year }
$$

Figure 5.8: Percentage changes in 1-7 day total runoff due to the projected simultaneous changes in (a) climate (rainfall of varying return periods and ET) and land cover, (b) climate and sea level of varying return periods, and (c) land cover and sea level of varying return periods under different future scenarios in the Saint Johns River Basin. 


\subsubsection{Under concurrent changes in climate and sea level}

Spatial mean 12 to $14 \mathrm{~mm}$ increases in 7-day extreme runoff volume were found across the Saint Johns River Basin when simultaneous projected 179 to $202 \mathrm{~mm}$ changes in 7-day 100-year rainfall and sea level along with projected changes in ET were considered (Figure 5.7b). The spatial patterns as well magnitude of runoff increases under concurrent changes in climate and sea level were identical to that under isolated changes in climate (Figure 5.5a), given no runoff changes at almost 99\% basin locations due to the projected SLR (Figure 5.5c). Major and developing urban centers spreading from the northern to the southern parts of the basin (e.g., Jacksonville, Palm Coast, Orlando, Clermont, Titusville, and Melbourne) together with regions in their vicinity experienced potential spatial mean 55 to $64 \mathrm{~mm}$ runoff increases. Except a few locations at the southern part of the basin, undeveloped lands (at the northern, northeastern, north-central, south-central, and southern parts of the basin) mostly had nominal spatial mean runoff increases of 1 to $3 \mathrm{~mm}$ (Figure 5.8b). 2080-RCP 8.5 represented maximum spatial mean increase in 7-day extreme runoff of $14 \mathrm{~mm}$ corresponding to maximum spatial mean increase in 7-day 100-year extreme rainfall (Figure A5.6a in Appendix 5) and maximum projected SLR (Table A5.4).

Under concurrent changes in climate and sea level, basin-wide 1-7 day runoff volume increases of 21 to $87 \%, 18$ to $80 \%, 17$ to $79 \%$, and 17 to $74 \%$ were observed under the 2080 RCP 8.5, 2050-RCP 8.5, 2050-RCP 4.5, and 2080-RCP 4.5 scenarios, respectively (Figure 5.8b). Higher potential increases in extreme rainfall (Figure A5.7) in conjunction with the maximum potential SLR (Table A5.4) resulted in higher increases in basin-scale runoff volume under the 2080-RCP 8.5 scenario. Similar to individual changes in climate (Figure 5.6a), combined changes in climate and land cover represented increasing runoff changes with increasing return 
period of the extreme rainfall events, and overall decreasing runoff changes with increasing event durations (Figure 5.8b). Potential higher increases in 1-day 100-year extreme rainfall and sea level in the 2080-RCP 8.5 gave the maximum basin-wide extreme runoff increase of $87 \%$

\subsubsection{Under concurrent changes in land cover and sea level}

As compared to combined projected changes in climate and land cover and in climate and sea

level, combined projected changes in land cover and sea level produced much lower spatial mean increases in 7-day extreme runoffs of 3 to $6 \mathrm{~mm}$ (Figure 5.7c). Concurrently changing land cover and 7-day 100-year sea level gave identical spatial patterns and magnitudes of runoff changes as compared to individually changing land cover (Figure 5.5b) on account of the apparent unchanged runoff responses at almost 99\% area of the Saint Johns River Basin (Figure 5.5c). Higher (than other basin locations) spatial mean runoff increases 13 to $25 \mathrm{~mm}$ were found at and around different urban centers (e.g., Jacksonville, Palm Coast, Orlando, Clermont, Titusville, and Melbourne) across the basin. The maximum projected spatial mean increase in imperviousness (Figure A5.6b) together with maximum projected SLR (Table A5.4) led to maximum spatial mean runoff increase under the 2080-RCP 8.5 scenario.

Concurrent land cover and sea level changes brought about basin-scale extreme runoff increases of 28 to $33 \%, 21$ to $25 \%, 13$ to $16 \%$, and 11 to $13 \%$, respectively, under the $2080-\mathrm{RCP}$ 8.5, 2050-RCP 8.5, 2080-RCP 4.5, and 2050-RCP 4.5 scenario (Figure 5.8c). Identical to individually changing land cover (Figure 5.6b), concurrently changing land cover and sea level resulted in decreasing runoff changes with increasing event return periods and overall decreasing runoff changes with increasing even durations (Figure 5.8c). Maximum potential increase in basin-scale extreme runoff volume of $33 \%$ was observed in the 2080-RCP 8.5 scenario for projected changes in 1-day 2-year extreme rainfalls and sea levels. 


\subsubsection{Extreme future runoffs under concurrent changes in all major drivers}

Simultaneous projected changes in 7-day 100-year extreme rainfall and sea level, ET, and imperviousness in the Saint Johns River Basin gave spatial mean increases in 7-day extreme runoffs of 17 to $24 \mathrm{~mm}$ (Figure 5.9). The spatial patterns as well as magnitudes of runoff changes across different future scenarios under combined changes in all of the drivers were identical to that under combined changes in climate and land cover, due to minimal impacts of potential SLR (see Section 5.3.4.3). Spatial mean 78 to $104 \mathrm{~mm}$ increases in extreme runoff were expected for the urban centers and their neighboring areas across a stretch from the northern to the southern parts of the basin (e.g., Jacksonville, Palm Coast, Orlando, Clermont, Titusville, and Melbourne; Figure 5.9). Spatial mean projected rainfall and imperviousness increases of 193 to $221 \mathrm{~mm}$ and 4 to 8 percentage points, respectively (Figure A5.6a, b), together with projected SLR of 0.38 to $1.14 \mathrm{~m}$ (Table A5.4) contributed to these runoff increases.

Most of the undeveloped lands (e.g., croplands, pasture lands, grasslands, forests, and wetlands) located at the northern, northeastern, north-central, south-central, and southern parts of the basin represented nominal spatial mean runoff increases of 2 to $3 \mathrm{~mm}$. On the contrary, probable drainage congestions and GWI likely caused high spatial mean runoff increases of 155 to $186 \mathrm{~mm}$ at a few undeveloped lands at the southern parts of the Saint Johns River Basin (Figure 5.9). Subject to maximum potential spatial mean increases in extreme rainfall and imperviousness (Figure A5.6a, b) as well as maximum potential SLR (Table A5.4), maximum spatial mean increase in extreme runoff of $24 \mathrm{~mm}$ was found in the 2080-RCP 8.5 scenario. 

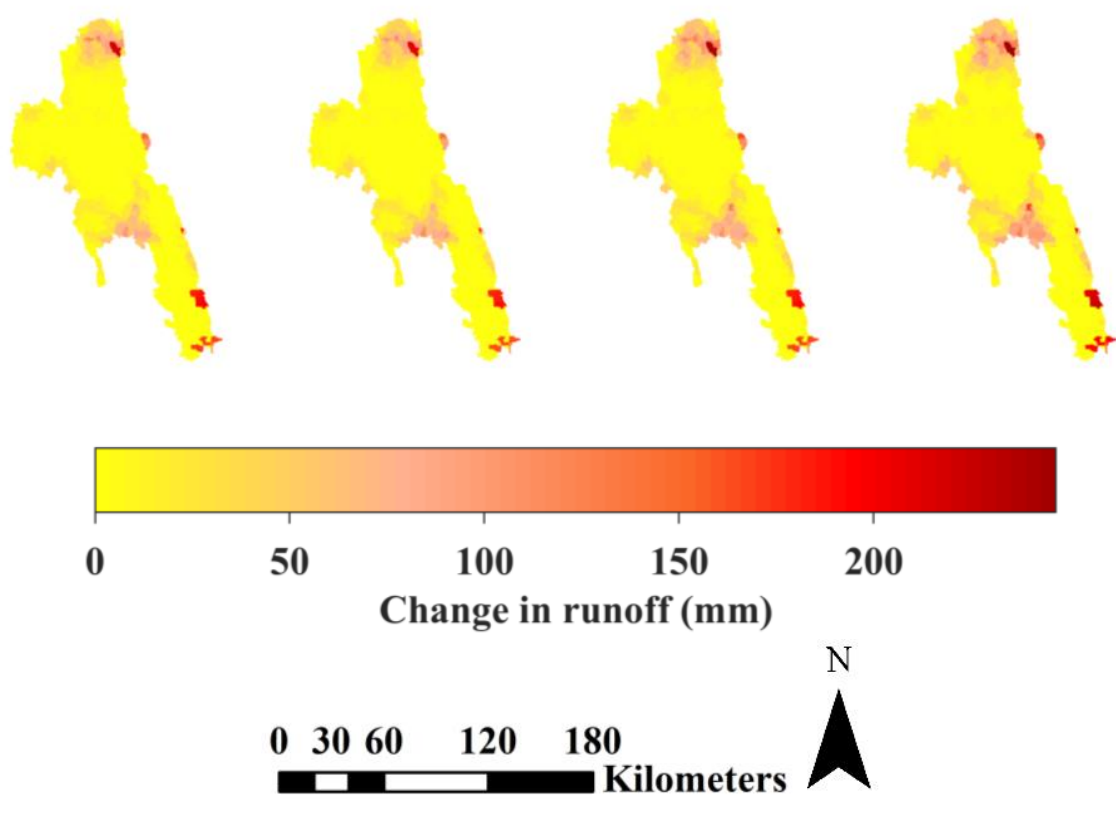

Figure 5.9: Spatial variation of the predicted changes 7-day total runoff depth due to the projected simultaneous changes in climate (100-year rainfall together with ET), land cover, and 100-year sea level in the Saint Johns River Basin.

Moderate to high relative increase in basin-wide extreme runoff volume, under simultaneous projected changes in climate, land cover, and sea level were noted under all future scenarios: 2080-RCP 8.5 (58 to 132\%), 2050-RCP 8.5 (46 to 113\%), 2080-RCP 4.5 (34 to 95\%), and 2050-RCP 4.5 (32 to 96\%) (Figure 5.10). Basin-scale runoff increases under concurrent changes in all major drivers intensified under increasing event return periods for extreme rainfalls and sea levels; the runoff increases generally attenuated under increasing event durations for extreme rainfalls and sea levels. Highest relative increase in basin-scale extreme runoff volume of $132 \%$ was observed in the 2080-RCP 8.5 scenario under high relative increases in 1-day 100-year rainfall, maximum potential increases in basin-average imperviousness (Table 
A5.3), and maximum projected SLR (Table A5.4). The potential increases in basin-scale extreme runoff volume outlined 2050-RCP 8.5 and 2080-RCP 8.5 as the most critical near-term and longterm future scenarios, respectively in the coastal-natural Saint Johns River Basin for management of extreme runoff problems and pluvial flooding risks.

\subsection{Discussion}

\subsubsection{Historical and future extreme rainfall, sea level, and runoff scenarios}

At 5\% statistical significance level, most (78\%) of the 50-year rainfall stations in the Saint Johns River Basin (Figure 5.3) did not represent monotonic trends in 1-7 day annual maximum rainfalls during 1964-2013 (Table 5.2). Station 084797 demonstrated statistically significant increasing trends in annual maximum rainfalls of 1, 2, and 6-day duration while station 085076 gave significant increasing trend for 7-day annual maximum rainfalls only. Significant increasing trends in 1-7 day annual maximum water levels of 1964-2013 were noted for the tide station 8720218 (Table 5.3). Following the trend analyses results, the estimated stationary 1-7 day extreme rainfalls of varying return periods in 2010, across different stations, ranged from 87 to $430 \mathrm{~mm}$ (Table 5.4). The estimated non-stationary 1-7 extreme sea levels for the tide station 8720218 in 2010, across different return periods, ranged from 0.14 to 0.44 m NAVD 88 (Table 5.5). Basin-scale 1-7 day extreme runoff volume of varying return periods in 2010 (Table 5.7) ranged from 118 to 466 million $\mathrm{m}^{3}$. 

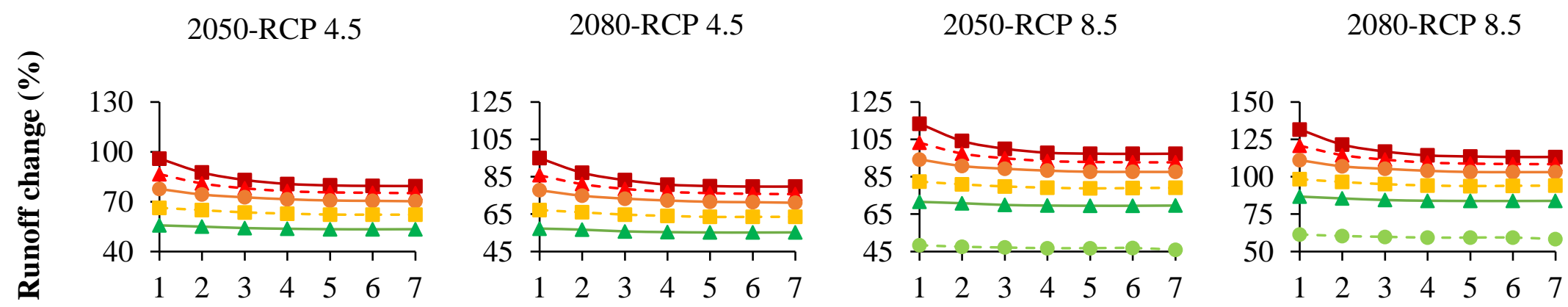

\section{Duration (day)}

$$
-\bullet \text { - 2-year } \longrightarrow \text {-year }-₫-10 \text {-year } \longrightarrow 25 \text {-year }-\star-50 \text {-year } \rightarrow-100 \text {-year }
$$

Figure 5.10: Percentage changes in 1-7 day total runoff due to the projected simultaneous changes in climate (rainfall of varying return periods and ET), land cover, and sea level of varying return periods under different future scenarios in the Saint Johns River Basin. 
Individual projected changes in climate (rainfall and ET) as wells as in land cover led to high runoff increases for many major and growing urban centers in the Saint Johns River Basin (e.g., Jacksonville, Palm Coast, Orlando, Clermont, Titusville, and Melbourne) and their neighboring regions (Figure 5.5a, b). Most of the unbuilt lands across the basin (croplands, pasture, grasslands, forests, and wetlands), except for a few unbuilt areas at its southern part, were expected to have nominal runoff increases due to individually changing climate and land cover. Projected changes in SLR were, apparently, not impactful on extreme runoff generation for vast majority (99\%) of the basin locations (Figure 5.5c). Concurrent changes in two (especially for concurrent changes in climate and land cover) and three major drivers resulted in greater and more widespread runoff increases (Figure 5.7; Figure 5.9). The spatial patterns of potential runoff increases under concurrent projected changes in climate and land cover as well as in climate, land cover, and sea level were mostly similar to that under isolated changes in climate (Figure 5.5a).

Relative to the baseline 2010, potential climatic changes were expected to bring basinscale extreme runoff volume increases of 17 to $87 \%$ across different future scenarios, event durations, and return periods (Figure 5.6a). Relatively lower potential 11 to $33 \%$ and 0 to $0.4 \%$ relative increases in basin runoff volume, respectively (Figure 5.6b, c), under isolated changes in land cover and sea level outlined potential climatic changes as the dominant driver of future extreme runoff increases in the coastal-natural Saint Johns River Basin. Simultaneous projected changes in climate, land cover, and sea level, brought about higher relative increases in basin runoff volume of 58 to $132 \%$ for the $2080-\mathrm{RCP} 8.5$ scenario which is, apparently, the most critical future scenario for extreme runoff and pluvial flooding risk managements. 
Potential changes in basin-scale extreme runoff volume under projected individual changes in rainfall represented increasing trends with increasing event return periods (Figure 5.6a). Basin-scale extreme runoff changes due to projected individual land cover changes (Figure 5.6b) attenuated with increasing event durations; extreme runoff changes due to projected SLR (Figure 5.6c) did not show any definite trends. Except for sea level, potential future changes in extreme runoff volume in the Saint Johns River Basin generally outlined decreasing trends with increasing event durations. These decreasing trends in runoff changes are probable indicators of reduced influences of potential climatic and land cover changes when more sustaining rainfall events bring the soil to saturation.

\subsubsection{Comparison of the study outcomes with existing relevant literature}

The study findings for the Saint Johns River Basin were concordant with the existing relevant research on Florida as well as different environments around the world. The current study outlined locally significant ( $p$-value $\leq 0.05$ ) increasing trends in annual maximum rainfalls of 1 , 2, 6, and 7-day durations for $11 \%$ (1 out of 9) stations across northeast Florida (Table 5.2) during 1964-2013. Mahjabin and Abdul-Aziz (2020) reported locally significant ( $p$-value $\leq 0.10$ ) increasing trends in 4-7 day annual maximum rainfalls for 6\% (1 out of 18) stations across Florida during 1960-2010. Meanwhile, for 1950-2008, Irizarry-Ortiz et al. (2013) found statistically significant ( $p$-value $\leq 0.05$ ) decreasing trends in 2-3 day maximum rainfalls for $6 \%$ (2 out of 32) and in 5 and 7-day maximum rainfalls for 3\% (1 out of 32) of different stations across Florida. Across the Saint Johns River Basin, no statistically significant decreasing trends were found for the 9 rainfall stations (Table 5.2). The differences in trend direction between the study on Florida conducted by Irizarry-Ortiz et al. (2013) and the current study on northeast Florida can be attributed to the difference in the gauging stations between the two studies where 
locally significant trends were found, and also, to the difference in study periods. For the tide station near Jacksonville, significant increasing trends in 1-7 day annual maximum sea levels were noted during 1964-2013 (Table 5.3) — denoting notable SLR. Much existing research has also reported consistent SLR at various locations across Florida (e.g., Park and Sweet, 2015; Gerlach et al., 2017; Valle-Levinson et al., 2017; Domingues et al., 2018).

The projected future extreme runoff scenarios for the Saint Johns River Basin in 2050 and 2080 outlined climate (i.e., rainfall) as its dominant driver (Figure 5.5 and 5.6) in comparison with land cover and sea level. On a similar note, Akter et al. (2018) concluded that climate change impacts would be more impactful on generating peak flows than urbanization by the end of the $21^{\text {st }}$ century for the Schijn River of Belgium. Arnone et al. (2018) also found runoff extremes to be more strongly controlled by the potential changes in climatic regimes than potential urban growth under hypothetical future climate conditions and by imposing an urbanization trend for the Peacheater Creek basin at Oklahoma, USA.

Projected future climatic changes in the Saint Johns River Basin suggested intensified extreme runoff responses in the year 2050 and 2080 (Figure 5.5a and 5.6a). Najafi and Moradkhani (2015) found overall future extreme runoff increases under projected climatic changes as well for the Pacific Northwest Region of USA during 2041-2070. Wrzesien and Pavelsky (2020) assessed potential impacts of projected future changes in extreme rainfalls on extreme runoffs across the western USA during 2091-2100 under the RCP 8.5 scenario. They reported increases in 1-day 100-year runoff of 1 to $142 \%$ subject to increases in 1-day 100-year precipitation of 17.1 to $33.6 \%$ for different Sierra Nevada Basins along the eastern edge of the state of California. In comparison, 55\% increase in 1-day 100-year rainfall in the 2080-RCP 8.5 scenario for the Saint Johns River Basin (Figure A5.7) gave a corresponding increase in 1-day 
runoff of $87 \%$ (Figure 5.6a). Suttles et al. (2018) evaluated impacts of simultaneous climatic changes and urbanizations on extreme streamflows during 2050-2070 for the Yadkin-Pee Dee watershed of North Carolina, USA. Their findings denoted 73 to $151 \%$ relative increases in 100year streamflow in their study basin across different combined climate and land cover change scenarios. The relative runoff increases in 100-year streamflow reported by Suttles et al. (2018) are comparable to 79 to $132 \%$ increases in 1-7 day extreme runoff in the Saint Johns River Basin across different future scenarios subject to concurrent projected changes in 100-year rainfalls and land cover.

\subsubsection{Potential hydrologic and environmental implications}

Potential future extreme runoff increases in the Saint Johns River Basin may adversely affect its hydrologic and environmental sustainability along with its coastal-natural ecosystem components. High potential increases in runoff extremes at and around the major and growing urban centers across the basin (e.g., Jacksonville, Palm Coast, Orlando, Clermont, Titusville, and Melbourne) as well as a few unbuilt areas at its southern parts suggested elevated risks of pluvial flooding. Increased extreme runoffs can also cause overflowing of the open channel drainage systems and the subsequent floodplain flooding. Mitigation of the potential intensified flooding risks under the changing regimes of extreme climatic events over northeast Florida might require enhancement of existing flood control measures (locks, spillways, pump stations, levees, etc.). The extreme runoff volume responses under projected land cover changes in the Saint Johns River Basin outlined possible higher runoff increases for more frequent rainfall events. In light of that, potential future land development activities might bring greater flooding risks to roadways across many locations in northeast Florida since their cross drainage facilities (permanent culverts, bridge-culverts) and bridges are usually designed based on the 10 and 25- 
year floods (FDOT, 2020). Furthermore, the increased agricultural and urban runoffs from the Saint Johns River Basin might also bring enhanced nutrient loading, including nitrogen and phosphorus, to the Saint Johns River and its tributaries. Both nitrogen and phosphorous enrichment can promote algal bloom, which can lead to death of many aquatic species and release harmful toxins.

\subsubsection{Limitations, caveats, and uncertainties}

Potential future changes in extreme runoff regimes in the Saint Johns River Basin were evaluated assuming similarities in drainage systems and stream geometric properties between the historical and future periods. Furthermore, identical hourly extreme rainfall distributions were considered for hourly disaggregation of historical and future extreme rainfall depths in light of inadequacy of capabilities of the GCMs in representing hourly rainfall variabilities. Since the potential SLR projections did not give hourly sea level variations, historical hourly sea level distributions were used for hourly disaggregation of both historical and future extreme sea levels. Design sea levels at outlet of the Saint Johns River were used at outlet of the other streams across the Saint Johns River Basin, by taking the elevation differences of the stream beds into account, due to unavailability of long-term hourly sea level data at or near the other stream outlets. These are noteworthy limitations and caveats of the current study because potential changes in hourly distributions of rainfalls and sea levels together with arrangements and features of the drainage system would contribute to probable overall alterations of the extreme runoff generation process.

The CMIP5 climatic projections are expected to impart uncertainties into the estimated future extreme runoffs due to the disagreements between the 20 GCMs. The current study on the Saint Johns River Basin, therefore, employed ensembled future runoff scenarios. Meanwhile, the seasonal climatic variabilities in northeast Florida often undergo irregularities under the 
influences of the large-scale ocean-atmospheric phenomena such as El Niño-Southern Oscillation (ENSO; Misra and DiNapoli, 2013), and also under that of the tropical storms/hurricanes. The climatic projections given by the CMIP5 GCMs do not appropriately represent the impacts of these phenomena (Zhao et al., 2017; Lu et al., 2018) - giving rise to the consequent additional uncertainties into the extreme runoff estimations. Potential uncertainties in the land cover and SLR projections due to the highly dynamic human-land use interactions and sea surface behavior, respectively, are possible sources of uncertainties in the anticipated future extreme runoff regimes as well.

\subsection{Conclusions}

The goal of this study was to investigate the potential future changes in extreme runoff regimes in response to projected changes in climate (rainfall and ET), land cover (imperviousness), and sea level in coastal-natural environments. Considering the Saint Johns River Basin of northeast Florida as the study area, a large-scale $\left(24928 \mathrm{~km}^{2}\right)$ mechanistic hydrologic model was developed using U.S. EPA SWMM 5.1. The model was calibrated and validated (NSE $=0.70$ to $0.82, \operatorname{RSR}=0.43$ to 0.55$)$ with daily observed streamflow of 2004-2013. Significance ( $p$-value $\leq$ 0.05 ) and direction of monotonic trends in annual maximum rainfalls and sea levels of 1-7 day durations for the historical 50-year period of the 2000s (1964-2013) were then evaluated employing the non-parametric Mann-Kendall test and the Theil-Sen slope estimator. 11\% of the 9 rainfall stations across the basin represented locally significant increasing trends in 1, 2, 6, and 7-day historical annual maximum rainfalls while statistically significant rainfall trends were missing among the remaining stations. Annual maximum sea levels demonstrated locally significant trends for all event durations for the only tide station used in this study. 
Stationary design rainfalls and non-stationary design sea levels of 1-7 day durations, in light of the trend analyses outcomes, were estimated with varying return periods $(2,5,10,25,50$, and 100 year) for the historical as well as future periods using the Gumbel extreme value distribution. Design rainfalls in 2010, representing the 2000s, ranged from 87 (for a 1-day 2-year event) to $430 \mathrm{~mm}$ (for a 7-day 100-year event) across the rainfall stations. Design sea levels in 2010 ranged from 0.14 (for a 6-day 2-year event) to 0.44 m NAVD 88 (for a 1-day 100-year event). Future design rainfalls were computed for two 50-year periods: the 2050s (2025-2074) and the 2080s (2050-2099) under RCP 4.5 and 8.5 based on the rainfall projections from the 20 CMIP5 GCMs. Future design sea levels were found using the SFRCCC SLR projections for southeast Florida. The calibrated and validated Saint Johns River Basin model was then implemented for extreme runoff estimations in the year 2010, 2050, and 2080, representing the 2000s, 2050s, and 2080s, respectively. Extreme rainfalls and sea levels in 2050 and 2080 together with the CMIP5 projections of ET and EPA ICLUS land cover projections were used in computing the future extreme runoffs under both individual and combined projected changes in climate, land cover, and sea level.

High increases in runoff extremes in 2050 and 2080, relative to 2010, were noted for the major and emerging urban centers and the neighboring regions across the Saint Johns River Bain. Isolated climatic changes led to 21 to $87 \%, 18$ to $80 \%, 18$ to $79 \%$, and 17 to $74 \%$ increases in 1-7 day extreme runoff volumes of different return periods in the 2080-RCP 8.5, 2050-RCP 8.5, 2050-RCP 4.5, and 2080-RCP 4.5 scenario, respectively. Runoff changes due to changes in climate were significantly higher than that in land cover and sea level — denoting climate as the controlling driver of extreme runoff in coastal-natural environments. Relative increases in basin runoff volume intensified with increases in return periods for individually changing climate. 
Potential SLR apparently did not have any noteworthy impacts on extreme runoff generation in the Saint Johns River Basin.

In case of concurrent changes in two drivers, concurrent climatic-land cover changes gave higher basin runoff increases, than other combinations, of 58 to $132 \%, 46$ to $113 \%, 32$ to $96 \%$, and 34 to $95 \%$ in the 2080-RCP 8.5, 2050-RCP 8.5, 2050-RCP 4.5, and 2080-RCP 4.5 scenario, respectively. Subject to simultaneous changes in in climate, land cover, and sea level, relative basin runoff increases ranged from 58 to $132 \%, 46$ to $113 \%, 32$ to $96 \%$, and 34 to $95 \%$ for the 2080-RCP 8.5, 2050-RCP 8.5, 2050-RCP 4.5, and 2080-RCP 4.5 scenario, respectively. Higher potential runoff increases in the 2080-RCP 8.5 scenario outlined it as the most critical future scenario for extreme runoff and pluvial flooding risk management in northeast Florida.

The study findings provide valuable insights for management of stormwater and environmental sustainability in coastal-natural environments of northeast Florida and other ecosystems around the world. The future runoff projections in 2050 and 2080 outlined critical areas across northeast Florida subject to elevated risks of pluvial flooding as well as environmental pollutions. Existing flood control measures in this area might need significant enhancements to account for the intensified flooding risks. It would also be vital to manage the influx of enhanced nutrient loading, due to increased agricultural and urban runoffs, to the Saint Johns River for protecting its aquatic habitats. The study findings would be applicable for unbuilt areas with likelihoods of rainfall increases, particularly, in the high latitudes, and in the wet tropical and subtropical environments (IPCC, 2014a). 


\section{Acknowledgements}

This research was funded by a National Science Foundation (NSF) Critical Resilient Interdependent Infrastructure Systems and Processes (CRISP 2.0) Award to Dr. Omar I. AbdulAziz (NSF CMMI Award \#1832680), and by the "Florida Public Hurricane Loss Model Enhancements" project's freshwater flood modeling award to Dr. Omar I. Abdul-Aziz. The research on climate, land cover, and sea level change impacts on runoff extremes was exclusively funded by the NSF project. The findings and conclusions of this research are those of the authors, and do not necessarily reflect the views of NSF and the State of Florida or any of its sub-agencies. 


\section{Appendix 5}

Table A5.1: Streamflow stations used for calibrations and validations of the Saint Johns River Basin model.

\begin{tabular}{cccc}
\hline Station & Agency & Calibration period & Validation period \\
\hline $\begin{array}{c}\text { Saint Johns River near } \\
\text { Melbourne }\end{array}$ & USGS & $01 / 01 / 2004-12 / 31 / 2008$ & $01 / 01 / 2009-12 / 31 / 2013$ \\
$\begin{array}{c}\text { Saint Johns River near } \\
\text { DeLand }\end{array}$ & USGS & $01 / 01 / 2004-12 / 31 / 2008$ & $03 / 01 / 2009-12 / 31 / 2013$ \\
$\begin{array}{c}\text { Saint Johns River near } \\
\text { Satsuma }\end{array}$ & USGS & $06 / 01 / 2004-12 / 31 / 2008$ & $01 / 01 / 2009-12 / 31 / 2013$ \\
$\begin{array}{c}\text { Saint Johns River near } \\
\text { Jacksonville }\end{array}$ & USGS & $02 / 01 / 2004-12 / 31 / 2008$ & $01 / 01 / 2009-12 / 31 / 2013$ \\
\hline
\end{tabular}

Note: SFMWD refers to South Florida Water Management District 
Table A5.2: List of the Coupled Model Intercomparison Project's fifth phase (CMIP5) general circulation models (GCMs) used for future projections of rainfall and potential evapotranspiration in the Saint Johns River Basin.

\begin{tabular}{|c|c|c|}
\hline Name & Agency & $\begin{array}{l}\text { Resolution } \\
\text { (Long. } \times \text { Lat.) }\end{array}$ \\
\hline bcc-csm1-1 & Beijing Climate Center, China Meteorological Administration & $2.8^{\circ} \times 2.8^{\circ}$ \\
\hline bcc-csm1-1-m & Beijing Climate Center, China Meteorological Administration & $1.12^{\circ} \times 1.12^{\circ}$ \\
\hline BNU-ESM & $\begin{array}{c}\text { College of Global Change and Earth System Science, Beijing } \\
\text { Normal University, China }\end{array}$ & $2.8^{\circ} \times 2.8^{\circ}$ \\
\hline CanESM2 & Canadian Centre for Climate Modeling and Analysis & $2.8^{\circ} \times 2.8^{\circ}$ \\
\hline CCSM4 & National Center of Atmospheric Research, USA & $1.25^{\circ} \times 0.94^{\circ}$ \\
\hline CNRM-CM5 & National Centre of Meteorological Research, France & $1.4^{\circ} \times 1.4^{\circ}$ \\
\hline CSIRO-Mk3-6-0 & $\begin{array}{c}\text { Commonwealth Scientific and Industrial Research } \\
\text { Organization/Queensland Climate Change Centre of } \\
\text { Excellence, Australia }\end{array}$ & $1.8^{\circ} \times 1.8^{\circ}$ \\
\hline GFDL-ESM2M & NOAA Geophysical Fluid Dynamics Laboratory, USA & $2.5^{\circ} \times 2.0^{\circ}$ \\
\hline GFDL-ESM2G & NOAA Geophysical Fluid Dynamics Laboratory, USA & $2.5^{\circ} \times 2.0^{\circ}$ \\
\hline$\underline{\text { HadGEM2-ES }}$ & Met Office Hadley Center, UK & $1.88^{\circ} \times 1.25^{\circ}$ \\
\hline HadGEM2-CC & Met Office Hadley Center, UK & $1.88^{\circ} \times 1.25^{\circ}$ \\
\hline inmcm4 & Institute for Numerical Mathematics, Russia & $2.0^{\circ} \times 1.5^{\circ}$ \\
\hline IPSL-CM5A-LR & Institut Pierre Simon Laplace, France & $3.75^{\circ} \times 1.8^{\circ}$ \\
\hline IPSL-CM5A-MR & Institut Pierre Simon Laplace, France & $2.5^{\circ} \times 1.25^{\circ}$ \\
\hline IPSL-CM5B-LR & Institut Pierre Simon Laplace, France & $2.75^{\circ} \times 1.8^{\circ}$ \\
\hline MIROC5 & $\begin{array}{l}\text { Atmosphere and Ocean Research Institute (The University of } \\
\text { Tokyo), National Institute for Environmental Studies, and } \\
\text { Japan Agency for Marine-Earth Science and Technology }\end{array}$ & $1.4^{\circ} \times 1.4^{\circ}$ \\
\hline MIROC-ESM & $\begin{array}{l}\text { Japan Agency for Marine-Earth Science and Technology, } \\
\text { Atmosphere and Ocean Research Institute (The University of } \\
\text { Tokyo), and National Institute for Environmental Studies }\end{array}$ & $2.8^{\circ} \times 2.8^{\circ}$ \\
\hline$\frac{\text { MIROC-ESM- }}{\text { CHEM }}$ & $\begin{array}{l}\text { Japan Agency for Marine-Earth Science and Technology, } \\
\text { Atmosphere and Ocean Research Institute (The University of } \\
\text { Tokyo), and National Institute for Environmental Studies }\end{array}$ & $2.8^{\circ} \times 2.8^{\circ}$ \\
\hline MRI-CGCM3 & Meteorological Research Institute, Japan & $1.1^{\circ} \times 1.1^{\circ}$ \\
\hline NorESM1-M & Norwegian Climate Center, Norway & $2.5^{\circ} \times 1.9^{\circ}$ \\
\hline
\end{tabular}

Source: https://climate.northwestknowledge.net/MACA/GCMs.php; Note: Lat. and Long., respectively, refer to latitude and longitude. 
Table A5.3: Baseline values and future basin-average percent changes in evapotranspiration (ET), and imperviousness for the Saint Johns River Basin relative to the baseline year of 2010.

\begin{tabular}{cccccc}
\hline \multirow{2}{*}{ Variable } & Baseline & \multicolumn{4}{c}{ Projected changes $(\%)$} \\
& 2010 & \multicolumn{4}{c}{} \\
\cline { 3 - 6 } & values & 2050-RCP 4.5 & 2080-RCP 4.5 & 2050-RCP 8.5 & 2080-RCP 8.5 \\
\hline ET & $3.6 \mathrm{~mm} /$ day & +3.8 & +5.4 & +5.9 & +11.2 \\
Imperviousness & $4.6 \%$ & +16.3 & +19.3 & +30.7 & +40.4 \\
\hline
\end{tabular}

Note: Positive sign indicates increases.

Table A5.4: Sea level rise (SLR) (m) projections, relative to 2010, for the NOAA tide station 8724580 at Key West used for future extreme runoff estimations in the Saint Johns River Basin.

\begin{tabular}{ccc}
\hline \multirow{2}{*}{ Year } & \multicolumn{2}{c}{ SLR $(\mathrm{m})$} \\
\cline { 2 - 3 } & RCP 4.5 & RCP 8.5 \\
\hline 2050 & 0.38 & 0.49 \\
2080 & 0.83 & 1.14 \\
\hline
\end{tabular}




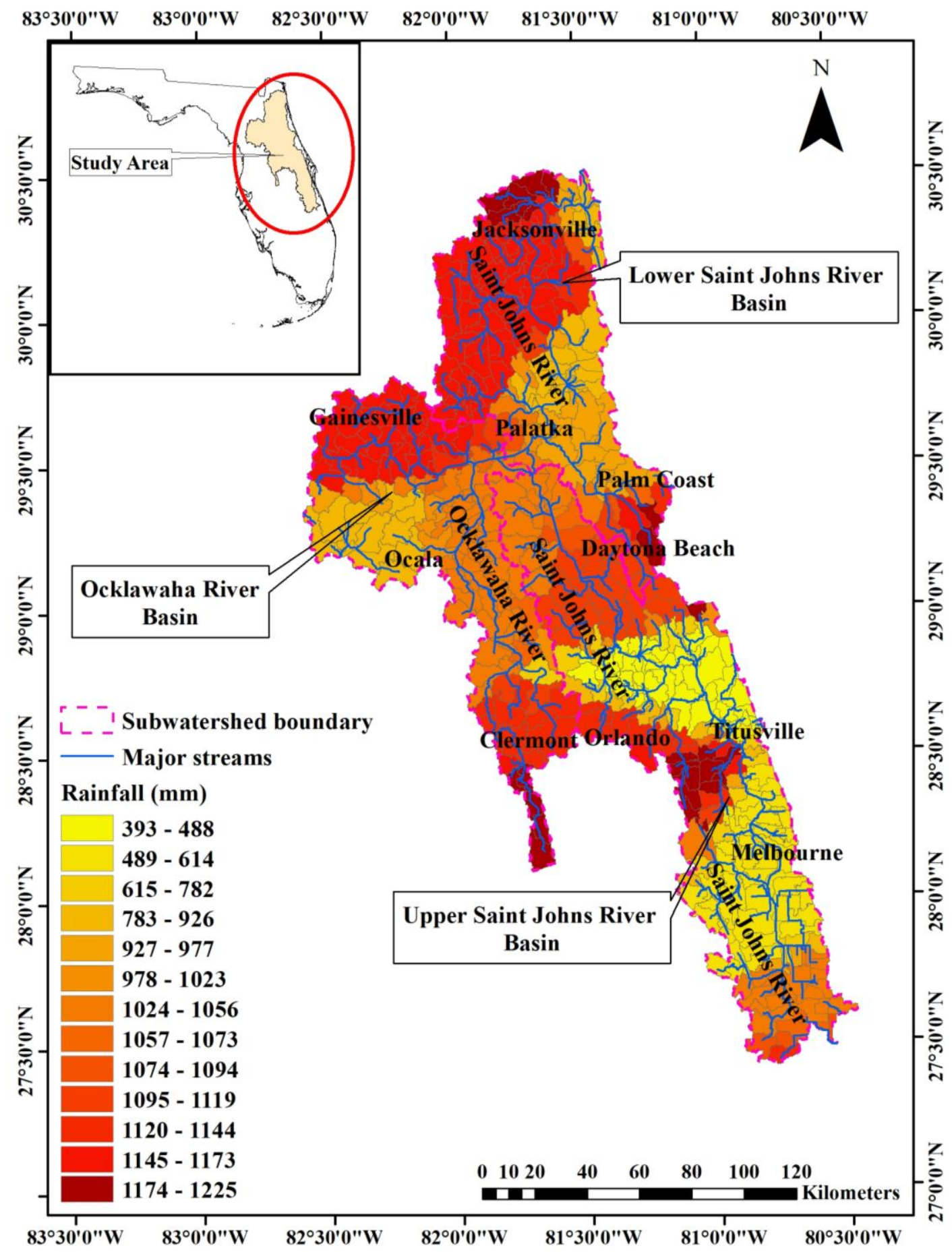

Figure A5.1: Spatial variation of observed 10-year mean annual rainfall in the Saint Johns River Basin for 2004-2013 (2010s). The inset showing location of the study area in the state of Florida is not drawn to the map-scale. 


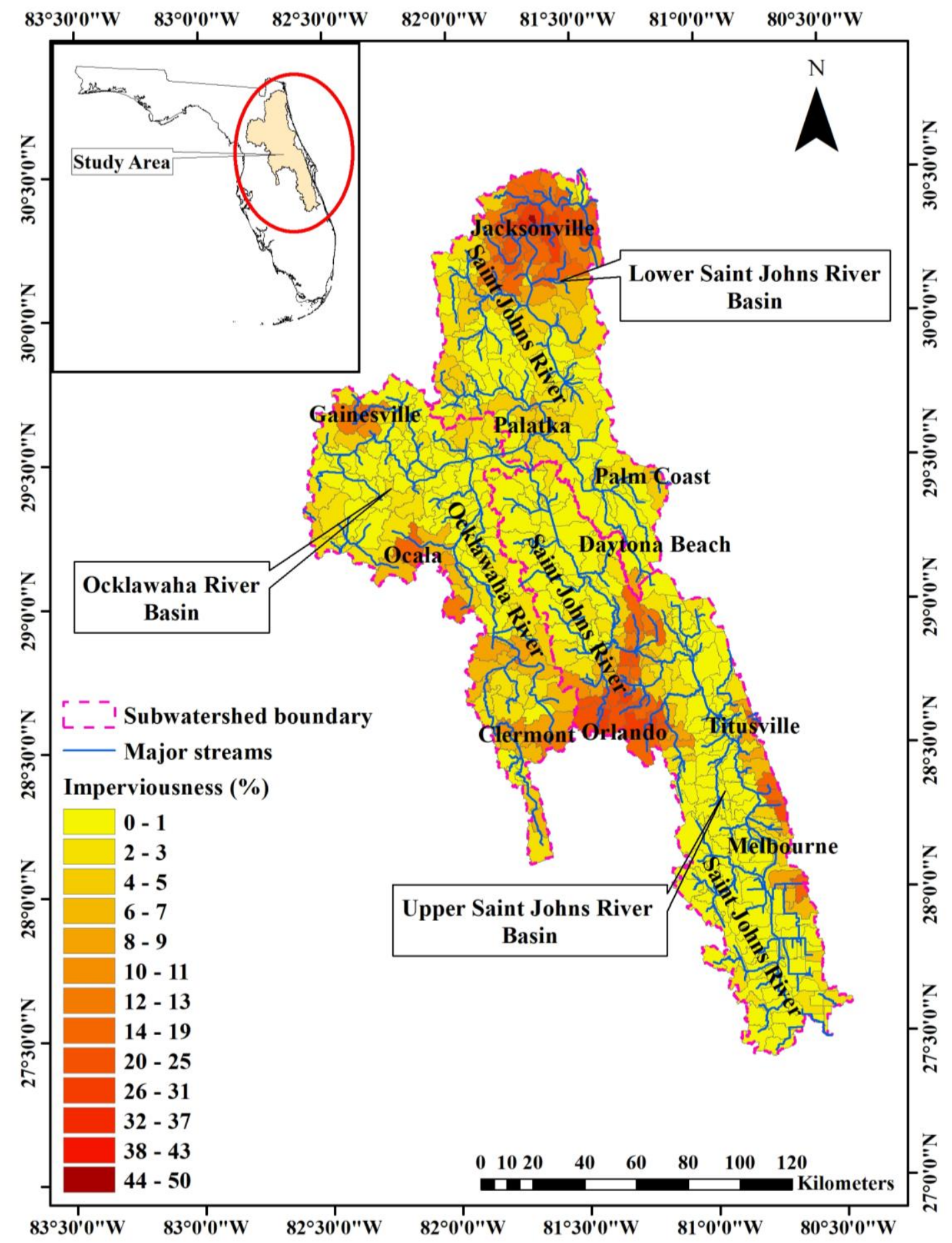

Figure A5.2: Spatial variation of imperviousness in the Saint Johns River Basin for 2004-2013 (2010s). The inset showing location of the study area in the state of Florida is not drawn to the map-scale. 


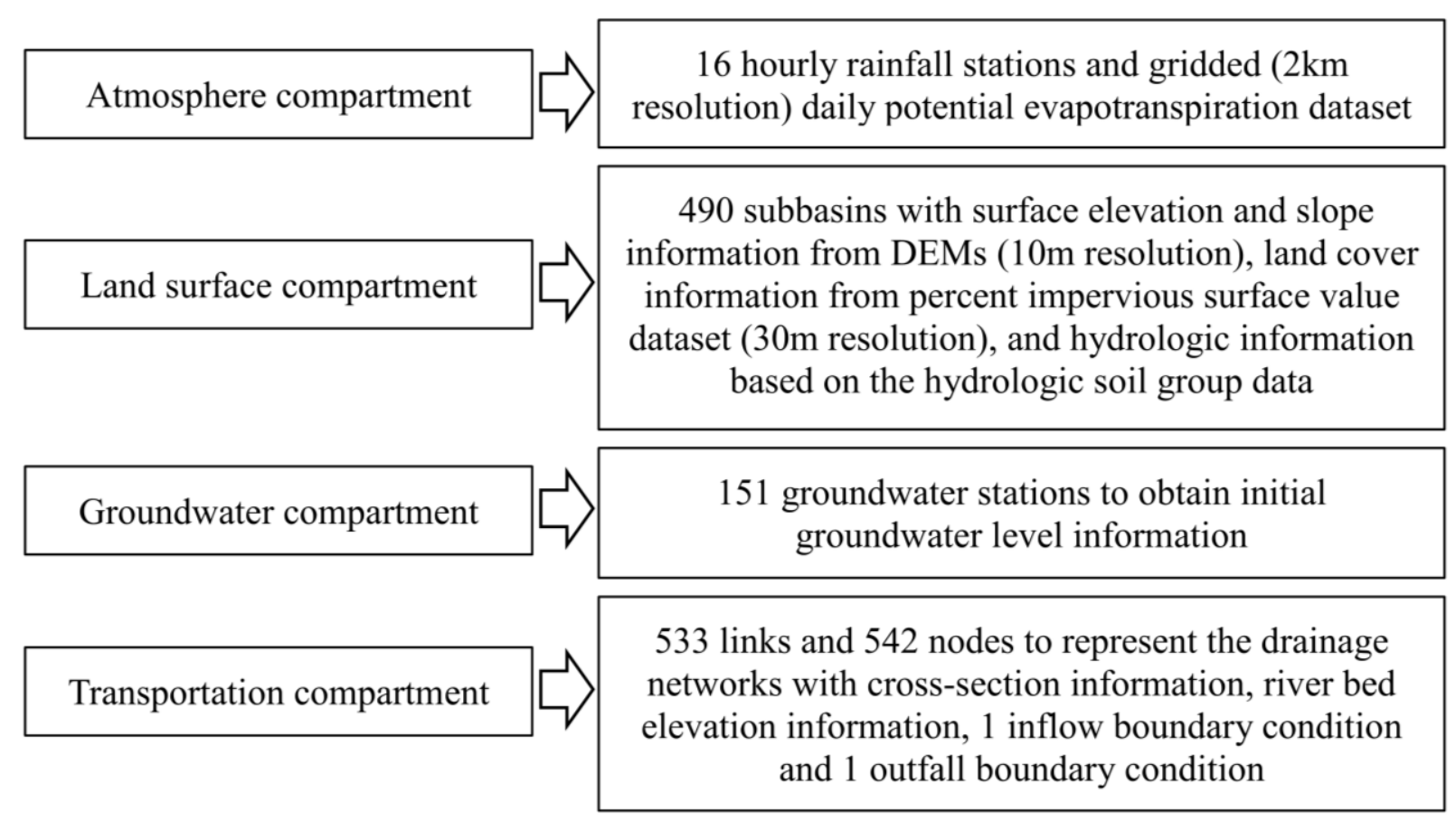

Figure A5.3: Summary of SWMM developments for the Saint Johns River Basin. 

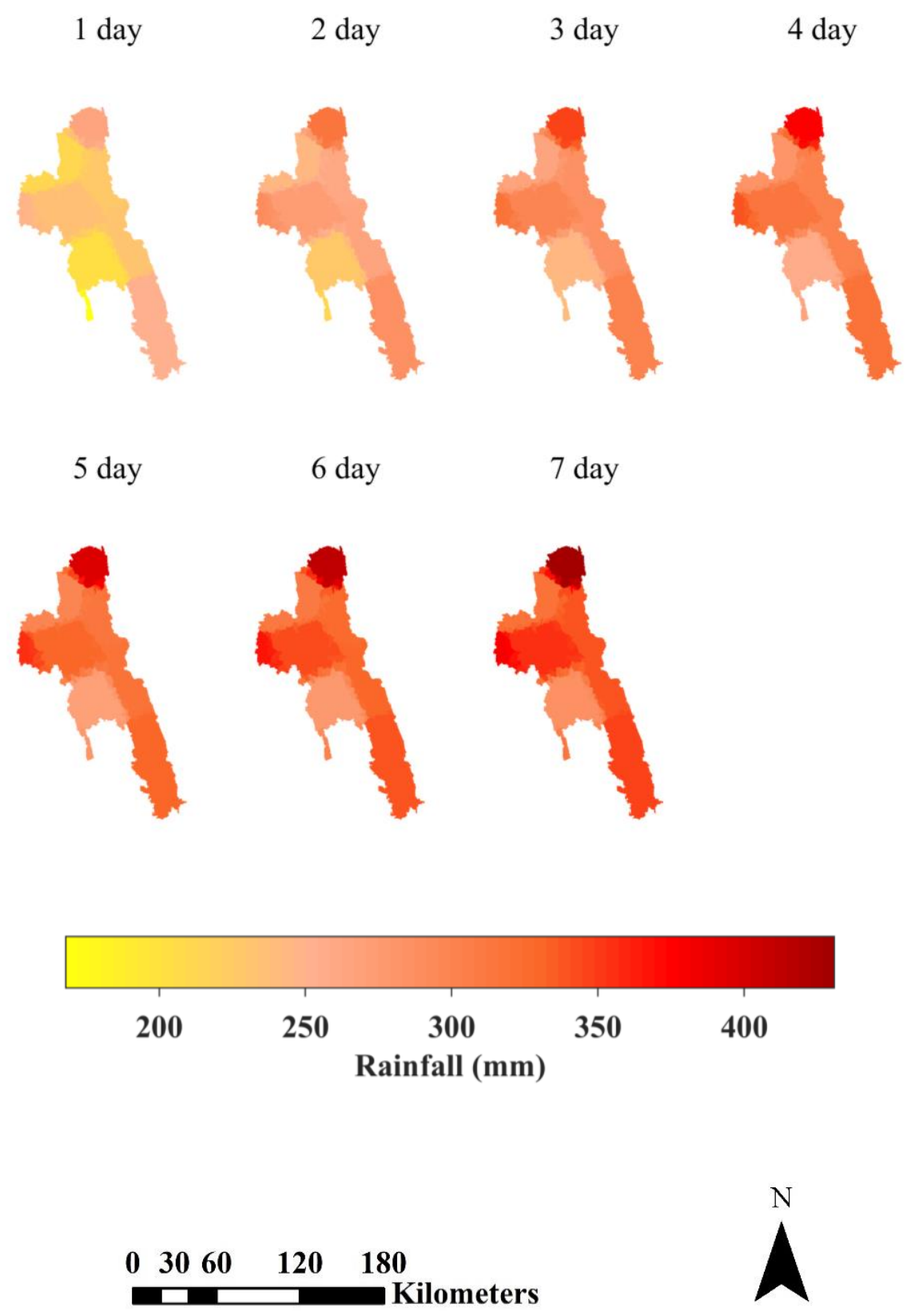

Figure A5.4: Spatial variation of accumulated rainfall depth for the 100-year event with varying durations on 2010 in the Saint Johns River Basin. 

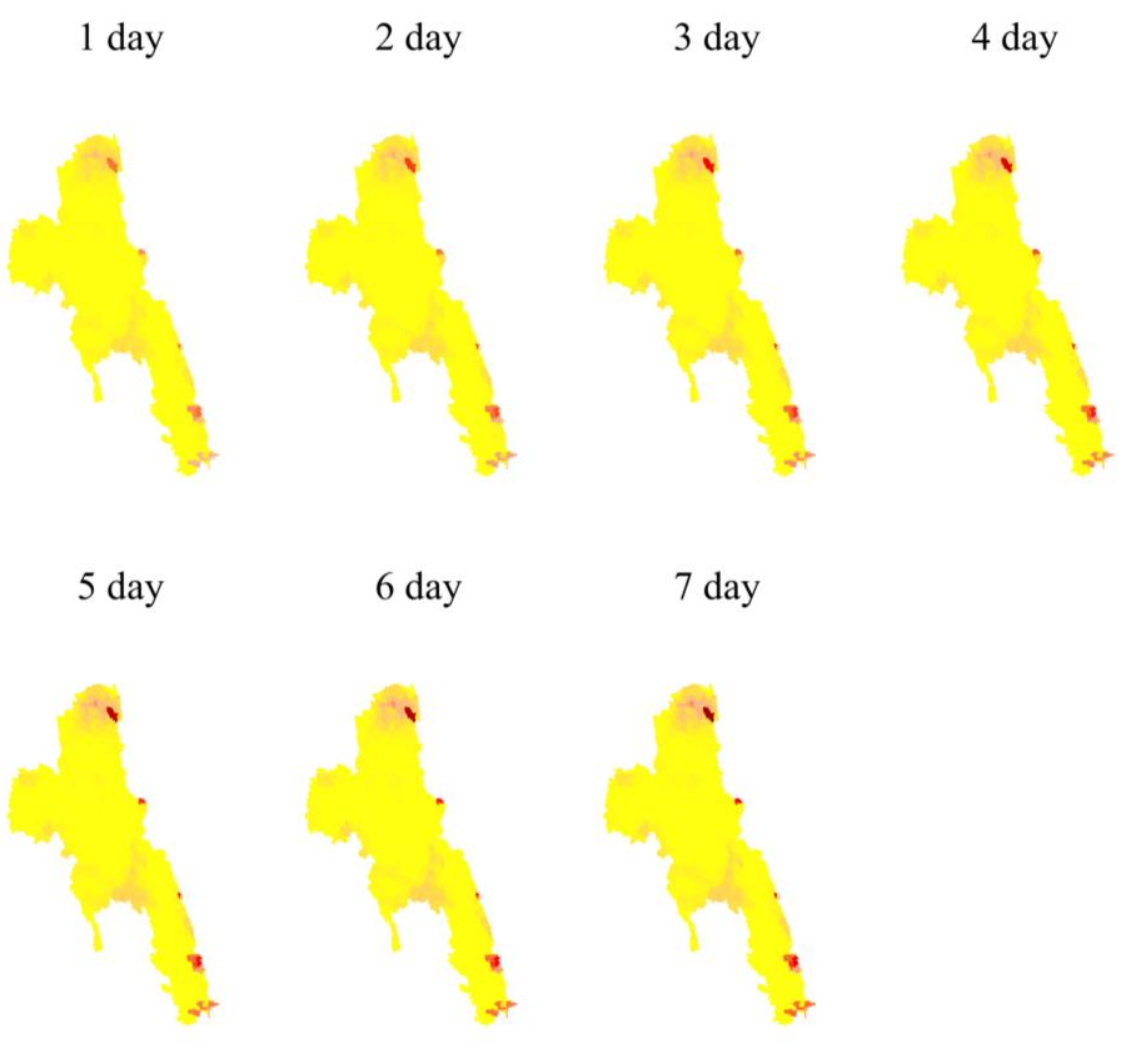

7 day
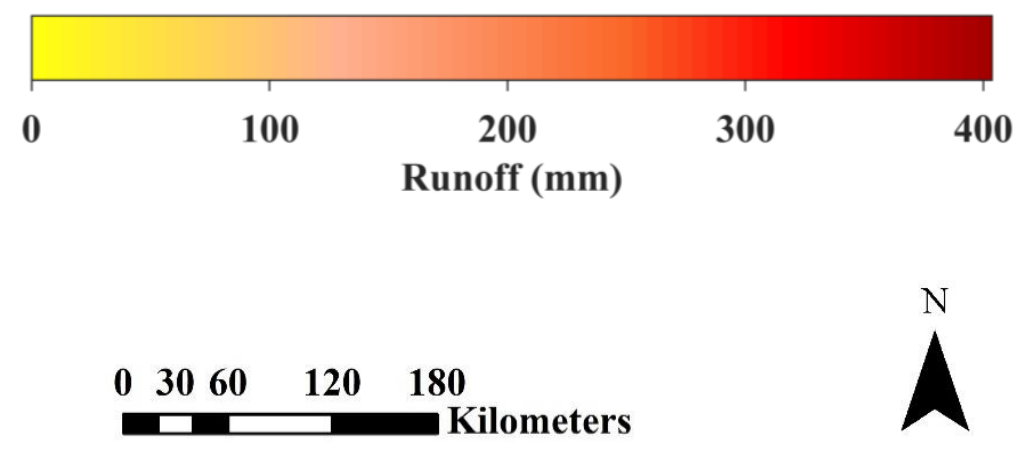

Figure A5.5: Spatial variation of accumulated runoff depth on 2010 with varying durations in the Saint Johns River Basin due to 100-year rainfall and sea level events. 
(a) Rainfall
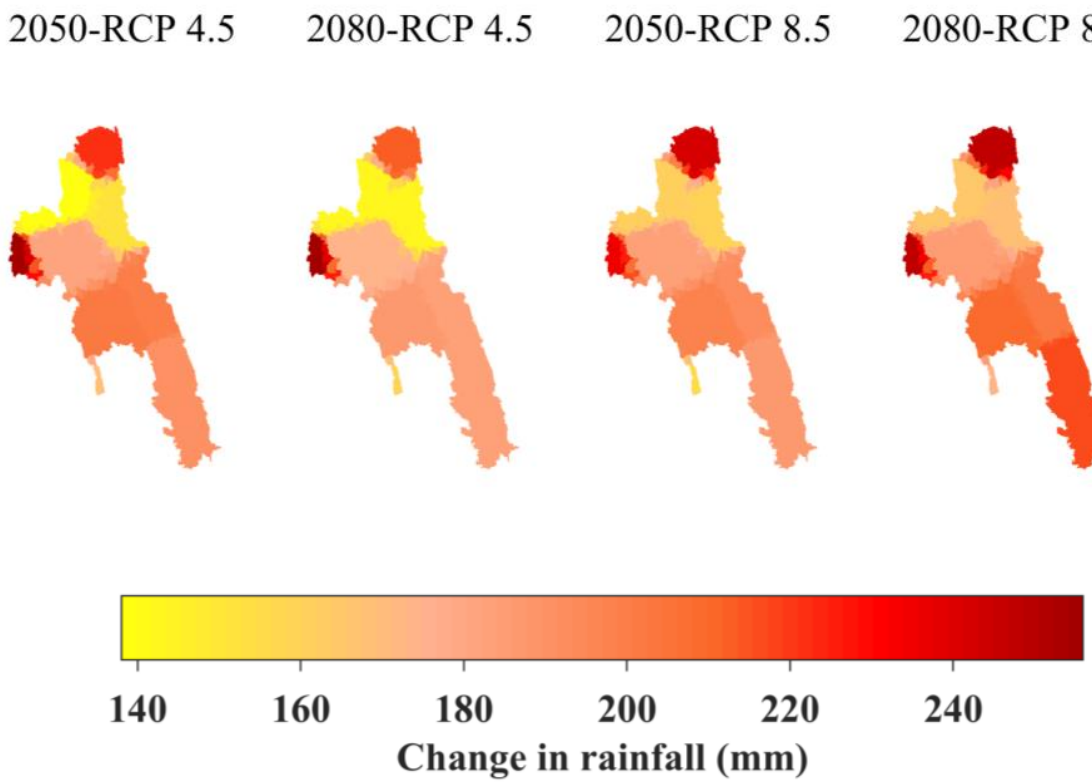

(b) Imperviousness
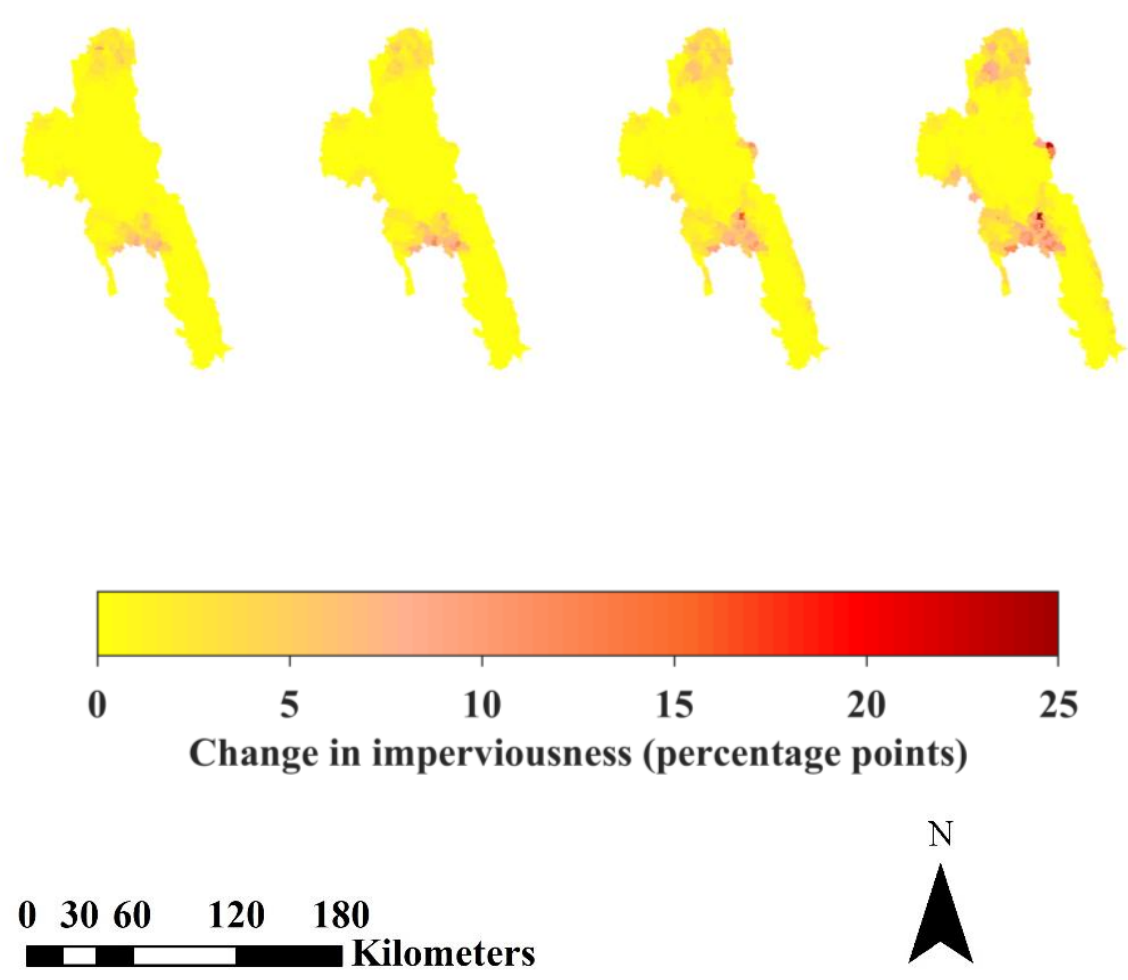

Figure A5.6: Spatial variation of (a) changes in 7-day accumulated rainfall depth for 100-year return period based on ensemble mean design rainfall projections from the 20 general circulation models (GCMs), and (b) percentage points change imperviousness under different future scenarios in the Saint Johns River Basin. 


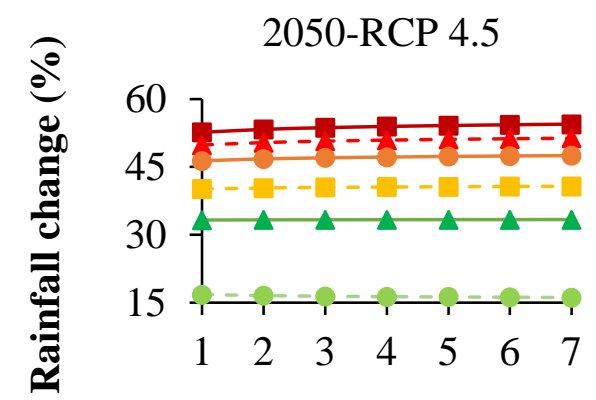

2080-RCP 4.5

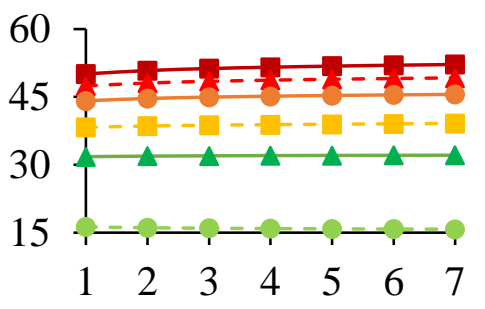

2050-RCP 8.5

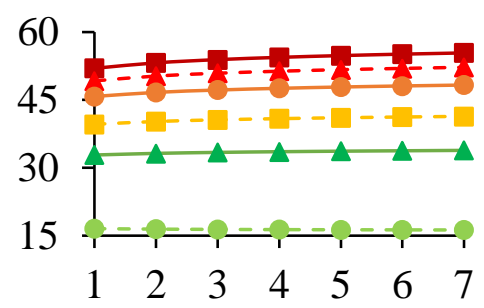

2080-RCP 8.5

60

45

30

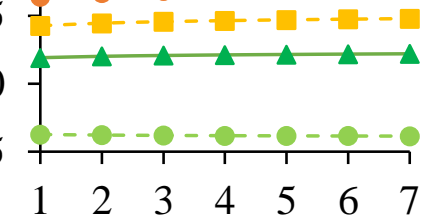

\section{Duration (day)}

$$
-\bullet \text { - 2-year } \longrightarrow \text { - } \text {-year }-\varpi-10 \text {-year } \rightarrow-25 \text {-year }-\star-50 \text {-year } \rightarrow-100 \text {-year }
$$

Figure A5.7: Projected percentage changes in 1-7 day total rainfall of varying return periods under different future scenarios in the Saint Johns River Basin. 


\section{Chapter 6: Summary and conclusions}

This dissertation investigated the potential impacts of changing climate, land cover, and sea level on the future stormwater budget and extreme runoff in coastal urban-natural environments. The central research hypothesis was that potential changes in stormwater runoff responses in coastal environments would represent similarities in runoff sensitivities, stormwater budget changes, and extreme runoff regime changes across the urban-natural gradient under a changing climate, land cover, and sea level. Two large-scale (7117 and $24928 \mathrm{~km}^{2}$ ) mechanistic hydrologic models were developed for the Southeast Coasts Basin and the Saint Johns River Basin of southeast and northeast Florid of USA, representing gradients in urban and natural land uses/cover along the Florida Atlantic Coasts. The basins were considered as prototype of, respectively, coastal-urban and coastal-natural environments. The coastal-urban and coastal-natural stormwater runoffs showed notably varying seasonal sensitivities to climate and land cover. Under simultaneously changing climate and land cover, nonlinear runoff responses were observed as compared to superposition of their isolated impacts for both of the basins. Projected future changes in climate and land cover contributed to potential high increases in runoff budget in southeast and northeast

Florida. Finally, projected changes in extreme rainfall and sea level and in land cover contributed to substantial potential increases in both coastal-urban and coastal-natural runoffs - suggesting elevated pluvial flooding risks. The future stormwater budget scenarios together with extreme runoff projections for southeast and northeast Florida offer valuable insights for stormwater management and ecosystem protection. 
Chapter 2 and 3 of the dissertation tested the first two component hypotheses by developing large-scale models for coastal-urban Southeast Coasts Basin and coastal-natural Saint Johns River Basin using the U.S. EPA Stormwater Management Model (SWMM) 5.1. The models were calibrated and validated with 10-year observed historical streamflow for the baseline 2004-2013, defined as the 2010s. The simulated baseline runoffs showed notably varying seasonal sensitivities to changing climate and land cover with substantially stronger influence of climate (rainfall) over land cover in coastal-urban and coastal-natural stormwater runoff generation. Nonlinear runoff responses subject to concurrent rainfall-land cover and rainfall-ET changes were noted as compared to their aggregated individual impacts for both Southeast Coasts Basin and Saint Johns River Basin. The projected future climatic and land cover changes in the 2050s (2044-2053) and the 2080s (2076-2085), relative to the 2010s, produced very high relative increases in coastal-urban and coastal-natural runoff volume, as simulated by the calibrated and validated models. Higher potential future runoff increases were expected during October-May for both coastal-urban Southeast Coasts Basin and coastal-natural Saint Johns River Basin.

Chapter 4 and 5 tested the final component hypotheses by investigating the potential future changes in coastal-urban and coastal-natural stormwater runoff extremes. Projected changes in extreme rainfall and sea level together with changes in land cover were used as inputs to the calibrated and validated Southeast Coasts Basin and Saint Johns River Basin model. The models predicted very high relative increases in extreme runoffs in 2050 and 2080, relative to 
2010. Higher (than other locations) runoff increases are expected at and around major urban centers in both southeast (e.g. Miami, West Palm Beach, Fort Lauderdale) and northeast (e.g., Jacksonville, Gainesville, Orlando) Florida. These population growth centers would be prone to subsequent elevated risks of pluvial flooding and environmental pollutions. Both the potential future coastal-urban and coastal-natural extreme runoffs were substantially more influenced by changes in climate (rainfall) than that in land cover and sea level.

This dissertation performed a comprehensive evaluation of impacts of changing climate, land cover, and sea level on stormwater runoff budget and extreme runoff in both coastal-urban and coastal-natural environments. By doing that, it successfully expanded the previous pilot study by Abdul-Aziz and Al-Amin (2015) on the Miami River Basin of southeast Florida. The similarities in runoff responses across the two large-scale basins, in terms of seasonal variations in runoff sensitivities, nonlinear runoff responses, and stronger climatic control on runoff generation, offered valuable management implications for coastal environments around the world that are characterized by gradients in land cover. The runoff sensitivity results as well as the future relative runoff increases reported by the study can be used as references for stormwater management and ecosystem protection in coastal-urban and costal-natural environments for other global regions. Further research may investigate the similarities in runoff responses across other coastal regions (e.g., along the coasts of Pacific Ocean, along the coasts of Gulf of Mexico) which would offer beneficial insights for the respective communities and ecosystems. 


\section{References}

Abatzoglou, J. T., Brown, T. J., 2012. A comparison of statistical downscaling methods suited for wildfire applications. Int. J. Climatol. 32(5), 772-780.

https://doi.org/10.1002/joc.2312.

Abdul-Aziz, O. I., Al-Amin, S., 2015. Climate, land use and hydrologic sensitivities of stormwater quantity and quality in a complex coastal-urban watershed. Urban Water J. 13(3), 302-320. https://doi.org/10.1080/1573062X.2014.991328.

Abdul-Aziz, O. I., Wilson, B.N., Gulliver, J.S., 2010. Two-zone model for stream and river ecosystems. Hydrobiologia, 638(1), 85-107. https://doi.org/10.1007/s10750-009-0011-7.

Akter, T., Quevauviller, P., Eisenreich, S.J., Vaes, G., 2018. Impacts of climate and land use changes on flood risk management for the Schijn River, Belgium. Environ. Sci. Policy 89, 163-175. https://doi.org/10.1016/j.envsci.2018.07.002.

Ali, A., Abtew, W., 1999. Regional rainfall frequency analysis for central and south Florida. Technical publication WRE 380. South Florida Water Management District, West Palm Beach, FL, USA.

Ali, H., Modi, P., Mishra, V., 2019. Increased flood risk in Indian sub-continent under the warming climate. Weather Clim. Extrem. 25, 100212. https://doi.org/10.1016/j.wace.2019.100212. 
Allen, R. G., Pereira, L. S., Raes, D., Smith, M., 1998. Crop evapotranspiration: Guidelines for computing crop water requirements. FAO Irrigation and drainage paper, vol. 56. Food and Agriculture Organization, Rome, Italy. http://www.fao.org/docrep/x0490e/x0490e00.htm.

Arnone, E., Pumo, D., Francipane, A., La Loggia, G., Noto, L. V., 2018. The role of urban growth, climate change, and their interplay in altering runoff extremes. Hydrol. Process. 32, 1755-1770. https://doi.org/10.1002/hyp.13141.

AVSWAT-X. (2006). ArcView SWAT, version 2005. From Soil and Water Assessment tool (SWAT), SWAT2005 interfaces website.

Baker, T.J., Miller, S.N., 2013. Using the Soil and Water Assessment Tool (SWAT) to assess land use impact on water resources in an East African watershed. J. Hydrol. 486, 100111. https://doi.org/10.1016/j.jhydrol.2013.01.04.

Berghuijs, W. R., Larsen, J. R., Van Emmerik, T. H., Woods, R. A., 2017. A global assessment of runoff sensitivity to changes in precipitation, potential evaporation, and other factors. Water Resour. Res. 53(10), 8475-8486. https://doi.org/10.1002/2017WR021593.

Bhagat, N., 2017. Flood Frequency Analysis Using Gumbel\&apos;s Distribution Method: A Case Study of Lower Mahi Basin, India. J. Water Resour. Ocean Sci. 6, 51. https://doi.org/10.11648/j.wros.20170604.11. 
Boesch, D. F., Anderson, D. M., Horner, R. A., Shumway, S. E., Tester, P. A., Whitledge, T. E., 1997. Harmful algal blooms in coastal waters: Options for prevention, control and mitigation, vol. 46. NOAA coastal ocean program decision analysis series no. 10. NOAA Coastal Office, Sliver Spring, MD, USA. 201-261. https://repository.library.noaa.gov/view/noaa/1513.

Borah, D. K., Xia, R., Bera, M., 2002. DWSM - a dynamic watershed simulation model. Water Resources Publications, LLC. Highlands Ranch, CO, USA.

Borah, D.K., Arnold, J.G., Bera, M., Krug, E.C., Liang, X.-Z., 2007. Storm Event and Continuous Hydrologic Modeling for Comprehensive and Efficient Watershed Simulations. J. Hydrol. Eng. 12, 605-616. https://doi.org/10.1061/(asce)10840699(2007)12:6(605).

Brunner, G.W., CEIWR-HEC, 2016. HEC-RAS River Analysis System User's Manual. US Army Corps of Engineers-Hydrologic Engineering Center 1-790. https://www.hec.usace.army.mil/software/hec-ras/documentation/HECRAS\%205.0\%20Users\%20Manual.pdf.

Budyko, M.I., 1974. Climate and Life. International Geophysics Series, vol. 18. Academic Press, New York. 
Bulti, D.T., Abebe, B.G., 2020. Analyzing the impacts of urbanization on runoff characteristics in Adama city, Ethiopia. SN Appl. Sci. 2, 1-13. https://doi.org/10.1007/s42452-0202961-3.

Carter, J.G., Cavan, G., Connelly, A., Guy, S., Handley, J., Kazmierczak, A., 2015. Climate change and the city: Building capacity for urban adaptation. Prog. Plann. 95, 1-66. https://doi.org/10.1016/j.progress.2013.08.001.

Chakravarti, A., Joshi, N., Panjiar, H., 2015. Rainfall Runoff Analysis using Artificial Neural Network. Indian J. Sci. Technol. 8. https://doi.org/10.17485/ijst/2015/v8i14/54370.

Chang, H., Jung, I.W., 2010. Spatial and temporal changes in runoff caused by climate change in a complex large river basin in Oregon. J. Hydrol. 388, 186-207. https://doi.org/10.1016/j.jhydrol.2010.04.040.

Chen, J., Brissette, F.P., Chaumont, D., Braun, M., 2013. Finding appropriate bias correction methods in downscaling precipitation for hydrologic impact studies over North America. Water Resour. Res. 49, 4187-4205. https://doi.org/10.1002/wrcr.20331.

Chen, S.M., Wang, Y.M., Tsou, I., 2013. Using artificial neural network approach for modelling rainfall-runoff due to typhoon. J. Earth Syst. Sci. 122, 399-405. https://doi.org/10.1007/s12040-013-0289-8. 
Chiew, F. H. S., McMahon, T. A., 1991. Improved modelling of the groundwater processes in MODHYDROLOG,. In: Proc. Int. Hydrology and Water Resources Symp., Perth, Western Australia, October 1991, Inst. Eng. Aust., NOAA, Silver Spring, MD, Nat. Conf. Publ. 91/22(2), 492-497.

Chiew, F. H. S., McMahon, T. A., 2002. Modelling the impacts of climate change on Australian streamflow. Hydrol. Processes. 16(6), 1235-1245. https://doi.org/10.1002/hyp.1059.

Cuo, L., Beyene, T.K., Voisin, N., Su, F., Lettenmaier, D.P., Alberti, M., Richey, J.E., 2011. Effects of mid-twenty-first century climate and land cover change on the hydrology of the Puget Sound basin, Washington. Hydrol. Process. 25, 1729-1753. https://doi.org/10.1002/hyp.7932.

Cuo, L., Zhang, Y., Gao, Y., Hao, Z., Cairang, L., 2013. The impacts of climate change and land cover/use transition on the hydrology in the upper Yellow River Basin, China. J. Hydrol. 502, 37-52. https://doi.org/10.1016/j.jhydrol.2013.08.003.

DiGiano, F. A., Adrian, D. D., Mangarella, P. A. (Eds.), 1977. Short Course Proceedings: Applications of Stormwater Management Models - 1976, report EPA-600/2-77-065. Municipal Environmental Research Laboratory, Office of Research and Development, U.S. Environmental Protection Agency. Cincinnati, Ohio, USA. 
Domingues, R., Goni, G., Baringer, M., Volkov, D., 2018. What Caused the Accelerated Sea Level Changes Along the U.S. East Coast During 2010-2015? Geophys. Res. Lett. 45, 13,36713,376. https://doi.org/10.1029/2018GL081183.

Donohue, R.J., Roderick, M.L., McVicar, T.R., 2011. Assessing the differences in sensitivities of runoff to changes in climatic conditions across a large basin. J. Hydrol. 406, 234-244. https://doi.org/10.1016/j.jhydrol.2011.07.003.

Downer, C.W., Ogden, F.L., 2006. Gridded Surface Subsurface Hydrologic Analysis (GSSHA) user's manual, version 1.43 for Watershed Modeling System 6, report ERDC/CHL SR06-1. Engineering research and development center, coastal and hydraulics laboratory, U.S. Army Corp of Engineers. Vicksburg, MS, USA.

Falconer, R.H., Cobby, D., Smyth, P., Astle, G., Dent, J., Golding, B., 2009. Pluvial flooding: new approaches in flood warning, mapping and risk management J. Flood Risk Manage. 2(3), 198-208. https://doi.org/10.1111/j.1753-318X.2009.01034.x.

Fang, N., Shi, Z., Chen, F., Wang, Y., 2015. Partial least squares regression for determining the control factors for runoff and suspended sediment yield during rainfall events. Water (Switzerland) 7, 3925-3942. https://doi.org/10.3390/w7073925.

FDOT (Florida Department of Transportation), 2020. Drainage Manual. Florida Department of Transportation (1987). Drainage Manual, Tallahassee, FL, USA. 
https://fdotwww.blob.core.windows.net/sitefinity/docs/defaultsource/roadway/drainage/files/drainagemanual2021.pdf?.

Fischer, E.M., Knutti, R., 2016. Observed heavy precipitation increase confirms theory and early models. Nat. Clim. Chang. https://doi.org/10.1038/nclimate3110.

Fletcher, T.D., Andrieu, H., Hamel, P., 2013. Understanding, management and modelling of urban hydrology and its consequences for receiving waters: A state of the art. Adv. Water Resour. 51, 261-279. https://doi.org/10.1016/j.advwatres.2012.09.001.

Franczyk, J., Chang, H., 2009. The effects of climate change and urbanization on the runoff of the Rock Creek Basin in the Portland metropolitan area, OR, USA. Hydrol. Processes. 23(6), 805-815. https://doi.org/10.1002/hyp.7176.

Fry, J. A., Xian, G., Jin, S., Dewitz, J. A., Homer, C. G., Yang, L., Barnes, C. A., Herold, N. D., Wickham, J.D., 2011. Completion of the 2006 National land cover database for the conterminous United States. Photogramm. Eng. Remote Sens. 77(9), 858-864. https://cfpub.epa.gov/si/si_public_record_report.cfm?Lab=NERL\&dirEntryId=237844.

Gavrilov, M.B., Marković, S.B., Janc, N., Nikolić, M., Valjarević, A., Komac, B., Zorn, M., Punišić, M., Bačević, N., 2018. Assessing average annual air temperature trends using the Mann-Kendall test in Kosovo. Acta Geogr. Slov. 58, 7-25. https://doi.org/10.3986/AGS.1309. 
Gerlach, M.J., Engelhart, S.E., Kemp, A.C., Moyer, R.P., Smoak, J.M., Bernhardt, C.E., Cahill, N., 2017. Reconstructing Common Era relative sea-level change on the Gulf Coast of Florida. Mar. Geol. 390, 254-269. https://doi.org/10.1016/j.margeo.2017.07.001.

Goovaerts, P., 1997. Geostatistics for Natural Resources Evaluation. Oxford University Press, New York, New York, USA.

Gori, A., Blessing, R., Juan, A., Brody, S., Bedient, P., 2019. Characterizing urbanization impacts on floodplain through integrated land use, hydrologic, and hydraulic modeling. J. Hydrol. 568, 82-95. https://doi.org/10.1016/j.jhydrol.2018.10.053.

Granata, F., Gargano, R., de Marinis, G., 2016. Support vector regression for rainfallrunoffmodeling in urban drainage: A comparison with the EPA's storm water management model. Water (Switzerland) 8, 1-13. https://doi.org/10.3390/w8030069.

Groisman, P.Y., Knight, R.W., Easterling, D.R., Karl, T.R., Hegerl, G.C., Razuvaev, V.N., Groisman, P.Y., Knight, R.W., Easterling, D.R., Karl, T.R., Hegerl, G.C., Razuvaev, V.N., 2005. Trends in Intense Precipitation in the Climate Record. J. Clim. 18, 13261350. https://doi.org/10.1175/JCLI3339.1. 
Guimares Nobre, G., Jongman, B., Aerts, J., Ward, P.J., 2017. The role of climate variability in extreme floods in Europe. Environ. Res. Lett. 12, 084012. https://doi.org/10.1088/17489326/aa7c22.

Habel, S., Fletcher, C.H., Rotzoll, K., El-Kadi, A.I., 2017. Development of a model to simulate groundwater inundation induced by sea-level rise and high tides in Honolulu, Hawaii. Water Res. 114, 122-134. https://doi.org/10.1016/j.watres.2017.02.035.

Hadi, S.J., Tombul, M., 2018. Long-term spatiotemporal trend analysis of precipitation and temperature over Turkey. Meteorol. Appl. 25, 445-455. https://doi.org/10.1002/met.1712.

Hallegatte, S., Green, C., Nicholls, R. J., Corfee-Morlot, J., 2013. Future flood losses in major coastal cities. Nat. Clim. Change. 3(9), 802-806. https://doi.org/10.1038/NCLIMATE1979.

Hamdi, R., Termonia, P., Baguis, P., 2011. Effects of urbanization and climate change on surface runoff of the Brussels Capital Region: a case study using an urban soil-vegetationatmosphere-transfer model. Int. J. Climatol. 31(13), 1959-1974. https://doi.org/10.1002/joc.2207.

Hanasaki, N., Kanae, S., Oki, T., Masuda, K., Motoya, K., Shirakawa, N., Shen, Y., Tanaka, K., 2008a. An integrated model for the assessment of global water resources-Part 1: Model 
description and input meteorological forcing. Hydrol. Earth Syst. Sci. 12(4), 1007-1025. https://www.hydrol-earth-syst-sci.net/12/1007/2008/.

Hanasaki, N., Kanae, S., Oki, T., Masuda, K., Motoya, K., Shirakawa, N., Shen, Y., Tanaka, K., 2008b. An integrated model for the assessment of global water resources-Part 2:

Applications and assessments. Hydrol. Earth Syst. Sci. 12(4), 1027-1037.

https://www.hydrol-earth-syst-sci.net/12/1027/2008/.

Hanel, M., Pavlásková, A., Kyselý, J., 2016. Trends in characteristics of sub-daily heavy precipitation and rainfall erosivity in the Czech Republic. Int. J. Climatol. 36, 1833-1845. https://doi.org/10.1002/joc.4463.

Hawley, R. J., Bledsoe, B. P., 2011. How do flow peaks and durations change in suburbanizing semi-arid watersheds? A southern California case study. J. Hydrol. 405(1-2), 69-82. https://doi.org/10.1016/j.jhydrol.2011.05.011.

Hirabayashi, Y., Mahendran, R., Koirala, S., Konoshima, L., Yamazaki, D., Watanabe, S., Kim, H., Kanae, S., 2013. Global flood risk under climate change. Nat. Clim. Chang. 3, 816821. https://doi.org/10.1038/nclimate1911.

Homer, C., Dewitz, J., Yang, L., Jin, S., Danielson, P., Xian, G., Coulston, J., Herold, N., Wickham, J., Megown, K., 2015. Completion of the 2011 National land cover database for the conterminous United States-Representing a decade of land cover change 
information. Photogramm. Eng. Remote Sens. 81(5), 345-354.

https://pubs.er.usgs.gov/publication/70146301.

Hoover, D.J., Odigie, K.O., Swarzenski, P.W., Barnard, P., 2017. Sea-level rise and coastal groundwater inundation and shoaling at select sites in California, USA. J. Hydrol. Reg. Stud. 11, 234-249. https://doi.org/10.1016/j.ejrh.2015.12.055.

Hovenga, P.A., Wang, D., Medeiros, S.C., Hagen, S.C., Alizad, K., 2016. The response of runoff and sediment loading in the Apalachicola River, Florida to climate and land use land cover change. Earth's Futur. 4, 124-142. https://doi.org/10.1002/2015EF000348.

Huang, H. J., Cheng, S. J., Wen, J. C., Lee, J. H., 2008. Effect of growing watershed imperviousness on hydrograph parameters and peak discharge. Hydrol. Processes. 22(13), 2075-2085. https://doi.org/10.1002/hyp.6807.

Hughes, J. D., White, J. T., 2016. Hydrologic conditions in urban Miami-Dade County, Florida, and the effect of groundwater pumpage and increased sea level on canal leakage and regional groundwater flow (ver. 1.2, July 2016). U.S. Geological Survey Scientific Investigations Report 2014-5162. https://doi.org/10.3133/sir20145162.

IPCC (Intergovernmental Panel on Climate Change), 2014a. Climate Change 2014: Impacts, Adaptation, and Vulnerability. Part A: Global and Sectoral Aspects. Contribution of Working Group II to the Fifth Assessment Report of the Intergovernmental Panel on Climate Change [C.B. Field, V.R. Barros, D.J. Dokken, K.J. Mach, M.D. Mastrandrea, 260 
T.E. Bilir, M. Chatterjee, K.L. Ebi, Y.O. Estrada, R.C. Genova, B. Girma, E.S. Kissel, A.N. Levy, S. MacCracken, P.R. Mastrandrea, and L.L. White (eds.)]. Cambridge University Press, Cambridge, UK and New York, NY, USA. https://www.ipcc.ch/site/assets/uploads/2018/02/WGIIAR5-PartA_FINAL.pdf.

IPCC (Intergovernmental Panel on Climate Change), 2014b. Climate Change 2014: Synthesis Report. Contribution of Working Groups I, II and III to the Fifth Assessment Report of the Intergovernmental Panel on Climate Change [Core Writing Team, R.K. Pachauri and L.A. Meyer (eds.)]. IPCC, Geneva, Switzerland. https://epic.awi.de/id/eprint/37530/.

Irizarry-Ortiz, M.M., Obeysekera, J., Park, J., Trimble, P., Barnes, J., Park-Said, W., Gadzinski, E., 2013. Historical trends in Florida temperature and precipitation. Hydrol. Process. 27, 2225-2246. https://doi.org/10.1002/hyp.8259.

Jacobson, C. R., 2011. Identification and quantification of the hydrological impacts of imperviousness in urban catchments: A review. J. Environ. Manage. 92(6), 1438-1448. https://doi.org/10.1016/j.jenvman.2011.01.018.

Jagtap, S.S., Jones, J.W., Hildebrand, P., Letson, D., O’Brien, J.J., Podestá, G., Zierden, D., Zazueta, F., 2002. Responding to stakeholder's demands for climate information: From research to applications in Florida. Agric. Syst. 74, 415-430. https://doi.org/10.1016/S0308-521X(02)00048-3. 
Jena, P.P., Chatterjee, C., Pradhan, G., Mishra, A., 2014. Are recent frequent high floods in Mahanadi basin in eastern India due to increase in extreme rainfalls? J. Hydrol. 517, 847862. https://doi.org/10.1016/j.jhydrol.2014.06.021.

Ji, Z., Li, N., Xie, W., Wu, J., Zhou, Y., 2013. Comprehensive assessment of flood risk using the classification and regression tree method. Stoch. Environ. Res. Risk Assess. 27, 18151828. https://doi.org/10.1007/s00477-013-0716-z.

Johnson, T., Butcher, J., Deb, D., Faizullabhoy, M., Hummel, P., Kittle, J., McGinnis, S., Mearns, L. O., Nover, D., Parker, A., Sarkar, S., Srinivasan, R., Tuppad, P., Warren, M., Weaver, C., Witt, J., 2015. Modeling streamflow and water quality sensitivity to climate change and urban development in 20 US watersheds. JAWRA J. Am. Water Resour. Assoc. 51(5), 1321-1341. https://doi.org/10.1111/1752-1688.12308.

Jones, M.C., Wingard, G.L., Stackhouse, B., Keller, K., Willard, D., Marot, M., Landacre, B., E. Bernhardt, C., 2019. Rapid inundation of southern Florida coastline despite low relative sea-level rise rates during the late-Holocene. Nat. Commun. 10. https://doi.org/10.1038/s41467-019-11138-4.

Jothityangkoon, C., Hirunteeyakul, C., Boonrawd, K., Sivapalan, M., 2013. Assessing the impact of climate and land use changes on extreme floods in a large tropical catchment. J. Hydrol. 490, 88-105. https://doi.org/10.1016/j.jhydrol.2013.03.036. 
Kendall, M.G., 1938. A new measure of rank correlation. Biometrika. 1938, 30, 81-93. https://www.jstor.org/stable/2332226 30, 81-93.

Kendall, M.G., 1976. Rank Auto Correlation Methods. 4th ed.; Griffin: Oxford, UK.

Khan, I.M.P., Moglen, G.E., Hubacek, K., Brubaker, K.L., 2019. Future Storm Frequency and Runoff in Small US Mid-Atlantic Watersheds Evaluated Using Capture Depth. J. Sustain. Water Built Environ. 5, 05019001. https://doi.org/10.1061/jswbay.0000879.

Kohnová, S., Rončák, P., Hlavčová, K., Szolgay, J., 2019. Impacts of Future Climate Change on Runoff in Selected Catchments of Slovakia. Clim. Chang. Manag. 7, 279-292. https://doi.org/10.1007/978-3-030-03383-5_19.

Koren, V., Reed, S., Smith, M., Zhang, Z., Seo, D.J., 2004. Hydrology laboratory research modeling system (HL-RMS) of the US national weather service, in: Journal of Hydrology. Elsevier, pp. 297-318. https://doi.org/10.1016/j.jhydrol.2003.12.039.

Kottek, M., Grieser, J., Beck, C., Rudolf, B., Rubel, F., 2006. World map of the Köppen-Geiger climate classification updated. Meteorol. Z. 15(3), 259-263. https://doi.org/10.1127/09412948/2006/0130.

Lamichhane, S., Shakya, N.M., 2019. Integrated assessment of climate change and land use change impacts on hydrology in the Kathmandu Valley watershed, Central Nepal. Water (Switzerland) 11. https://doi.org/10.3390/w11102059. 
Langousis, A., Mamalakis, A., Deidda, R. and Marrocu, M., 2016. Assessing the relative effectiveness of statistical downscaling and distribution mapping in reproducing rainfall statistics based on climate model results. Water Resour. Res. 52(1), 471-494. https://doi.org/10.1002/2015WR017556.

Lapointe, B. E., Herren, L. W., Bedford, B. J., 2012. Effects of hurricanes, land use, and water management on nutrient and microbial pollution: St. Lucie Estuary, Southeast Florida. J. Coast. Res. 28(6), 1345-1361. https://doi.org/10.2112/JCOASTRES-D-12-00070.1.

Le Moigne, P., Boone, A., Calvet, J. C., Decharme, B., Faroux, S., Gibelin, A. L., Lebeaupin, C., Mahfouf, J. F., Martin, E., Masson, V. Mironov, D., Noilhan, J., Tulet, P., Van Den Hurk, B., 2009. SURFEX scientific documentation. Note de centre (CNRM/GMME), MétéoFrance, CNRM, Toulouse, France.

Leavesley, G.H., Stannard, L.G., 1995. The precipitation-runoff modeling system - PRMS. In: Singh, V.P. (Ed.), Computer Models of Watershed Hydrology. Water Resources Publications, Highlands Ranch, Colorado, pp. 281-310.

Li, Z., Liu, W. Z., Zhang, X. C., Zheng, F. L., 2009. Impacts of land use change and climate variability on hydrology in an agricultural catchment on the Loess Plateau of China. J. Hydrol. 377(1-2), 35-42. https://doi.org/10.1016/j.jhydrol.2009.08.007. 
Liang, X., Lettenmaier, D. P., Wood, E. F., 1994. A simple hydrologically based model of land surface water and energy fluxes for general circulation models. J. Geophys. Res. Atmos. 99(D7), 14415-14428. https://doi.org/10.1029/94JD00483.

Liu, D., Mishra, A.K., Zhang, K., 2017. Runoff sensitivity over Asia: Role of climate variables and initial soil conditions. J. Geophys. Res. Atmos. 122, 2218-2238. https://doi.org/10.1002/2016JD025694.

Lu, Z., Fu, Z., Hua, L., Yuan, N., Chen, L., 2018. Evaluation of ENSO simulations in CMIP5 models: A new perspective based on percolation phase transition in complex networks. Sci. Rep. 8(1), 14912. https://doi.org/10.1038/s41598-018-33340-y.

M.S. Wigmosta, B. Nussen, P. Storck., 2002. The distributed hydrology soil vegetation model V.P. Singh, D.K. Frevert (Eds.), Mathematical Models of Small Watershed Hydrology and Applications, Water Resources Publications LLC, 7-42.

Mahdi, E.S., Mohamedmeki, M.Z., 2020. Analysis of rainfall intensity-duration-frequency (IDF) curves of Baghdad city, in: IOP Conference Series: Materials Science and Engineering. Institute of Physics Publishing, p. 012066. https://doi.org/10.1088/1757$\underline{899 X / 888 / 1 / 01206}$.

Mahjabin, T., Abdul-Aziz, O.I., 2020. Trends in the magnitude and frequency of extreme rainfall regimes in Florida. Water (Switzerland) 12. https://doi.org/10.3390/W12092582. 
Maidment, D., Morehouse, S., 2002. ArcHydro: GIS for water resources. ESRI Press, Redlands, CA, USA.

Mann, H.B., 1945. Nonparametric Tests Against Trend. J. Econ. Soc. 13, 245-259. https://www.jstor.org/stable/1907187.

Martinez, C.J., Maleski, J.J., Miller, M.F., 2012. Trends in precipitation and temperature in Florida, USA. J. Hydrol. 452-453, 259-281. https://doi.org/10.1016/j.jhydrol.2012.05.066.

Mateus, C., Tullos, D. D., Surfleet, C. G., 2015. Hydrologic sensitivity to climate and land use changes in the Santiam River Basin, Oregon. JAWRA J. Am. Water Resour. Assoc. 51(2), 400-420. https://doi.org/10.1111/jawr.12256.

McMahon, G., Bales, J.D., Coles, J.F., Giddings, E.M.P., Zappia, H., 2003. Use of stage data to characterize hydrologic conditions in an urbanizing environment. J. Am. Water Resour. Assoc. 39, 1529-1546. https://doi.org/10.1111/j.1752-1688.2003.tb04437.x.

Miller, J.D., Kim, H., Kjeldsen, T.R., Packman, J., Grebby, S., Dearden, R., 2014. Assessing the impact of urbanization on storm runoff in a peri-urban catchment using historical change in impervious cover. J. Hydrol. 515, 59-70. https://doi.org/10.1016/j.jhydrol.2014.04.011.

Mishra, V., Cherkauer, K.A., Niyogi, D., Lei, M., Pijanowski, B.C., Ray, D.K., Bowling, L.C., Yang, G., 2010. A regional scale assessment of land use/land cover and climatic changes 
on water and energy cycle in the upper Midwest United States. Int. J. Climatol. 30, 20252044. https://doi.org/10.1002/joc.2095.

Misra, V., DiNapoli, S.M., 2013. Understanding the wet season variations over Florida. Clim. Dyn. 40, 1361-1372. https://doi.org/10.1007/s00382-012-1382-4.

Molnar, P., Fatichi, S., Gaál, L., Szolgay, J., Burlando, P., 2015. Storm type effects on super Clausius-Clapeyron scaling of intense rainstorm properties with air temperature. Hydrol. Earth Syst. Sci. 19, 1753-1766. https://doi.org/10.5194/hess-19-1753-2015.

Moriasi, D. N., Arnold, J. G., Van Liew, M. W., Bingner, R. L., Harmel, R. D., Veith, T. L., 2007. Model evaluation guidelines for systematic quantification of accuracy in watershed simulations. Trans. ASABE. 50(3), 885-900. https://pubag.nal.usda.gov/catalog/9298.

Morris, F. W., 1986. Bathymetry of the St. Lucie estuary. Technical publication 86-4. Water resources division, resource planning management, South Florida Water Management District, West Palm Beach, FL, USA.

Myhre, G., Alterskjær, K., Stjern, C.W., Hodnebrog, Marelle, L., Samset, B.H., Sillmann, J., Schaller, N., Fischer, E., Schulz, M., Stohl, A., 2019. Frequency of extreme precipitation increases extensively with event rareness under global warming. Sci. Rep. 9, 1-10. https://doi.org/10.1038/s41598-019-52277-4. 
Najafi, M.R., Moradkhani, H., 2015. Multi-model ensemble analysis of runoff extremes for climate change impact assessments. J. Hydrol. 525, 352-361. https://doi.org/10.1016/j.jhydrol.2015.03.045.

Nakicenovic, N., Alcamo, J., Davis, G., Vries, B.d., Fenhann, J., Gaffin, S., Gregory, K., Gru“bler, A., Jung, T. Y., Kram, T., Rovere, E. L. L., Michaelis, L., Mori, S., Morita, T., Pepper, W., Pitcher, H., Price, L., Riahi, K., Roehrl, A., Rogner, H.-H., Sankovski, A., Schlesinger, M., Shukla, P., Smith, S., Swart, R., Rooijen, S. v., Victor, N., Dadi, Z., 2000. Special report on emissions scenarios, A special report of working group III of the intergovernmental panel on climate change. Cambridge University Press, Cambridge, UK. http://pure.iiasa.ac.at/id/eprint/6101/.

Nash, J. E., Sutcliffe, J. V., 1970. River flow forecasting through conceptual models part I-A discussion of principles. J. Hydrol. 10(3), 282-290. https://doi.org/10.1016/0022$\underline{1694(70) 90255-6 .}$.

Nations, U., 2018. World Urbanization Prospects, Demographic Research. https://doi.org/10.4054/demres.2005.12.9.

Neitsch, S. L., Arnold, J. G., Kiniry, J. R., Williams, J. R., 2005. Soil and Water Assessment Tool theoretical documentation version 2005. Soil and Water Research Laboratory, ARS, Temple, TX, USA. 
Niu, G.Y., Yang, Z.L., Mitchell, K.E., Chen, F., Ek, M.B., Barlage, M., Kumar, A., Manning, K., Niyogi, D., Rosero, E., Tewari, M., Xia, Y., 2011. The community Noah land surface model with multiparameterization options (Noah-MP): 1. Model description and evaluation with local-scale measurements. J. Geophys. Res. Atmos. 116, 1-19. https://doi.org/10.1029/2010JD015139.

Novotny, E. V., Stefan, H.G., 2007. Stream flow in Minnesota: Indicator of climate change. J. Hydrol. 334, 319-333. https://doi.org/10.1016/j.jhydrol.2006.10.011.

Obeysekera, J., Park, J., Irizarry-Ortiz, M., Trimble, P., Barnes, J., VanArman, J., Said, W., Gadzinski, E., 2011. Past and projected trends in climate and sea level for south Florida. South Florida Water Management District interdepartmental climate change group, hydrologic and environmental systems modeling technical report. July 5, 2011, West Palm Beach, FL, USA. https://www.sfwmd.gov/document/past-and-projected-trendsclimate-and-sea-level-south-florida.

Obeysekera, J., Barnes, J., Nungesser, M., 2015. Climate sensitivity runs and regional hydrologic modeling for predicting the response of the greater Florida Everglades ecosystem to climate change. Environ. Manage. 55(4), 749-762. https://doi.org/10.1007/s00267-014$\underline{0315-X}$. 
Olang, L. O., Fürst, J., 2011. Effects of land cover change on flood peak discharges and runoff volumes: model estimates for the Nyando River Basin, Kenya. Hydrol. Processes. 25(1), 80-89. https://doi.org/10.1002/hyp.7821.

Olivera, F., DeFee, B. B., 2007. Urbanization and its effect on runoff in the Whiteoak Bayou Watershed, Texas 1. JAWRA J. Am. Water Resour. Assoc. 43(1), 170-182. https://doi.org/10.1111/j.1752-1688.2007.00014.x.

ORNL DAAC, 2017. Spatial Data Access Tool (SDAT). ORNL DAAC, Oak Ridge, TN, USA. Accessed on September 12, 2017 from https://doi.org/10.3334/ORNLDAAC/1388.

Öztürk, M., Copty, N. K., Saysel, A. K., 2013. Modeling the impact of land use change on the hydrology of a rural watershed. J. Hydrol. 497, 97-109. https://doi.org/10.1016/j.jhydrol.2013.05.022.

Pan, S., Liu, D., Wang, Z., Zhao, Q., Zou, H., Hou, Y., Liu, P., Xiong, L., 2017. Runoff responses to climate and land use/cover changes under future scenarios. Water (Switzerland) 9. https://doi.org/10.3390/w9070475.

Papalexiou, S.M., Montanari, A., 2019. Global and Regional Increase of Precipitation Extremes Under Global Warming. Water Resour. Res. 55, 4901-4914. https://doi.org/10.1029/2018WR024067. 
Park, J., Sweet, W., 2015. Accelerated sea level rise and Florida Current transport. Ocean Sci. 11, 607-615. https://doi.org/10.5194/os-11-607-2015.

Pathak, C. S., 2001. Frequency analysis of daily rainfall maxima for central and south Florida. Technical publication EMA-390. South Florida Water Management District, West Palm Beach, FL, USA.

Pedersen, A.N., Mikkelsen, P.S., Arnbjerg-Nielsen, K., 2012. Climate change-induced impacts on urban flood risk influenced by concurrent hazards. J. Flood Risk Manag. 5, 203-214. https://doi.org/10.1111/j.1753-318X.2012.01139.x.

Pérez-Rodríguez, P., Vaquera-Huerta, H., Villaseñor-Alva, J.A., 2009. A Goodness-of-Fit Test for the Gumbel Distribution Based on Kullback-Leibler Information. Commun. Stat. Theory Methods 38, 842-855. https://doi.org/10.1080/03610920802316658.

Pirnia, A., Golshan, M., Darabi, H., Adamowski, J., Rozbeh, S., 2019. Using the mann-kendall test and double mass curve method to explore stream flow changes in response to climate and human activities. J. Water Clim. Chang. 10, 725-742. https://doi.org/10.2166/wcc.2018.162.

Rahmani, V., Hutchinson, S.L., Harrington, J.A., Hutchinson, J.M.S., 2016. Analysis of frequency and magnitude of extreme rainfall events with potential impacts on flooding: a case study from the central United States. Int. J. Climatol. 36, 3578-3587. https://doi.org/10.1002/joc.4577. 
Rawls, W. J., Brakensiek, D. L., Miller, N., 1983. Green-Ampt infiltration parameters from soils data. J. Hydraul. Eng. 109(1), 62-70. https://doi.org/10.1061/(ASCE)07339429(1983)109:1(62).

Reitz, M., Sanford, W.E., Senay, G.B., Cazenas, J., 2017. Annual Estimates of Recharge, QuickFlow Runoff, and Evapotranspiration for the Contiguous U.S. Using Empirical Regression Equations. JAWRA J. Am. Water Resour. Assoc. 53, 961-983. https://doi.org/10.1111/1752-1688.12546.

Rosenzweig, B.R., McPhillips, L., Chang, H., Cheng, C., Welty, C., Matsler, M., Iwaniec, D., Davidson, C.I., 2018. Pluvial flood risk and opportunities for resilience. Wiley Interdiscip. Rev.: Water. 5(6), 1-18. https://doi.org/10.1002/wat2.1302.

Rossman, L. A., 2015. Storm Water Management Model user's manual, version 5.1, report EPA600/R-14/413b. National risk management research laboratory, office of research and development, U.S. Environmental Protection Agency. Cincinnati, OH, USA. http://nepis.epa.gov/Exe/ZyPDF.cgi?Dockey=P100N3J6.TXT.

Rossman, L. A., Huber, W., 2016. Storm Water Management Model reference manual volume IHydrology (revised), report EPA/600/R-15/162A. National risk Management research laboratory, office of research and development, U.S. Environmental Protection Agency. Cincinnati, OH, USA. http://nepis.epa.gov/Exe/ZyPDF.cgi?Dockey=P100NYRA.txt. 
Rotzoll, K., Fletcher, C.H., 2013. Assessment of groundwater inundation as a consequence of sea-level rise. Nat. Clim. Chang. 3, 477-481. https://doi.org/10.1038/nclimate1725.

Rubel, F., Brugger, K., Haslinger, K., Auer, I., 2017. The climate of the European Alps: Shift of very high resolution Köppen-Geiger climate zones 1800-2100. Meteorol. Zeitschrift 26, 115-125. https://doi.org/10.1127/metz/2016/0816.

Salathé, E.P., Hamlet, A.F., Mass, C.F., Lee, S.-Y., Stumbaugh, M., Steed, R., 2014. Estimates of twenty-first-century flood risk in the Pacific Northwest based on regional climate model simulations. J. Hydrometeorol. 15, 1881-1899.

Salathé, E.P., Hamlet, A.F., Mass, C.F., Lee, S-Y., Stumbaugh, M., Steed, R., 2014. Estimates of Twenty-first Century flood risk in the Pacific Northwest based on regional scale climate model simulations. J. Hydrometeorology 15(5): 1881-1899. http://dx.doi.org/10.1175/JHM-D-13-0137.1.

Sayemuzzaman, M., Jha, M., Mekonnen, A., Jha, M.K., 2013. Spatio-temporal long-term (19502009) temperature trend analysis in North Carolina, United States Article in Theoretical and Applied Climatology. Springer 120, 159-171. https://doi.org/10.1007/s00704-014$\underline{1147-6 .}$

Sayemuzzaman, M., Jha, M.K., 2014. Seasonal and annual precipitation time series trend analysis in North Carolina, United States. Atmos. Res. 137, 183-194. https://doi.org/10.1016/j.atmosres.2013.10.012. 
Schmidt, N., Lipp, E. K., Rose, J. B., Luther, M. E., 2001. ENSO influences on seasonal rainfall and river discharge in Florida. J. Clim. 14(4), 615-628. https://doi.org/10.1175/15200442(2001)014<0615:EIOSRA>2.0.CO;2.

Sedighi, F., Vafakhah, M., Javadi, M.R., 2016. Rainfall-Runoff Modeling Using Support Vector Machine in Snow-Affected Watershed. Arab. J. Sci. Eng. 41, 4065-4076. https://doi.org/10.1007/s13369-016-2095-5.

Sen, P.K., 1968. Estimates of the Regression Coefficient Based on Kendall's Tau. J. Am. Stat. Assoc. 63, 1379-1389. https://doi.org/10.1080/01621459.1968.10480934.

SFRCCC (Southeast Florida Regional Climate Change Compact) Sea Level Rise Work Group, 2020. Unified Sea Level Rise Projection for Southeast Florida. A document prepared for the Southeast Florida Regional Climate Change Compact Climate Leadership Committee. 136.

SFWMD (South Florida Water Management District), 2017. DBHYDRO (environmental data). Accessed on January 10, 2017 from https://www.sfwmd.gov/science-data/dbhydro.

Sharif, H.O., Hassan, A.A., Bin-Shafique, S., Xie, H., Zeitler, J., 2010. Hydrologic Modeling of an extreme flood in the guadalupe river in Texas. J. Am. Water Resour. Assoc. 46, 881-891. https://doi.org/10.1111/j.1752-1688.2010.00459.x. 
Siddique, R., Karmalkar, A., Sun, F., Palmer, R., 2020. Hydrological extremes across the Commonwealth of Massachusetts in a changing climate. J. Hydrol. Reg. Stud. 32, 100733. https://doi.org/10.1016/j.ejrh.2020.100733.

Siddique, R., Palmer, R., 2020. Climate Change Impacts on Local Flood Risks in the U.S. Northeast: A Case Study on the Connecticut and Merrimack River Basins. JAWRA J. Am. Water Resour. Assoc. 1752-1688.12886. https://doi.org/10.1111/1752-1688.12886.

Sinha, R.K., Eldho, T.I., Subimal, G., 2020. Assessing the impacts of land cover and climate on runoff and sediment yield of a river basin. Hydrol. Sci. J. 1-19. https://doi.org/10.1080/02626667.2020.1791336.

Sinha, S., Singh, V., Jakhanwal, M.P., 2015. Rainfall Runoff Modeling of Punpun River Basin using ANN - A Case Study. Int. J. Res. Eng. Soc. Sci. 5, 2249-9482.

Skougaard Kaspersen, P., Høegh Ravn, N., Arnbjerg-Nielsen, K., Madsen, H., Drews, M., 2017. Comparison of the impacts of urban development and climate change on exposing European cities to pluvial flooding. Hydrol. Earth Syst. Sci. 21, 4131-4147. https://doi.org/10.5194/hess-21-4131-2017.

Sukop, M.C., Rogers, M., Guannel, G., Infanti, J.M., Hagemann, K., 2018. High temporal resolution modeling of the impact of rain, tides, and sea level rise on water table flooding in the Arch Creek basin, Miami-Dade County Florida USA. Sci. Total Environ. https://doi.org/10.1016/j.scitotenv.2017.10.170. 
Suttles, K.M., Singh, N.K., Vose, J.M., Martin, K.L., Emanuel, R.E., Coulston, J.W., Saia, S.M., Crump, M.T., 2018. Assessment of hydrologic vulnerability to urbanization and climate change in a rapidly changing watershed in the Southeast U.S. Sci. Total Environ. 645, 806-816. https://doi.org/10.1016/j.scitotenv.2018.06.287.

Swain, D.L., Singh, D., Touma, D., Diffenbaugh, N.S., 2020. Attributing Extreme Events to Climate Change: A New Frontier in a Warming World. One Earth. 2, 522-527. https://doi.org/10.1016/j.oneear.2020.05.011.

Sweet, W. V., Horton, R., Kopp, R. E., LeGrande, A. N., \& Romanou, A., 2017a. 12: Sea Level Rise. Climate Science Special Report: Fourth National Climate Assessment, Volume I [Wuebbles, D.J., D.W. Fahey, K.A. Hibbard, D.J. Dokken, B.C. Stewart, and T.K. Maycock (eds.)]. U.S. Global Change Research Program, Washington, DC, USA. https://doi. org/10.7930/J0VM49F2.

Sweet, W.V., Kopp, R.E., Weaver, C.P., Obeysekera, J., Horton, R.M., Thieler, E.R., Zervas, C., 2017b. Global and regional sea level rise scenarios for the United States. NOAA Technical Report NOS CO-OPS 083. Silver Spring, MD, USA.

Teutschbein, C., Seibert, J., 2012. Bias correction of regional climate model simulations for hydrological climate-change impact studies: Review and evaluation of different methods. J. Hydrol. 456-457, 12-29. https://doi.org/10.1016/j.jhydrol.2012.05.052. 
Theil, H., 1950. A rank-invariant method of linear and polynomial regression analysis, 3; confidence regions for the parameters of polynomial regression equations. Stichting Mathematisch Centrum. Statistische Afdeling, 1-16.

Tian, H., Lu, C., Ciais, P., Michalak, A.M., Canadell, J.G., Saikawa, E., Huntzinger, D.N., Gurney, K.R., Sitch, S., Zhang, B., Yang, J., Bousquet, P., Bruhwiler, L., Chen, G., Dlugokencky, E., Friedlingstein, P., Melillo, J., Pan, S., Poulter, B., Prinn, R., Saunois, M., Schwalm, C.R., Wofsy, S.C., 2016. The terrestrial biosphere as a net source of greenhouse gases to the atmosphere. Nature 531, 225-228. https://doi.org/10.1038/nature16946.

Trenberth, K.E., Dai, A., Rasmussen, R.M., Parsons, D.B., 2003. The changing character of precipitation. Bull. Am. Meteorol. Soc. 84, 1205-1217+1161. https://doi.org/10.1175/BAMS-84-9-1205.

Tukey, J. W., 1977. Exploratory data analysis. Reading, Massachusetts: Addison-Wesley. https://doi.org/10.1002/bimj.4710230408.

U.S. EPA (United States Environmental Protection Agency), 2010. ICLUS tools and datasets (Version 1.3.2). U.S. Environmental Protection Agency, Washington, D.C., USA. EPA/600/R-09/143F. Accessed on October 30, 2017 from https://cfpub.epa.gov/ncea/global/recordisplay.cfm?deid=257306. 
Urban Drainage and Flood Control District, 2016. Urban storm drainage criteria manual: volume 1 management, hydrology, and hydraulics. Urban Drainage and Flood Control District. Denver, CO, USA. https://udfcd.org/volume-one.

USACE (United States Army Corps of Engineers), 2000. Hydrologic modeling system HECHMS users manual, version 2.0. Hydrologic engineering center, US Army Corps of Engineers, Davis, CA, USA.

USDA (United States Department of Agriculture), NRCS (Natural Resources Conservation Service), 2009. National engineering handbook, title 210-VI, part 630, chapter 7. Washington, D.C., USA. Accessed on April 08, 2017 from https://www.nrcs.usda.gov/wps/portal/nrcs/detailfull/national/water/?\&cid=stelprdb1043 $\underline{063 .}$

USDA (United States Department of Agriculture), NRCS (Natural Resources Conservation Service), 2015. Soil survey geographic (SSURGO) database for Florida - June 2012. Accessed on January 05, 2015 from http://www.fgdl.org/metadataexplorer/explorer.jsp.

USGS (United States Geological Survey), 2016a. The National Map. Accessed on February 03, 2016 from https://viewer.nationalmap.gov/basic/.

USGS (United States Geological Survey), 2016b. National elevation dataset (NED). Accessed on February 16, 2016 from https://ta.cr.usgs.gov/NED. 
USGS (United States Geological Survey), 2016c. Evapotranspiration information and data. Accessed on February 20, 2016 from https://fl.water.usgs.gov/et/.

USGS (United States Geological Survey), 2017. Water data for the nation. Accessed on January 08, 2017 from https://waterdata.usgs.gov/nwis.

USGS (United States Geological Survey), 2018. Water data for the nation. Accessed on October 23, 2018 from https://waterdata.usgs.gov/nwis.

Valle-Levinson, A., Dutton, A., Martin, J.B., 2017. Spatial and temporal variability of sea level rise hot spots over the eastern United States. Geophys. Res. Lett. 44, 7876-7882. https://doi.org/10.1002/2017GL073926.

Van Vuuren, D. P., Carter, T. R., 2014. Climate and socio-economic scenarios for climate change research and assessment: reconciling the new with the old. Clim. Change. 122(3), 415-429. https://doi.org/10.1007/s10584-013-0974-2.

Vemula, S., Raju, K.S., Veena, S.S., Kumar, A.S., 2019. Urban floods in Hyderabad, India, under present and future rainfall scenarios: a case study. Nat. Hazards. 95, 637-655. https://doi.org/10.1007/s11069-018-3511-9.

Vidal, I., 2014. A Bayesian analysis of the Gumbel distribution: An application to extreme rainfall data. Stoch. Environ. Res. Risk Assess. 28, 571-582. https://doi.org/10.1007/s00477-013-0773-3. 
Vieux B.E., 2016. Vflo®—Software for Distributed Hydrology. In: Distributed Hydrologic Modeling Using GIS. Water Science and Technology Library, vol. 74. Springer, Dordrecht. https://doi.org/10.1007/978-94-024-0930-7_12.

Volk, M., Hoctor, T., Nettles, B., Hilsenbeck, R., Putz, F., 2017. Florida Land Use and Land Cover Change in the Past 100 Years. Florida's Clim. Chang. Var. Impacts 51-82. https://doi.org/10.17125/fci2017.ch02.

Wachnicka, A., Browder, J., Jackson, T., Louda, W., Kelble, C., Abdelrahman, O., Stabenau, E., Avila, C., 2020. Hurricane Irma's Impact on Water Quality and Phytoplankton Communities in Biscayne Bay (Florida, USA). Estuaries and Coasts 43, 1217-1234. https://doi.org/10.1007/s12237-019-00592-4.

Wagesho, N., Jain, M. K., Goel, N. K., 2012. Effect of climate change on runoff generation: Application to Rift Valley Lakes Basin of Ethiopia. J. Hydraul. Eng. 18(8), 1048-1063. https://doi.org/10.1061/(ASCE)HE.1943-5584.0000647.

Wang, G., Zhang, J., He, R., Liu, C., Ma, T., Bao, Z., Liu, Y., 2017. Runoff sensitivity to climate change for hydro-climatically different catchments in China. Stoch. Environ. Res. Risk Assess. 31, 1011-1021. https://doi.org/10.1007/s00477-016-1218-6.

Wang, H., Stephenson, S. R., 2018. Quantifying the impacts of climate change and land use/cover change on runoff in the lower Connecticut River Basin. Hydrol. Processes. 32(9), 1301-1312. https://doi.org/10.1002/hyp.11509. 
Wang, S., Fu, B.-J., He, C.-S., Gao, G.-Y., 2011. A comparative analysis of forest cover and catchment water yield relationships in northern China. For. Ecol. Manag. 2621189-1198 262, 1189-1198. https://doi.org/10.1016/j.foreco.2011.06.013.

Wang, Z. M., Batelaan, O., De Smedt, F., 1996. A distributed model for water and energy transfer between soil, plants and atmosphere (WetSpa). Phys. Chem. Earth. 21(3), 189193.

Wdowinski, S., Bray, R., Kirtman, B. P., Wu, Z., 2016. Increasing flooding hazard in coastal communities due to rising sea level: Case study of Miami Beach, Florida. Ocean Coast. Manag. 126, 1-8. https://doi.org/10.1016/j.ocecoaman.2016.03.002.

White, M. D., Greer, K. A., 2006. The effects of watershed urbanization on the stream hydrology and riparian vegetation of Los Peñasquitos Creek, California. Landscape Urban Plann. 74(2), 125-138. https://doi.org/10.1016/j.landurbplan.2004.11.015.

Wrzesien, M.L., Pavelsky, T.M., 2020. Projected Changes to Extreme Runoff and Precipitation Events From a Downscaled Simulation Over the Western United States. Front. Earth Sci. 7. https://doi.org/10.3389/feart.2019.00355.

Yin, J., Gentine, P., Zhou, S., Sullivan, S.C., Wang, R., Zhang, Y., Guo, S., 2018. Large increase in global storm runoff extremes driven by climate and anthropogenic changes. Nat. Commun. 9. https://doi.org/10.1038/s41467-018-06765-2. 
Yuan, Z., Xu, J., Wang, Y., 2018. Projection of Future Extreme Precipitation and Flood Changes of the Jinsha River Basin in China Based on CMIP5 Climate Models. Int. J. Environ. Res. Public Health 15, 2491. https://doi.org/10.3390/ijerph15112491.

Zhang, H., Yang, Q., Shao, J., Wang, G., 2019. Dynamic Streamflow Simulation via Online Gradient-Boosted Regression Tree. J. Hydrol. Eng. 24, 04019041. https://doi.org/10.1061/(asce)he.1943-5584.0001822.

Zhang, W., Villarini, G., Vecchi, G.A., Smith, J.A., 2018. Urbanization exacerbated the rainfall and flooding caused by hurricane Harvey in Houston. Nature 563, 384-388. https://doi.org/10.1038/s41586-018-0676-z.

Zhang, X., Zhang, L., Zhao, J., Rustomji, P., Hairsine, P., 2008. Responses of streamflow to changes in climate and land use/cover in the Loess Plateau, China. Water Resour. Res. 44(7). https://doi.org/10.1029/2007WR006711.

Zhang, X.C., 2013. Verifying a temporal disaggregation method for generating daily precipitation of potentially non-stationary climate change for site-specific impact assessment. Int. J. Climatol. 33(2), 326-342. https://doi.org/10.1002/joc.3425.

Zhang, Y., Wang. G., 2007. Impact of climate change on hydrology and water resources. China Science Press, Beijing, China. 
Zhao, R.J., Liu, X.R., Singh, V.P, 1995. The Xinanjiang model. Comput. Model. watershed Hydrol. 215-232.

Zhao, S., Deng, Y., Black, R. X., 2017. Observed and simulated spring and summer dryness in the United States: the impact of the Pacific Sea surface temperature and beyond. J. Geophys. Res. Atmos. 122(23), 12713-12731. https://doi.org/10.1002/2017JD027279.

Zheng, H., Chiew, F. H., Charles, S., Podger, G., 2018. Future climate and runoff projections across South Asia from CMIP5 global climate models and hydrological modelling. J. Hydrol.: Reg. Stud., 18, 92-109. https://doi.org/10.1016/j.ejrh.2018.06.004.

Zope, P.E., Eldho, T.I., Jothiprakash, V., 2016. Impacts of land use-land cover change and urbanization on flooding: A case study of Oshiwara River Basin in Mumbai, India. Catena 145, 142-154. https://doi.org/10.1016/j.catena.2016.06.009. 